\title{
Regulation des mitochondrialen Zerfalls innerhalb der neuronalen Apoptose
}

\author{
Dissertation \\ zur Erlangung des Doktorgrades \\ der Mathematisch-Naturwissenschaftlichen Fakultäten \\ der Georg-August Universität zu Göttingen
}

vorgelegt von

Katrin Meuer

aus Darmstadt

Göttingen 2007 
D 7

Referent: Herr Prof. Dr. R. Hardeland

Korreferent: Herr Prof. Dr. K. von Figura

Tag der mündlichen Prüfung: 02.05.2007 
Unser Verständnis der Welt ist aus unzähligen Schichten errichtet.

Jede Schicht verdient erforscht zu werden,

solange wir nicht vergessen, dass es nur eine von vielen ist.

Wenn wir alles wüssten, was man von einer Schicht wissen kann

-ein höchst unwahrscheinlicher Fall-

so würden uns das nicht viel über den Rest belehren.

Erwin Chargaff (*1905), östr.-amerik. Biochemiker und Schriftsteller 


\section{Inhalt}

1 EINLEITUNG 1

1.1 Mitochondrien 1

1.1.1 Morphologie der Mitochondrien 1

1.1.2 Funktion der Mitochondrien 3

1.1.2.1 Funktion im Energiestoffwechsel 3

1.1.2.2 Funktion während der Apoptose 3

1.1.3 Mitochondriale Mutationen und Anomalien 6

$\begin{array}{lll}\text { 1.1.4 Transport von Mitochondrien } & 7\end{array}$

1.1.5 Mitochondriale Zerteilung und Verschmelzung 8

1.1.5.1 Der mitochondriale Zerteilungsapparat $\quad 9$

1.1.5.2 Der mitochondriale Verschmelzungsapparat 13

1.1.5.3 Physiologische Bedeutung der mitochondrialen Zerteilungs- und

1.2 Cykline- abhängige Kinasen 17

1.2.1 Regulation der Cyklin-abhängigen Kinase $5 \quad 18$

1.2.2 Cyclin-abhängige Kinase 5 und neuronaler Zelltod 21

$\begin{array}{lll}1.3 & \text { Zielsetzung } & 25\end{array}$

2 MATERIAL UND METHODEN 26

$2.1 \quad$ Verwendete Zelltypen 26

2.1.1 Kultur von CSM 14.1 Neuronen 26

$\begin{array}{lll}\text { 2.1.2 Kultur von primären Mittelhirnneuronen } & 27\end{array}$

2.2 Molekularbiologische Methoden 29

2.2.1 Plasmide 29

2.2.1.1 Herstellung transformationskompetenter E. coli Zellen 31

2.2.1.2 Transformation von E .coli Zellen 31

2.2.1.3 Isolierung von Plasmid DNS aus E . coli 31

2.2.2 Transfektionen 32

2.2.2.1 Transiente Transfektion mittels Lipofectamine 32

2.2.2.1.1 DNS Transfektion 32

2.2.2.1.2 Kotransfektionen von DNS und siRNS 33

2.2.2.2 Transiente Transfektion mittels Elektroporation 34

2.2.2.2.1 DNS Transfektionen 34

2.3 Proteinchemische Methoden 35

2.3.1 Zelllysierung $\quad 35$

2.3.2 Bestimmung der Proteinkonzentration 35

2.3.3 Western-Blot-Analyse $\quad 35$

2.3.3.1 SDS-Polyacrylamidgel-Elektrophorese 36

2.3.3.2 Proteintransfer 36

2.3.3.3 Antikörper Detektion 37

2.3.4 Bestimmung der CDK5-Aktivität 37

2.4 Zellbiologische Methoden $\quad 39$

2.4.1 Vorbehandlung der Neurone 39

2.4.2 Apoptoseinduktion $\quad 40$

2.4.3 Apoptosenachweis $\quad 41$

2.4.3.1 Messung der Cytochrom c Freisetzung 41 
2.4.3.2 Studien zur Kernmorphologie

2.4.4 Beurteilung der Mitochondrienmorphologie an fixierten Zellen 42

2.4.5 Beurteilung der Mitochondrienmorphologie an lebenden Zellen 42

2.4.6 Zytoskelettstudien $\quad 44$

$2.5 \quad$ Medien und Puffer $\quad 46$

2.5.1 Medien für Bakterien $\quad 46$

2.5.2 Medien für CSM14.1 Neurone $\quad 46$

2.5.3 Medien für primäre Mittelhirnneurone 46

$\begin{array}{lll}2.5 .4 & \text { Puffer } & 46\end{array}$

$\begin{array}{lll}2.5 .5 & \text { Antikörper } & 47\end{array}$

$\begin{array}{lll}3 & \text { ERGEBNISSE } & 48\end{array}$

3.1 dCSM14.1 Neurone $\quad 48$

3.1.1 Mitochondrienmorphologie während der Apoptose 49

3.1.2 Dynamik der mitochondrialen Zerteilung 50

3.1.3 Bedeutung von Fis1 und Drp1 in der neuronalen Apoptose 51

3.1.3.1 Regulation der mitochondrialen Morphologie 51

3.1.3.2 Einfluss von Drp1 und Fis1 auf den neuronalen Zelltod 58

3.1.4 Mitochondriale Fragmentation unter Tat Bcl-xL 63

3.1.5 Bedeutung des Zytoskeletts für die mitochondriale Zerteilung 64

3.1.6 Einfluss der Cyclin- abhängigen Kinase 5 auf die Mitochondrien 69

3.1.6.1 Einfluss von CDK5 auf die mitochondriale Morphologie 70

3.1.6.2 Regulation der CDK5- Aktivität bei Apoptoseinduktion 72

3.1.6.3 Toxische Wirkung von CDK5 auf Mitochondrien und Zellkerne 75

3.1.6.4 Bedeutung des endogenen CDK5 für die mitochondriale Zerteilung 76

3.1.6.4.1 Hemmung von CDK5 durch CDK5 ${ }_{\mathrm{N} 144} \quad 76$

3.1.6.4.2 Hemmung von CDK5 durch Indolinon A 81

3.1.6.4.3 Herabregulation von CDK5 durch siRNS 85

3.2 Primäre Mittelhirnneurone $\quad \mathbf{8 8}$

3.2.1 Zeitverlauf des mitochondrialen Zerfalls 89

3.2.2 Drp1 in Mittelhirnneuronen 90

$\begin{array}{lll}\text { 3.2.3 CDK5 in Mittelhirnneuronen } & 92\end{array}$

4 DISKUSSION $\quad 95$

$\begin{array}{lll}\text { 4.1 } & \text { Mitochondriale Morphologie } & 95\end{array}$

$\begin{array}{lll}4.2 & \text { Funktion von Drp1 und Fis1 } & 98\end{array}$

$\begin{array}{lll}4.3 & \text { Einfluss von Drp1 und Fis1 auf die Apoptose } & 101\end{array}$

$\begin{array}{lll}\text { 4.4 Mitochondrialer Zerfall und Apoptose } & 104\end{array}$

4.5 Regulation der mitochondrialen Zerteilung durch CDK5 106

4.6 Einordnung von CDK5 in die neuronale Apoptosekaskade 109

5 ZUSAMMENFASSUNG $\quad 112$

$6 \quad$ LITERATURVERZEICHNIS 113 


\section{Einleitung}

Die eukaryontische Zelle ist in verschiedene Kompartimente eingeteilt, die unterschiedliche zelluläre Prozesse räumlich voneinander trennen. Die einzelnen Kompartimente sind von Lipidmembranen umgeben. Man unterscheidet Kompartimente, die von einer einfachen Membran umgeben sind (wie z.B. Endoplasmatisches Retikulum, Golgi-Apparat, Peroxisome und Lysosomen), und solche die einen komplexeren Aufbau besitzen (z.B. Zellkern, Mitochondrien und Chloroplasten).

\subsection{Mitochondrien}

Die ersten mikroskopischen Beobachtungen von Mitochondrien reichen mehr als 100 Jahre zurück. So wurde der Begriff Mitochondrion, der sich aus dem Griechischen ableitet und übersetzt „Fadenkörperchen“ bedeutet (mitos, griech. Faden; chondros, griech. Korn) 1898 zum ersten Mal von C. Benda bei der Beschreibung intrazellulärer Strukturen verwendet. Mitochondrien können bei der Zellteilung nicht de novo entstehen, sondern vermehren sich durch Teilung. Sie besitzen einen Durchmesser von ca. 0,5-1 $\mu$ m und eine Länge von 0,5-10 $\mu \mathrm{m}$.

Mitochondrien sind an vielen Stoffwechselprozessen beteiligt, ihre Hauptaufgabe ist die Bereitstellung von Energie in Form von ATP. Hierzu nutzen sie die oxidative Phosphorylierung, die von der Atmungskette katalysiert wird. Des Weiteren sind die Mitochondrien am Fettsäureabbau, der Assemblierung von prosthetischen Eisen/Schwefel-Gruppen, bei Schritten des Harnstoffzyklus und der Synthese des Hämmoleküls, der Pyrimidine, der Nukleotide und von Phospholipiden beteiligt (Scheffler 2001).

Die Mitochondrien nehmen eine zentrale Rolle in der Integration und Überwachung des Zellstatus sowie während der Apoptose und Zellalterung ein. Dabei wurde die Bedeutung der Morphologie und Dynamik der Mitochondrien in der Regulierung dieser zentralen zellulären Prozesse erst seit kurzem erkannt.

\subsubsection{Morphologie der Mitochondrien}

In den 50er Jahren des vorigen Jahrhunderts war es erstmals mittels elektromikroskopischer Aufnahmen möglich komplexe intramitochondriale Strukturen sichtbar zu machen (Palade 1952). Mitochondrien sind von zwei hochspezialisierten Membranen umgeben und können somit in vier Kompartimente eingeteilt werden: die Außenmembran, den Intermembranraum, die Innenmembran und die Matrix (siehe Abbildung 1). Die äußere Membran ähnelt in ihrer Lipid- und Proteinzusammensetzung der Zellmembran, während die innere Membran 
in ihrem Aufbau eher Bakterienmembranen entspricht (Endosymbiontentheorie). Die Innenmembran kann in zwei Subkompartimente unterteilt werden, in den Abschnitt der Innenmembran, welche in engem Kontakt zur Außenmembran steht (innere Grenzschicht) sowie die Einstülpungen der Innenmembran in die Matrix (Cristae). Der Intermembranraum wird somit durch die Cristae in physiologisch unterschiedliche Kompartimente unterteilt (Frey und Mannella 2000). Die innere Grenzschicht ist hochspezialisiert. Sie enthält große Mengen des „Doppel“- Phospholipids Cardiolipin, das die Permeabilität der Membran für Ionen verringert. Außerdem enthält sie eine Reihe von Transportproteinen, welche jene Moleküle durch die Membran leiten, die in der Matrix verstoffwechselt werden sollen. Die Oberflächenvergrößerung der inneren Membran, durch die Ausbildung der Cristae dient der ATP Produktion, da die Proteine der Atmungskette an der inneren Membran lokalisiert sind. Die Anzahl der Cristae in Mitochondrien einer Herzmuskelzelle ist beispielsweise dreimal höher als bei den Mitochondrien einer Leberzelle, die weniger Energie benötigt (Alberts et al. 1997).

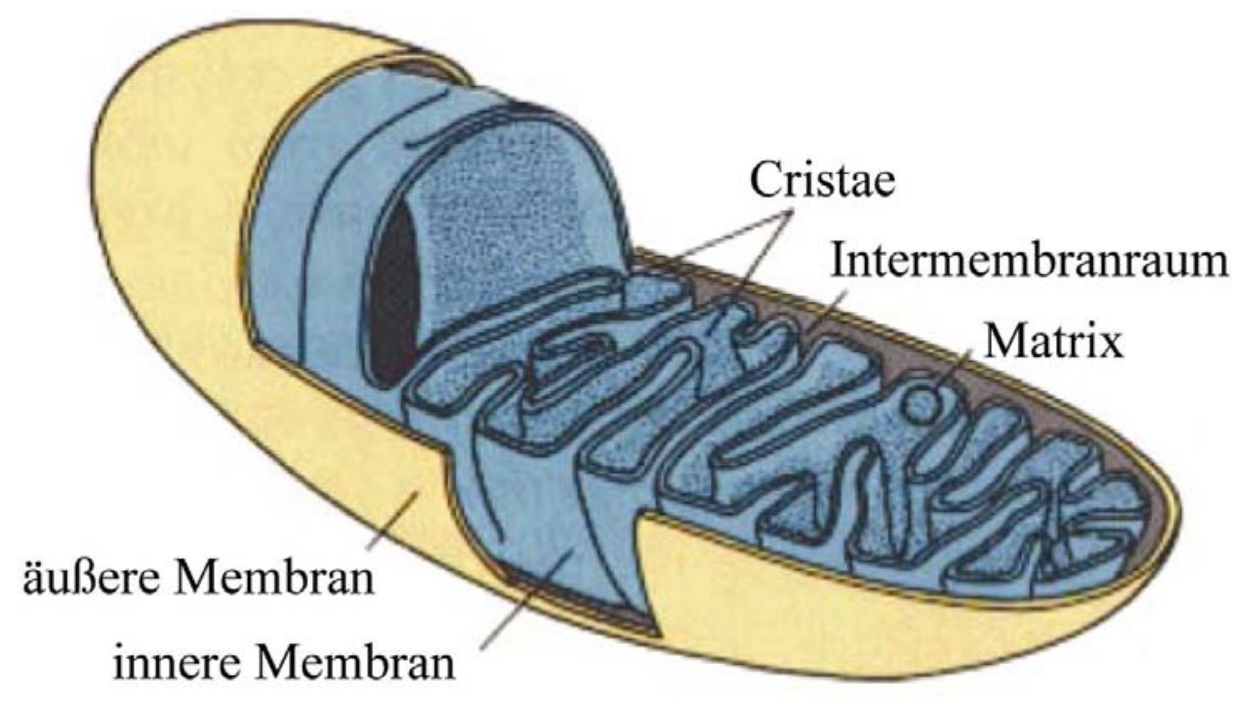

Abbildung 1: Baffle-Modell der Mitochondrien (Palade 1952).

Die äußere Membran umschließt das ganze Mitochondrium. Die innere Membran bildet Cristae genannte Einstülpungen, wodurch die Oberfläche erheblich vergrößert wird. Sie umschließt die Matrix, die interne Flüssigkeit des Mitochondriums.

Nach der Endosymbiontentheorie stammen die Mitochondrien von atmungskompetenten $\alpha$ Proteobakterien ab, die vor 1,5 Milliarden Jahren eine Symbiose mit anaeroben Archeabakterien eingingen (Gray et al. 1999). Aufgrund ihres bakteriellen Ursprungs besitzen Mitochondrien eine eigene ringförmig vorliegende DNS und eine bakterienähnliche Transkriptions- und Translationsmaschinerie. Proteine, welche auf der mitochondrialen DNS (mtDNS) kodiert sind, können von den Mitochondrien selbst synthetisiert werden. Der 
prozentuale Anteil der von den Mitochondrien selbst synthetisierten Proteine ist jedoch geringer, er beträgt beispielsweise in der Bäckerhefe nur ca. $1 \%$. Die restlichen in den Mitochondrien lokalisierten Proteine sind kernkodiert und werden posttranslational mit Hilfe verschiedener Translokalisationsmechanismen aus dem Zytosol in die Mitochondrien importiert (Neupert 1997, Schatz und Dobberstein 1996).

Die Matrix enthält mehrere identische Kopien des mitochondrialen Genoms, spezielle mitochondriale Ribosome, transfer-RNSs und verschieden Enzyme für die Expression der Mitochondriengene (Hobbs et al. 2001).

\subsubsection{Funktion der Mitochondrien}

\subsubsection{Funktion im Energiestoffwechsel}

Mitochondrien nehmen eine zentrale Stellung im Energiestoffwechsel der Zelle ein. In ihnen sind die Enzyme der Atmungskette lokalisiert, ebenso sind sie involviert in der Fettsäureoxidation und in dem Zitronensäurezyklus.

Der Enzymkomplex der mitochondrialen Atmungskette ist in der inneren Membran lokalisiert. Die mitochondriale Atmungskette besteht aus mehr als 20 Elektronen-Carrier, die in vier Enzymkomplexe gruppiert sind. Die mitochondriale Atmungskette katalysiert den Elektronentransport der im Zitronensäurezyklus, der Glykolyse und dem Fettsäure-Abbau entstehenden Reduktionsäquivalente $\mathrm{NADH} / \mathrm{H}^{+}$und $\mathrm{FADH}_{2} \mathrm{zu}$ dem letztlichen Elektronenakzeptor $\mathrm{O}_{2}$. Anhand isolierter Enzymkomplexe konnte gezeigt werden, dass die Enzymkomplexe Protonen durch die Membran pumpen, sobald Elektronen transportiert werden (Mitchell 1961). In der nativen Membran vervollständigen die beweglichen Elektronen-Carrier Ubichinon und Cytochrom c die Elektronen-Transportkette, indem sie zwischen den Enzymkomplexen pendeln. Die Enzymkomplexe der mitochondrialen Atmungskette koppeln den energetisch günstigen Elektronentransport mit dem Export von Protonen aus der Matrix. Dadurch bildet sich ein elektrochemischer Protonengradient über die innere Mitochondrienmembran aus. Dieser Protonengradient treibt die ATP-Synthetase (innere Mitochondrienmembran) an, welche die freiwerdende chemi-osmotische Energie dazu nutzt, anorganische Phosphate auf ADP zu übertragen. Durch die ATP-Synthetase fließen die Protonen zurück in die Matrix. Das in dieser Reaktion synthetisierte ATP stellt die wichtigste Speicher- und transportierbare Energieform für die Zelle dar.

\subsubsection{Funktion während der Apoptose}

Erst in jüngerer Zeit ist die zentrale Rolle der Mitochondrien in der Regulation und Auslösung des programmierten Zelltodes (Apoptose) erkannt worden (Kroemer 1998). Im Gegen- 
satz zu Nekrose (provozierter Zelltod), die meist durch eine Schädigung der Zelle von außen verursacht wird und zu einer Entzündungsreaktion im umliegenden Gewebe führt, kommt es bei der Apoptose zu keiner Entzündungsreaktion und zu keiner Schädigung des angrenzenden Gewebes (Kerr et al. 1972).

Apoptose ist ein wichtiger Mechanismus, um den Organismus vor potentiellen Gefahren wie z.B. genotoxisch geschädigten oder viral infizierten Zellen zu schützen (Shub 1994). Ebenso ist die Apoptose ein wichtiges Funktionselement bei der Strukturbildung innerhalb der Embryonalentwicklung (Jacobson et al. 1997). Wie die Apoptose kann ebenfalls die Autophagie zum Absterben der Zellen führen und somit das Wachstum von vielzelligen Organismen und Hefen regulieren (Alberts et al. 1997).

Bei der Regulation der Apoptose unterscheidet man zwischen einem extrinsischen und intrinsischen Weg (siehe Abbildung 2). Welcher der beiden Signaltransduktionswege tatsächlich wirksam wird, hängt neben dem apoptotischen Stimulus auch von dem jeweiligen Zelltyp ab.

Der extrinsische Signalweg wird durch die Aktivierung von Zelloberflächenrezeptoren vermittelt. Rezeptoren wie z.B. der TNF-Rezeptor (tumor necrosis factor) leiten apoptotische Signale in die Zelle weiter und führen zur Aktivierung einer Kaskade sich autokatalytisch spaltender Caspasen. Caspasen gehören zur Familie von Proteasen mit einem Cystein im aktiven Zentrum. Sie spalten Peptidbindungen C-terminal von Aspartat, daher ihr Name (cysteinyl-aspartate-cleaving proteases). Sie sind homolog zueinander, werden während der Apoptose aktiviert und induzieren den Zelltod (Scaffidi et al. 1998). Es wird zwischen Initiator- und Effektorcaspasen unterschieden. Erstere spalten die Vorläuferformen nachgeschalteter Effektorcaspasen. Caspasen werden als inaktive Pro-Enzyme synthetisiert, die aus drei Domänen bestehen, einer N-terminalen Pro-Domäne sowie einer großen (20 kDa) und einer kleinen (10 kDa) Untereinheit. Die aktive Caspase entsteht durch eine Abspaltung der Pro-Domäne und einer Trennung der kleinen und großen Untereinheit. Sie bildet in allen bisher untersuchten Fällen ein Tetramer, bestehend aus jeweils zwei kleinen und zwei großen Untereinheiten mit zusammen zwei aktiven Zentren. Caspasen sind im Laufe der Evolution stark konserviert geblieben, es gibt sie sowohl im Menschen wie auch Insekten, Nematoden und sogar in Hydra (Budihardjo et al. 1999, Cikala et al. 1999, Earnshaw et al. 1999). Zur Zeit sind 14 verschiedene Caspasen bekannt. 


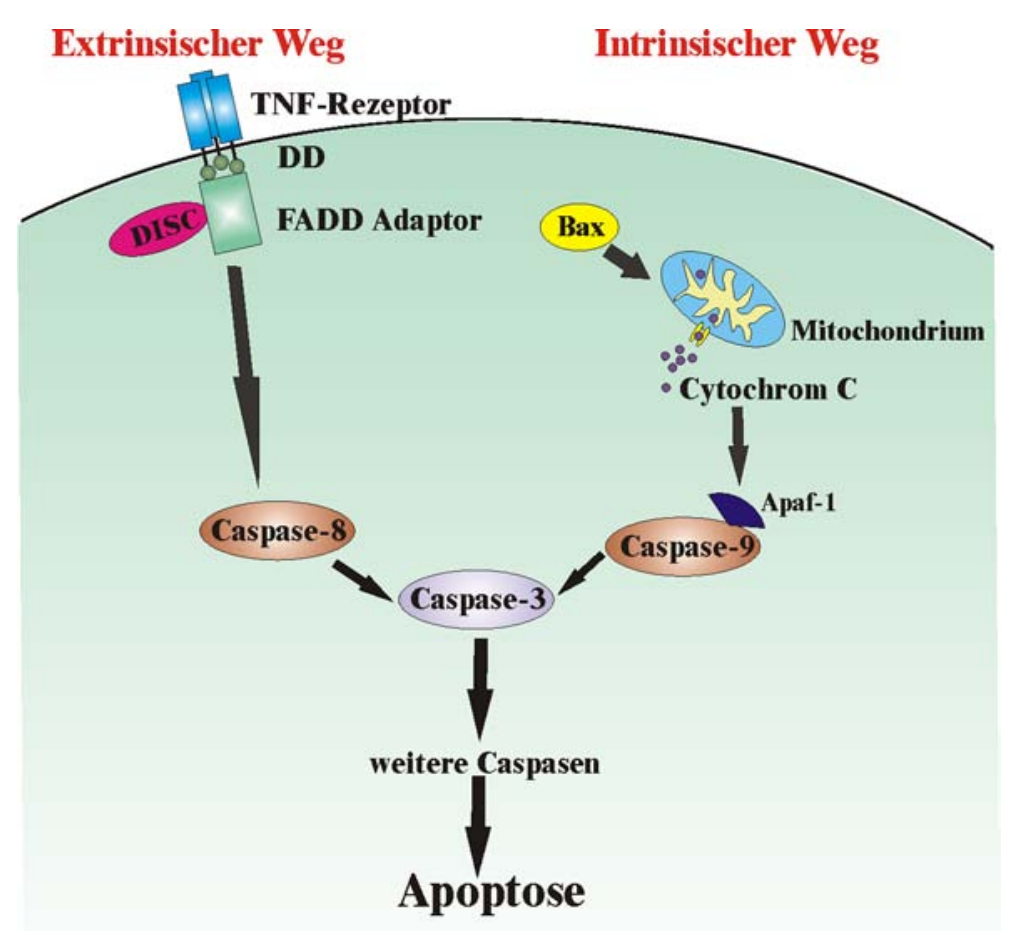

Abbildung 2: Überblick über den extrinsischen und intrinsischen Apoptoseweg.

Die Aktivierung des extrinsischen Apoptosesignalweges erfolgt über die Bindung von Liganden an z.B. TNFRezeptoren. Aktive TNF-Rezeptoren formen einen membrangebundenen Signalkomplex, welcher aus den zytoplasmatisch gelegenen DD (death domain), den Rezeptoren und den Adaptermolekülen FADD (Fas associated death domain) besteht. Dieser Komplex rekrutiert durch die Adapterproteine FADD mehrere Procaspase 8 Moleküle. Durch die dadurch resultierende große räumliche Nähe der Procaspase-8 Moleküle können diese sich, durch ihre geringe intrinsische Protease-Aktivität, gegenseitig aktivieren. Aktive Caspase 8 Moleküle aktivieren dann eine Kaskade von Caspasen. Der intrinsische Apoptoseweg wird über endogene Signale eingeleitet und führt zur Permeabilisierung der äußeren Mitochondrienmembran. Es kommt zur Freisetzung von proapoptotischer Proteine (z. B. Cytochrom c) aus den Mitochondrien in das Zytosol. Durch die Bildung des Apoptosom aus Cytochrom c, Procaspase-9 und Apaf-1 (Apoptotic Protease Activating Factor) werden dann weitere Caspasen aktiviert.

Die beiden Signaltransduktionswege treffen bei der Aktivierung der Caspase-3 aufeinander. Eine Interaktion zwischen den beiden Signaltransduktionswegen ist ebenfalls möglich.

Der intrinsische Weg kann z.B. durch DNS-Schädigung, oxidativen Stress oder hohe $\mathrm{Ca}^{2+}$ Konzentration induziert werden (Kaufmann und Earnshaw 2000). Es kommt dabei zur Permeabilisierung der äußeren Mitochondrienmembran. Die zur Permeabilisierung der Membran führenden Mechanismen sind vielfältig. Zum einen bilden Proteine der Bcl-2 Familie (z.B. Bax und Bak) einen Kanal in der äußeren Membran. Zum anderen kann eine Permeabilitätspore (PTPC, permeability transition pore complex) gebildet werden, die unter anderem aus dem spannungsabhängigen Anionen-Kanal (VDAC, voltage-dependent anion channel) und Adenin-Nukleotid-Translokator (ANT) besteht. Diese Permeabilitätspore führt zu einer Öffnung der inneren und äußeren Membran (Green und Kroemer 2004). Durch die Permeabilisierung der Membran werden Intermembranproteine wie z.B. Cytochrom c und AIF (Apoptose induzierender Faktor) ins Zytosol freigesetzt (Luo et al. 1998). Das freie 
Cytochrom c bildet zusammen mit dem Apaf-1 und anderen Proteinen (z.B. Pro-Caspase-9) das Apoptosom, welches zur Aktivierung von Caspasen führt, die wie bei dem extrinsischen Apoptoseweg den Zelltod herbeiführen.

Mitochondrien bilden somit ein äußerst wichtiges Entscheidungszentrum für den Ablauf der intrinsischen Apoptose (Alnemri 1999, Kroemer und Reed 2000). Die Permeabilisierung der mitochondrialen Membranen (Halestrap et al. 1998, Kroemer und Reed 2000) ist dabei ein wichtiger Parameter für die Einleitung des intrinsischen Apoptoseweges.

\subsubsection{Mitochondriale Mutationen und Anomalien}

Im Hinblick auf den Alterungsprozess der Zelle spielt die mitochondriale DNS eine Rolle. Da die Nukleotide den membranassoziierten Atmungskettenkomponenten nah benachbart sind, unterliegen sie durch die in der oxidativen Phosphorylierung entstehenden freien Radikale einer erhöhten Mutationswahrscheinlichkeit. Das Mutationsrisiko wird in den Mitochondrien durch fehlende schützende Histone verstärkt. Ebenso besitzen Mitochondrien ein geringes Spektrum an DNS-Reparaturmechanismen (Croteau et al. 1999, Sawyer und Van Houten 1999). Durch homologe Rekombination mit benachbarten Nukleotiden kann allerdings eine Häufung von somatischen Mutationen in den Mitochondrien verhindert werden (Nakada et al. 2001, Ono et al. 2001). Hierbei stellen kontinuierliche Teilungs- und Verschmelzungsprozesse eine ständige Durchmischung der mitochondrialen DNS sicher und verhindern somit eine frühzeitige Zellalterung.

Beim Menschen sind eine Reihe von Erkrankungen bekannt, die auf Mutationen der mitochondrialen DNS zurückzuführen sind. Meist sind Gewebe mit hohem Energiebedarf betroffen, wie z. B. das Herz, die Muskeln, das renale und endokrine System. In einer Zelle können sowohl Mitochondrien mit normaler mtDNS als auch mit mutierter mtDNS vorliegen (Heteroplasmie). Deswegen kann eine Mutation zu unterschiedlichen Schweregraden und auch zu unterschiedlichen Krankheitsbildern führen. Auch die Inaktivierung kernkodierter Genprodukte, die wichtig für die mitochondriale Funktion und Biogenese sind, führt zu verschiedenen Krankheiten. Typische mitochondriale Erkrankungen, die auf mitochondriale Mutationen zurückzuführen sind, sind: Enzephalomyopathie, FBSN (Familäre bilaterale striatale Nekrose), Lebersche Optikusatrophie, Leigh-Syndrom, MELAS (Myopathie, Enzephalopathie, Laktatazidose und Schlaganfall-ähnliche Episoden), MERRF (MyoklonusEpilepsie), MILS (MateRNSl vererbtes Leigh-Syndrom), NARP (Neuropathie, Ataxie und Retinis pigmentosa), Kearns-Syndrom und Keratodermia palmoplantaris. 


\subsubsection{Transport von Mitochondrien}

Nicht nur die Gestalt der Mitochondrien, auch die Anzahl und Verteilung innerhalb der Zelle unterliegt dynamischen Veränderungen und passt sich energetischen Bedürfnissen der Zelle an. In der Nähe der präsynaptischen Membran der Nervenzelle sind viele Mitochondrien zu finden, ebenso in Muskelzellen nahe zu den ATP-verbrauchenden Aktin-Myosin-Komplexen (Bakeeva et al. 1978). Im Gegensatz hierzu sind Fibroblasten energetisch homogen und ihre Mitochondrien sind gleichmäßig in der Zelle verteilt.

Die molekularen Mechanismen der Positionierung von Mitochondrien sind nur unzureichend verstanden. Da die Mitochondrien selbst weder Cilien noch Flagellen besitzen, nutzen sie das Zytoskelett, um sich innerhalb der Zelle zielgerichtet zu bewegen. In der Literatur wird sowohl von einem Aktinzytoskelett- abhängigen Transport, als auch von einem Mikrotubuligestützten Mechanismus berichtet (Ligon und Steward 2000, Nangaku et al. 1994, Pereira et al. 1997).

In tierischen Zellen erfolgt der mitochondriale Transport meist entlang von Mikrotubuli. Der Transport entlang der Axone von Nervenzellen ist ein besonders eindrucksvolles Beispiel für eine gerichtete Organellenbewegung. Dabei werden die Mitochondrien entlang von Mikrotubuli über lange Strecken vom Zellkörper zu den Synapsen und dem Wachstumskegel der Neurone transportiert (Hollenbeck 1996).

Die Mitochondrienbewegung in Schizosaccharomyces pombe ist ebenfalls von einem intakten Mikrotubulizytoskelett abhängig (Yaffe et al. 1996).

In tierischen Zellen konnte die Beteiligung mehrerer Kinesinisoformen (Kif1b, KLP67A, Kif5b) am mitochondrialen Transport gezeigt werden (Khodjakov et al. 1998, Nangaku et al. 1994, Pereira et al. 1997, Tanaka et al. 1998). Kif1b kolokalisiert mit Mitochondrien in vivo und ist bei der Subfraktionierung von Zellen in der mitochondrialen Fraktion angereichert. Ebenso wurde in vitro gezeigt, dass das isolierte Protein Kif1b Mitochondrien entlang von Mikrotubuli bewegen kann (Nangaku et al. 1994). Die Isoform des konventionellen Kif5B kolokalisiert mit Mitochondrien in Säugetierzellen (Khodjakov et al. 1998) und Deletionen innerhalb der Isoform führen zur einer Aggregation von Mitochondrien in der Nähe des Zellkerns (Tanaka et al. 1998). In Drosophila konnte eine Kolokalisation von KLP67A mit Mitochondrien nachgewiesen werden (Pereira et al. 1997).

Die Erkenntnisse über den Aktin-abhängigen Transport von Mitochondrien stammen überwiegend aus Untersuchungen an der Bäckerhefe (Hermann und Shaw 1998). Temperatursensitive Mutationen in Genen, welche das Aktinzytoskelett depolymerisieren oder destabilisieren, führen zur Hemmung der mitochondrialen Bewegung und Vererbung (Drubin et al. 
1993, Simon et al. 1995). Ein großer Teil der Hefemitochondrien kolokalisiert mit Aktinfilamenten. In in vitro Experimenten konnten isolierte Mitochondrien an Aktinfilamente gebunden werden. Diese Interaktion erfolgte in ATP- abhängiger Weise und wird von peripher mit der Außenmembran von Mitochondrien verbundenen Proteinen vermittelt (Lazzarino et al. 1994). Des Weiteren konnte eine ATP- abhängige Motoraktivität auf der Außenmembran von Mitochondrien nachgewiesen werden (Simon et al. 1995). Für den Aktinzytoskelettabhängigen Transport konnten jedoch bisher keine beteiligten Motorproteine identifiziert werden, die eine Interaktion der Organelle mit dem Aktinzytoskelett vermitteln. Es existieren lediglich Hinweise, dass der an der Nukleation von Aktin beteiligte Arp2/3- Komplex während der Zellteilung am Transport der Hefemitochondrien in die Tochterzellen involviert ist (Boldogh et al. 2001).

Die Mitochondrienbewegung in dem filamentösen Pilz A. nidulans erfolgt ebenfalls entlang des Aktinzytoskeletts (Suelmann und Fischer 2000). Ebenso wurde der mitochondriale Transport in den Photozellen der Heuschrecke Schistocerca gregaria als Aktin- abhängig beschrieben, da er sich durch Aktinzytoskelett- depolymerisierende Substanzen inhibieren lässt (Sturmer et al. 1995).

\subsubsection{Mitochondriale Zerteilung und Verschmelzung}

Obwohl die interne Struktur der Mitochondrien stark konserviert ist, kann ihre äußere Gestalt sogar von Zelle zu Zelle stark variieren. Die Veränderung der Mitochondrienmorphologie stellt eine Anpassung des Organells an externe und interne Signale der Zelle dar (z.B. Energiestatus, Apoptose). Die Vielfalt der Formen reicht von kleinen, kugelförmigen Organellen bis hin zu langgestreckten, netzartigen Mitochondrien (Bereiter-Hahn und Voth 1994). Die in den meisten Zelltypen auftretenden mitochondrialen Erscheinungsformen sind hoch dynamisch und komplex. Sie werden von kontinuierlichen Zerteilungs- und Verschmelzungsereignissen bestimmt (siehe Abbildung 3). Der Verlust von Proteinen, die an der mitochondrialen Zerteilung beteiligt sind, führt zur Bildung von zusammenhängenden, netzartigen Organellen. Der Phänotyp ergibt sich aus dem Fortschreiten der Fusionsvorgänge, während die Zerteilung unterbunden ist. Zellen, die sowohl einen Defekt in der Fusion als auch in der Zerteilung aufweisen, zeigen auch eine netzartige mitochondriale Morphologie. Diese Beobachtung unterstützt die Annahme, dass die Mitochondrienmorphologie durch ein ausgeglichenes Verhältnis von Zerteilung und Verschmelzung aufrechterhalten wird. Die an der mitochondrialen Dynamik beteiligten Proteine werden im Folgenden näher beschrieben. 


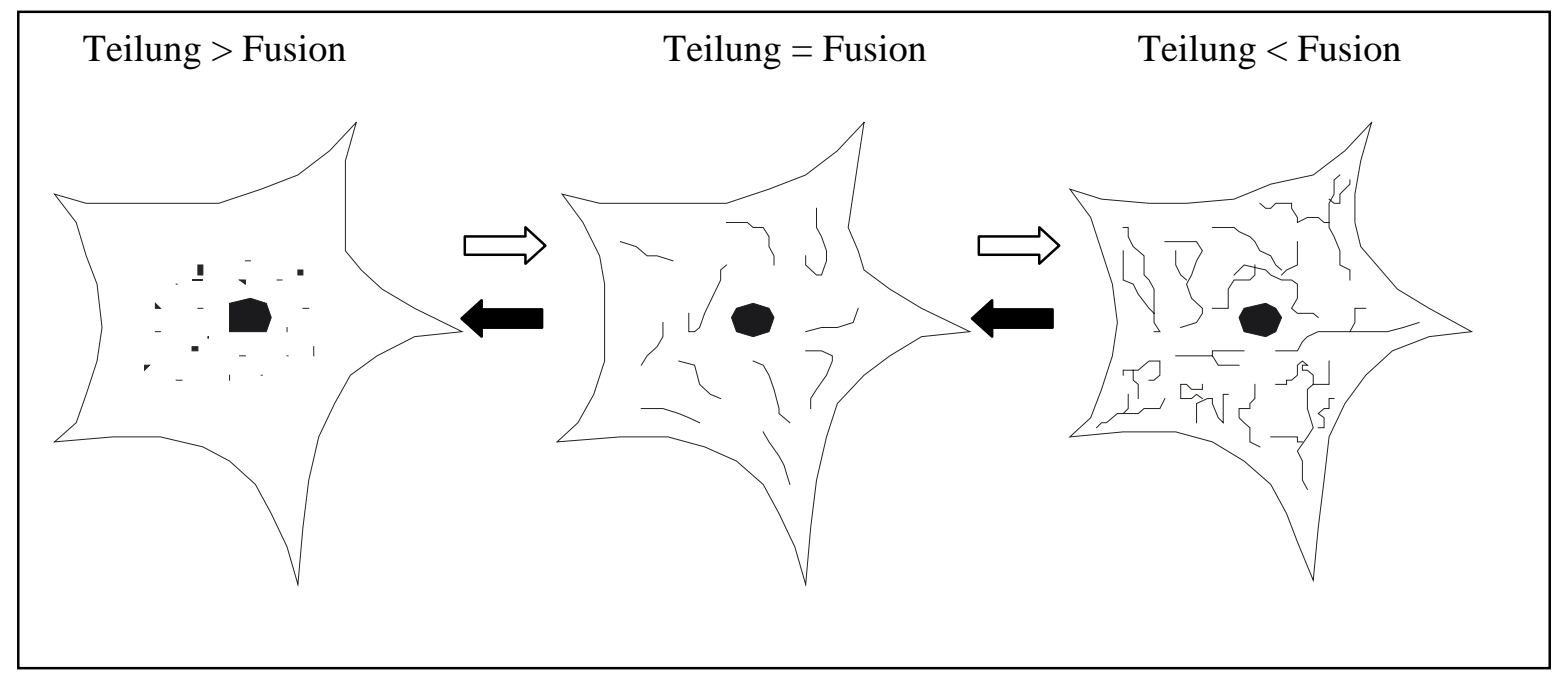

Abbildung 3: Das mitochondriale Netzwerk wird durch ausbalancierte Verschmelzungs- und Zerteilungsereignisse gebildet.

Die Morphologie der Mitochondrien ergibt sich aus dem Gleichgewicht von Zerteilung und Fusion der einzelnen Mitochondrien. Überwiegen allerdings die Fusionsereignisse über die Zerteilungsrate kommt es zur Ausbildung von netzartigen Strukturen. Wird die Zerteilung in den Mitochondrien inhibiert kommt es zur Fragmentation der Mitochondrien.

\subsubsection{Der mitochondriale Zerteilungsapparat}

Da Mitochondrien nicht de novo entstehen können, müssen sie bei der Vererbung auf die Tochterzellen durch Zerteilung vermehrt werden.

Das Mitochondrium ist von einer Doppelmembran umgeben, für beide Membranen existieren zwei unabhängige voneinander agierende Zerteilungsmechanismen. Studien in $C$. elegans zeigten, dass die Zerteilungsfähigkeit der Innenmembran nicht verloren geht, wenn der Zerteilungsapparat der Außenmembran funktionsunfähig ist (Labrousse et al. 1999). Eine vermehrte Zerteilungsrate der Innenmembran ist häufig in Zelltypen mit sich schnell teilenden Mitochondrien zu beobachten z.B. in Fettzellen von metamorphosierenden Schmetterlingen (Larsen W.J. 1970). Die Matrix wird dabei durch Scheidewände (Septen) der Innenmembran aufgeteilt, wobei sich die Außenmembran erst in einem späteren Schritt teilt. Diese Septenbildung ist ebenfalls häufig im Herzmuskelgewebe zu beobachten (Tandler et al. 1969).

Das einzige bekannte Protein, welches bei der Zerteilung der mitochondrialen Innenmembran involviert ist wurde in Hefe entdeckt und als Mdm33 bezeichnet (Messerschmitt et al. 2003). Zellen, denen das Mdm33-Protein fehlt, enthalten ringähnliche miteinander verbundene Mitochondrien, welche große Hohlkugeln ausbilden können. Diese Organellen weisen extrem auseinander gezogene Abschnitte der Außen- und Innenmembran auf, die einen sehr schmalen Matrixspalt umschließen. Die Überexpression von Mdm33 führt zur Einstellung des Wachstums, die Mitochondrien aggregieren, und es entwickelt sich eine stark veränderte 
Innenmembranstruktur. Es bilden sich verstärkt Septen aus, die den Matrixraum mehrfach unterteilen, oder die Innenmembran verliert die Cristae und fragmentiert.

Die Zerteilung der Außenmembran wird durch zwei Proteine gesteuert: Drp1 (dynamin related protein) und Fis1 (mitochondrial fission).

Drp1 nimmt bei dem mitochondrialen Zerteilungsvorgang eine Schlüsselrolle ein (Labrousse et al. 1999, Sesaki und Jensen 1999, Smirnova et al. 1998). Es gehört zu der Familie der dynaminähnliche GTPase, welche GTP bindet und dieses hydrolysiert (Fukushima et al. 2001). Die dynaminähnlichen GTPasen sind an Signaltransduktion, Proteinsynthese, Zelldifferenzierung und -proliferation, Regulation des vesikulären Transports und Membrantranslokation von Proteinen beteiligt. Da alle Dynamine einen ähnlichen Aufbau besitzen (siehe Abbildung 64) besteht Drp1 wie die anderen Dynamine aus einer N-terminalen GTPase Domäne, einer Mitteldomäne, einer hydrophilen Region von bisher noch unbekannter Funktion (Insert B) und einer C-terminalen GTPase-Effektor Domäne (GED). Der limitierenden Faktor bei der mitochondrialen Zerteilung ist die Bindung des GTP's an Drp1 und nicht dessen Hydrolyse. Sowohl in Hefe als auch in humanen Zellen wurde gezeigt, dass Mutationen in der GTPase Domäne oder Transfektionen mit dominant negativem Drp1 sich in einer verminderten Zerteilungsaktivität widerspiegeln.

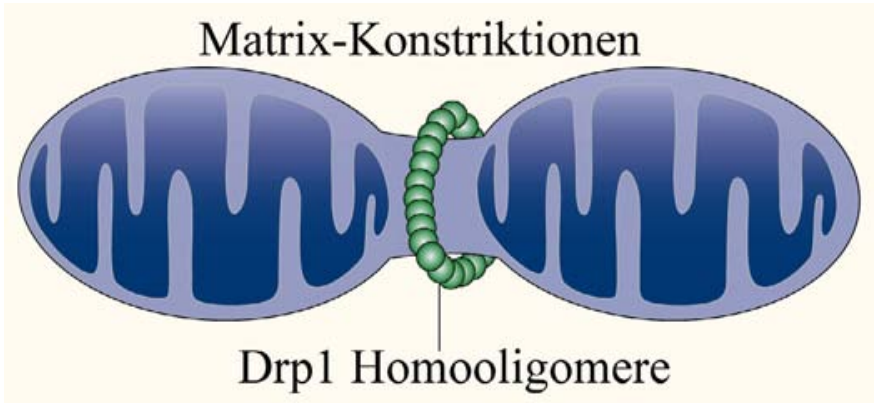

\section{Abbildung 4: Ausbildung der Matrix-Konstriktionen (Youle und Karbowski 2005).}

Die Ausbildung von Einschnürungen (Matrix-Konstriktionen) ist einer der ersten Schritte bei der mitochondrialen Zerteilung. Vermutlich sind diese Einschnürungen notwendig für die Ausbildung der Drp1 Spirale, die das Mitochondrium endgültig durchschnürt.

Der erste Schritt in der mitochondrialen Zerteilung ist die Ausbildung von Einschnürungen (Matrix-Konstriktionen, siehe Abbildung 4). Dabei lagert sich Drp1 in Clustern an die zytoplasmatische Seite der äußeren Mitochondrienmembran an (Bleazard et al. 1999), die während der mitochondrialen Zerteilung Homooligomere bilden (Fukushima et al. 2001). Die Mehrzahl der Drp1 Homooligomeren ist nicht an aktuellen Zerteilungsvorgängen beteiligt, während eine Minderheit dieser Homooligomeren vermutlich spiralförmige Strukturen 
um die zuvor gebildeten Matrix-Konstriktionen ausbilden und das Mitochondrium durchschnüren (Shaw und Nunnari, 2002).

Der Ablauf der mitochondrialen Zerteilung ähnelt sehr der Abschnürung von Vesikeln wie sie zum Beispiel aus der Endocytose und Sekretion bekannt ist. Dort oligomerisieren die beteiligten Dynamine zu Ringen und Helices (Carr und Hinshaw 1997, Hinshaw und Schmid 1995, Klockow et al. 2002, Kochs et al. 1998, Sweitzer und Hinshaw 1998, Takei et al. 1995, Zhang et al. 2000). Diese Oligomerisierung bewirkt eine Stimulation der GTPaseAktivität (Barylko et al. 1998, Herskovits et al. 1993, Shpetner und Vallee 1989, Tuma et al. 1993, Tuma und Collins 1994, Warnock et al. 1996). Die Dynamine verursachen durch Kontraktion der Helix die Abschnürung neugebildeter Vesikel von der Plasmamembran (Sweitzer und Hinshaw 1998). Ein weiteres Modell beschreibt, dass durch die GTPase Aktivität der Abstand der einzelnen Helices vergrößert wird (Stowell et al.,1999). Danach würde Dynamin ein entstehendes Vesikel nicht durch Kontraktion der Helix von der Membran abschnüren, sondern durch Überdehnung des Vesikelhalses. Welcher genaue Mechanismus nun der mitochondrialen Zerteilung zu Grunde liegt ist bis zum heutigen Zeitpunkt noch nicht aufgeklärt.

In vitro wurden Drp1 Spiralen mit einem Durchmesser von $100 \mathrm{~nm}$ beobachtet (Ingerman et al. 2005). Da der Mitochondriendurchmesser jedoch 350-500 nm (Egner et al. 2002) beträgt, stellt die Ausbildung von Matrixkonstriktionen vermutlich eine Vorbedingung zur Anlagerung von Drp1-Spiralen dar. Wahrscheinlich induziert die Hydrolyse von GTP eine Konformationsänderung der Spirale und führt zur Trennung der Stränge (Fukushima et al. 2001).

Die Signaltransduktion, welche die Zerteilung der Mitochondrien reguliert ist bis zum heutigen Zeitpunkt nicht bekannt. Neuere Studien benennen SUMO1 (Small Ubiquitin-related Modifier) als einen regulierenden Faktor in der Drp1 Aktivität bei Säugerzellen (Harder et al. 2004).

Fis1 ist ein evolutionär konserviertes integrales Protein der mitochondrialen Außenmembran, welches gleichmäßig auf der Mitochondrienoberfläche verteilt ist (siehe Abbildung 5). Der C-Terminus von Fis1 ragt in den Intermembranraum, während der N-terminale Abschnitt ins Zytoplasma ragt und sechs $\alpha$-Helices aufweist (Mozdy et al. 2000). Fis1 ist in zwei Schritten am mitochondrialen Zerteilungsvorgangs beteiligt (Tieu et al. 2002). In der frühen Phase bindet es Drp1 zur mitochondrialen Membran (Tieu et al. 2002), in einer späteren Phase ist es zusammen mit Drp1 am eigentlichen Zerteilungsprozess beteiligt (Cerveny und Jensen 2003, Shaw und Nunnari 2002, Tieu et al. 2002). Neben Fis1 wurde in Säugerzellen beobachtet, dass Komponenten des Zytoskeletts die Rekrutierung des Drp1 zu 
den Mitochondrien vermitteln (De Vos et al. 2005, Varadi et al. 2004). In CV1-4A-Zellen (Nierenzellen aus der grünen Meerkatze, Cercophithecus aethiops) wurde gezeigt, dass die Zerstörung des F-Aktin zu einer gestörten Rekrutierung des Zerteilungsproteins Drp1 zu den Mitochondrien führt und somit zu einer verminderten Zerteilungsaktivität der Mitochondrien (De Vos et al. 2005). In HeLa Zellen wurde dagegen von einer Dynein/Dynaktin-abhängigen Drp1 Rekrutierung zu den Mitochondrien berichtet.

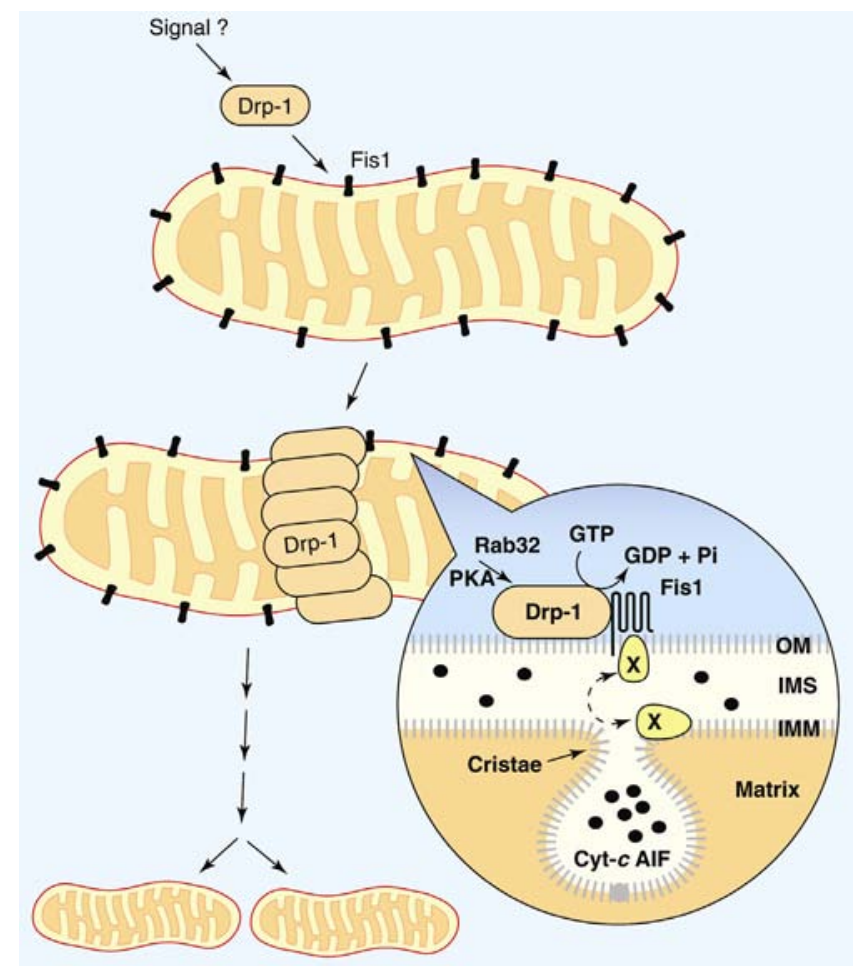

Abbildung 5: Schematische Darstellung der mitochondrialen Zerteilungsvorgänge (Bossy-Wetzel et al. 2003).

Drp1 wird durch ein noch unbekanntes Signal aktiviert. In der aktiven Form bindet es über Fis1 an die äußere Membran der Mitochondrien. Es kommt zur Ausbildung einer Drp1 Spirale. Die Durchschnürung des Mitochondriums erfolgt in Abhängigkeit des GTP-Status und führt zur Trennung des Mitochondriums. Rab32 wird durch die Protein Kinase A (PKA) aktiviert und fungiert als regulierendes Protein.

In Hefe wurden zwei weitere für die Zerteilung verantwortliche Proteine identifiziert, Mdv1p (mitochondrial division protein) und Caf4p (CCR4 associated factor) (Mozdy et al. 2000, Tieu und Nunnari 2000). Sie fungieren dort als molekulare Adaptoren zwischen Fis1 und Drp1 (Griffin et al. 2005, Tieu und Nunnari 2000). Mdv1p wird in Abhängigkeit von Fis1 zu den Mitochondrien rekrutiert, während es sich in Dnm1p-abhängiger Weise (Hefehomolog zu Drp1) zu punktförmigen Strukturen auf der äußeren Membran anlagert (Tieu und Nunnari 2000). Experimente mit Dnm1p GTPase-Mutanten deuten auf eine GTP-abhängige Regulation der Dnm1p-Mdv1p-Interaktion hin (Cerveny und Jensen 2003). Caf4p weist eine starke Homologie zu Mdv1p auf, daher wird eine ähnliche Wirkungsweise als molekularer Adaptor postuliert (Griffin et al. 2005). 


\subsubsection{Der mitochondriale Verschmelzungsapparat}

Die Verschmelzung von Membranen ist für eine Reihe verschiedenster zellulärer Prozesse erforderlich. Zum Beispiel spielt die Verschmelzung von membranumhüllten intrazellulären Kompartimenten und Transportvesikeln eine wichtige Rolle beim gerichteten Transport von Proteinen in der Zelle. Bei den Verschmelzungsprozessen im sekretorischen Apparat sind Andock- und Fusionsproteine auf beiden Membranen für diese Vorgänge verantwortlich, die sogenannten SNARE-Proteine (soluble NSF attachment receptor), welche spezifisch auf den subzellulären Kompartimenten lokalisiert sind (Rothman, 1994; Weber et al., 1998). Diese sorgen normalerweise für die korrekte Verschmelzung zweier Membranen, da jedes Organell bzw. Vesikel sein einzigartiges SNARE-Protein-System besitzt. Ein großes Problem bei der mitochondrialen Fusion stellt die Koordination der miteinander zu verschmelzenden inneren und äußeren Membranen dar. Im Gegensatz zu anderen Membranverschmelzungen sind hierbei keine SNARE-Proteine beteiligt.

\begin{tabular}{|c|c|c|c|c|}
\hline Protein & \begin{tabular}{|l|} 
Hefe Ho- \\
molog
\end{tabular} & Phänotyp der Mutante & Zelluläre Lokalisation & Funktion \\
\hline Mfn1/2 & Fzo & $\begin{array}{l}\text { Fragmentierte Mitochondrien; } \\
\text { Fusionsdefekt }\end{array}$ & $\begin{array}{l}\text { Mitochondriale } \\
\text { Außenmembran }\end{array}$ & $\begin{array}{l}\text { GTPase; } \\
\text { Transmembran- } \\
\text { protein }\end{array}$ \\
\hline OPA1 & Mgm1 & $\begin{array}{l}\text { Fragmentierte und aggregierte } \\
\text { Mitochondrien; Fusionsdefekt }\end{array}$ & $\begin{array}{l}\text { Mitochondrialer Inter- } \\
\text { membranraum, asso- } \\
\text { ziiert mit der Innen- } \\
\text { membran }\end{array}$ & dynaminähnliche GTPase \\
\hline Drp1 & Dnm1 & $\begin{array}{l}\text { Netzartige Mitochondrien; } \\
\text { Zerteilungsdefekt }\end{array}$ & $\begin{array}{l}\text { Zytosol und mitochon- } \\
\text { driale Außenmembran }\end{array}$ & dynaminähnliche GTPase \\
\hline Fis1 & Fis1 & $\begin{array}{l}\text { Netzartige Mitochondrien; } \\
\text { Zerteilungsdefekt }\end{array}$ & $\begin{array}{l}\text { Mitochondriale } \\
\text { Außenmembran }\end{array}$ & $\begin{array}{l}\text { Transmembran- } \\
\text { protein }\end{array}$ \\
\hline Ugo1 & Ugo1 & $\begin{array}{l}\text { Fragmentierte Mitochondrien; } \\
\text { Fusionsdefekt }\end{array}$ & $\begin{array}{l}\text { Mitochondriale } \\
\text { Außenmembran }\end{array}$ & $\begin{array}{l}\text { Transmembran- } \\
\text { protein }\end{array}$ \\
\hline Mdv1p & Mdv1 & $\begin{array}{l}\text { Netzartige Mitochondrien; } \\
\text { Zerteilungsdefekt }\end{array}$ & Zytosol & Adapterprotein \\
\hline Caf4p & Caf4p & $\begin{array}{l}\text { Netzartige Mitochondrien; } \\
\text { Zerteilungsdefekt }\end{array}$ & Zytosol & Adapterprotein \\
\hline
\end{tabular}

Tabelle 1: Zusammenfassung der wichtigsten Proteine, die an der mitochondrialen Dynamik beteiligt sind.

Mfn1/2 und OPA1 sind GTPasen, die an der Fusion zweier mitochondrialer Membranen beteiligt sind. Drp1 und Fis1 regulieren die mitochondriale Zerteilung eines Mitochondriums. Ugo1, Mdv1 und Caf4p sind bis zum heutigen Zeitpunkt nur an der mitochondrialen Fusion in Hefen beschrieben. Von Mdv1 und Caf4p ist bekannt, dass sie als molekulare Adapterproteine zwischen Mgm1 und Fzo fungieren. 
Untersuchungen an Drosophila melanogaster (Hwa et al. 2002) identifizierten das an der mitochondrialen Verschmelzung beteiligte Gen „fuzzy onions“ (fzo). Das Gen kodiert eine membranständige GTPase, die in Drosophila während der Spermatogenese die korrekte Strukturierung der Mitochondrien am Flagellum bewirkt (Hales und Fuller 1997). Fzo und seine später entdeckten Homologe, die wegen ihrer Bedeutung bei der mitochondrialen Verschmelzung als Mitofusine (Mfn) bezeichnet werden, sind in der mitochondrialen Außenmembran lokalisiert (Hales und Fuller 1997). Sie sind sowohl im Pilz- als auch im Tierreich konserviert. Höhere Metazoen wie Insekten, Fische oder Säuger haben jeweils zwei fzo-verwandte Gene, die man als Mitofusin 1 (Mfn1) und Mitofusin 2 (Mfn2) bezeichnet.

Die beiden humanen Isoformen werden in einer Vielzahl von Geweben exprimiert, wie z.B. Gehirn, Fibroplasten, Herz, Niere, Leber, Muskel und Testis (Legros et al. 2002). Alle fzo-Familienmitglieder haben eine ähnliche Domänenstruktur und Topologie. Sie besitzen zwei Transmembrandomänen nahe dem C-Terminus, die es in der äußeren Membran verankern. Der Abschnitt zwischen den beiden Transmembrandomänen (siehe Abbildung 6) sorgt durch die Interaktion mit einem bislang unbekannten Innenmembranprotein für die Assoziation der beiden mitochondrialen Membranen (Fritz et al. 2001).

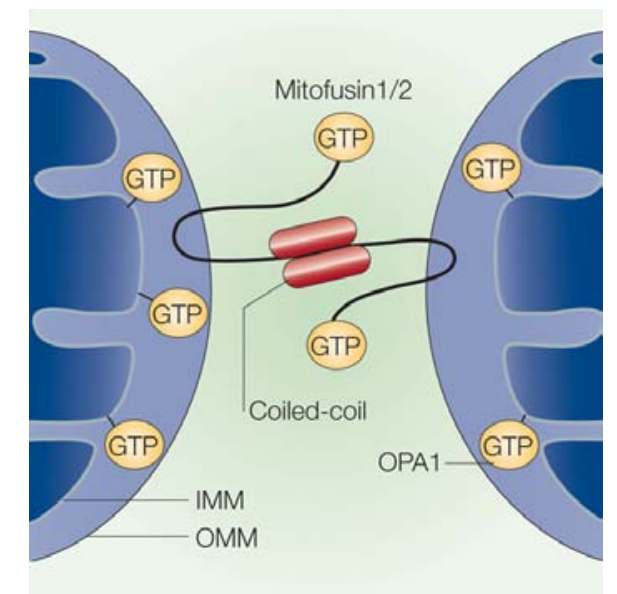

Abbildung 6: Verschmelzung zweier mitochondrialer Membranen (Youle und Karbowski 2005).

Dargestellt ist die modellhafte Vorstellung der mitochondrialen Membranfusion. Die daran beteiligten GTPasen Mitofusine1/2 sind mit ihren nahe dem C-Terminus gelegenen Transmembrandomänen in der äußeren Mitochondrienmembran verankert. Die Verschmelzung der beiden mitochondrialen Membranen wird über die coiledcoil Domäneninteraktion der Mitofusine1/2 eingeleitet.

Eine weitere an der Verschmelzung beteiligte GTPase ist OPA1 (optic atrophy, Delettre et al. 2000, Pelloquin et al. 1998). Mutationen in OPA1 führen zur autosomal dominanten optischen Atrophie (ADOA), welche die erste direkte Verbindung der mitochondrialen Morphologie mit einem Krankheitsbild darstellt. Die beobachtete Pathologie beruht auf dem Absterben der retinalen Ganglienzellen (Alexander et al. 2000). Es ist bisher nicht voll- 
ständig geklärt, ob der Defekt auf einer energetischen Unterversorgung der Zellen durch den sekundären Verlust der Atmungskette oder einer erhöhten Sensitivität gegenüber Apoptose durch Sauerstoffradikale zurückzuführen ist (Carelli et al. 2004).

OPA1 wird durch proteolytische Spaltung seiner Transmembrandomäne aktiviert und liegt somit frei im Intermembranraum vor (siehe Abbildung 7). Dort kommt es zur Interaktion und Komplexbildung mehrerer OPA1-Proteine. Diese OPA1-Komplexe sind an der Einfaltung der inneren Membran und somit an der Cristae-Bildung beteiligt, sie können jedoch auch an dem Mechanismus der Annäherung zweier gegenüberliegender innerer Membranen beteiligt sein (Olichon et al. 2003).

Ugo1 (japanisch für „Zerteilung“) wurde bisher nur in Pilzen identifiziert. Obwohl es typische Sequenzmotive eines Transporters aufweist, liegt es integriert in der äußeren Membran vor (Sesaki und Jensen 1999). Ugo1 fungiert als Adapter zwischen Mfn1/2 und OPA1 und könnte somit die Verschmelzung der inneren und äußeren Membranen koordinieren (Sesaki und Jensen 2001).

Die koordinierte Fusion der Mitochondrien wird vermutlich über einen Mechanismus erreicht, der einen engen Kontakt zwischen äußerer und innerer Membran vermittelt. Der erste Schritt der mitochondrialen Membranfusion könnte dem Mechanismus ähneln, der auch für SNARE- vermittelte Membranfusion gilt (Meeusen et al. 2004). Zuerst ist ein Andocken der ins Zytosol ragenden Bestandteile der Mfn1/2 mit dem Partner auf der gegenüberliegenden Membran erforderlich. Die Assemblierung des Fusionskomplexes ist möglicherweise von Konformationsänderungen begleitet, welche die Vermischung der Lipide in den Außenmembranen begünstigen. Die Kopplung der Außenmembran mit der Innenmembran durch den Fusionskomplex in den Kontaktstellen könnte dafür verantwortlich sein, dass die Verschmelzung der Innenmembranen initiiert wird, nachdem die Verschmelzung der Außenmembranen abgeschlossen ist. Dadurch fällt ein Andocken der Innenmembranen weg, da sich die Innenmembranen schon in einer optimalen Position für die Verschmelzung befindet. Zum Schluss beendet die Trennung der fusionierten Innenmembranen und die Vermischung des Matrixinhaltes den mitochondrialen Fusionsprozess (Fritz et al. 2001). 


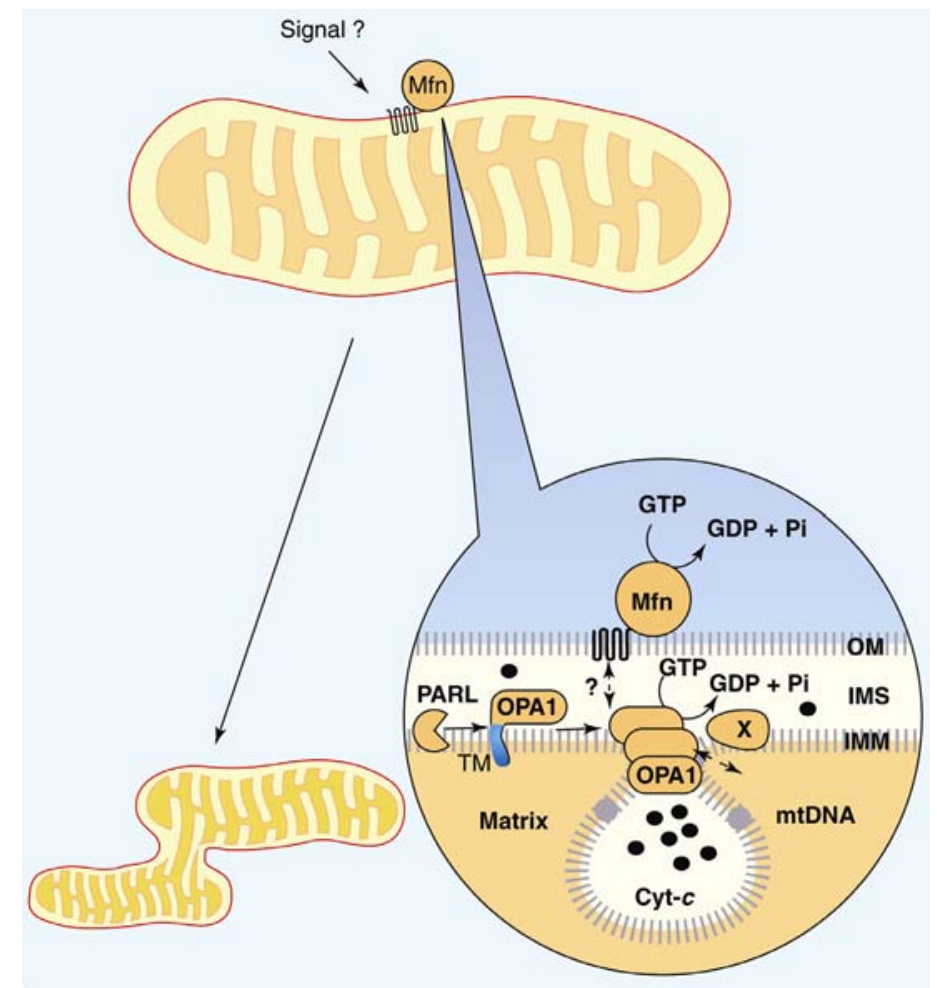

Abbildung 7: Schematische Darstellung der mitochondrialen Verschmelzung (Bossy-Wetzel et al. 2003).

Die an der mitochondrialen Membranfusion beteiligten Mitofusine1/2 sind mit ihren Transmembrandomänen in der äußeren Mitochondrienmembran verankert. Sie sorgen durch die Interaktion mit einem bislang unbekannten Innenmembranprotein für die Assoziation der beiden mitochondrialen Membranen. Durch ein unbekanntes Signal kommt es zur Hydrolyse von GTP zu GDP.

OPA1 wird durch eine von PARL vermittelte proteolytische Spaltung seiner Transmembrandomäne aktiviert. Das freigewordene OPA1 bildet nun unterstützt durch seine GTPase Aktivität ringförmige Komplexe aus, welche an den Verschmelzungen der beiden Membranen beteiligt sind. OPA1 kann möglicherweise mit anderen Faktoren (hier mit X gekennzeichnet) interagieren.

\subsubsection{Physiologische Bedeutung der mitochondrialen Zerteilungs- und Ver- schmelzungsvorgänge}

Verschiedenste zelluläre Funktionen werden durch die mitochondriale Morphologie, Dynamik und Verteilung entscheidend beeinflusst. In einigen Zellen kommen morphologisch und funktionell unterscheidbare Mitochondrienpopulationen vor (Collins et al. 2002). Neben der Morphologie der Mitochondrien variiert auch die intrazelluläre Verteilung zwischen den verschiedenen Zelltypen eines Organismus (Bereiter-Hahn und Voth 1994, Griparic und van der Bliek 2001). Zerteilungsvorgänge sind von großer Bedeutung für die Vererbung von Mitochondrien (Labrousse et al. 1999). Ferner wurde beobachtet, das sich Mitochondrien im Verlauf der Apoptose vermehrt teilen (Frank et al. 2001). Die Verschmelzung von Mitochondrien dient im Gegensatz dazu eine verfrühte Zellalterung zu verhindern. Innerhalb der mitochondrialen Verschmelzung kommt es zur Durchmischung der mitochondrialen Membranen und somit zu einer Möglichkeit das mitochondriale Genom zu rekombinieren (Ono et al. 2001). 
Eine weitere wichtige Bedeutung kommt der mitochondrialen Verschmelzung bei der Differenzierung bestimmter Zellen zu. So erfolgt bei der Ausbildung der Spermien in Drosophila melanogaster eine drastische Umstrukturierung der Mitochondrien, bei der Verschmelzungsvorgänge essentiell sind (Hales und Fuller 1997). Des Weiteren kann das bei der Fusionierung der Mitochondrien entstehende Netzwerk dazu benutzt werden, chemiosmotische Energie in verschiedene Bereiche der Zelle zu übertragen. So werden in Muskelzellen mehrere Schichten von Mitochondrien direkt unterhalb der Plasmamembran (Sarkolemma) gefunden, die über mitochondriale Filamente mit den Mitochondrien im sauerstoffarmen Zellinneren verbunden sind (Skulachev, 2001).

\subsection{Cykline- abhängige Kinasen}

Das Kontrollsystem des Zellzyklus beruht auf zwei Proteinfamilien. Die erste Familie ist die Familie der cyklin- abhängigen Proteinkinasen (kurz CDK's), die nachgeordnete Prozesse durch die Phosphorylierung bestimmter Proteine an Serin- und Threonin- Resten auslösen. Die Zweite ist eine Familie spezialisierter Aktivierungsproteine sogenannter Cykline, die an CDK’s binden und deren Fähigkeit kontrollieren, Zielproteine zu phosphorylieren,. Cykline werden sie genannt, weil sie bei jeder Zellteilung Synthese und anschließendem Abbau unterworfen sind. Die periodische Zusammenlagerung, Aktivierung und das Zerfallen von Cyklin-CDK-Komplexen sind die zentralen Ereignisse, die den Zellzyklus steuern.

Die Cyklin-abhängige Kinase 5 (CDK5) wurde in den frühen 1990er Jahren beschrieben (Dhavan und Tsai 2001). Sie ist eine Prolin-gerichtete Kinase, die hohe Sequenzhomologie zu anderen CDK’s aufweist, jedoch im Unterschied zu diesen nicht an der Regulation des Zellzyklus beteiligt ist.

Physiologische Bedeutung hat CDK5 bei der Entwicklung des zentralen Nervensystems, der Regulation der Neuronenmigration, dem Lernen und Gedächtnis sowie an der synaptischen Übertragung. Der Verlust von CDK5 führt beispielsweise zu einer Fehlentwicklung des Gehirns. Es kommt zu einer invertierten Anordnung der Schichten des cerebralen Kortex (Smith et al. 2001). Ebenso ist CDK5 an vielen Abläufen innerhalb der Zelle beteiligt z.B. Organisation des Zytoskeletts, Endo- und Exocytose, Zelladhäsion und der Regulierung von Signalwegen (siehe Tabelle 2). Eine gestörte Regulation von CDK5 resultiert in der Degeneration von Neuronen und kann somit zu neurodegenerativen Erkrankungen wie z.B. Morbus Alzheimer und ALS (Amyotropher Lateralsklerose) führen (Smith et al. 2001). 


\subsubsection{Regulation der Cyklin-abhängigen Kinase 5}

CDK5 wird im Gegensatz zu den anderen CDK's nicht durch Cykline aktiviert, sondern durch die Bindung mit den Cyklin-verwandten Proteinen p35 und p25 sowie durch Phosphorylierung (siehe Abbildung 8, Tanaka et al. 2001). Neben p35 und p25 kann CDK5 auch durch das p35-Homolog p39 aktiviert werden. p39 und p35 weisen eine Sequenzhomologie von 57\% auf (Dhavan und Tsai 2001). Im monomerischen Zustand hat CDK5 keine enzymatische Aktivität (Tsai et al. 1994). Das CDK5 Aktivatorprotein p35 ist durch Myrisitinsäure in der Zellmembran verankert. Im Fall der Aktivierung durch p35 wird CDK5 an einer Seite des katalytischen Spaltes von p35 gebunden (Maccioni et al. 2001), so dass ein p35/CDK5 Komplex entsteht. Dieser Komplex stellt die aktive Form des CDK5 dar. Serin 159 im CDK5 ist essentiell für die Bindung an p35 und somit notwendig für eine maximale Aktivierung des CDK5. Phosphorylierung des Serins 159 durch Protein Kinase A inhibiert die Bindung an p35 (Grand et al. 2001, Tarricone et al. 2001). Der p35/CDK5 Komplex phosphoryliert Proteine wie z.B. Synapsin (reguliert die synaptische Transmission), ß-Catein (reguliert Zelladhäsion), Nudel (reguliert Dynein-vermittelten Transport) und Amphiphysin 1 (reguliert Endocytose der synaptischen Vesikel). Eine Auflistung der wichtigsten CDK5 Substrate sind in der Tabelle 2 zusammengefasst.

Die beiden Aktivatorproteine p35 und p39 können durch Calpain, in Anwesenheit von Calcium in kleinere Fragmente p25 und p29 gespalten werden (Lee et al. 2000, Patzke und Tsai 2002).

Calpain ist während der Apoptose besonders aktiv, was zu einer häufigen Spaltung der CDK5 Aktivatorproteine bei neurotoxischen Bedingungen in vitro und in vivo führt (Lee et al. 2000, Patzke und Tsai 2002). CDK5 kann p35 phosphorylieren, was die Calpain abhängige Spaltung von p35 verhindert und auf eine mögliche Autoregulation hindeutet. So konnte beispielsweise in fötalen Gehirngeweben gezeigt werden, dass eine Spaltung von p35 durch Phosphorylierung des Aktivatorproteins verhindert wird (Saito et al. 2003). Des Weiteren kann CDK5 seine Aktivierung eigenständig regulieren, indem es NMDA Rezeptoren phosphoryliert. Es kommt zu einem Calcium Einstrom, der zu einer Aktivierung von Calpain führt, was wiederum in einer Spaltung von p35 zu p25 und einer Aktivitätssteigerung von CDK5 resultiert.

Die Calpain abhängige Spaltung der CDK5 Aktivatorproteine hat mehrere Auswirkungen auf die Aktivität von CDK5. Bei der Spaltung von p35 zu p25 wird der N-terminale Teil von p35 abgespalten, durch welchen p35 über Myrisitinsäure in der Zellmembran verankert ist (Amin et al. 2002, Patrick et al. 1999, Poon et al. 1997, Tarricone et al. 2001). p25 besteht 
somit nur noch aus dem C-terminalen Teil, welcher für die CDK5 Bindung und Aktivierung verantwortlich ist und befindet sich frei im Zytosol (Lee et al. 2000, Patrick et al. 1999, Patzke und Tsai 2002). Somit kann wodurch der p25/CDK5 Komplex Proteine phosphorylieren, die sich nicht in Membrannähe befinden wie z.B. Tau (siehe Tabelle 2 und Abbildung 8).

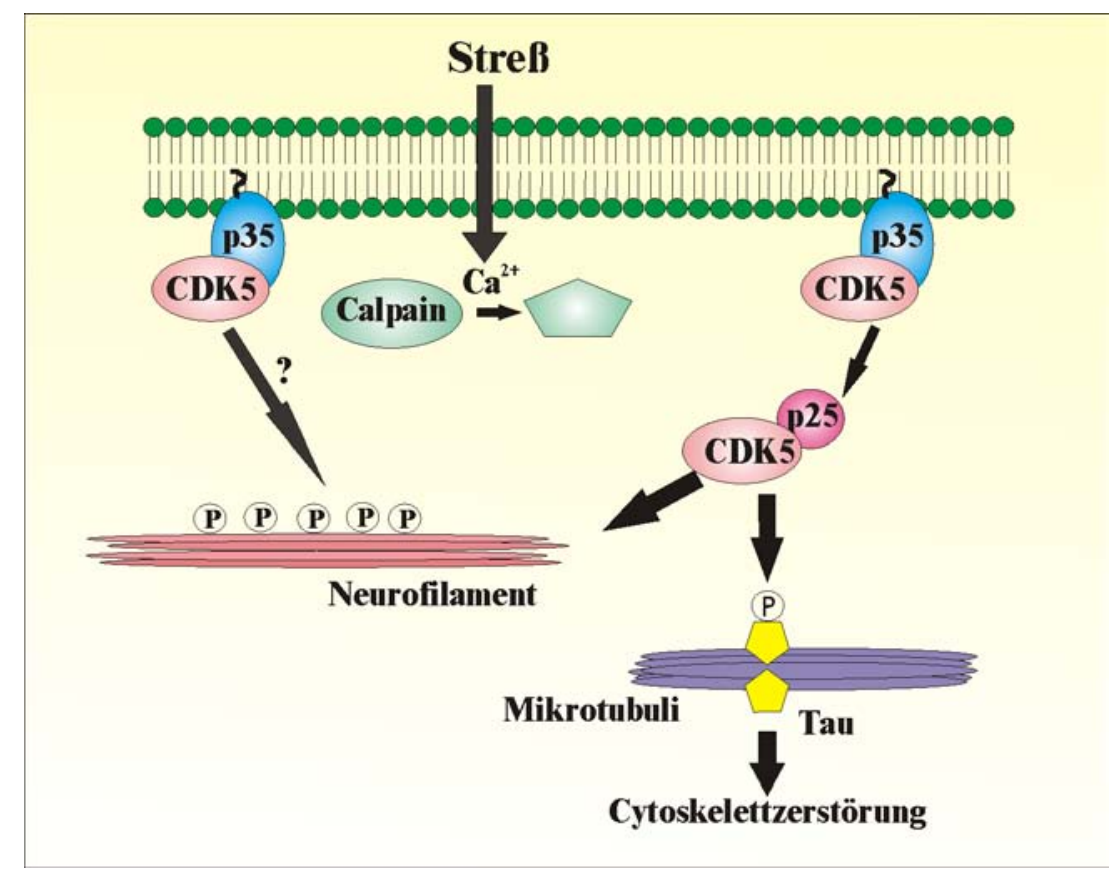

\section{Abbildung 8: Die Spaltung von p35 zu p25 ist neurotoxisch.}

Der p35/CDK5 Komplex ist über Myrisitinsäure in der Zellmembran verankert und phosphoryliert von dort verschiedene Substrate. Durch Stress (z.B. oxidativem Stress) wird Calpain aktiviert, welches p35 in p25 und p10 spaltet. Da p25 nicht durch Myrisitinsäure in der Membran verankert ist, kann der p25/CDK5 Komplex ins Zytoplasma diffundieren und dort Substrate wie das Tau-Protein oder die Neurofilamente phosphorylieren. Eine verstärkte Phosphorylierung dieser Proteine könnte zu zytoskelettalen Veränderungen und damit zum Zelltod führen (Dhavan und Tsai 2001).

Die Spaltung von p35 zu p25 resultiert in einer quantitativen Veränderung der CDK5- Aktivität, da p25 im Vergleich mit p35 der stärkere Aktivator von CDK5 ist. Er weist eine wesentlich längere Halbwertzeit (>60 Minuten, p35: 20-30 Minuten) und stärkere Bindung auf (Amin et al. 2002, Patrick et al. 1999).

Neben der Aktivierung von CDK5 durch die beiden Aktivatorproteine p35 und p39 bzw. deren Fragmente kann die CDK5- Aktivität durch Bindung anderer Proteine reguliert werden. So ist eine Inhibition der CDK5- Aktivität durch Bindung von L34 (ribosomales Protein), dbpA (DNS Bindeprotein) und Casein Kinase 2 beschrieben (Ching et al. 2002, Lim et al. 2004, Moorthamer et al. 1999, Moorthamer und Chaudhuri 1999). Die Bindung von SET (nukleäres Protein) aktiviert dagegen den p35/CDK5 Komplex (Qu et al. 2002). 


\begin{tabular}{|c|c|c|c|c|c|c|}
\hline \multirow{2}{*}{$\begin{array}{l}\text { CDK5 Sub- } \\
\text { strat }\end{array}$} & \multicolumn{2}{|l|}{ Funktion } & \multicolumn{4}{|c|}{ Lokalisation } \\
\hline & & & Aktin & Mikotubli & Synapse & $\begin{array}{l}\text { Wachstums- } \\
\text { kegel }\end{array}$ \\
\hline Synapsin 1 & \multirow[t]{4}{*}{ Exocytose } & $\begin{array}{l}\text { Regulation der synap- } \\
\text { tischen Transmission }\end{array}$ & - & - & + & - \\
\hline MUNC18 & & $\begin{array}{l}\text { Zerstörung des } \\
\text { MUNC18/Syntaxin 1A } \\
\text { Komplexes }\end{array}$ & - & - & + & + \\
\hline L-VDCC & & $\begin{array}{l}\text { Unterdrückt SNARE- } \\
\text { Protein Bindung }\end{array}$ & & & & \\
\hline PIPKI $\gamma$ & & Regulation der Exocytose & & & & \\
\hline Cables & \multirow[t]{8}{*}{ Zytoskelett } & $\begin{array}{l}\text { Regulation der Interak- } \\
\text { tion mit c- } A b l\end{array}$ & + & - & - & + \\
\hline Tau & & $\begin{array}{l}\text { Abnahme der Bindung an } \\
\text { Mikrotubuli }\end{array}$ & - & + & - & - \\
\hline MAP1B & & $\begin{array}{l}\text { Regulation der Mikro- } \\
\text { tubulistabilität }\end{array}$ & - & + & - & - \\
\hline ß-APP & & $\begin{array}{l}\text { Regulation der APP } \\
\text { Lokalisation, Membran- } \\
\text { transport }\end{array}$ & - & - & + & + \\
\hline Src & & $\begin{array}{l}\text { Regulation der Zelladhä- } \\
\text { sion }\end{array}$ & + & + & + & + \\
\hline Nudel & & $\begin{array}{l}\text { Regulation des Dynein- } \\
\text { vermittelnden axonalen } \\
\text { Transports }\end{array}$ & - & + & - & + \\
\hline NFH/NFM & & $\begin{array}{l}\text { Regulation der inter- } \\
\text { mediären Filamenten- } \\
\text { struktur }\end{array}$ & & & & \\
\hline Trio & & $\begin{array}{l}\text { Reorganisation des } \\
\text { Aktinzytoskellets }\end{array}$ & & & & \\
\hline $\begin{array}{l}\text { Amphyphysin } \\
1\end{array}$ & \multirow[t]{2}{*}{ Endocytose } & $\begin{array}{l}\text { Regulation der synapti- } \\
\text { schen Vesikel }\end{array}$ & + & - & + & + \\
\hline Dynamin & & $\begin{array}{l}\text { Regulation der synapti- } \\
\text { schen Vesikel }\end{array}$ & & & & \\
\hline DARPP32 & \multirow[t]{4}{*}{ Signalweg } & $\begin{array}{l}\text { Regulation des Dopamin- } \\
\text { Signalweges }\end{array}$ & - & - & + & + \\
\hline $\begin{array}{l}\text { Tyrosin } \\
\text { Hydroxylase }\end{array}$ & & Synthese von Dopamin & - & - & + & + \\
\hline PP1-Inhibitor & & $\begin{array}{l}\text { Modulation der Ampli- } \\
\text { tude des cAMP- abhän- } \\
\text { gigenSignalweges }\end{array}$ & - & - & + & + \\
\hline ERbB & & $\begin{array}{l}\text { Regulation der Über- } \\
\text { tragung an der neuro- } \\
\text { muskulären Synapse }\end{array}$ & - & - & + & - \\
\hline ß-Catenin & Zelladhäsion & $\begin{array}{l}\text { Regulation der Zelladhä- } \\
\text { sion }\end{array}$ & - & + & + & + \\
\hline MEF2 & Zelltod & $\begin{array}{l}\text { Reduziert MEF2 ver- } \\
\text { mittelte Transkription }\end{array}$ & & & & \\
\hline
\end{tabular}

Tabelle 2: Zusammenstellung der bekannten CDK5 Substrate, ihre Funktion sowie ihre Lokalisation.

Ein gemeinsames Merkmal in der Regulation von CDK's ist der kontrollierte Abbau zu verschiedenen Zeitpunkten des Zellzykluses auf dem Ubiquitin-Proteasomen Weg. Obwohl 
CDK5 nicht an der Regulation des Zellzykluses beteiligt ist, wird es über den gleichen molekularen Mechanismus abgebaut. Die Phosphorylierung von p35 durch CDK5 begünstigt dessen Degradation (Patrick et al. 1998, Saito et al. 2003). Dies deutet auf eine autoregulatorische Funktion der CDK5- Aktivität hin.

Das Proteinexpressionslevel von CDK5, p35 und p39 variiert während der Entwicklung des zentralen Nervensystems stark. Studien an Nagern zeigten, dass die Aktivatorproteine erst in post-mitotischen Neuronen nachweisbar sind (Tsai et al. 1993, Tsai et al. 1994). Übereinstimmend hierzu konnte ein Anstieg des CDK5 und p35 Proteinexpressionslevels während der Entwicklung des zentralen Nervensystems nachgewiesen werden, welcher seinen Maximalwert im adulten Gehirn erreicht (Tsai et al. 1993). Die Expression von CDK5 ist im gesamten Gehirn nachweisbar, jedoch im Hippocampus und Mesencephalon am stärksten (Delalle et al. 1997). Die Expression von p39 unterscheidet sich räumlich und zeitlich von der p35 Expression. Die p39 Expression während der frühen Entwicklung niedrig, steigt erst zwischen der ersten und dritten Woche nach Geburt deutlich an. Im adulten Gehirn ist sie überwiegend auf das Cerebellum beschränkt (Cai et al. 1997).

CDK5 ist im sich entwickelnden Nervensystem in den Zellkörpern lokalisiert, wohingegen es im adulten Gehirn eher in Axonen und Zellkernen exprimiert wird (Matsushita et al. 1996, Tomizawa et al. 1996). p35 ist hauptsächlich in den Zellkörpern und Dendriten lokalisiert, axonales p35 konnte nur während der Entwicklung und kurz nach Geburt detektiert werden (Matsushita et al. 1996, Tomizawa et al. 1996), p39 ist in neuronalen Somata und Dendriten vorzufinden (Jeong et al. 2003).

Das Vorhandensein der CDK5 aktivierenden Proteine ausschließlich in post-mitotischen Neuronen, lässt darauf schließen, dass die neuronale Differenzierung die Expression dieser Proteine aktiviert. Unterstützt wird dies durch eine verstärkte Expression von CDK5, p35 und p39 in kultivierten Zellen nach Differenzierung durch Retinalsäure (Fu et al. 2002, Lee und Kim 2004). Ebenso konnte gezeigt werden, dass neutrotrophe Faktoren die Expression von p35 in PC12 Zellen stimuliert (Harada et al. 2001, Tokuoka et al. 2000).

\subsubsection{Cyclin-abhängige Kinase 5 und neuronaler Zelltod}

CDK5 übt wichtige Funktionen im Überleben und Zelltod eines Neurons aus (siehe Abbildung 9). Bei Streß zeigen Neurone eine signifikante CDK5 Veränderung. Unter neuropathologischen Bedingungen wurde eine vermehrte Calpain abhängige Spaltung der CDK5 Aktivatorproteine und eine daraus resultierende erhöhte CDK5- Aktivität beobachtet. Neben den Hinweisen, dass eine abnormal erhöhte CDK5- Aktivität die Apoptose begünstigt, gibt es auch Evidenzen, dass CDK5 eine wichtige Funktion im neuronalen 
Überleben ausübt. Daher ist es denkbar, dass der bevorzugte Effekt von CDK5 bei Stress von Faktoren wie Intensität, Dauer und subzellulärer Lokalisation der CDK5- Aktivität abhängt.

Studien in verschiedenen neuronalen Zelltodmodellen zeigen eine wichtige Funktion von Calpain bei der Aktivierung von CDK5. Dies steht im Einklang zu der erhöhten intrazellulären Calciumkonzentration während der Apoptose. So konnte zum Beispiel eine verstärkte Spaltung der Aktivatorproteine p35 oder p39 in Zellkulturen nach Behandlung mit Ionophoren, Glutamatsäure, $\mathrm{H}_{2} \mathrm{O}_{2}$ oder Staurosporin beobachtet werden (Canudas et al. 2004, Kusakawa et al. 2000, Lee et al. 2000, Nath et al. 2000, Patzke und Tsai 2002). Eine ebensolche Calpain abhängige Spaltung wurde bei Ischämie beobachtet (Lee et al. 2000, Nath et al. 2000, Patzke und Tsai 2002).

In neuronalen Kulturen wurde ein verstärktes wie auch vermindertes Proteinlevel von CDK5 und p35 unter toxischen Bedingungen nachgewiesen. In späteren Apoptosestadien schien CDK5 und p35 in vivo in den Zellkernen und Körpern akkumuliert zu sein (Henchcliffe und Burke 1997, Neystat et al. 2001). In Gehirnen von Ratten wurde p35 und CDK5 besonders häufig im Zytoplasma und in den Kernen nach Verschluss der mittleren Arteria cerebri media beobachtet (Hayashi et al. 1999). Bei der Alzeimer'schen Krankheit wurde ebenfalls eine neuronale Akkumulation von CDK5 beobachtet (Yamaguchi et al. 1996). Das höchste CDK5 Proteinlevel wurde in Neuronen detektiert, die eine geringe Phosphorylierung von Tau aufwiesen, was daraufhin deutet, dass CDK5 überwiegend in Neuronen mit früher Neurofibrillendegradation exprimiert wird (Pei et al 1998). Eine erhöhte CDK5 Expression konnte ebenfalls in Motorneuronen von ALS Patienten nachgewiesen werden (Bajaj et al. 1998, Nakamura et al. 1997). Übereinstimmend hierzu wiesen Mäuse, die mutierte Superoxid Dismutase 1 (SOD1) überexprimieren eine Anhäufung von CDK5 innerhalb der spinalen Motorneurone auf. Ebenso wurde in diesen Tieren eine erhöhte Spaltung von p35 zu p25 sowie eine erhöhte CDK5- Aktivität im Rückenmark nachgewiesen (Nguyen et al. 2001). Des Weiteren konnte CDK5 und p35 in Lewi Bodys bei der Parkinsonschen Erkrankung detektiert werden (Brion und Couck 1995). In Mäusen, welche mit MPTP behandelt wurden, um eine dopaminerge Depletion zu induzieren, konnte ebenso eine gesteigerte Expression von CDK5 und Calpain abhängige Spaltung von p35 in dopaminergen Neuronen der Substantia Nigra beobachtet werden (Smith et al. 2003). Weiterhin wurde auch in einem Tiermodel für multiple Sklerose eine erhöhte Spaltung von p35 durch Calpain nachgewiesen (Schneider et al. 2004). 
In neuronalen Zellkulturen wurde die Apoptose, induziert durch ß-Amyloid, Colchicin oder Staurosporin, durch spezifische CDK5 Inhibitoren verhindert (Alvarez et al. 2001, Lee et al. 2000, Weishaupt et al. 2003). Ebenso führte die Überexpression einer dominant negativen Mutante von CDK5 zu einer verminderten Glutamtat- induzierten Apoptose (Gong et al. 2003). In einem Ischämie-Modell konnte gezeigt werden, dass CDK5 den Zelltod verstärkt, wohingegen eine Hemmung von CDK5 durch Virus vermittelte Überexprimierung einer dominant negativen Mutante zu einer Abschwächung des Zelltodes im Hippocampus führt (Wang et al. 2003). In Tiermodellen für neuronale degenerative Erkrankungen resultiert eine CDK5 Hemmung in einer verminderten neuronalen Degeneration (Smith et al. 2003) oder in einer verminderten Phosphorylierung von Tau (Zhang et al. 2004).

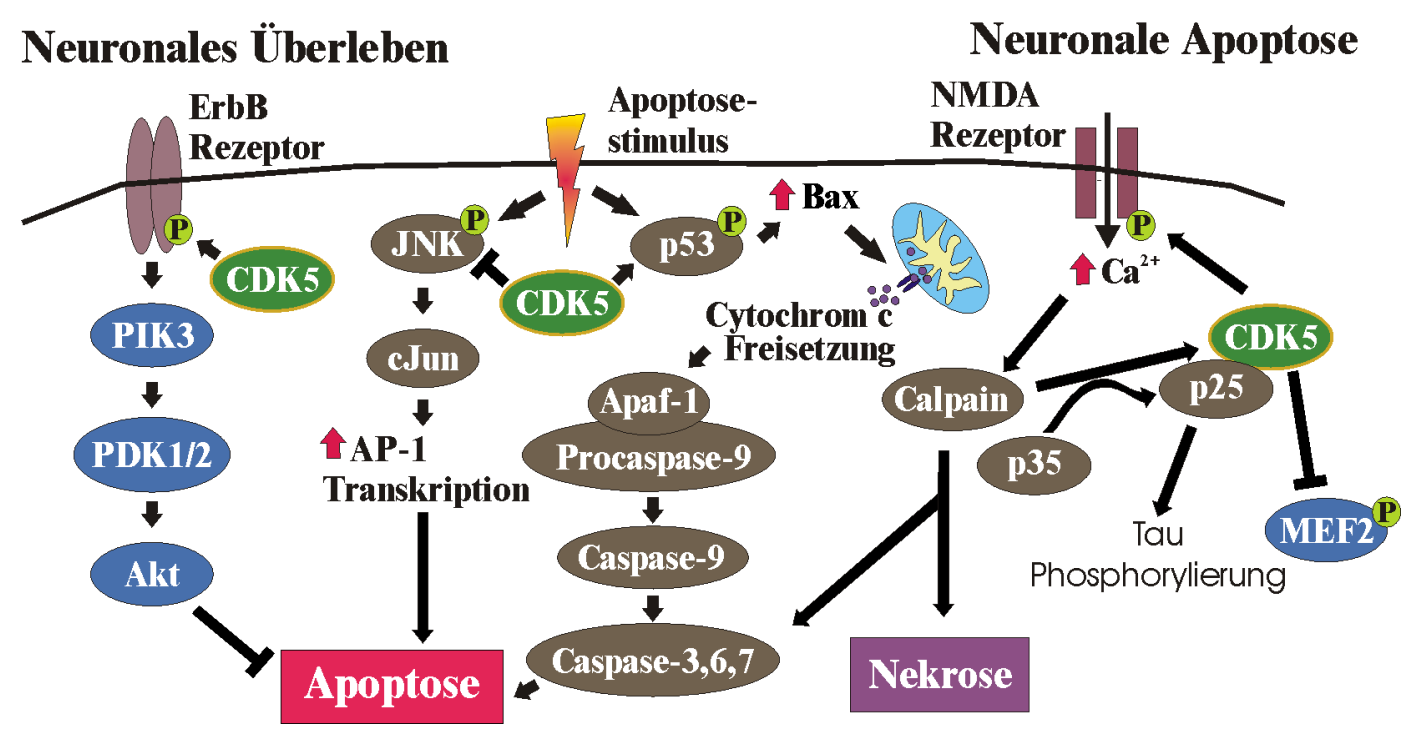

Abbildung 9: Funktion der Cyklin-abhängigen Kinase 5.

Schematische Zusammenfassung der im text zitierten Befunde zur Wirkweise vonCDK5.

Verschiedene molekulare Mechanismen sind bekannt, durch die CDK5 den Prozess der Apoptose beeinflusst. Zum Beispiel wurde gezeigt, dass durch eine CDK5 vermittelte Phosphorylierung von p53 der Expressionslevel des p53 Transkriptionsfaktors ansteigt und somit die Expression von Bax stimuliert (Zhang et al. 2002). Die durch CDK5 induzierte Phosphorylierung verursachte Inhibition von MEK1 (mitogen-activated protein kinase 1) hemmt die Phosphorylierung und Aktivierung von ERK1/2 (Sharma et al. 2002). Neben MEK1 phosphoryliert CDK5 den RasGRF2 Faktor (Ras guanine nucleotide releasing factor 2), wodurch die Ras und ERK1/2 Aktivität vermindert wird (Kesavapany et al. 2004). Die Phosphorylierung des für das Zellüberleben notwendigen Transkriptionsfaktors MEF2 (myocyte enhancer factor 2) durch CDK5 hemmt diesen und begünstigt somit die Apoptose 
(Gong et al. 2003). Da CDK5 spezifische Inhibitoren mitochondriale Fehlfunktionen blockieren können, kann davon ausgegangen werden, dass CDK5 sehr früh in die Apoptosekaskade eingreift (Weishaupt et al. 2003).

Eine erhöhte p35/CDK5 Expression und/oder eine Calpain abhängige Spaltung der CDK5 Aktivatorproteine ist häufig in der neuronalen Apoptosekaskade zufinden. Dennoch kann keine klare Aussage getroffen werden, ob die Veränderungen von CDK5 ursächlich für die Apoptose oder eine Folgeerscheinung dessen ist.

Es existieren jedoch auch einige Evidenzen, dass CDK5 Apoptose nicht nur induzieren, sondern auch hemmen kann. So inhibiert CDK5 proapoptotische Proteine wie zum Beispiel Nterminale Kinase 3 c-Jun (JNK3) und verhindert somit den programmierten Zelltod (Yang et al. 1997). Zur Familie der JNK’s gehören neben JNK3 noch zwei weitere Proteine JNK1 und JNK2. Alle drei Proteine sind an der sogenannten Stress- Kinasekaskade beteiligt, die zur Apoptose führt. Des Weiteren verhindert der CDK5 Inhibitor Roscovitin die Aktivierung der Akt Kinase. Die wichtigsten Funktionen von CDK5 sind in Abbildung 9 graphisch zusammengefasst. 


\subsection{Zielsetzung}

Die Apoptose von Neuronen hat eine herausragende Bedeutung sowohl für die Systemintegrität als auch für die Auslösung von Anomalien im zentralen Nervensystem. Für viele neurodegenerative Erkrankungen wie z.B.den Morbus Parkinson scheint eine Steuerung und gezielte Unterdrückung des programmierten Zelltodes ein zielführender Therapieansatz zu sein.

Die Mitochondrien nehmen in der intrinsischen Apoptosekaskade eine zentrale Funktion wahr, da sie Cytochrom c ausschütten, das den unumkehrbaren Ablauf der Apoptose einleitet (Kroemer und Reed 2000). Ungeklärt ist hierbei der Zusammenhang zwischen der Freisetzung von Cytochrom c und der Zerteilung der Mitochondrien, die im Verlauf der Apoptose stattfindet. Insbesondere ist unklar, ob eine Unterdrückung des mitochondrialen Zerteilungsprozesses die Apoptose von Neuronen verhindert.

Ziel dieser Arbeit ist zunächst die Charakterisierung der mitochondrialen Mechanismen, durch die der Zerfall der Mitochondrien während der Apoptose gesteuert wird. Hierbei soll insbesondere untersucht werden, ob die Steuerung des mitochondrialen Zerfalls den Verlauf der Apoptose beeinflusst. Damit soll geklärt werden, ob der mitochondriale Zerfall ein Teil der Apoptosekaskade ist oder eine unabhängig neben dem Apoptoseprozess stattfindende Veränderung der Zelle darstellt.

Des Weiteren soll nach Regulationsmechanismen der mitochondrialen Zerteilung gesucht werden, die nach Möglichkeit eine medikamentöse Beeinflussung erlauben. Hierbei ist wiederum die Einflussnahme auf den Ablauf der Apoptose von besonderer Bedeutung.

Die Experimente wurden an dopaminergen Neuronen in Kultur durchgeführt, um die Übertragung der Resultate auf ein Modell der Parkinson-Krankheit zu ermöglichen. Die Daten aus den Zellkulturen sollen in primären Mittelhirnneuronen verifiziert werden, um zu prüfen, ob Effekte allgemeiner Natur sind oder lediglich Besonderheiten der kultivierten neuronalen Zelllinie darstellen. 


\section{Material und Methoden}

Die häufig eingesetzten Puffer und Medien werden im Text nur mit ihren Namen/Abkürzungen genannt. Die genauen Zusammensetzungen sind in Kapitel 2.5 angegeben.

\subsection{Verwendete Zelltypen}

\subsubsection{Kultur von CSM 14.1 Neuronen}

In der vorliegenden Arbeit wurden überwiegend CSM14.1 Neurone verwendet (siehe Abbildung 10). CSM14.1 Neurone sind immortalisierte, nigrostriatale Rattenzellen (Haas und Wree 2002). Die Neurone können als dopaminerge Zelllinie charakterisiert werden, da sie die dopaminergen Marker Nurr1, Tyrosin Hydroxylase und ALDH2 exprimieren. Bei $32{ }^{\circ} \mathrm{C}, 5 \% \quad \mathrm{CO}_{2}$ und Wasserdampf-gesättigter Atmosphäre wurden die Neurone in Kulturmedium (DMEM Vollmedium, PAA, Cölbe) befüllten $10 \mathrm{~cm} \varnothing$ Zellkulturschalen (Greiner bio-one, Solingen) kultiviert (Inkubator: Function line, Heraeus, Hannover). Die Zellen besitzen ein Temperatur-sensitives Antigen über das sie differenziert werden können. Die Differenzierung erfolgte durch Kultivierung der Neurone für 14 Tage bei erhöhter Inkubationstemperatur von $39^{\circ} \mathrm{C}$ anstatt $32^{\circ} \mathrm{C}$ unter ansonst gleichen Bedingungen. Während der Differenzierung entwickeln die Zellen einen neuronalen Phänotyp sowie ein vergrößertes Zytoplasma, was die Beobachtung der Mitochondrienmorphologie vereinfachtete. In der vorliegenden Arbeit wurden ausschließlich differenzierte CSM14.1 Neurone (dCSM14.1) genutzt.

Sobald die CSM14.1 bzw. dCSM14.1 Neurone nahezu konfluent (ca. 90 \% Flächenbelegung) gewachsen waren, wurden sie auf eine neue Kulturschale passagiert (in der Regel alle 3-4 Tage). Zum Passagieren unter sterilen Bedingungen (biologische Sicherheitssterilwerkbank, Heraguard, Heraeus, Hannover) wurde das Kulturmedium abgesaugt und die Neurone einmal mit PBS gewaschen. Zum Lösen des Zellrasens wurden $3 \mathrm{ml}$ 1\%-ige Trypsinlösung (PAA, Cölbe) auf die Platten gegeben. Sobald sich der Zellrasen gelöst hatte wurde die Zellsuspension in ein Reaktionsgefäß überführt und $6 \mathrm{ml}$ Kulturmedium zu den Neuronen gegeben. Das in dem Kulturmedium enthaltene fötale Kälberserum (PAA, Cölbe) inaktiviert das Trypsin. Die Neurone wurden 5 min mit 1500 rpm bei Raumtemperatur zentrifugiert. Nach Verwerfen des Überstandes wurden sie in $1 \mathrm{ml}$ Kulturmedium resuspendiert und ca. $150 \mu \mathrm{l}$ der Neuronenlösung auf neue Kulturschalen ausplattiert, welche bis zur erneuten Passagierung kultiviert wurden. 
Zur Bestimmung einer definierten Zellzahl wurde nach dem Resuspendieren des Pellets eine Probe der Neuronensuspension von $10 \mu \mathrm{l}$ entnommen, mit $90 \mu \mathrm{l}$ Trypanblau (Sigma, Steinheim) versetzt und die Zellen lichtmikroskopisch in einer Neubauer-Zählkammer (Hecht-Assistent, Sondheim) ausgezählt, so dass der Neuronengehalt der Suspension bestimmt wurde und anschließend ein definiertes Suspensionsvolumen ausplattiert werden konnte.

Um einen Vorrat an dCSM14.1 Neuronen zu erhalten wurden die Zellen anstatt in einem Milliliter Kulturmedium in $750 \mu$ l Einfrierlösung resuspendiert und in Kryoröhrchen (Nunc, Wiesbaden) zunächst bei $-20^{\circ} \mathrm{C}$ eingefroren. Nach $1-2 \mathrm{~h}$ wurden die Kryoröhrchen in flüssigen Stickstoff überführt, wo sie bis zum Gebrauch verblieben.

Die eingefrorenen Neurone wurden nach schnellem Auftauen bei $37^{\circ} \mathrm{C}$ in eine $10 \mathrm{~cm} \varnothing$ Kulturschale befüllt mit Kulturmedium überführt und unter den üblichen Bedingungen erneut kultiviert.

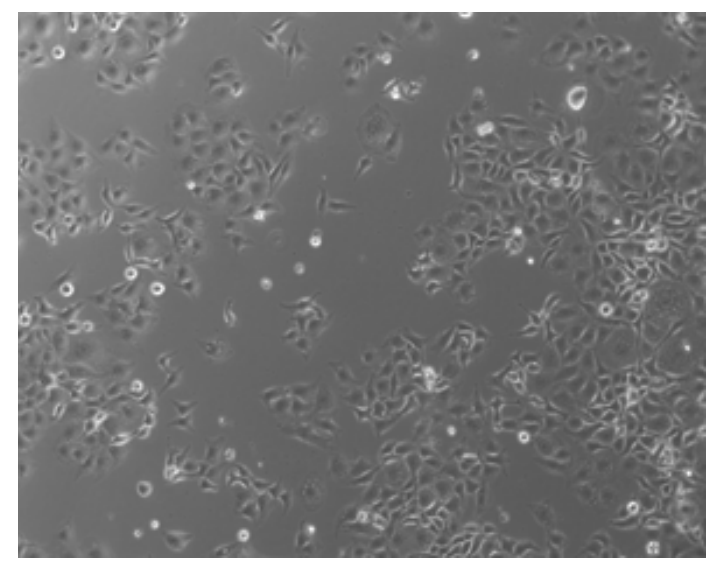

\section{Abbildung 10: dCSM14.1 Neurone.}

Abgebildet ist ein Phasenkontrastbild (10-fach vergrößert) einer differenzierten dCSM14.1 Kultur. Die Zellen weisen ein großes Zytoplasma auf sowie kurze Fortsätze.

\subsubsection{Kultur von primären Mittelhirnneuronen}

Adulte weibliche Ratten (Hannover-Wistar, Charles River/Sulzfeld) wurden am 14. Tag nach Verpaarung durch $\mathrm{CO}_{2}$-Begasung getötet. Der Bauch wurde mit Ethanol (70\%) gereinigt und das Peritoneum geöffnet. Die Uteri wurden entnommen, in CMF-Medium überführt und geöffnet. Die gewonnenen Embryonen wurden sofort in neues eiskaltes CMF-Medium transferiert. Die folgenden Schritte fanden in eiskaltem CMF - Medium unter visueller Kontrolle mit einem binokularen Mikroskop statt (Stemi 2000, Zeiss, Göttingen). Zuerst wurde der Kopf der Embryonen abgetrennt und das Gehirn entnommen. Der Hirnstamm wurde isoliert, die Hirnhäute entfernt und die Verbindung zwischen Diencephalon und Mesencephalon durchtrennt. Als Referenz diente hierbei die Colliculi des 
Diencephalons. Der Hirnstamm wurde mit der dorsalen Seite nach unten ausgerichtet. Das Tektum wurde ausgebreitet und der rostrale Teil des ventralen Hirnstammes sowie der rostrale Teil des Tektums entfernt. Der mediale Teil des verbleibenden rostralen Hirnstammes (ca. 1,0 $\mathrm{mm}^{3}$ ) wurde herausgeschnitten und in ein mit eiskaltem CMF-Medium befüllten Reaktionsgefäß überführt.

Alle so präparierten Gewebestücke wurden gesammelt und anschließend zentrifugiert (700 rpm, 4 min, $4^{\circ} \mathrm{C}$ ). Der Überstand wurde verworfen und das Zellpellet 15 min mit $750 \mu \mathrm{l}$ Trypsin $(0,25 \%)$ im Wasserbad bei $37^{\circ} \mathrm{C}$ inkubiert. Danach wurde das Trypsin mit $750 \mu \mathrm{l}$ eiskaltem fötalen Kälberserum (FCS) inaktiviert und die Suspension 3 min lang bei Raumtemperatur mit $40 \mu \mathrm{l}$ DNAse (10 mg/ml; Sigma, Steinheim) versetzt. Bei der vorsichtigen Trituierung mittels einer flammengerundeten silanisierten Pasteur-Pipette wurden die Gewebestücke mechanisch dissoziiert. Nach Absetzen der verbliebenen Gewebestücke wurde der Überstand in ein neues Gefäß überführt und das nicht dissoziierte Gewebe zum zweiten mal einer Trypsinierung und Trituierung unterzogen. Die so gewonnene Zellsuspension wurde erneut bei $700 \mathrm{rpm} 4 \mathrm{~min}$ lang bei $4^{\circ} \mathrm{C}$ zentrifugiert und das Pellet in $1 \mathrm{ml}$ Mittelhirn-Kulturmedium $\left(4^{\circ} \mathrm{C}\right)$ resuspendiert (für Weiterbehandlung der Neurone siehe Kapitel 2.2.2.2.1) und ausplattiert (siehe Abbildung 11). Auszählungen ergaben, das die Kultur vorwiegend GABAerge und bis zu 20 \% TH-positive Neurone enthielt. Diese stellen sämtliche Neurone des dopaminergen Phänotyps dar, da durch die Topographie des Präparationsgebietes die ebenfalls TH-positiven noradrendergen und adrenergen Neurone ausgeschlossen wurden (Shimoda et al. 1992).

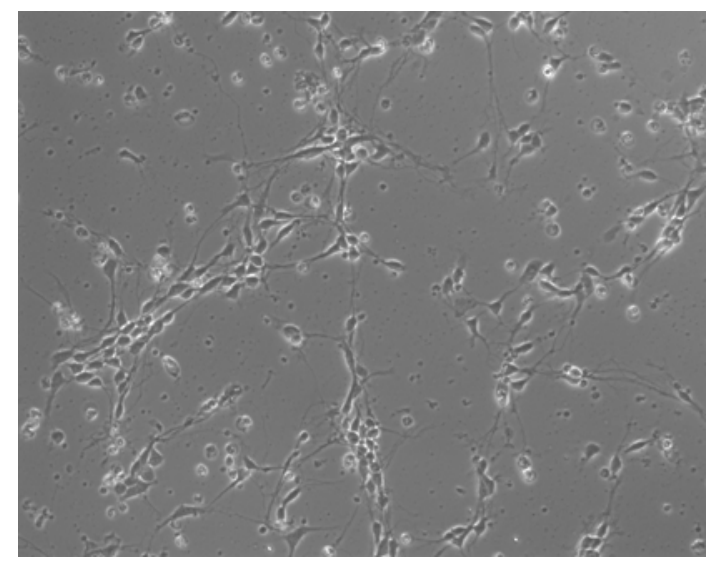

\section{Abbildung 11: Primäre Mittelhirnkultur.}

Dargestellt ist ein Phasenkontrastbild (20-fach vergrößert) einer primären Mittelhirnkultur. Die Neurone bilden lange Fortsätze aus und nehmen somit Kontakt zu anderen Neuronen auf.

Zur besseren Haftung der Primärneurone erfolgt die Kultivierung auf Poly-L-Ornithin/Laminin (Sigma, Steinheim) beschichteten Zellkulturplatten. Zur 
Beschichtung wurden die Platten für mindestens $4 \mathrm{~h}$ mit Poly-L-Ornithin $(0,1 \mathrm{mg} / \mathrm{ml})$ bei Raumtemperatur benetzt. Nach zweimaligem waschen mit destilliertem Wasser wurden die Platten mit Laminin $(1 \mu \mathrm{g} / \mathrm{ml})$ überschichtet und über Nacht bei $37^{\circ} \mathrm{C}$ inkubiert. Vor der Zellaussaat wurden die Platten nochmals mit DMEM-F12 (PAA, Cölbe) gewaschen. Eine gute Haftung der Primärneurone wurde erzielt, wenn die Platten nicht länger als 48 h vor Zellaussaat beschichtet wurden.

Die primären Mittelhirnkulturen wurden bei $37^{\circ} \mathrm{C}, 5 \% \mathrm{CO}_{2}$ und Wasserdampf-gesättigter Atmosphäre kultiviert (Inkubator: Function line, Heraeus, Hannover). Die Lebensdauer der Kultur betrug ca. 10 Tage. Medienwechsel erfolgten jeweils am 1. Tag nach der Präparation und darauffolgend an jedem zweiten Tag.

\subsection{Molekularbiologische Methoden}

\subsubsection{Plasmide}

In der vorliegenden Arbeit wurden verschiedene Plasmide verwendet (siehe Tabelle 3). Es wurde unterschieden zwischen Plasmiden, die nur zur Markierung der Mitochondrien dienten und solchen deren Einfluss auf die mitochondriale Zerteilung untersucht werden sollte.

Die Plasmide wurden durch unterschiedliche Transfektionsverfahren in die Neurone eingebracht (siehe Kapitel 2.2.2). Der Mechanismus der Transfektion ist noch nicht genau bekannt, es wird davon ausgegangen, dass die transfizierte DNS in das Zytoplasma der Zelle gelangt und in den Zellkern transportiert wird. Die DNS wird dort transkribiert, wobei eine komplementäre mRNS entsteht. Diese wird aus dem Zellkern zu den Ribosomen ins Zytoplasma transportiert und dort translatiert.

Ein Schwerpunkt der vorliegenden Arbeit war die Bewertung der mitochondrialen Morphologie im Verlauf der Apoptose. Alle Neurone wurden mit den Plasmiden pDsRed2-Mito oder mito-GFP transfiziert, da diese Plasmide ein Sequenzstück der Untereinheit 4 der Cytochrom c Oxidase enthielten und ihre Expression zu einer spezifischen Markierung der Mitochondrien führte. Des Weiteren sollte der Einfluss von verschiedenen Proteinen auf die mitochondriale Morphologie und Apoptose untersucht werden. Hierzu wurden Kotransfektionen mit dem zu untersuchenden Plasmid durchgeführt.

Fis1 und Drp1 sind funktionell in der mitochondrialen Zerteilung involviert (siehe Kapitel 1.1.5.1). Es sollte untersucht werden, ob die Expression der Proteine einen Einfluss auf die neuronale Apoptose (siehe Kapitel 2.4.3) sowie auf die Morphologie der Mitochondrien (siehe Kapitel 2.4.4 und 2.4.5) besaß. Dazu wurden Kotransfektionen mit Drp $1_{\mathrm{K} 38 \mathrm{~A}}$-ECFP 
einer dominant negativen Mutante von Drp1-ECFP durchgeführt. Die dominant negative Mutante kann wie Drp1 transkribiert und translatiert werden, ist jedoch auf Grund der Punktmutation nicht funktionsfähig.

\begin{tabular}{|l|l|l|l|l|}
\hline Plasmid & Lokalisation & mitochondriale Funktion & $\begin{array}{l}\text { Excitations- } \\
\text { Maximum [nm] }\end{array}$ & $\begin{array}{l}\text { Emissions- } \\
\text { Maximum } \\
{[\mathrm{nm}]}\end{array}$ \\
\hline pDsRed2-Mito & Mitochondrien & Markierung der Mitochondrien & 543 & 590 \\
\hline mt-GFP & Mitochondrien & Markierung der Mitochondrien & 488 & 525 \\
\hline Fis-GFP & Mitochondrien & $\begin{array}{l}\text { Regulation der mitochondrialen } \\
\text { Zerteilung }\end{array}$ & 488 & 525 \\
\hline CDK5-GFP & Zytoplasma & unbekannt & 488 & 525 \\
\hline CDK5 ${ }_{\text {N144-GFP }}$ & Zytoplasma & unbekannt & 488 & 525 \\
\hline Drp1-ECFP & $\begin{array}{l}\text { Zytoplasma/ } \\
\text { Mitochondrien }\end{array}$ & $\begin{array}{l}\text { Regulation der mitochondrialen } \\
\text { Zerteilung }\end{array}$ & 543 & 475 \\
\hline Drp1 K38A $_{\text {ECFP }}$ & $\begin{array}{l}\text { Zytoplasma/ } \\
\text { Mitochondrien }\end{array}$ & $\begin{array}{l}\text { Zemmung der mitochondrialen } \\
\text { Zerteilung }\end{array}$ & 543 & 475 \\
\hline p25-GFP & Zytoplasma/Kern & unbekannt & 488 & 525 \\
\hline p35 & Zytoplasma/Kern & unbekannt & - \\
\hline
\end{tabular}

Tabelle 3: In dieser Tabelle sind die verwendeten Plasmide und Vektoren zusammengefasst.

Die Plasmide pDsRed2-Mito und mito-GFP besitzen ein Sequenzstück der Untereinheit 4 der Cytochrom c Oxidase, so dass die Transfektion mit ihnen ausschließlich der Darstellung der Mitochondrien dienten. Transfektionen mit Fis-GFP, CDK5-GFP und Drp1-ECFP wurden durchgeführt, um den Einfluss der Expression der Plasmide auf die mitochondriale Morphologie bzw. die neuronale Apoptose zu untersuchen. Hierfür wurden zusätzlich die dominant negativen Mutanten $\mathrm{CDK}_{\mathrm{N} 144}-\mathrm{GFP}$ und Drp1 $1_{\mathrm{K} 38 \mathrm{~A}}$-ECFP verwendet. p25-GFP und p35 sind die beiden spezifischen Aktivatorproteine von CDK5 und wurden daher immer mit CDK5 kotransfiziert.

Des Weiteren ist der Tabelle die Lokalisation der Proteine innerhalb der Zelle zu entnehmen bzw. welche mitochondrialen Funktionen sie besitzen.

Alle Plasmide bis auf das p35 Plasmide waren mit einem Fluorophor fusioniert, so dass die Expression der Plasmide mittels eines Fluoreszenzmikroskops geprüft werden konnte. Die Excitations- und Emissionsmaxima der einzelnen Plasmide sind ebenfalls aufgelistet.

Der Einfluss von CDK5 auf die Mitochondrien ist völlig unbekannt und wurde erst in der vorliegenden Arbeit beleuchtet. Dies erfolgte durch Transfektionen mit CDK5-GFP sowie der dominant negativen Mutante CDK5 $144-$ GFP. Transfektionen von CDK5 wurden immer in Kombination mit p25-GFP oder p35 durchgeführt, da dies die beiden Aktivatorproteine von CDK5 sind (siehe Kapitel 1.2.1). Neben dem Einfluss auf die mitochondriale Morphologie während der Apoptose wurde ebenfalls untersucht, welche Wirkung die Expression

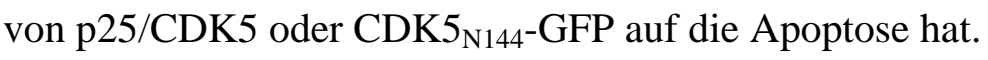

Alle Plasmide bis auf das p35-Plasmid waren mit einem Fluorophor fusioniert, somit konnte ihre Expression mittels eines Fluoreszenzmikroskops (Axiovert200, Zeiss, Göttingen) über- 
prüft werden. Die Excitations- und Emissionsmaxima der einzelnen Plasmide sind der Tabelle 3 zu entnehmen. Alle Plasmide enthielten eine Antibiotika-Resistenz und konnten über diese selektiert werden.

\subsubsection{Herstellung transformationskompetenter $\boldsymbol{E}$. coli Zellen}

Zur Vervielfältigung der Plasmide werden transformationskompetente E.coli Zellen (Invitrogen, Karlsruhe) benötigt. Diese Zellen sind in der Lage, freie DNS aufzunehmen und zu vervielfachen. Um Fremd-DNS in Bakterien einschleusen zu können, müssen die Zellen zunächst in den Zustand der Kompetenz gebracht werden.

Hiezu wurden $500 \mathrm{ml}$ LB-Medium mit einer $E$.coli-DH5 $\alpha$-Kolonie angeimpft und bei $37^{\circ} \mathrm{C}$ bis zur logarithmischen Wachstumsphase $\left(\mathrm{OD}_{578}\right.$ etwa 0,5) kultiviert. Die Bakteriensuspension wurde $30 \mathrm{~min}$ bei $4^{\circ} \mathrm{C}$ und $3000 \mathrm{rpm}$ abzentrifugiert und in $250 \mathrm{ml}$ steriler $50 \mathrm{mM}$ $\mathrm{CaCl}_{2}$ Lösung resuspendiert. Die Zellen wurden für mindestens 30 min auf Eis inkubiert, erneut abzentrifugiert, der Überstand verworfen, die Zellen in $25 \mathrm{ml}$ Einfrierlösung resuspendiert und eine Stunde auf Eis inkubiert. Danach wurden die Zellen aliquotiert und in flüssigem Stickstoff schockgefroren. Die Lagerung erfolgte bei $-80^{\circ} \mathrm{C}$.

\subsubsection{Transformation von $\boldsymbol{E}$.coli Zellen}

Das Einschleusen der Plasmide in transformationskompetente E coli DH5 $\alpha$-Bakterien erfolgte durch eine Calciumchlorid-vermittelte Transformation mit Hilfe von schneller Temperaturänderung. Für die Transformation wurden jeweils $100 \mu$ l kompetente E. coli-Bakterien (Herstellung siehe Kapitel 2.2.1.1) mit je 100 ng Plasmid DNS versetzt. Nach Inkubation des Ansatzes 30 min lang auf Eis wurde dieser einem Hitzeschock bei $42^{\circ} \mathrm{C}$ für $45 \mathrm{sec}$ ausgesetzt und anschließend sofort auf Eis für 2 min abgekühlt. Zur Vermehrung der Bakterien wurden die Proben in je $200 \mu \mathrm{l}$ sterilem SOC-Medium aufgenommen und eine Stunde bei $37^{\circ} \mathrm{C}$ inkubiert. Ein selektives Wachstum von einzelnen Bakterienkolonien wurden durch das Ausstreichen der Bakterien auf LB-Agar-Platten mit $100 \mu \mathrm{g} / \mathrm{ml}$ Ampicillin oder $40 \mu \mathrm{g} / \mathrm{ml}$ Kanamycin erreicht. Die Platten wurden über Nacht kopfüber bei $37^{\circ} \mathrm{C}$ inkubiert und danach bei $4^{\circ} \mathrm{C}$ gelagert.

\subsubsection{Isolierung von Plasmid DNS aus $E$. coli}

Zur Herstellung größerer Mengen Plasmid-DNS wurden einzelne Klone der LB-AgarPlatten (siehe Kapitel 2.2.1.2) gepickt und in flüssiges Antibiotika-haltiges LB-Medium (3 ml für Mini-Präparation, $200 \mathrm{ml}$ für Maxi-Präparation) überführt. Die Kulturen wurden über Nacht bei $37^{\circ} \mathrm{C}$ in einem Schüttler (Thermoshake, Gerhardt) inkubiert. 
Die Präparation der Plasmid-DNS aus E.coli erfolgte unter Verwendung von Plasmid-Präparations-Kits (Marchinnery und Nagel: NucleoSpin ${ }^{\circledR}$ Plasmid, Qiagen: Plasmid Maxi Kit) nach Herstellerangaben. Das Prinzip beruht bei beiden Kits auf der alkalischen Lyse der Zellen (Birnboim und Doly 1979) und der DNS-Adsorption an Silikat bei hohen Salzkonzentrationen. Die Konzentration der DNS wurde mit einer photospektrometrischen Messung (Biophotometer, Eppendorf, Hamburg) bei einer Wellenlänge von $260 \mathrm{~nm}$ bestimmt. Die Bestimmung beruht auf der Tatsache, dass die OD einer $50 \mu \mathrm{g} / \mathrm{ml}$ konzentrierten DNS-Lösung bei einer Wellenlänge von 260 nm eins beträgt. Des Weiteren wurde die OD bei einer Wellenlänge von $280 \mathrm{~nm}$ bestimmt, da das Absorptionsmaximum für Proteine, basierend auf der Absorption der aromatischen Aminosäurereste, bei $280 \mathrm{~nm}$ liegt. Durch Bestimmung des Verhältnisses von $\mathrm{OD}_{260} \mathrm{zu} \mathrm{OD}_{280}$ konnte ermittelt werden, wie stark die DNS-Lösung durch Proteinreste verunreinigt ist. Der Quotient von $\mathrm{OD}_{260} / \mathrm{OD}_{280}$ sollte zwischen 1,6 und 1,8 liegen. Die Plasmid-DNS wurde bei $4^{\circ} \mathrm{C}$ gelagert.

\subsubsection{Transfektionen}

Die Expression von exogenen Proteinen in den Neuronen wurde durch die Transfektion mit Plasmiden (siehe Kapitel 2.2.1) erreicht. In der vorliegenden Arbeit wurden zwei verschiedene Transfektionsverfahren angewendet. Bei der Transfektion mit Lipofectamine wird die Plasmid-DNS mit Hilfe von kationischen Liposomen in die Zellen eingebracht. Bei der Elektroporation dagegen wird die Zellmembran durch Spannungspulse für die DNS permeabelisiert. Die verwendeten Plasmide (siehe Tabelle 3) besaßen einen eukaryontischen Promotor und konnten daher in der Zielzelle exprimiert werden.

\subsubsection{Transiente Transfektion mittels Lipofectamine}

Es wird zwischen transienten und stabilen Transfektionen unterschieden, in der vorliegenden Arbeit wurden ausschließlich transiente Transfektionen durchgeführt. Die Expression des transfizierten Plasmides konnte an bis zu fünf Tagen beobachtet werden. dCSM14.1 Neurone wurden dazu mit dem Transfektionsreagenz Lipofectamine 2000 (Invitrogen, Karlsruhe) transfiziert, um eine hohe Transfektionseffizienz zu erhalten.

\subsection{DNS Transfektion}

Für die Plasmid-DNS Transfektionen wurden die Neurone einen Tag zuvor in Zellkulturschalen verschiedener Größe (Acht bzw. 24 well Platten) ausplattiert. Für eine gute Transfektionseffizienz erwies es sich als nützlich, wenn die Zellen am Tag der Transfektion eine Konfluenz von ca. 60-70 \% besaßen. Für Transfektionen einer Acht well Platte wurde pro well 0,3 $\mu$ g des zu untersuchenden Plasmids sowie 0,75 $\mu$ l Lipofectaminelösung in jeweils 
37,5 $\mu$ l Opti-MEM Medium (PAA, Cölbe) verdünnt und 5 min bei Raumtemperatur inkubiert. Die entsprechenden Volumen- und Konzentrationsangaben für die Transfektion einer 24 well Platte sind der Tabelle 4 zu entnehmen. Anschließend wurden beide Ansätze vereint, gemischt und für weitere $20 \mathrm{~min}$ bei Raumtemperatur inkubiert, wodurch ein DNS-Lipofectamine-Komplex gebildet wurde. Das Kulturmedium wurde von den Zellkulturplatten entfernt, die Neurone einmalig mit PBS gewaschen und $75 \mu$ l frisches Medium pro well einer Acht well Platte zugegeben. Das neue Medium enthielt im Gegensatz zu dem normalen Kulturmedium kein FCS und keine Antibiotikazusätze, da diese die Transfektion negativ beeinflussen.

Nach Ablauf der 20 minütigen Inkubationszeit wurde der DNS/Lipofectamine-Komplex zu den Neuronen gegeben. Nach vier stündiger Inkubation wurde das Medium von den Neuronen abgenommen und nach einem PBS-Waschschritt durch frisches Kulturmedium ersetzt. Dieses Medium enthielt nun wieder die entsprechenden Antibiotika- und FCS Zusätze.

\subsection{Kotransfektionen von DNS und siRNS}

Bei der RNS-Interferenz handelt es sich um eine Methode der Gen-Ausschaltung auf mRNSEbene. In die Zielzelle werden kurze doppelsträngige RNS-Fragmente eingeschleust, die sogenannten small interfering RNSs (siRNSs). Hierdurch schneiden Endonucleasen der Zelle die zur siRNS komplementäre zelleigene mRNS.

\begin{tabular}{|l|l|l|l|l|l|l|}
\hline Kulturgefäß & $\begin{array}{l}\text { Oberfläche } \\
\text { eines wells } \\
{\left[\mathrm{cm}^{2}\right]}\end{array}$ & $\begin{array}{l}\text { Kulturmedium } \\
{[\mu \mathrm{l}]}\end{array}$ & $\begin{array}{l}\text { DNS } \\
{[\mu \mathrm{g}]}\end{array}$ & siRNS [pmol] & $\begin{array}{l}\text { Lipofectamine 2000 } \\
{[\mu \mathrm{l}]}\end{array}$ & Opti-MEM [ $\mu \mathrm{ll}]$ \\
\hline Acht-well Platte & 0,45 & 75 & 0,3 & 7,5 & 0,75 & $2 \mathrm{x} 37,5$ \\
\hline 24-well Platte & 2 & 400 & 0,8 & 20 & 2,0 & $2 \times 50$ \\
\hline
\end{tabular}

Tabelle 4: Konzentration von DNS, siRNS und Volumen von Lipofectamine in Abhängigkeit des Kulturgefäßes.

Die Tabelle gibt die entsprechenden Konzentrations- bzw. Volumenangaben an, die während einer Transfektion mit Lipofectamine 2000 benötigt werden.

Die Konzentrations- bzw. Volumenangaben sind abhängig von der Oberfläche des verwendeten Kulturgefäßes.

\begin{tabular}{|l|l|l|}
\hline siRNS & CDK5 & Kontroll-siRNS \\
\hline sense & GAG GAU CUU UCG ACU GCU A & GCA AGC UGA CCC UGA AGU UCA U \\
\hline antisense & UAG CAG UCG AAA GAU CCU C & GAA CUU CAG GGU CAG CUU GCC G \\
\hline Zielsequenz & AAG AGG ATC TTT CGA CTG CTA & CGG CAA GCT GAC CCT GAA GTT CAT \\
\hline
\end{tabular}

Tabelle 5: Sequenzen der verwendeten siRNS's.

Die Tabelle gibt die Sequenzen der CDK5- und Kontroll siRNA an. 
Die siRNS gegen CDK5 wurde von der Firma Qiagen bezogen. Sie enthielten am 5' Ende eine Fluoreszenzmodifikation (Cy3), so dass nach den Transfektionen ermittelt werden konnte, welche Neurone transfiziert worden waren. Das Emissionsspektrum von Cy3 liegt bei $568 \mathrm{~nm}$, das Excitationsmaximum bei $544 \mathrm{~nm}$. Um sicherzustellen das der beobachtete Effekt nicht auf die Prozedur der Transfektion zurückzuführen war, sondern spezifisch auf die transfizierte CDK5 siRNS wurden Transfektionen in Kontrollexperimenten mit einer unfunktionellen siRNS durchgeführt. Die Kontroll-siRNS wurden ebenfalls von Qiagen bezogen. Tabelle 5 enthält die Sequenzen der verwendeten siRNSs sowie deren Zielsequenz. Die siRNS Transfektionen wurden wie die DNS Transfektionen mit dem Tranfektionsreagenz Lipofectamine 2000 durchgeführt (siehe Kapitel 2.2.2.1.1). Für Studien zum Einfluss von CDK5 auf die mitochondriale Zerteilung wurden die Neurone mit siRNS und Plasmid-DNS kotransfiziert. Als Plasmid DNS wurde mito-GFP verwendet. Die entsprechenden Konzentrationen und Volumina von DNS, siRNS und Lipofectamine sind der Tabelle 4 zu entnehmen.

\subsubsection{Transiente Transfektion mittels Elektroporation}

Im Gegensatz zu der Lipofectamine 2000 gesteuerten Transfektion der dCSM14.1 Neurone wurden die primären Mittelhirnneurone mittels Elektroporation (Nucleofector, Amaxa, Köln) transient transfiziert. Diese Methode ist weniger toxisch für die Zellen als die Behandlung mit Lipofectamine und wurde daher ausschließlich für Transfektionen primärer Mittelhirnneurone verwendet.

\subsection{DNS Transfektionen}

Für DNS Transfektionen wurde das „Basic Nucleofector Kit; Primary Neurons“ (Nucleofector, Amaxa, Köln) nach Hersteller-Angaben verwendet. Die Transfektion erfolgte sofort nach der Präparation der primären Mittelhirnkulturen (siehe Kapitel 2.1.2). Für jeden Ansatz wurden $2 \times 10^{6}$ Neurone und $2 \mu$ g Plasmid-DNS verwendet. Die Zellen wurden 5 min bei $700 \mathrm{rpm}$ und $4^{\circ} \mathrm{C}$ zentrifugiert, das Mittelhirnmedium abgenommen und das Zellpellet in $90 \mu \mathrm{l}$ Nucleofector ${ }^{\mathrm{TM}}$ Solution resuspendiert. $2 \mu \mathrm{g}$ der zu transfizierenden DNS wurden in $10 \mu \mathrm{l} \mathrm{H}_{2} \mathrm{O}$ verdünnt und zu den $90 \mu \mathrm{l}$ gegeben. Die Lösung wurde in die Elektroporationsküvette überführt wobei Luftblasen vermieden wurden und elektroporiert (Programm O-003, Nucleofector, Amaxa, Köln). Die elektroporierten Zellen wurden in $500 \mu \mathrm{l} 37^{\circ} \mathrm{C}$ vorgewärmtes Mittelhirn-Medium transferiert und auf beschichteten Zellkulturplatten ausgesät (siehe Kapitel 2.1.2). 


\subsection{Proteinchemische Methoden}

\subsubsection{Zelllysierung}

Um eine Gesamtproteinfraktion von Zellen zu erhalten wurden diese lysiert. Dabei wurden die Membranen der Zellen durch Hochsalz und verschiedene Detergenzien solubilisiert und Proteinkomplexe teilweise zerstört, so dass die Proteine frei vorliegen. Vor der Lysierung wurden die Neurone einmalig mit PBS gewaschen. Die Lysierung dieser erfolgte durch die Inkubation mit Lysepuffer. Das Volumen des Lysepuffers richtete sich nach der Größe der verwendeten Kulturschale (24-well Platte: $25 \mu \mathrm{l} /$ well, 6-well Platte: $75 \mu \mathrm{l} /$ well, $10 \mathrm{~cm} \varnothing$ Kulturschale: $500 \mu \mathrm{l} /$ well). Die Neurone wurden mit einem Zellschaber von der Platte gelöst, in ein 1,5 ml Reaktionsgefäß überführt und 20 min auf Eis inkubiert. Bei der anschließenden Zentrifugation (13.000 rpm, 15 min, $4^{\circ} \mathrm{C}$ ) wurden alle unlösliche Stoffe (z.B. DNS) abzentrifugiert. Der Proteinhaltige Überstand wurde bis zur weiteren Analyse bei $20^{\circ} \mathrm{C}$ gelagert.

\subsubsection{Bestimmung der Proteinkonzentration}

Die Proteinbestimmung erfolgte durch das BCA-Assay Reagenz (Pierce, USA). Der Test beruht auf der Biuret-Reaktion, bei der Proteine in alkalischer Umgebung $\mathrm{Cu}^{2+} \mathrm{zu} \mathrm{Cu}^{1+}$ reduzieren. $\mathrm{Cu}^{1+}$ bildet mit dem BCA Reagenz (Bicinchoninsäure) einen lilafarbigen Komplex, da er für Licht einer Wellenlänge von 562 nm eine deutliche, ausgeprägte Absorption aufweist. Der Messbereich liegt in einem Konzentrationsbereich von ca. $20 \mu \mathrm{g} / \mathrm{ml}$ bis $2000 \mu \mathrm{g} / \mathrm{ml}$.

Die Konzentrationsmessung des Proteinlysates erfolgte in einer Doppelbestimmung. Dazu wurden die Reagenzien A und B (BCA-Kit, Pierce, USA) im Verhältnis 50:1 gemischt. Die nötige Anzahl an wells einer 96 well Platte (Nunc, Wiesbaden) wurden jeweils mit $200 \mu \mathrm{l}$ der Lösung und $1 \mu \mathrm{l}$ Proteinlysat befüllt. Nach einer Inkubation über 30 min bei $37^{\circ} \mathrm{C}$ wurde in einem Elisa-Reader (Rainbow, Tecan, Crailsheim) die Absorption der einzelnen Proben bei $562 \mathrm{~nm}$ bestimmt. Zunächst wurde mit Proben bekannter Proteinkonzentration eine Eichkurve erstellt. Die lineare Regressionsgerade dieser Eichkurve wurde zur Ermittlung der unbekannten Proteinkonzentrationen genutzt.

\subsubsection{Western-Blot-Analyse}

Bei der Western-Blot-Analyse werden in einem SDS-Gel (sodium-dodeclylsulfat) elektrophoretisch aufgetrennte Proteingemische auf eine Membran transferiert. Die Proteine werden anschließend mit Hilfe von z.B. Meerrettich-Peroxidase-markierten Antikörpern sichtbar gemacht. 


\subsubsection{SDS-Polyacrylamidgel-Elektrophorese}

Die elektrophoretische Auftrennung von denaturierten Proteinen erfolgte durch vertikale, diskontinuierliche Natriumdodecylsulfat (SDS)-Polyacrylamid-Gelelektrophorese nach Laemmli (Laemmli 1970) in dem Biorad Mini-PROTEAṆ 3 cell-System.

Die verwendeten Gele setzten sich aus einem 3,75 \% igem Sammel- und einem 10 \% igem Trenngel zusammen. Die Trenngellösung wurde gemischt und die Polymerisation durch Zugabe von TEMED (Radikalerzeuger) und APS (Start-Radikale) gestartet. Die Lösung wurde luftblasenfrei zwischen die Glasplatten der Gelkammer bis ca. 2 cm unter den oberen Rand eingefüllt und mit Isopropanol überschichtet. Nach der Polymerisation des Trenngels wurde das Isopropanol entfernt und das Trenngel mit der Sammelgellösung überschichtet. Der Gelkamm wurde eingesetzt und nach der Polymerisation des Gels wieder entfernt. Der Übergang vom Sammelgel zum Trenngel mit einem $\mathrm{pH}$ - Sprung von 6,8 auf 8,8 diente der Fokussierung der Proteine.

Die Proben (20 $\mu$ g Protein) wurden mit 1,7 $\mu$ l SDS-Probenpuffer versetzt und vor dem Auftrag 5 min bei $95^{\circ} \mathrm{C}$ denaturiert. SDS ist ein stark negativ geladenes Detergenz, welches an die hydrophoben Regionen der Proteine bindet, wodurch sich diese zu gestreckten Polypeptidketten entfalten. Dadurch verlieren die Proteine ihre Assoziationen mit anderen Proteinen und liegen freilöslich in der Lösung vor. Der SDS Probenpuffer enthält Mercaptoethanol, welches die S-S Brücken zwischen den Proteinen auflöst, so dass alle Polypeptide, die ein aus vielen Untereinheiten bestehendes Molekül aufbauen, getrennt analysiert werden können. Das SDS lagert sich an die Hauptkette der Proteine an und verleiht ihnen eine negative Ladung. Beim Anlegen eines elektrischen Feldes wanderten die in SDS-Micellen eingelagerten Proteine zur Anode und wurden durch den Siebeffekt des Gelmaterials gebremst, wobei kleinere Moleküle schneller wandern als größere.

Die elektrophoretische Auftrennung der Proteine erfolgte zwei Stunden lang in mit Elektrophorese-Puffer befüllten vertikalen Kammern (Biorad Mini-PROTEAṆ 3 cellSystems) bei $400 \mathrm{~mA}$ (Power Pac 300, Bio-Rad, München). Nach Beendigung der Elektrophorese wurden die Proteine auf Nitrozellulose- oder Polyvinyliden-Difluorid Membranen übertragen (siehe Kapitel 2.3.3.2). Die auftrennten Proteine wurden an Hand ihrer molekularen Größe charakterisiert. Als Molekulargewichtsstandard diente der Dual-ProteinMarker (Biorad, München).

\subsubsection{Proteintransfer}

Um die mittels SDS-PAGE aufgetrennten Proteine immunologisch nachweisen zu können, müssen sie zunächst auf eine Nitrozellulose- (Schleicher \& Schüll, Dassel) oder PVDF- 
Membran (Applichem, Darmstadt) übertragen werden (Towbin et al. 1979). Dabei wurde die Membran und das Gel zwischen Transfer-Puffer getränkte Whatman-3MM-Filterpapiere (Roth, Karlsruhe) angeordnet, wobei die Membran näher zur Anode als das Gel zu liegen kam. Der Transfer erfolgte im mit Transfer-Puffer befüllten Mini-Protean 3 Blotting System (Bio-Rad, München) über $1 \mathrm{~h}$ bei $4^{\circ} \mathrm{C}$ und $1 \mathrm{~mA} / \mathrm{cm}^{2}$ (Power Pac 300, Bio-Rad, München).

\subsubsection{Antikörper Detektion}

Um ein spezifisches Protein aus dem aufgetrennten Proteingemisch immunologisch nachweisen zu können wurden Antikörper gegen das Protein verwendet. Ein zweiter Meerrettich Peroxidase-markierter Antikörper bindet den ersten und verstärkt somit das messbare Signal. Bevor die Antikörper-Detektion erfolgen konnte wurde die Membran drei mal 10 min in TBS-T-Puffer gespült und $1 \mathrm{~h}$ bei Raumtemperatur in TBS-T-Puffer mit $5 \%$ Magermilchpulver auf dem Kipp-Schüttler inkubiert (Polymax, Heidolph Instruments). Dieser Schritt verhinderte unspezifische Bindungen des Primärantikörpers. Anschließend wurde die Membran kurz mit TBS-T-Puffer gewaschen und über Nacht bei $4^{\circ} \mathrm{C}$ mit dem in TBS-T-Puffer verdünnten Primärantikörper (siehe Tabelle 6) inkubiert. Anschließend wurde die Membran drei mal 10 min mit TBS-T-Puffer gewaschen. Die Inkubation mit dem Sekundärantikörper (Verdünnung des Sekundärantikörpers siehe Tabelle 7) erfolgte über $1 \mathrm{~h}$ bei Raumtemperatur auf einem Kipp-Schüttler (Polymax, Heidolph Instruments). Abermals wurde die Membran drei mal 10 min mit TBS-T-Puffer gewaschen.

Die Detektion des zweiten mit Meerrettich-Peroxidase markierten Antikörpers erfolgte durch ECL („enhanced“; verstärkte Chemolumineszenz). Dazu wurde ein ECL-Detektionskit (Pierce, USA) verwendet. Es wurde $1 \mathrm{ml}$ der ECL-Lösung auf die Membran gegeben und diese nach einer Minute wieder entfernt. Die Peroxidase am sekundären Antikörper verursacht enzymatisch eine Lichtreaktion des Luminols (Bestandteil der ECL-Lösung).

Die Detektion der Chemolumineszenz erfolgte über Autoradiographie-Filme (Hyperfilme ${ }^{\mathrm{TM}} \mathrm{ECL}^{\mathrm{TM}}$, Amersham Biosciences, Freiburg). Der Autoradiographie-Film wurde auf die zwischen zwei Folien eingebettete Membran aufgelegt und in einer Autoradiographie-Kassette (Hypercassette ${ }^{\mathrm{TM}}$, Amersham phamacia biotech) für unterschiedliche Zeiten (empirisch ermittelt) exponiert. Anschließend wurde der Film entwickelt (Curix 60, Agfa, Köln).

\subsubsection{Bestimmung der CDK5-Aktivität}

Die Veränderung der CDK5- Aktivität innerhalb der Apoptose wurde mit einem CDK5 Kinase Assay ermittelt. Die in $10 \mathrm{~cm} \varnothing$ Kulturschalen ausplattierten dCSM14.1 Neurone 
wurden bis zu einer Flächendichte von ca. 80 \% kultiviert. Nachdem das Kulturmedium von den einzelnen Platten abgesaugt und die Zellen einmalig mit PBS gewaschen waren, wurden sie für unterschiedlich lange Zeitpunkte mit $1 \mu \mathrm{M}$ Staurosporin-haltigem Kulturmedium unter üblichen Bedingungen kultiviert. Staurosporin (Sigma, Steinheim) wurde als Apoptose- induzierende Substanz verwendet (siehe Kapitel 2.4.2). Anschließend wurden die Neurone lysiert, um die Proteine zu extrahieren (siehe Kapitel 2.3.1).

Der erste Schritt des CDK5 Kinase Assays war eine Immunopräzipitation gegen CDK5. Alle Inkubationsschritte erfolgten bei $4^{\circ} \mathrm{C}$. Die eingesetzte Proteinmenge betrug $500 \mu \mathrm{g}$. Die Immunopräzipitation erfolgte mittels Protein A beschichteten Sepharosekügelchen (ProteinA-Sepharose ${ }^{\circledR} 4 \mathrm{~B}$ conjugate, Zymed Laboratories, San Francisco). Protein A ist ein Bestandteil der Zellwand von Streptokokken-Stämmen und bindet mit hoher Spezifität an die Fc-Region der meisten Säugetier-Immunglobuline. Um unspezifisch an den CDK5 Antikörper bindende Proteine zu entfernen, erfolgte zunächst eine Vorinkubation des Proteinlysates mit $30 \mu \mathrm{l}$ in Lysepuffer vorgewaschen Protein-A-Sepharosekügelchen. Die Sepharosekügelchen wurden nach $1 \mathrm{~h}$ abzentrifugiert (5 min, $6000 \mathrm{rpm}, 4^{\circ} \mathrm{C}$ ) und verworfen. Der Überstand wurde mit $10 \mu \mathrm{l}$ unverdünnter CDK5 Antikörperlösung (Tabelle 6) $1 \mathrm{~h}$ rotierend inkubiert. Dem Ansatz wurden dann $30 \mu \mathrm{l}$ in Lysepuffer vorgewaschen Protein-A-Sepharosekügelchen zugegeben und er wurde erneut für $1 \mathrm{~h}$ rotierend inkubiert, wobei CDK5 über den Antikörper an Sepharosekügelchen gebunden wird. Nach drei Waschschritten mit Lysepuffer (5 min, $6000 \mathrm{rpm}, 4^{\circ} \mathrm{C}$ ) und drei Waschschritten mit Kinase-Puffer (5 min, $6000 \mathrm{rpm}, 4^{\circ} \mathrm{C}$ ) erfolgte die eigentliche Kinasereaktion. Dazu wurden die Sepharosekügelchen zentrifugiert (5 min, $6000 \mathrm{rpm}, 4^{\circ} \mathrm{C}$ ), der Überstand verworfen und das Pellet in $20 \mu$ l Kinase-Puffer aufgenommen. Es wurden $2 \mu \mathrm{l}$ Histon H1-Lösung $(5 \mu \mathrm{g} / \mu \mathrm{l}$ Sigma, Steinheim) sowie $0,5 \mu \mathrm{l}{ }^{32} \mathrm{P}-\mathrm{ATP}(10 \mu \mathrm{Ci} / \mu \mathrm{l}$ Amersham Biosciece, Europa) hinzugefügt und der Ansatz über 30 min bei $30^{\circ} \mathrm{C}$ (Thermostat plus, Eppendorf, Hamburg) inkubiert. Histon $\mathrm{H} 1$ wird durch CDK5 mit dem zugesetzten ${ }^{32} \mathrm{P}$-ATP phosphoryliert, so dass die Radioaktivität des Histon $\mathrm{H} 1$ als Maß für die CDK5- Aktivität genutzt werden kann. Nach der Zentrifugation der Proben (5 min, $6000 \mathrm{rpm}, 4^{\circ} \mathrm{C}$ ) wurde $10 \mu$ l SDS Probenpuffer zugegeben und die Proben 5 min bei $95^{\circ} \mathrm{C}$ denaturiert (Thermostat plus, Eppendorf, Hamburg). Die Proben wurden über ein $10 \%$ SDS-Polyacrylamid-Gel innerhalb von $1,5 \mathrm{~h}$ bei $100 \mathrm{~V}$ aufgetrennt (siehe Kapitel 2.3.3). Nach dem SDS-PAGE (siehe Kapitel 2.3.3.1) wurde das Sammelgel entfernt. Das Trenngel wurde zunächst für eine Stunde mit Fixierungslösung bei Raumtemperatur fixiert und zweimal 10 min mit destilliertem Wasser gewaschen. 
Über Nacht erfolgte eine Anfärbung des Gels mit Coomassie-Färbelösung bei Raumtemperatur. Anschließend wurde das Gel mit 1 \% Essigsäure entfärbt, so dass alle nicht gebundenen Coomasie Partikel entfernt wurden. Die Coomassiefärbung diente als Nachweis, dass in allen Bedingungen die gleiche Menge CDK5 durch die Immunopräzipitation isoliert wurde (Ladekontrolle) und die Phosphorylierungsunterschiede von Histon H1 somit nicht auf unterschiedlicher CDK5 Konzentration beruhten. Zur Dokumentation der Coomassiefärbung wurde das getrocknete Gel fotografiert.

Zum Nachweis des phosphorylierten Histon H1 wurde das getrocknete und gefärbte Gel vier Stunden lang direkt auf Phosphorimaging-Platten (Fujifilm) exponiert und die Intensität der radioaktiv markierten Proteinbanden mit einem Phosphorimager (BAS-5000, Fujifilm) bestimmt. Die densiometrische Auswertung der Proteinbanden erfolgte in Matlab (Version 6.0, eigenes Skript). Hierzu wurden die Grauwerte pixelweise über die Bandenbreite gemittelt. Die sich ergebenden Profile wurden in Längsrichtung an Hand der Maxima/Banden ausgerichtet und der jeweilige Hintergrund von den Profilen substrahiert. Anschließend wurde die Fläche unter den Banden bestimmt. Sie stellt ein Maß für die Strahlungsmenge der Bande dar, die wiederum durch die CDK5- Aktivität bestimmt ist.

\subsection{Zellbiologische Methoden}

\subsubsection{Vorbehandlung der Neurone}

\section{$\underline{\text { TAT-Bcl-xL }}$}

TAT-Bcl-xL gehört zu der Familie der anti- apoptotischen Proteine. Es wurde im Kulturmedium zu einer Endkonzentration von $500 \mathrm{nM}$ verdünnt. Um sicherzugehen, dass der Effekt nicht auf den Puffer, in dem das TAT-Bcl-xL gelöst war zurückzuführen ist, wurde als Kontrolle das entsprechende Volumen des TAT-Bcl-xL-Puffers in Kulturmedium verdünnt. Mit beiden Medien wurden die dCSM14.1 Neurone zwei Stunden lang unter üblichen Bedingungen kultiviert.

\section{Indolinon A}

Für die Hemmung von CDK5 wurde Indolinon A (Boehringer Ingelheim) verwendet. Im Kulturmedium wurde es zu einer Endkonzentration von 250 nM verdünnt. Die Neurone wurden 24 Stunden lang mit dem Indolinon A haltigen Kulturmedium unter normalen Bedingungen kultiviert.

Für Zeitreihenaufnahmen dagegen wurden die Neurone 60 min vor dem Beginn der Aufnahme mit Indolinon A in gleicher Konzentration behandelt. Das Medium blieb die gesamte Beobachtungsdauer auf den Zellen. 


\section{zVAD-fmk}

Der Caspase Inhibitor zVAD-fmk (Bachem, Bubendorf, Schweiz) wurde im Kulturmedium zu einer Endkonzentration von $100 \mu \mathrm{M}$ verdünnt. Die Neurone wurden 24 Stunden lang mit dem zVAD-fmk -haltigen Kulturmedium unter normalen Bedingungen kultiviert.

\section{Cytochalasin D und Nocodazol}

In Experimenten in denen der Einfluss des Zytoskeletts untersucht werden sollte, wurde dieses durch die Zugabe der Substanzen Nocodazol (10 $\mu \mathrm{g} / \mathrm{ml}$, Sigma, Steinheim) und Cytochalasin D (10 $\mu \mathrm{g} / \mathrm{ml}$, Alexis, Grünberg) zerstört. Hierfür wurde zunächst das Kulturmedium von den Neuronen entfernt, diese einmalig mit PBS gewaschen und die Zytoskelett zerstörenden Substanzen in der angegebenen Endkonzentration im Kulturmedium verdünnt zugegeben. Die Behandlung der Neurone erfolgte 30 min vor Beginn der Zeitreihenaufnahme unter üblichen Kulturbedingungen. Das Medium wurde die komplette Beobachtungsdauer auf den Zellen gelassen.

\subsubsection{Apoptoseinduktion}

Apoptose wurde in der vorliegenden Arbeit mit drei verschiedenen Apoptose auslösenden Substanzen induziert. Am häufigsten wurde Staurosporin (1 $\mu \mathrm{M}$, Sigma, Steinheim) genutzt. Staurosporin wird aus Streptomyces staurosporeus Bakterien isoliert und gilt als Induktor des intrinsischen, mitochondrialen Apoptoseweges (Chae et al. 2000). Da es sich bei den verwendeten Neuronen (siehe Kapitel 2.1) um dopaminerge Zelltypen handelt wurde Des Weiteren $\mathrm{MPP}^{+}\left(1 \mathrm{mM}\right.$, Sigma, Steinheim) verwendet. $\mathrm{MPP}^{+}$ist ein Metabolit des Neurotoxins MPTP, welches selektiv dopaminerge Neurone durch die Blockade der mitochondrialen Atmungskettenenzyme schädigt und zur Apoptose führt. Ebenso kam das Calciumionophor A23187 (50 nM, Alexis, Grünberg) zum Gebrauch, welches die Freisetzung von $\mathrm{Ca}^{2+}$ induziert. Eine erhöhte Calciumkonzentration aktiviert den intrinsischen Apoptoseweg (siehe Kapitel 1.1.2.2) innerhalb der Zelle.

Die Induktion der Apoptose erfolgte nach Abnahme des Kulturmediums und einem Waschschritt mit PBS. Die Apoptose induzierenden Substanzen wurden wie oben angegeben in Kulturmedium verdünnt. Die Dauer der Inkubation mit dem Apoptose induzierenden Kulturmedium unter den üblichen Kulturbedingungen variierte je nach Versuchsablauf und ist daher bei den Versuchsbeschreibungen angegeben. 


\subsubsection{Apoptosenachweis}

\subsubsection{Messung der Cytochrom c Freisetzung}

Ein weiterer messbarer Apoptoseindikator ist die Cytochrom c Freisetzung. Für die Analyse wurden dCSM14.1 Neurone auf Deckgläschen in 24-well Platten ausplattiert. Nach erfolgreicher Transfektion der Neurone (siehe Kapitel 2.2.2 und Kapitel 2.2.2.1.2) und Einleitung der Apoptose durch Behandlung mit Staurosporin (siehe Kapitel 2.4.2) wurde das Medium von den Neuronen entfernt und diese mit 4 \% PFA fixiert. Danach erfolgte die immuncytochemische Färbung gegen Cytochrom c. Die Neurone wurden dazu zunächst mit 0,1 \%Triton X-100 in PBS permeabilisiert. Nach einem Waschschritt mit PBS wurden sie 30 min in $5 \%$ NGS (normal goat serum, PAA, Cölbe) bei Raumtemperatur inkubiert, um unspezifische Bindungen des Antikörpers zu reduzieren. Nach der Überführung der Deckgläschen in eine wasserdampf-gesättigte Atmosphäre (feuchte Kammer) wurden diese mit Cytochrom c Antikörperlösung (siehe Tabelle 6) bedeckt und für 12 Stunden bei $4^{\circ} \mathrm{C}$ inkubiert. Nach waschen mit PBS erfolgte die einstündige Inkubation mit dem sekundären Antikörper (siehe Tabelle 7) bei Raumtemperatur. Nach abermaligem waschen mit PBS wurden die Deckgläschen mit DABCO (Fluka, Steinheim) eingedeckt. Alle Proben wurden bei $4^{\circ} \mathrm{C}$ bis zur mikroskopischen Auswertung gelagert.

Die mikroskopische Auswertung fand an einem inversen Fluoreszenzmikroskop (Axiovert200, Zeiss, Göttingen) mittels eines Öl-Objektives (63x, Zeiss, Göttingen) statt. Nach der Überprüfung der Expression des transfizierten Plasmids, wurde die Cytochrom c Verteilung klassifiziert. Zwei verschiedene Klassen wurden genutzt. Die erste genutzte Klasse von Neuronen wies eine in den Mitochondrien lokalisierte Cytochrom c Färbung auf, wohingegen die zweite Klasse durch ein diffuses Cytochrom c Verteilungsmuster charakterisiert war. Mischformen traten nicht auf.

\subsubsection{Studien zur Kernmorphologie}

Die Studien der Kernmorphologie dienten ebenfalls der Beurteilung der Apoptose. Bei Apoptose kondensiert Chromatin und es bilden sich Ausstülpungen der Kernmembran, die sich als sogenannte „apoptotische Körperchen“ abschnüren. Diese konnten durch fluoreszierende Kernfärbungen mit 4,6-Diamidino-2-phenylindol (DAPI, Sigma, Steinheim) sichtbar gemacht werden.

Die Neurone wurden mit den entsprechenden Substanzen vorbehandelt, deren Auswirkungen auf die Apoptose untersucht werden sollte (siehe Kapitel 2.4.1). In allen Versuchen wurde im Anschluss das Kulturmedium abgesaugt und die Neurone einmalig mit PBS gewaschen, 
bevor die Apoptose induziert wurde (siehe Kapitel 2.4.2). Die Inkubationsdauer mit dem Apoptose induzierenden Substanzen variierte von $30 \mathrm{~min}$ bis zu 12 Stunden und wurde durch Austausch des Apoptose induzierenden Kulturmediums gestoppt. Nach einem PBS Waschschritt erfolgte die Fixierung der Neurone mit 4 \% PFA bei Raumtemperatur, so dass die räumliche Ordnung der zellulären Proteine erhalten blieb. Nach abermaligem waschen mit PBS wurden die Zellen mit DAPI $(2 \mu \mathrm{g} / \mathrm{ml})$ inkubiert. Die auf Deckgläschen gewachsenen Neurone wurden abermals mit PBS gewaschen, aus den 24 well Platten entnommen und mit DABCO eingedeckt. Die Beurteilung der Kernmorphologie erfolgte an einem Fluoreszenzmikroskop (Axioplan, Zeiss, Göttingen). Die DAPI-Färbung der Kerne wurde mit $358 \mathrm{~nm}$ angeregt und bei $461 \mathrm{~nm}$ betrachtet. Die Neurone wurden auf Grund der Morphologie ihrer Zellkerne visuell zwei Kategorien (gesund oder pyknotisch/apoptotisch) zugeteilt.

\subsubsection{Beurteilung der Mitochondrienmorphologie an fixierten Zellen}

Für die Studien der Mitochondrienmorphologie wurden Neurone transfiziert (siehe Kapitel 2.2.2) und die Apoptose induziert (siehe Kapitel 2.4.2). Die Dauer der Inkubation mit dem Apoptose induzierenden Substanzen variierte wie bei den Studien zur Kernmorphologie (siehe Kapitel 2.4.3.2) von 30 min bis zu 12 Stunden, wonach es ausgetauscht wurde. Die Neurone wurden einmalig mit PBS gewaschen und mit $4 \%$ PFA 15 min bei Raumtemperatur fixiert. Nach einem weiteren Waschschritt wurden die auf Deckgläser gewachsenen Neurone aus den 24 well Platten entnommen und mit DABCO (Fluka, Steinheim) eingedeckt. Die Beurteilung der Mitochondrienmorphologie erfolgte mittels eines Öl-Objektives (Zeiss 63x) an einem Fluoreszenzmikroskop (Axioplan200, Zeiss, Göttingen). Dabei wurden die Neurone nach ihrer vorherrschenden mitochondrialen Morphologie visuell in zwei Kategorien (elongiert/tubulär oder fragmentiert/punktförmig) eingeteilt.

\subsubsection{Beurteilung der Mitochondrienmorphologie an lebenden Zellen}

Um ein quantitatives Maß zur Veränderung der Mitochondrienmorphologie zu erhalten, wurden Zeitreihenaufnahmen der transfizierten dCSM14.1 Zellen sowie der primären Mittelhirnneurone genutzt. Mit dieser Methode war es möglich über eine Zeitspanne von bis zu 2,5 Stunden die Dynamik der Mitochondrien zu untersuchen. Hierzu wurden die Neurone in Acht-well Platten kultiviert und wie in Kapitel 2.2.2 beschrieben transfiziert. Durch die Verwendung von Acht-well Platten konnten je vier wells parallel unter gleichen experimentellen Bedingungen beobachtet werden. Die Zellen wurden stellenweise wie unter Kapitel 2.4.1 beschrieben vorbehandelt. Sofern eine Kotransfektion vorlag, wurde jeweils zu 
Beginn der Sequenzaufnahmen überprüft, ob die zu filmende Zelle das zu untersuchende Protein exprimierte. Die Neuronen wurden in einer auf dem Mikroskoptisch aufgesetzte Klimakammer (Zeiss, Göttingen) überführt. Diese erlaubte die Beobachtung der Neurone über einen längern Zeitraum hinweg. Die Kulturbedingungen innerhalb der Klimakammer entsprachen den ansonsten üblichen Bedingungen mit entweder $39^{\circ} \mathrm{C}$ und $5 \% \mathrm{CO}_{2}$ für die dCSM14.1 Neurone oder $37^{\circ} \mathrm{C}$ und $5 \% \mathrm{CO}_{2}$ für die primären Mittelhirnneurone. Die Regulation der Beiheizung des Mikroskoptisches erfolgte über einen Temperaturregler (TempControler 37-2 digital, Zeiss, Göttingen). Ebenso wurde die $\mathrm{CO}_{2}$ Konzentration in der Klimakammer reguliert (CTI-Controler 3700 digital, Zeiss, Göttingen).

Die Zeitreihenaufnahme der Neurone erfolgte meist alle 10 min mit Hilfe eines Ölobjektives (63x, Zeiss Göttingen) an einem inversen Fluoreszenzmikroskop (Axiovert 200, Zeiss). Die Gesamtdauer der Zeitreihenaufnahmen betrug maximal 2,5 Stunden. Es wurde nur der Fluoreszenzkanal in welchem die Mitochondrien sichtbar waren aufgezeichnet. Nach 30 min wurde in das Kulturmedium der Neurone die Apoptose induzierenden Substanzen (siehe Kapitel 2.4.2) appliziert.

Nach Abschluss der Sequenzaufnahmen wurde in jedem aufgenommenen Bild die Länge von 10 Mitochondrien vermessen (Software Axiovison, Zeiss, Göttingen). Die Auswahl der Mitochondrien erfolgte stochastisch gleichverteilt über das gesamte Zytoplasma der zu analysierenden Zelle. Die Auswahl variierte von Sequenz zu Sequenz, so dass nicht in jedem Bild die Länge des gleichen Mitochondriums vermessen wurde, was meist wegen der starken Veränderung der Mitochondrien generell nicht möglich war.

Um sicherzustellen, das die morphologische Veränderung der Mitochondrien nicht auf die Inkubation der Neurone in der Klimakammer oder anderen Faktoren zurückzuführen sind, wurden Kontrollaufnahmen durchgeführt. In diesen wurde auf die Applikation der Apoptose induzierenden Substanz verzichtet (siehe Abbildung 12). Auch in der Kontrollbedingung zeigt sich eine schwache Längenreduktion der Mitochondrien, was vermutlich auf die nicht optimalen Kulturbedingungen in der Messkammer zurückzuführen ist. Um diesen Effekt aus den Messungen zu eliminieren wurde die Mitochondrienlänge auf die Veränderungen der Kontrollzellen normiert.

Um die zeitliche Entwicklung der Mitochondrienlänge zu charakterisieren, wurde versucht, sie durch einen exponentiellen Zerfall zu beschreiben. Zunächst wurde die durchschnittliche Mitochondrienlänge vor Apoptoseinduktion auf eins normiert, so dass alle Messkurven vergleichbar sind. Als Ausgleichsfunktion wurde die Exponentialfunktion: $L=\left(1-L_{\infty}\right) e^{-\lambda t}+L_{\infty}$ mit $\mathrm{L}=$ rel. Mitochondrienlänge, $\mathrm{L}_{\infty}=$ Endlänge der Mitochondrien, 
$\lambda=$ Zerfallskonstante verwendet, diese Funktion beschreibt einen Zerfall vom Ausgangswert 1 auf $\mathrm{L}_{\infty}$. Die beiden Parameter der Exponentialfunktion $\left(\mathrm{L}_{\infty}\right.$ und $\lambda$ ) wurden so gewählt, dass die Summe der Abstandquadraten zu den Messwerten minimal wurde (Matlab). Die Exponentialfunktion nähert so optimal die Daten an und der Parameter $\mathrm{L}_{\infty}$ nähert die vermutliche Endlänge der Mitochondrien an (nach langer Inkubation), während $\lambda$ die Zerfallsgeschwindigkeit (bei Inkubationsstart) beschreibt. Anstelle der . Zerfallskonstante wird meist die Zeit angegeben in der sich die Mitochondrienlänge halbiert (Halbwertszeit $\tau_{\frac{1}{2}}=\ln \frac{1-L_{\infty}}{0,5-L_{\infty}} / \lambda$ ), diese Angabe ist allerdings nur möglich, wenn die Mitochondrien in der jeweiligen Versuchsbedingung tatsächlich ihre durchschnittliche Länge mindestens halbieren.

Die einzelnen Bildaufnahmen wurden zu kleinen Filmsequenzen zusammengefügt (Matlab 6.5, eigenes Skript), um die Dynamik der Veränderung zu untersuchen.

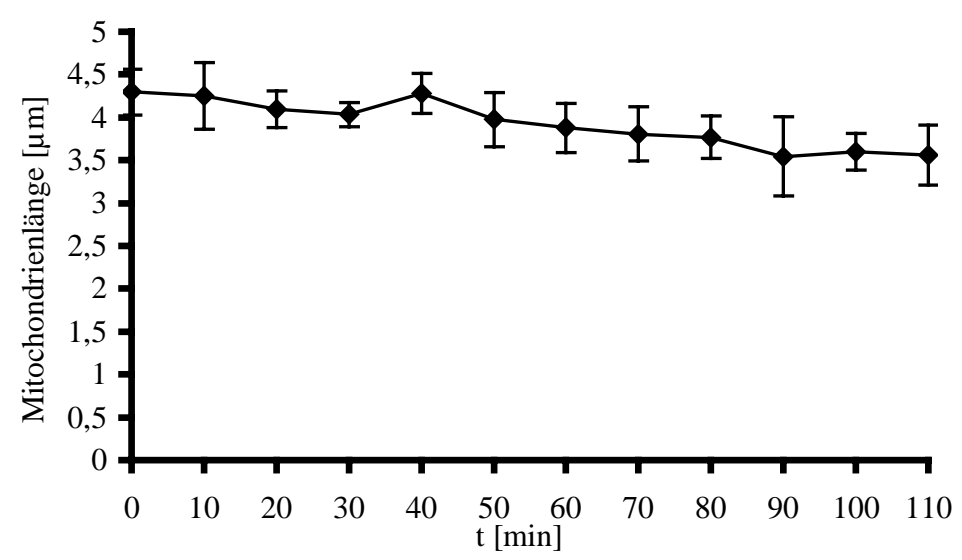

\section{Abbildung 12: Kontrollmessung.}

Dargestellt ist die Mitochondrienlänge (Ordinate) in Abhängigkeit von der Aufnahmedauer (Abszisse). Die Messwerte und Standardfehler ermitteln sich aus der Vermessung von je zehn Mitochondrien dreier einzelner dCSM14.1 Neurone. Die Mitochondrien waren durch pDsRed2-Mito Transfektion markiert.

Im Zeitverlauf ist eine geringfügige Längenreduktion der Mitochondrien erkennbar, die durch die nicht optimalen Inkubationsbedingungen erklärbar ist. Der Zerfall ist in dem betrachteten Zeitinterfall annähernd linear, die Regressionsgerade fällt mit $0,13 \%$ je Minute $\left(r^{2}=0,6\right)$. Alle durchgeführten Messungen wurden auf diese Vergleichswerte normiert.

\subsubsection{Zytoskelettstudien}

Zur Bestimmung des Einflusses des Zytoskeletts auf die mitochondrialen Zerteilungsvorgänge und die Apoptose dienten Studien zur Mitochondrien- und Kernmorphologie unter Ausschaltung des Zytoskeletts (siehe Kapitel 2.4.3.2 und 2.4.4). Die dCSM14.1 Neurone wurden auf Deckgläschen kultiviert, transfiziert (siehe Kapitel 2.2.2) und die Überexpression 
der Proteine wurde mittels Fluoreszenzmikroskopie sichergestellt. Danach wurden die Zellen wie in Kapitel 2.4.1 beschrieben mit Cytochalasin D oder Nocodazol behandelt.

Um die Zerstörung des Zytoskeletts beurteilen zu können, wurde das Aktinzytoskelett mittels der hochspezifischen Bindung von Phalloidin (Molecular Probes, Karlsruhe) einem primär aus Amanita phalloides isoliertem Peptidtoxin an Aktin angefärbt. Im Gegensatz zur Visualisierung des Aktins erfolgt die Detektion der Mikrotubuli mit spezifischen Antikörpern. Die Färbung erfolgte wie unter Kapitel 2.4.3.1 beschrieben.

Die Dokumentation des zerstörten Aktin- bzw. Tubulinzytoskeletts erfolgte mit Hilfe eines Fluoreszenzmikroskops (Axioplan200, Zeiss, Göttingen). Das Excitations-/Emissionsmaximum von Alexa-Fluor-488-konjugiertem Phalloidin beträgt 495/519 nm. 


\subsection{Medien und Puffer}

Die verwendeten Feinchemikalien und Lösungsmittel wurden, wenn im Text nicht anders angegeben, im Reinheitsgrad "zur Analyse" oder reiner Qualität von den Firmen Biometra (Göttingen), Boehringer (Mannheim), Merck (Darmstadt), Gibco BRL (Eggenstein) oder Sigma (Steinheim) bezogen.

\subsubsection{Medien für Bakterien}

Alle Medien für die Arbeiten mit Bakterien wurden autoklaviert.

LB-Medium (Luria-Bertani): 10 g/l Trypton, 5 g/l Hefeextrakt, 5 g/l NaCl

LB-Platte: $\quad$ LB-Medium, $2 \%(\mathrm{~m} / \mathrm{v})$ Agar

SOC-Medium: $\quad 20$ g/l Trypton, 5 g/l Hefeextrakt, 10 mM NaCl, 10 mM $\mathrm{MgCl}_{2}, 10 \mathrm{mM} \mathrm{MgSO}_{4}, 20 \mathrm{mM}$ Glucose

Einfrierlösung: $\quad 15 \%$ Glycerin, $50 \mathrm{mM} \mathrm{CaCl}_{2}$ versetzt

\subsubsection{Medien für CSM14.1 Neurone}

Kulturmedium:

DMEM (Dulbecco’s modifiziertes Eagle Medium, PAA, Cölbe), 10 \% (v/v) FCS, 5000 U/ml Penicillin/ 5000 g/ml Streptomycin

Einfrier-Medium: $\quad 10 \%$ DMSO in FCS

\subsubsection{Medien für primäre Mittelhirnneurone}

Mittelhirn-Kulturmedium: $\quad$ DMEM F12, 2,5 g/l BSA, 2 mM $\alpha$-Glutamin, 0,9 \% Glucose, 5 mg/l Insulin, $1 \%$ (w/v) N1, 5000 U/ml Penicillin/ $5000 \mu \mathrm{g} / \mathrm{ml}$ Streptomycin, $5 \%$ (v/v) DMEM-F12 ohne Glutamin

CMF-Medium: $\quad 90 \%(\mathrm{v} / \mathrm{v})$ destilliertes Wasser, $10 \%(\mathrm{v} / \mathrm{v}) \mathrm{HBSS}$

\subsubsection{Puffer}

Coomassie-Färbelösung: 0,1 \% (w/v) Coomassie Brillant Blue G250, 2 \% (w/v) orthoPhosphosäure, $10 \%(\mathrm{w} / \mathrm{v})$ Ammoniumsulfat, $20 \%(\mathrm{v} / \mathrm{v})$ Methanol

Elektrophorese-Puffer: $\quad 25 \mathrm{mM}$ Tris, 0,2 mM Glycin, 0,1 \% (v/v) SDS

Fixierungs-Lösung: $\quad 40$ \% (v/v) Ethanol, 10 \% (v/v) Essigsäure 
Kinase-Puffer:

Lyse-Puffer:

PBS:

Sammelgel-Puffer:

SDS-Probenpuffer:

TAT-BcLxl- Puffer:

TBS-T-Puffer:

Transfer-Puffer:

Trenngel-Puffer:
0,5 mM DTT, 5 mM MgCl 2,25 mM Hepes (pH 7,0), 0,5 $\mu \mathrm{M}$ ATP

$1 \%$ (v/v) Triton-X, 50 mM Tris HCl, 150 mM NaCl, 5 mM

EDTA, $10 \mathrm{mM}$ NaF, 2,5 mM Na 2 PP, $1 \mathrm{mM} \mathrm{NaOV}, 1 \mathrm{mM}$

PMSF, 1 mM DTT, 1 x Protease Inhibitor

$137 \mathrm{mM} \mathrm{NaCl}, 2,7 \mathrm{mM} \mathrm{KCl}, 10 \mathrm{mM} \mathrm{Na} 2 \mathrm{HPO}_{4}, 2 \mathrm{mM}$

$\mathrm{KH}_{2} \mathrm{PO}_{4}$

0,5 M Tris (pH 6,8), 0,4 \% (m/v) SDS

$2 \%$ (m/v) SDS, 60 mM Tris (pH 6,8), 10 \% (v/v) Glyzerin, $5 \%$ (v/v) ß-Mercaptoethanol, 0,02 \% (m/v) Bromphenolblau 10 mM Tris (pH 10), 50 \% (v/v) Glycerol, 0,1 mM EDTA, 0,1\% (v/v) pluronic, 0,02 \% Tween-80

$10 \mathrm{mM}$ Tris, $150 \mathrm{mM} \mathrm{NaCl}, 0,1 \%$ (v/v) Tween20

2,5 mM Tris, 19 mM Glycin, 20 \% (v/v) Methanol

1,5 mM Tris (pH 8,8), 0,4 \% (m/v) SDS

\subsubsection{Antikörper}

\begin{tabular}{|l|l|l|}
\hline Primärantikörper & Spezies (Hersteller) & Arbeitskonzentration \\
\hline Cytochrom c & Maus (BD) & $1: 1000$ \\
\hline ß-Tubulin & Maus (Sigma) & $1: 250$ \\
\hline CDK5 (C-8) & Kaninchen (Santa Cruz) & $1: 500$ \\
\hline p35 (C-19) & Kaninchen (Santa Cruz) & $1: 1000$ \\
\hline Drp1 & Maus (BD) & $1: 1000$ \\
\hline
\end{tabular}

Tabelle 6: Verwendete Primärantikörper.

\begin{tabular}{|l|l|l|}
\hline Sekundärantikörper gekoppelt an & Spezies (Hersteller) & Arbeitskonzentration \\
\hline $\mathrm{Cy}^{\mathrm{TM}} 3$ & Ziege $\alpha$ Kaninchen (Dianova) & $1: 1000$ \\
\hline $\mathrm{Cy}^{\mathrm{TM}} 3$ & Ziege $\alpha$ Maus (Dianova) & $1: 1000$ \\
\hline HRP & Ziege $\alpha$ Maus (Santa Cruz) & $1: 2000$ \\
\hline HRP & Ziege $\alpha$ Kaninchen (Santa Cruz) & $1: 2000$ \\
\hline
\end{tabular}

Tabelle 7: Verwendete Sekundärantikörper. 


\section{Ergebnisse}

Mitochondrien sind hochdynamische Organellen, die einer ständigen Zerteilung und Verschmelzung unterliegen. Auf innere und äußere Signale ihrer Umwelt können sie mit morphologischen Veränderungen reagieren. Während der Apoptose verlagert sich das Gleichgewicht aus Zerteilungs- und Verschmelzungsraten stark zur Zerteilung (Bossy-Wetzel et al. 2003). Der Zusammenhang zwischen vermehrter mitochondrialer Zerteilung und der Apoptose ist bis zum heutigen Zeitpunkt nicht gänzlich aufgeklärt. So sind nur wenige Faktoren bekannt, die den Prozess der mitochondrialen Zerteilung regulieren (siehe Kapitel 1.1.5.1).

Die vorliegende Arbeit soll einen Beitrag zur Aufklärung der Zusammenhänge zwischen vermehrter mitochondrialer Zerteilung, den daran beteiligten Proteinen und der Apoptose liefern.

\section{1 dCSM14.1 Neurone}

Die grundlegenden Untersuchungen zur Mitochondrienmorphologie fanden an Kulturen dopaminerger Neurone (dCSM14.1) statt. Zur Visualisierung der Morphologie müssen die Mitochondrien der Neurone markiert werden. Zunächst wurde versucht einen spezifischen mitochondrialen Farbstoff (MitoTracker ${ }^{\mathrm{TM}}$ orange) zu verwenden. Die Markierung erwies sich jedoch als zu unspezifisch, da auch nicht mitochondriale Membranen stark angefärbt wurden. Gute mitochondriale Markierungen wurden dagegen durch transiente Transfektionen mit pDsRed2-Mito (siehe Kapitel 2.2.2.1) erzielt. Sie resultierten in einer hochspezifischen stark fluoreszierenden mitochondrialen Markierung.

Alle in der vorliegenden Arbeit dargestellten Experimente nutzten transiente Transfektionen mit pDsRed2-Mito, um die Morphologie der Mitochondrien zu untersuchen.

Apoptoseinduktion erfolgte durch die Applikation verschiedener Apoptose induzierender Substanzen (siehe Kapitel 2.4.2). Verwendet wurden Staurosporin, ein Proteinkinase Inhibitor, der mit der ATP Bindungsstelle der Proteinkinasen interagiert (Tamaoki et al. 1986), $\mathrm{MPP}^{+}$der aktive Metabolit des Neurotoxins MPTP, welches spezifisch in dopaminergen Neuronen die mitochondrialen Atmungskettenenzyme schädigt und daher bei in vivo Parkinson Modellen zum Einsatz kommt (Meuer et al. 2006). Ebenso ein Calciumionophor (A23187), das eine erhöhte Calciumkonzentration im Zytoplasma herbei führt (Abbott et al. 1979). Alle drei Substanzen induzieren den intrinsischen Apoptoseweg (siehe Abbildung 2). 


\subsubsection{Mitochondrienmorphologie während der Apoptose}

In nicht apoptotischen Neuronen besitzen die Mitochondrien eine elongierte Form (siehe Abbildung 13). Wird jedoch durch Staurosporinbehandlung Apoptose induziert, zeigen sich die Mitochondrien als kleine runde Strukturen, die vermehrt um den Zellkern lokalisiert sind (siehe Abbildung 13). Die Morphologie der Mitochondrien verändert sich während der Apoptose stark, das ansonsten vorherrschende Gleichgewicht aus Verschmelzung- und Zerteilungsvorgängen ist gestört. Die schnelle Veränderung der mitochondrialen Morphologie nach Apoptoseinduktion wurde vermutlich durch eine erhöhte Zerteilungsrate der Mitochondrien verursacht (siehe Abbildung 14). In vielen Einzelfällen konnten Zerteilungen der Mitochondrien beobachtet werden, wobei die Dauer eines Zerteilungsvorganges unter einer Minute (minimaler Bildabstand) liegt.
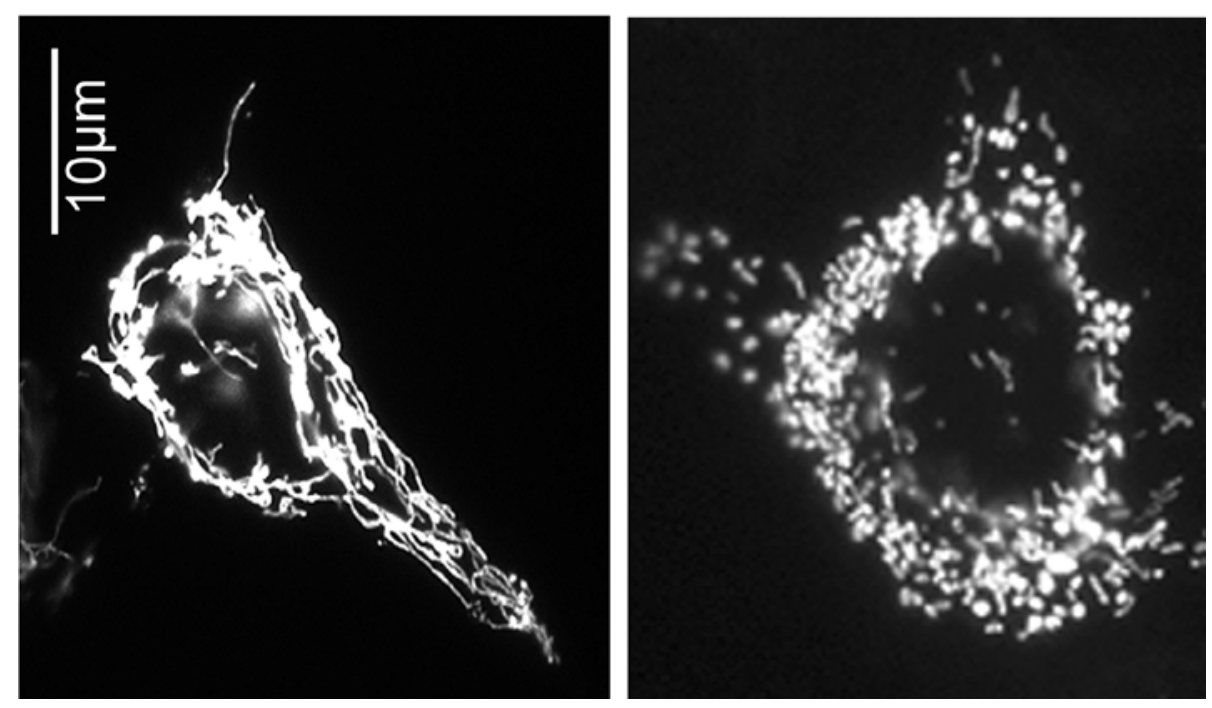

Abbildung 13: Neuronen mit und ohne Staurosporinbehandlung.

Dargestellt sind fluoreszenzmikroskopische Aufnahmen der Mitochondrien von zwei pDsRed2-Mito transfizierten dCSM14.1 Neuronen.

Die Mitochondrien der unbehandelten Zelle (links) besitzen eine elongierte Form. Die durchschnittliche Länge der Mitochondrien betrug 4,9 $\mu \mathrm{m} \pm 1,1 \mu \mathrm{m}$ (siehe Abbildung 21). Nach zweistündiger Behandlung mit $1 \mu \mathrm{M}$ Apoptoseinduktor Staurosporin (rechts) sind die Mitochondrien von kleiner runder Form und häufig vermehrt um den Zellkern lokalisiert. Es sind kaum noch Fortsätze erkennbar.
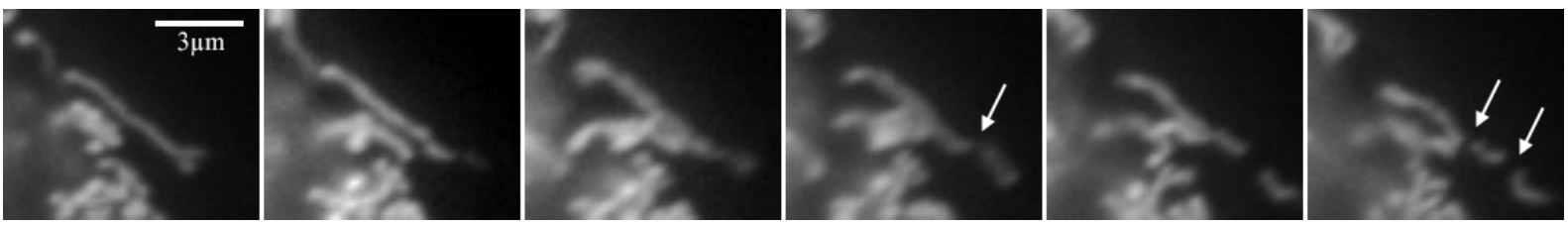

Abbildung 14: Mitochondriale Fragmentation bei Apoptose.

Die dargestellten Mitochondrien eines mit $1 \mu \mathrm{M}$ Staurosporin behandelten dCSM14.1 Neurons wurden in 1 Minuten Abständen (von links) beginnend abgelichtet. Sie sind durch Transfektion mit pDsRed2-Mito markiert.

Das Mitochondrium oben rechts teilt sich in drei Fragmente, die Zerteilungspositionen sind durch weiße Pfeile hervorgehoben. 


\subsubsection{Dynamik der mitochondrialen Zerteilung}

Die morphologische Veränderung der Mitochondrien während der Apoptose ist ein dynamischer Prozess, der in Zeitreihenaufnahmen von Neuronen (siehe Kapitel 2.4.5) analysiert wurde. Die Methode der Zeitreihenaufnahme ermöglicht es in einzelnen lebenden Zellen Vorgänge wie die mitochondriale Formveränderung während der Apoptose direkt über einen längeren Zeitraum zu untersuchen.

Nach Apoptoseinduktion setzten morphologische Veränderungen der Mitochondrien ein, die immer alle Mitochondrien einer Zelle betrafen (siehe Abbildung 15). Die Mitochondrien veränderten ihre Morphologie von einer elongierten zu einer fragmentierten Form. Ungefähr eine Stunde nach Apoptoseinduktion wurden ausschließlich Mitochondrien von kleiner runder Form gefunden (siehe Abbildung 15).
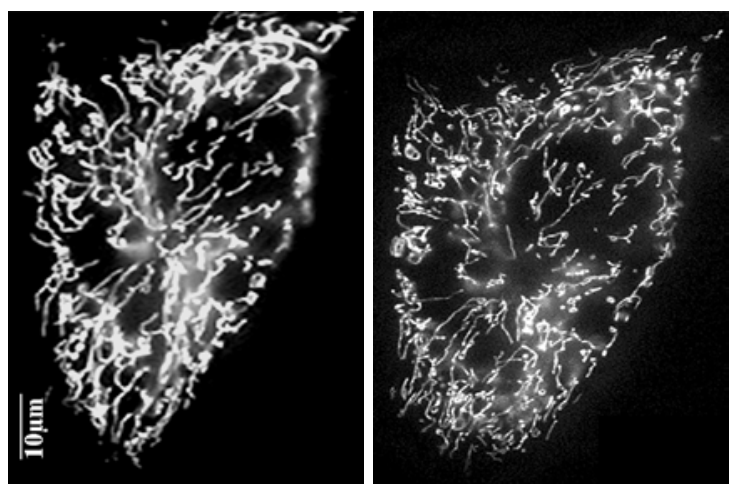

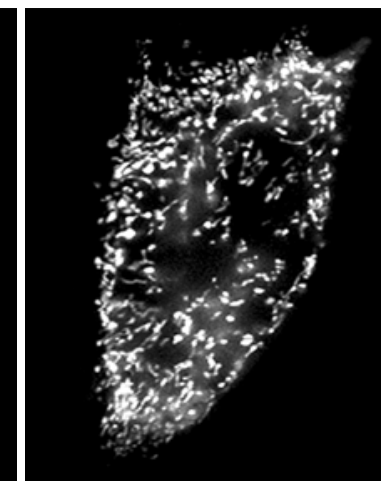

$\mathrm{MPP}^{+}$Inkubation:

$$
0 \min
$$

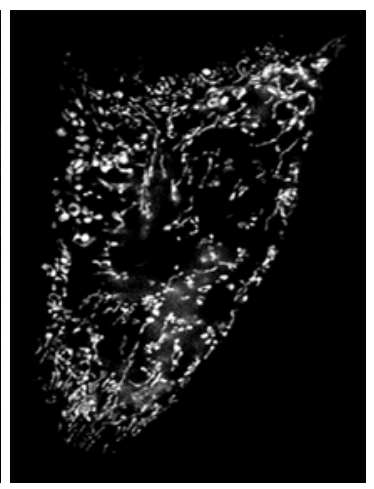

$60 \mathrm{~min}$
$90 \min$

Abbildung 15: Morphologische Veränderung der Mitochondrien während der Apoptose.

Dargestellt sind fluoreszenzmikroskopische Aufnahmen der Mitochondrien einer pDsRed2-Mito transfizierten dCSM14.1 Zelle. Die Zeitangaben geben die Beobachtungsdauer einer Zeitreihenaufnahme (siehe Kapitel 2.4.5) wieder. Nach der ersten Aufnahme (Zeitpunkt 0) wurde durch Zugabe von $1 \mathrm{mM} \mathrm{MPP}{ }^{+}$Apoptose induziert.

Das linke Bild zeigt Mitochondrien (unbehandelt) mit einer elongierten Morphologie. Schon nach halb stündiger Inkubation mit MPP ${ }^{+}$ändern die Mitochondrien ihre Morphologie von einer elongierten zu einer fragmentierten Form. Nach 90 min $\mathrm{MPP}^{+}$Inkubation sind alle Mitochondrien des Neurons kleine runde Strukturen.

Das Zellvolumen, in dem sich die Mitochondrien verteilen verringert sich im Verlauf der $\mathrm{MPP}^{+}$Inkubation, so dass sich die Mitochondrienfragmente zum Zellkern hin verlagern (rechts).

Da die morphologischen Veränderungen der Mitochondrien während der Apoptose durch Fragmentation dominiert waren, konnte die Mitochondrienlänge als Parameter für die Formveränderung genutzt werden. Direkt nach der Apoptoseinduktion setzte eine Abnahme der durchschnittlichen mitochondrialen Länge ein (siehe Abbildung 16). Der Abfall ähnelt einem exponentiellen Zeitverlauf, dies deutet darauf hin, dass alle Mitochondrien einer konstanten Zerfallswahrscheinlichkeit unterliegen. 


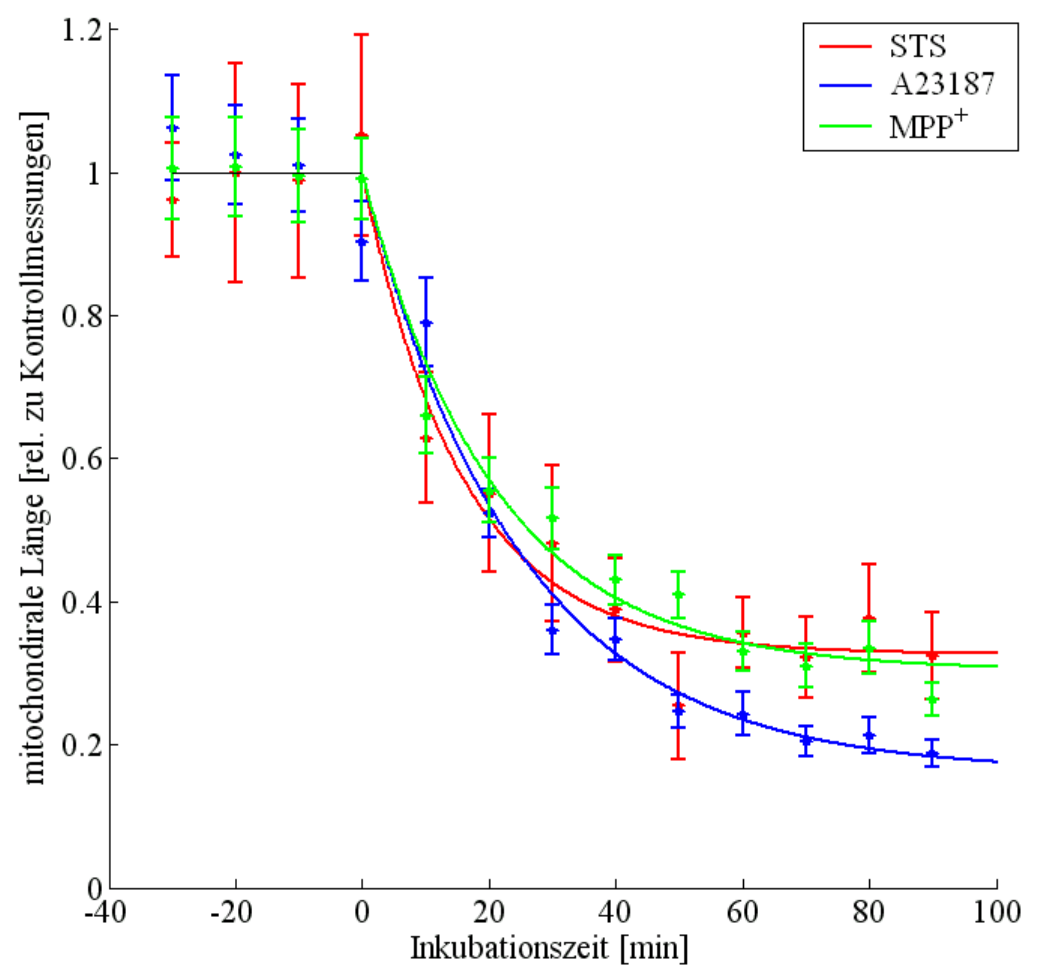

\begin{tabular}{|l|r|r|c|}
\hline Bedingung & $\begin{array}{c}\mathrm{L}_{\text {end }} \\
{[\%]}\end{array}$ & $\begin{array}{c}\tau_{1 / 2} \\
{[\mathrm{~min}]}\end{array}$ & $\mathrm{r}^{2}$ \\
\hline STS & $32,6 \%$ & 21,3 & 0,954 \\
\hline A23187 & $16,1 \%$ & 22,4 & 0,969 \\
\hline MPP $^{+}$ & $30,3 \%$ & 26,3 & 0,968 \\
\hline
\end{tabular}

\section{Abbildung 16: Reduktion der mitochondrialen Länge nach Apoptoseinduktion.}

Dargestellt ist die durchschnittliche Mitochondrienlänge in Abhängigkeit von der Inkubationsdauer Apoptose induzierender Substanzen. Auf der Abszisse ist die Messdauer aufgetragen. Zum Zeitpunkt 0 wurde die Apoptose induzierende Substanz (rot: $1 \mu \mathrm{M}$ Staurosporin (STS), blau: $100 \mathrm{nM}$ A23187 oder grün: $1 \mathrm{mM} \mathrm{MPP}^{+}$) appliziert. Die Mitochondrien waren durch pDsRed2-Mito Transfektion markiert. Die Messwerte und Standardfehler ermitteln sich aus der Vermessung von je zehn Mitochondrien aus je drei einzelnen dCSM14.1 Neuronen. Die Messwerte wurden auf die entsprechende Längenmessung einer Kontrollgruppe ohne Apoptoseinduktion normiert (siehe Abbildung 12). Neben den Messpunkten ist in gleicher Farbe eine exponentielle Ausgleichskurve dargestellt (durchgezogene Linie, siehe Kapitel 2.4.5). Die optimierten Parameter ( $\tau_{1 / 2}$ : Halbwertszeit in Minuten und $L_{\text {end }}$ : relative Endlänge, $r^{2}$ : Regressionskoeffizient) aller Ausgleichskurven sind der rechts dargestellten Tabelle zu entnehmen.

Nach Zugabe der Apoptose induzierenden Substanz ist eine Verkürzung der Mitochondrienlänge sichtbar. Dieser Effekt ist unabhängig von der Apoptose induzierenden Substanz. Alle Regressionskoeffizienten sind größer als 0,95 (siehe Tabelle), daher kann hier ein Zerfallsprozess angenommen werden. Die Zerfallsgeschwindigkeiten haben bei allen Apoptose induzierenden Substanzen die gleiche Größenordnung. In dCSM 14.1 Neuronen liegt die Halbwertszeit der mitochondrialen Fragmentation während der Apoptose somit durchschnittlich bei 23 min. Dies deutet daraufhin, dass die Geschwindigkeit der mitochondrialen Fragmentation während der Apoptose nicht von der Apoptose induzierenden Substanz abhängt, sondern einmal induziert mit konstanter Geschwindigkeit abläuft.

\subsubsection{Bedeutung von Fis1 und Drp1 in der neuronalen Apoptose}

\subsubsection{Regulation der mitochondrialen Morphologie}

Die Mechanismen der mitochondrialen Zerteilung während der neuronalen Apoptose sind weitgehend unbekannt und in den hier verwendeten neuronalen Zellen noch nicht untersucht. Daher wurde zunächst die Funktion der Drp1 und Fis1 Proteine (siehe Kapitel 1.1.5.1), die bekanntermaßen die mitochondriale Fragmentation ausführen, in dopaminergen Neuronen untersucht. 

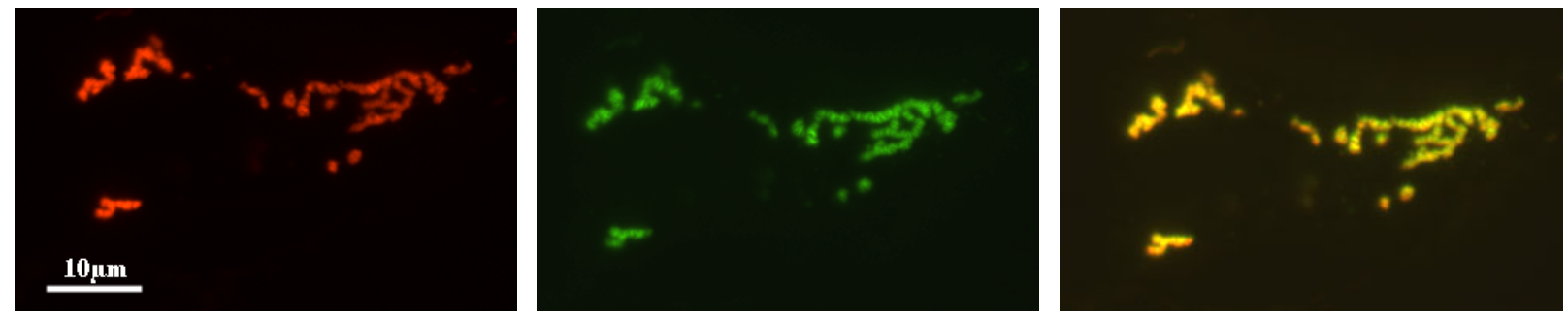

\section{Abbildung 17: Fis1 und Mitochondrien.}

Dargestellt sind fluoreszenzmikroskopische Aufnahmen einer pDsRed2-mito (links) und Fis1-GFP (Mitte) kotransfizierten dCSM14.1 Zelle. Die Mitochondrien waren durch Transfektion mit pDsRed2-mito markiert, die Überexpression von Fis1 resultiert in einer kolokalisierten Markierung nach Doppeltransfektion (rechts). Fis1 ist spezifisch in den Mitochondrien lokalisiert. Die Mitochondrien sind teilweise deutlich vergrößert und weisen eine alternierende gelb/grün Streifung auf.
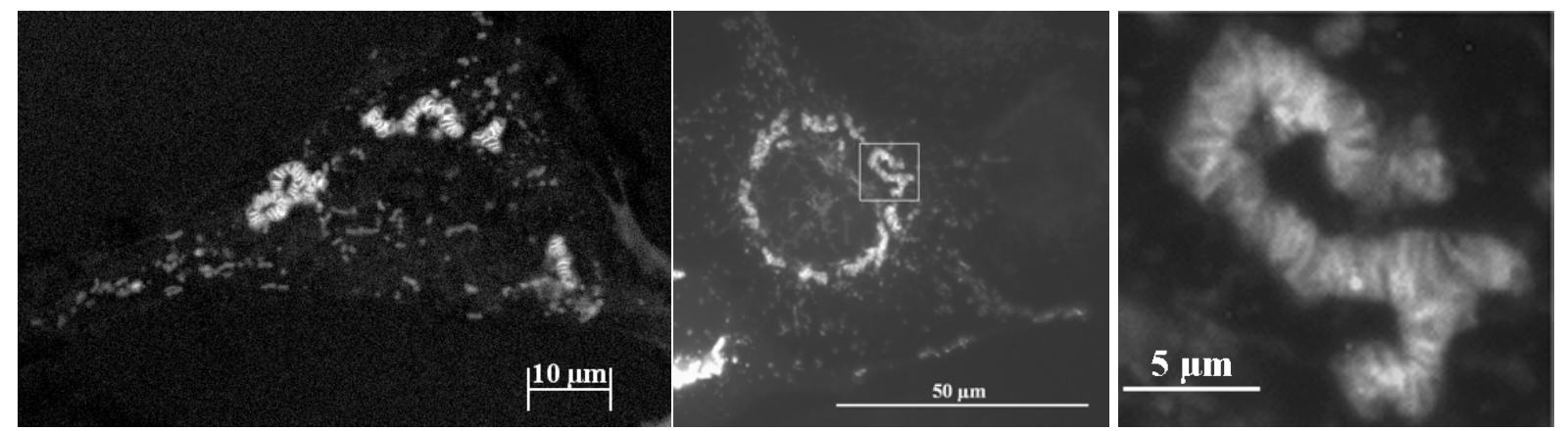

Abbildung 18: Fis1 Überexprimierung.

Abgebildet sind fluoreszenzmikroskopische Aufnahmen von Fis1-GFP transfizierten dCSM14.1 Zellen. Rechts ist eine Detailvergrößerung des mittlern Bildes (weißer Rahmen) dargestellt. Im Gegensatz zu diesem Neuron (Fluoreszenzmikroskopie) wurde das Neuron in Bild links durch konfokale Lasermikroskopie abgetastet.

Fis1 ist in den Mitochondrien lokalisiert, dies zeigen auch obige Abbildungen. Bei Überexpression von Fis1 bilden sich komplexe Mitochondrien, die vorwiegend um den Zellkern angeordnet sind (Mitte). Diese Komplexe besitzen einen deutlich größeren Durchmesser als unbehandelte Mitochondrien. In ihren Proportionen sind sie gestaucht. Die Struktur dieser mitochondrialen Gebilde weist eine auffällige Querstreifung auf, die auf umlaufende Fis1-Ringe hindeutet. Neben diesen anomalen Mitochondrien existieren auch wenige elongierte Mitochondrien in der Zelle. Diese scheinen in ihrer Morphologie den Mitochondrien nicht apoptotischer Zellen zu ähneln.

Fis1 ist ein mitochondriales Transmembranprotein (siehe Kapitel 1.1.5.1), die Transfektionen mit Fis1-GFP resultieren in einer spezifischen Markierung der Mitochondrien (siehe Abbildung 17). Nach Überexpression von Fis1 besitzen die Mitochondrien eine abnormale Form und Lokalisation (siehe Abbildung 18). Fis1 ist an der Formgestaltung der Mitochondrien in dopaminergen Zellen beteiligt, es verändert die mitochondriale Morphologie bereits ohne Apoptose Induktion wesentlich. Es bilden sich größere Konglomerate, die mit umlaufenden Fis1 Ringen (Streifen) ausgestattet sind (siehe Abbildung 18). Die Anomalie ist nicht identisch mit den ansonsten während der Apoptose stattfindenden Veränderungen der Mitochondrien. Es kommt nicht zu einer typischen Fragmentation und die Zellen begeben sich durch die abnormalen Mitochondrien nicht in die Apoptose (siehe Abbildung 29). Diese 
Konglomerate zeigten sich lediglich nach Fis1 Überexpression und nie im physiologisch unmodifizierten Zustand bzw. während der Apoptose.

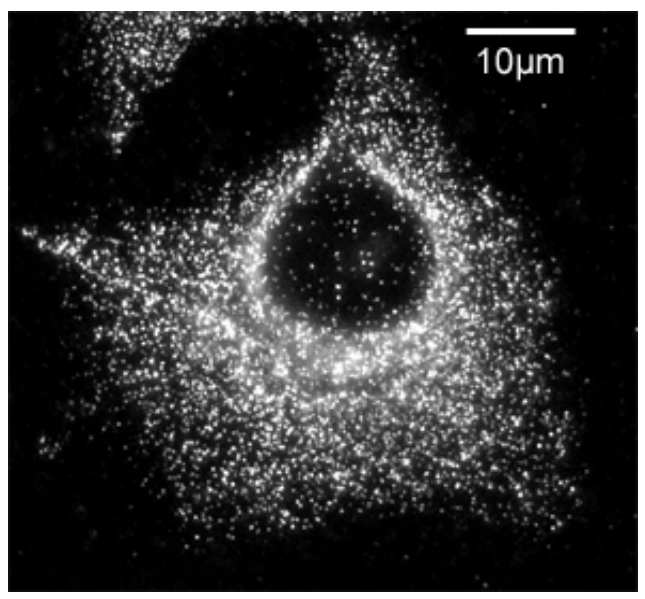

\section{Abbildung 19: Endogen exprimiertes Drp1.}

Dargestellt ist eine fluoreszenzmikroskopische Aufnahme einer dCSM14.1 Zelle. Drp1 wurde immunzytochemisch angefärbt, der Sekundärantikörper ist Cy3 markiert (siehe Tabelle 7).

Drp1 ist endogen im Zytoplasma vorhanden (weiße, punktförmige Strukturen), wobei das Protein nicht frei im Zytoplasma diffundiert. Es ist in kleinen spezifischen Einheiten organisiert, die im gesamten Zytoplasma vorhanden sind. Es ist unklar was die Ursache dieser Verteilung ist und ob die Einheiten an zelluläre Strukturen gekoppelt sind.
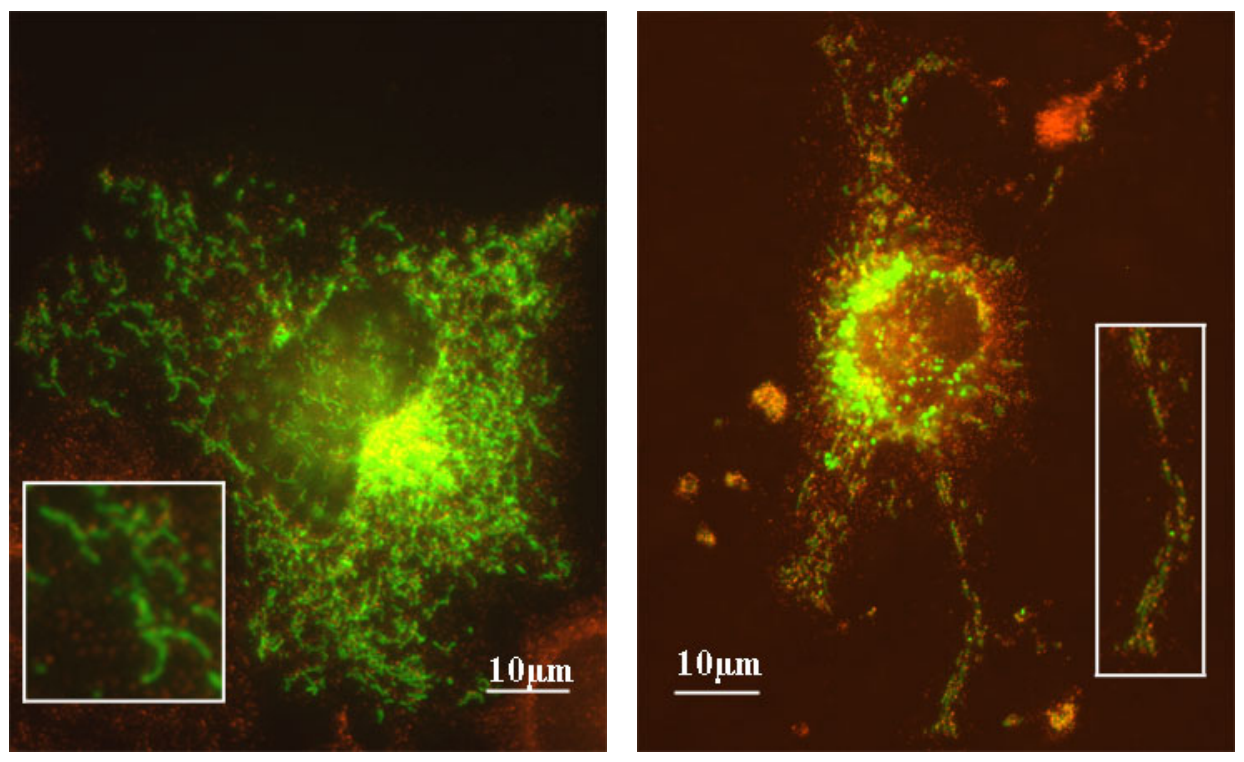

\section{Abbildung 20: Drp1 Lokalisation.}

Dargestellt sind fluoreszenzmikroskopische Aufnahmen von dCSM14.1 Zellen ohne (links) und mit zweistündiger Staurosporinbehandlung (1 $1 \mathrm{M}$, rechts). Die Mitochondrien sind durch Transfektion mit mt-GFP (grün) markiert. Endogenes Drp1 wurde immunzytochemisch angefärbt, der Sekundärantikörper ist Cy3 (rot) markiert. In nicht apoptotischen Zellen (links) ist das endogene Drp1 im Zytoplasma lokalisiert und es scheint selten Kolokalisation mit Mitochondrien zu geben. Während der Apoptose (rechts) ist hingegen häufig Kolokalisation mit Mitochondrien beobachtbar. Dies betrifft insbesondere die meist noch geringer fragmentierten Mitochondrien in der Zellperipherie. Häufig ist keine Überlagerung, sondern eine direkte Nachbarschaft zu beobachten (siehe Detailvergrößerung). 
Durch immunzytochemische Färbung konnte gezeigt werden, dass dCSM14.1 Neurone Drp1 endogen exprimieren und dieses nicht diffus im Zytoplasma vorliegt, sondern in engbegrenzten Strukturen (siehe Abbildung 19). Da Drp1 räumlich von Fis1 und den Mitochondrien separiert ist, muss es über noch unbekannte Mechanismen während der Apoptose zu den Mitochondrien transportiert werden (siehe Abbildung 20 und Abbildung 32), um dort mit Fis1 einen an ein Mitochondrium gekoppelten Komplex zu bilden, der die Zerteilung des Mitochondriums verursacht (siehe Kapitel 1.1.5.1).

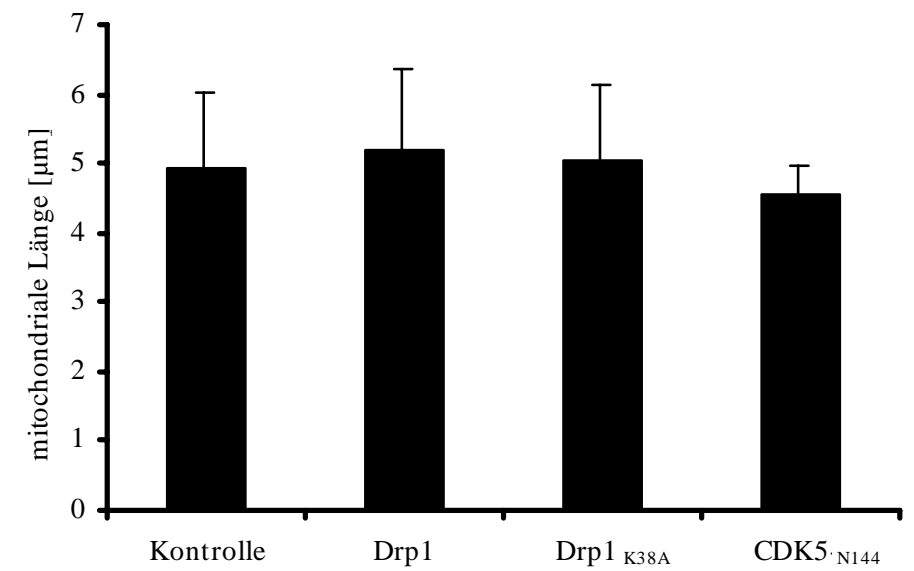

\section{Abbildung 21: Durchschnittliche Mitochondrienlänge.}

Dargestellt ist die Mitochondrienlänge (Ordinate) in Abhängigkeit von verschiedenen überexprimierenden Plasmiden (Abszisse). Die Messwerte und Standardfehler ermitteln sich aus der Vermessung von je zehn Mitochondrien fünf einzelner fixierter dCSM14.1 Neurone. Die Mitochondrien waren durch pDsRed2-Mito Transfektion markiert (Kontrolle), zusätzlich exprimierten die Neurone Drp1, Drp1 $1_{\mathrm{K} 38 \mathrm{~A}}$ oder $\mathrm{CDK} 5_{\mathrm{N} 144}$.

Nach der Markierungstransfektion wurde die durchschnittlich Länge der Mitochondrien zu 4,9 $\mu \mathrm{m} \pm 1,1 \mu \mathrm{m}$ bestimmt, auf eine Aussage bezüglich des Mitochondriendurchmessers wird bewusst verzichtet, da diese Größe nahe an der Auflösungsgrenze eines Lichtmikroskops lag. Die durchschnittliche Länge der Mitochondrien wird im Vergleich zur Kontrolle nicht durch Überexpression von Drp1 oder Drp1 $1_{\text {K38A }}$ signifikant beeinflusst, sie lag weiter bei $5,1 \mu \mathrm{m} \pm 1,1 \mu \mathrm{m}$ bzw. $5,0 \mu \mathrm{m} \pm 1,0 \mu \mathrm{m}$. Die Überexpression von $\mathrm{CDK}_{\mathrm{N} 144}$ führt zu geringfügig kürzeren Mitochondrien mit einer Länge von 4,5 $\mu \mathrm{m} \pm 0,4 \mu \mathrm{m}$.

Die Überexpression von Drp1 übt im Gegensatz zu der Fis1 Überexpression keine ersichtliche Wirkung auf die Mitochondrien aus. Die Mitochondrien zeigen annähernd die gleiche elongierte Form und Länge (siehe Abbildung 21). Wenn Drp1 für die mitochondriale Zerteilung notwendig ist, sind weitere Faktoren oder Proteine während der Apoptose notwendig, um die Zerteilung der Mitochondrien zu veranlassen. Drp1 müsste zunächst aktiviert und/oder zu den Mitochondrien transportiert werden. Auch während der Apoptose gab es keine signifikant unterschiedliche Reduktion der durchschnittlichen Mitochondrienlänge in Kontrollzellen und Drp1 überexprimierenden Zellen (siehe Abbildung 22). Die mitochondrialen Zerfallsgeschwindigkeiten der Kontrollzellen und Drp1 überexprimierenden 
Zellen wiesen unabhängig von der Apoptose induzierenden Substanz keine bedeutsamen Abweichungen auf.

Ebenso zeigen die Mitochondrien wenig Veränderungen bei Hemmung des Drp1 Proteins (siehe Abbildung 21). Hierzu wurde die Drp1 Funktionalität durch Überexpression der dominant negativen Mutante Drp1 $1_{\mathrm{K} 38 \mathrm{~A}}$ (siehe Tabelle 3) gehemmt. Dominant negative Mutanten werden in der Zelle exprimiert und nehmen die Position des nicht mutierten Proteins ein, sind jedoch durch die Mutation nicht mehr funktionsfähig. Drp1 $1_{\mathrm{K} 38 \mathrm{~A}}$ kann auf Grund der Punktmutation in der GTPase Domäne kein GTP mehr binden.

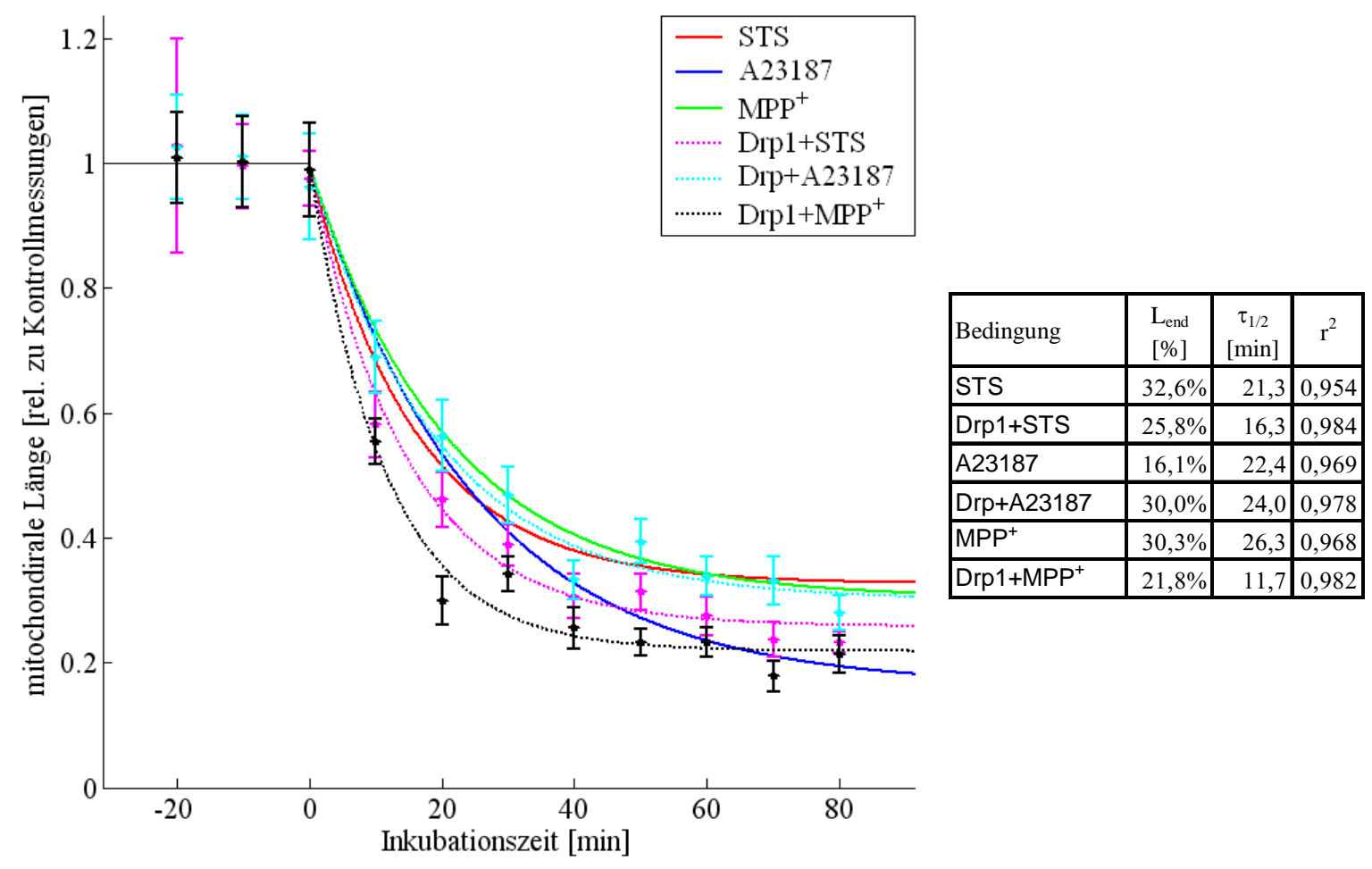

\section{Abbildung 22: Drp1 und mitochondriale Fragmentation.}

Dargestellt ist die durchschnittliche Mitochondrienlänge in Abhängigkeit von der Inkubationsdauer Apoptose induzierender Substanzen. Auf der Abszisse ist die Messdauer aufgetragen, zum Zeitpunkt 0 wurde die Apoptose induzierende Substanz (rot/magenta: STS, blau/cyan: A23187 oder grün/schwarz: MPP ${ }^{+}$) appliziert. Weitere Erläuterungen zur Darstellung siehe Abbildung 16. Die mit Standardfehler eingezeichneten Messpunkte (magenta, cyan und schwarz) wurden an Neuronen ermittelt die mit Drp1 transient kotransfiziert waren. Die gleichfarbigen gestrichelten Linien geben den angenäherten Zeitverlauf dieser Messungen wieder, während die durchgezogenen Linien als Vergleich die genäherte Reaktion auf den Apoptose Stimulus allein wiedergeben (vergleiche Abbildung 16).

Die Überexpression von Drp1 (gestrichelt) beeinflusst unabhängig vom Apoptosestimulus die Verkürzung der Mitochondrien nur unwesentlich. Die Messwerte zeigen wiederum einen annähernd exponentiellen Zerfall (Regressionskoeffizienten > 0,95, siehe Tabelle) auf ca. ein fünftel ihrer Ursprungslänge, die Halbwertszeiten fallen bei Drp1 Überexpression tendenziell (MPP ${ }^{+}$und STS) geringfügig kürzer aus. 
Die Überexpression von Drp1 $1_{\mathrm{K} 38 \mathrm{~A}}$ zeigte jedoch einen beachtenswerten Effekt auf die Morphologie der Mitochondrien während der Apoptose (siehe Abbildung 23). Sie führte zur einer Verzögerung der mitochondrialen Fragmentation (siehe Abbildung 24). Der Effekt der Hemmung ist unabhängig von der Apoptoseinduktion.
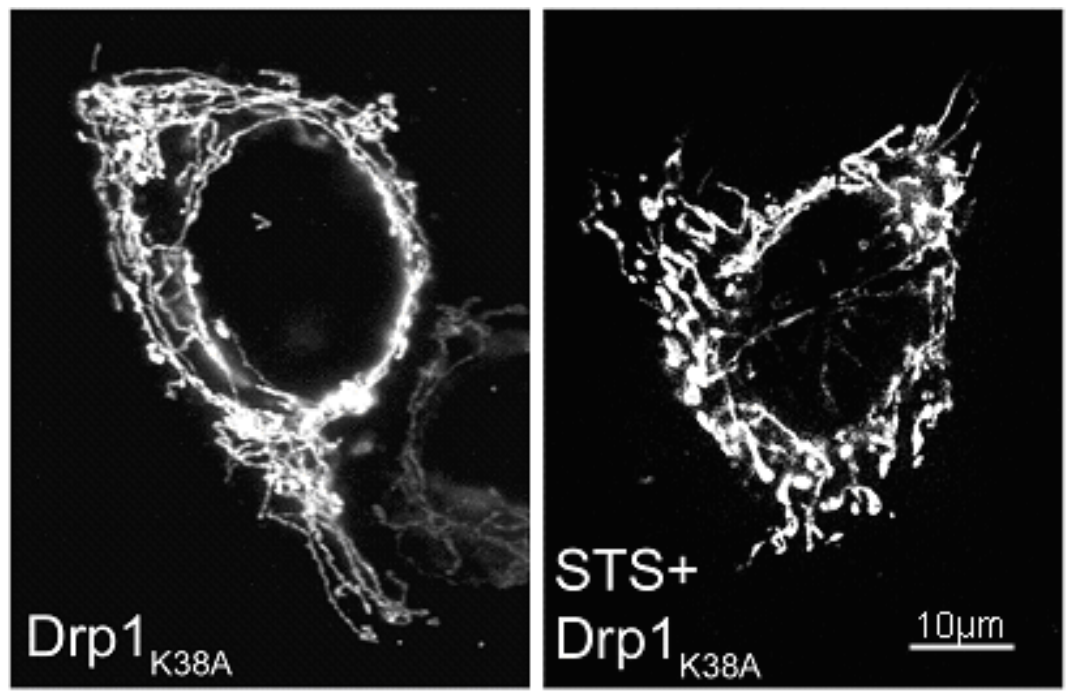

Abbildung 23: Drp1 $1_{\mathbf{k} 3 \mathrm{~A}}$ Überexpression und mitochondriale Fragmentation.

Abgebildet sind fluoreszenzmikroskopische Aufnahmen zweier dCSM14.1 Neurone. Die Mitochondrien sind durch pDsRed2-Mito Transfektion markiert, zusätzlich exprimierten die Zellen Drp1 $1_{\mathrm{K} 38 \mathrm{~A}}$.

Unbehandelt (links) besitzen die Mitochondrien eine elongierte Form. Nach zweistündiger Behandlung mit $1 \mu \mathrm{M}$ Staurosporin (STS, rechts) zeigen die Mitochondrien trotz der Apoptoseinduktion eine elongierte Form und gleichen somit den Mitochondrien der unbehandelten Zelle. Die üblichen apoptotischen Merkmale treten nur abgeschwächt in Erscheinung (vergleiche mit Abbildung 13 nach Staurosporinbehandlung).

Die bisher vorgestellten Daten basieren auf Zeitreihenaufnahmen, bei denen maximal vier Neurone parallel ausgewertet werden konnten. Somit war es möglich, das zeitliche Verhalten einzelner Zellen nicht jedoch die mittlere Reaktion einer großen Neuronenpopulation der selben Transfektionsreihe zu bestimmen. Ein weiterer Nachteil der Zeitreihenaufnahme ist die relativ kurze Beobachtungsdauer der Neurone, bedingt durch nicht optimale Bedingungen in der Klimakammer (siehe Kapitel 2.4.5). Daher wurden Untersuchungen zu Drp1 und Fis1 auch an fixierten dCSM14.1 Zellen ausgewertet. Mit diesen Messungen ist es möglich große Neuronenpopulationen unter gleichen Versuchsbedingungen zu bewerten, allerdings können zeitliche Veränderungen einzelner Mitochondrien nicht untersucht werden.

Bei der Klassifizierung der Neurone mit fragmentierten Mitochondrien ist auffällig, dass bereits ohne Apoptoseinduktion ein nennenswerter Anteil an Neuronen fragmentierte Mitochondrien zeigt (siehe Abbildung 25). Dies ist vermutlich auf die leichte Toxizität der Transfektion bzw. die weitere Behandlung der Zellen bedingt, könnte aber auch das normale 
Gleichgewicht von Zerteilung und Verschmelzung wiederspiegeln. Überexpression von Fis1 führt, wie bereits erläutert, zu einem hohen Anteil abnormaler Mitochondrien.

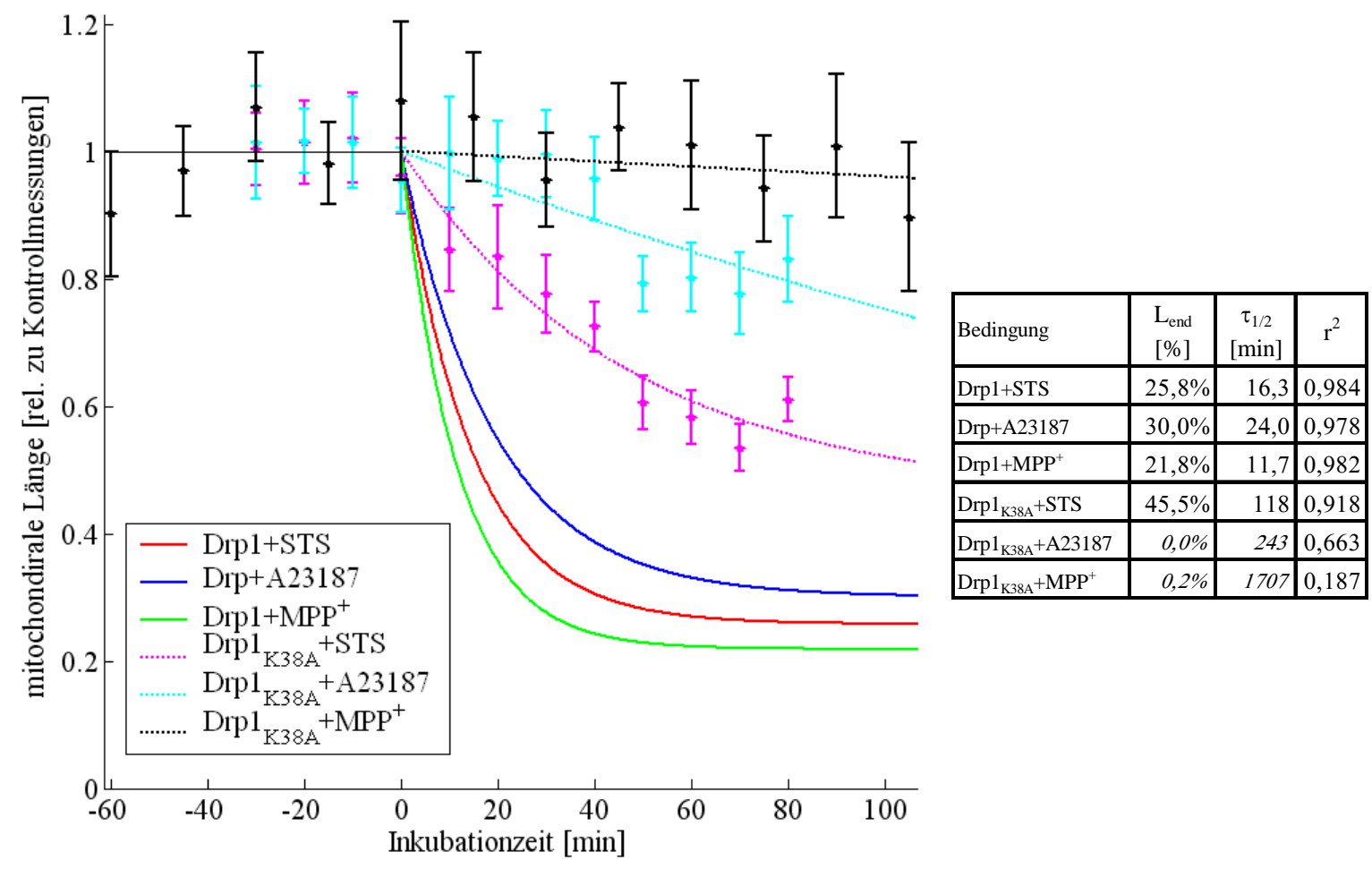

Abbildung 24: Drp1 $1_{\mathrm{K} 38 \mathrm{~A}}$ verzögert die mitochondriale Fragmentation innerhalb der Apoptose.

Dargestellt ist die durchschnittliche Mitochondrienlänge in Abhängigkeit von der Inkubationsdauer Apoptose induzierender Substanzen, zur genaueren Erläuterung siehe Abbildung 16. Die Messpunkte geben mit Standardfehlern die mittlere Mitochondrienlänge in Drp $1_{\text {Кз8А }}$ transfizierten Neuronen unter Einwirkung unterschiedlicher Apoptose induzierender Substanzen (magenta, cyan, schwarz, siehe Legende) an. Die Linien geben die angenäherten Zerfallskurven der Messwerte bzw. Vergleichsmessungen an Drp1 transfizierten Neuronen (aus Abbildung 22) wieder.

Bei Überexpression von Drp1 $1_{\mathrm{K} 38 \mathrm{~A}}$ zeigen die Mitochondrien keinen deutlichen exponentiellen Zerfall (kleinere $\mathrm{r}^{2}$ Werte in der Tabelle). Im Vergleich zu den Messungen mit Überexpression von Drp1 (durchgezogen) wird unabhängig vom Apoptosestimulus die Verkürzung der Mitochondrien durch Überexpression von Drp1 $1_{\text {Kз8A }}$ deutlich verzögert (gestrichelt). Halbwertszeiten erreichen selbst bei STS Behandlung mehr als 118 min. Die Mitochondrien bleiben länger.

Es bestätigte sich, dass die Formveränderung der Mitochondrien durch Apoptoseinduktion unmittelbar einsetzt. Der Anteil an Neuronen mit fragmentierten Mitochondrien nimmt generell mit andauernder Staurosporininkubation zu. Ebenso ließ sich bestätigen, dass die Formveränderung der Mitochondrien unabhängig vom Drp1 Expressionslevel ist, die Hemmung von Drp1 durch Drp1 $1_{\mathrm{K} 38 \mathrm{~A}}$ Überexpression jedoch zu einer Verminderung der mitochondrialen Fragmentation führt. Es scheint hierbei nicht nur eine verminderte Zerfallsgeschwindigkeit vorzuliegen, sondern Drp1 $1_{\mathrm{K} 38 \mathrm{~A}}$ konnte die Mitochondrien dauerhaft vor Fragmentation schützen. Dies zeigt, dass Drp1 für den Ablauf der mitochondrialen 
Zerteilung während der Apoptose notwendig, aber für die Induktion der Teilung nicht ausreichend ist.

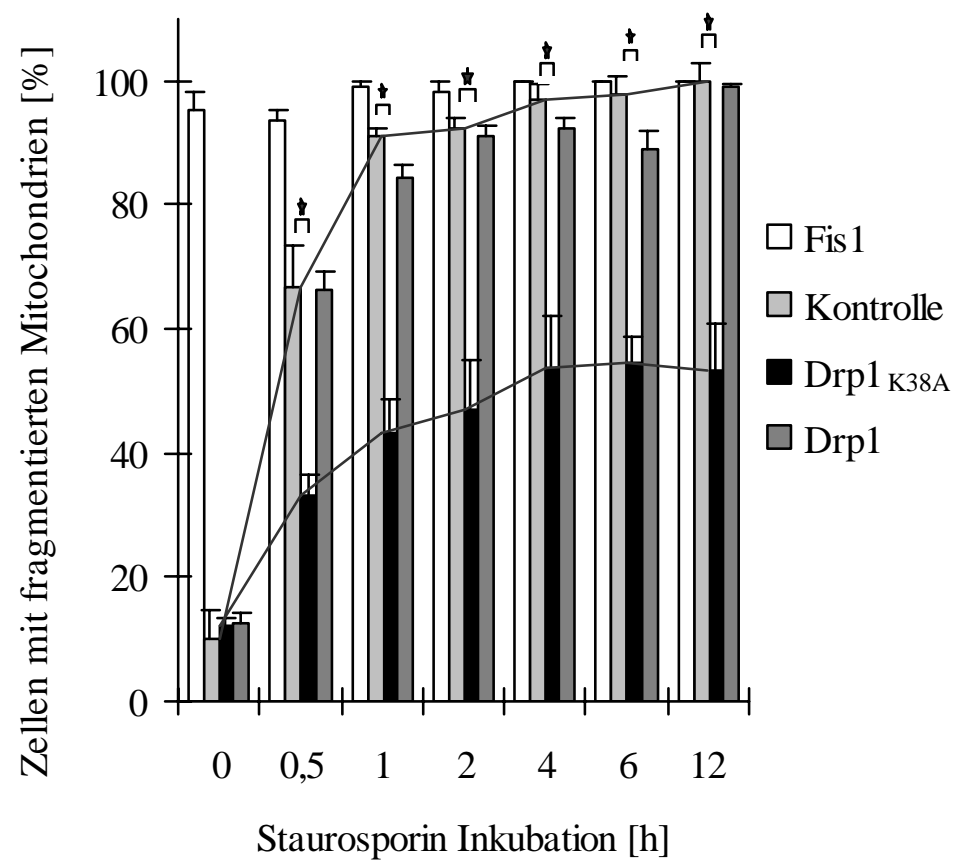

Abbildung 25: Beeinflussung der mitochondrialen Fragmentation durch die bekannten Fissionsproteine.

Die Anzahl der Neurone mit fragmentierten Mitochondrien (Abszisse) wurde nach unterschiedlichen Inkubationsdauern (Ordinate) mit $1 \mu \mathrm{M}$ Staurosporin durch Klassifizierung von 384 Neuronen (100 \%) aus drei unabhängigen fixierten Kulturen für jeden Messpunkt ermittelt. Die Mitochondrien aller Neurone waren durch pDsRed2-Mito Transfektion markiert. Außer der Kontrollbedingung (hellgrau) wurden Kotransfektionen mit Fis1 (weiß), Drp1 (dunkelgrau) und Drp1 $1_{\mathrm{K} 38 \mathrm{~A}}$ (schwarz) untersucht.

Im Verlauf der Apoptose induzierenden Staurosporininkubation nimmt der Anteil der Kontrollneurone mit fragmentierten Mitochondrien zu. Bei Überexpression von Fis1 besitzen die Mitochondrien eine abnormale Form (siehe Abbildung 18) und werden als fragmentiert gewertet, so dass nahezu alle Zellen bereits ohne Apoptoseinduktion fragmentierte Mitochondrien aufweisen (weiße Balken), wodurch allerdings nicht der programmierte Zelltod eintritt (Abbildung 29). Die Überexpression von Drp1 führt dagegen nicht zu einer signifikanten Veränderung in Relation zur Kontrolle. Die Hemmung der Drp1 Aktivität durch Expression von Drp1 $1_{\mathrm{K} 38 \mathrm{~A}}$ zeigt allerdings eine signifikant verminderte Fragmentation der Mitochondrien (Zeitverläufe durch Linien hervorgehoben, *: p<0,05, studentischer t-Test). Es scheint sich ein dauerhafter Schutz in $53 \%$ der Neurone gegen mitochondriale Fragmentation einzustellen.

\subsubsection{Einfluss von Drp1 und Fis1 auf den neuronalen Zelltod}

Es ist bekannt, dass die mitochondriale Fragmentation während des Apoptoseprozesses stattfindet (Bossy-Wetzel et al. 2003), so wie es in den vorangehenden Experimenten beschrieben wurde. Es ist jedoch ungeklärt in welchem Zusammenhang die mitochondriale Fragmentation zur Apoptosekaskade steht. Insbesondere ist nicht bekannt, ob bei Apoptose die Mitochondrien notwendigerweise fragmentieren oder ob umgekehrt der Zerfall der Mitochondrien zur Apoptose der Zelle führen muss. Aus den vorangegangen Resultaten stellt sich 
sogar die Frage, ob die Apoptose durch Hemmung der mitochondrialen Fragmentation blockiert werden kann oder ob es sich lediglich um zwei parallel ablaufende Prozesse handelt.

Die Apoptose resultiert aus einer Verkettung vieler verschiedener zellulärer Ereignisse, bekannt sind zum Beispiel die Cytochrom c Freisetzung, die Aktivierung der Caspasen sowie schließlich das Schrumpfen des Zellkerns und Kondensation des Chromatins (siehe Kapitel 1.1.2.2). Die Freisetzung des Cytochrom c aus den Mitochondrien in das Zytoplasma ist ein frühes Ereignis lange vor der Kondensation des Chromatins während der Apoptosekaskade (siehe Abbildung 2). Das freigewordene Cytochrom c bildet zusammen mit Apaf1 und Procaspase 9 das Apoptosom, welches weitere Caspasen aktiviert. Am Ende der Apoptosekaskade steht die Kondensation des Chromatins (apoptotische Körperchen) im Zellkern. Apoptotische Körperchen ließen sich in neuronalen dCSM14.1 Zellen nach Apoptoseinduktion feststellen (siehe Abbildung 26) und wurden daher als endgültiger Apoptosemarker genutzt.
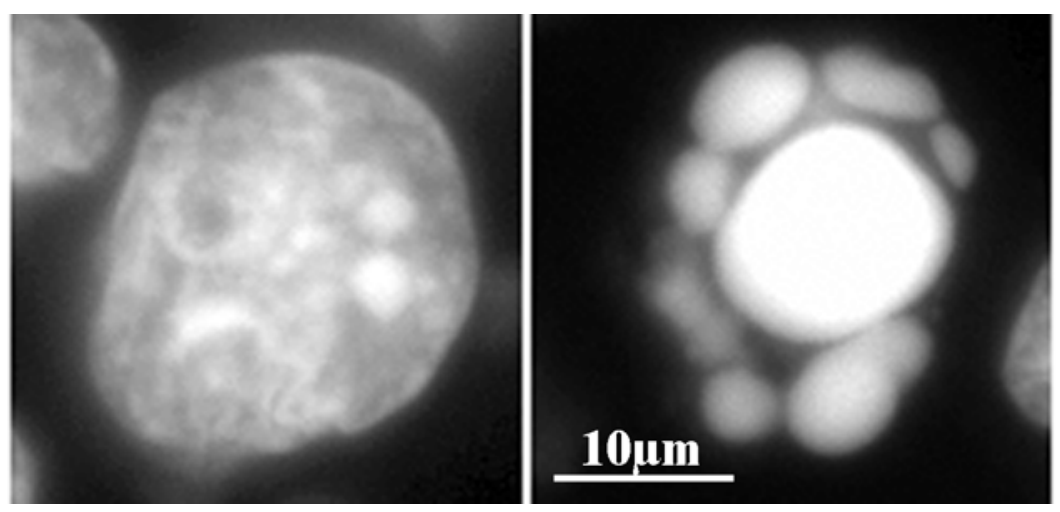

\section{Abbildung 26: Kernmorphologie.}

Dargestellt sind die DAPI gefärbten Kerne einer normalen (links) und einer apoptotischen Zelle (rechts). Die Induktion der Apoptose erfolgte $2 \mathrm{~h}$ Stunden vor Bildaufnahme durch Staurosporininkubation $(1 \mu \mathrm{M})$.

Der Zellkern der apoptotischen Zelle ist in viele apoptotische Körperchen zerfallen. Apoptotische Zellkerne zeigten eine wesentlich stärkere DAPI-Fluoreszenz, so dass im Kern keine Struktur mehr sichtbar ist.

Um zu überprüfen, ob Drp1 $1_{\mathrm{K} 38 \mathrm{~A}}$ neben der hemmenden Wirkung auf die mitochondriale Fragmentation auch einen Einfluss auf die Apoptose ausübt, wurde die Cytochrom c Freisetzung aus den Mitochondrien als Apoptosemarker unter Drp1 $1_{\mathrm{K} 38 \mathrm{~A}}$ Überexpression analysiert. Die Neurone wurden immunzytochemisch gegen Cytochrom c gefärbt (siehe Abbildung 27, Abbildung 28). Das Cytochrom c Verteilungsmuster ist in nicht apoptotischen Neuronen durch abgrenzbare Strukturen charakterisiert (siehe Abbildung 28). Dies resultiert aus der Lokalisation des Cytochrom c im Intermembranraum der Mitochondrien. Nach Apoptoseinduktion konnte die Ausschüttung des Cytochrom c durch das daraus resultierende 
diffuse Cytochrom c Verteilungsmuster im Zytoplasma (siehe Abbildung 27, Abbildung 28)

nachgewiesen werden. Die Zerstörung der mitochondrialen Organisation geht mit der Freisetzung des Cytochrom c aus den Mitochondrien in das Zytoplasma einher.

Kontrolle

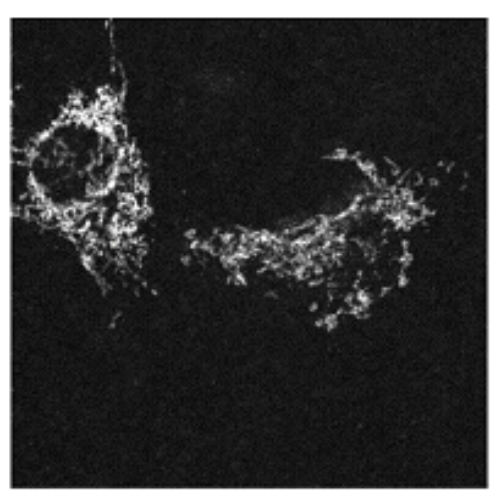

Staurosporin $[1 \mu \mathrm{M}]$
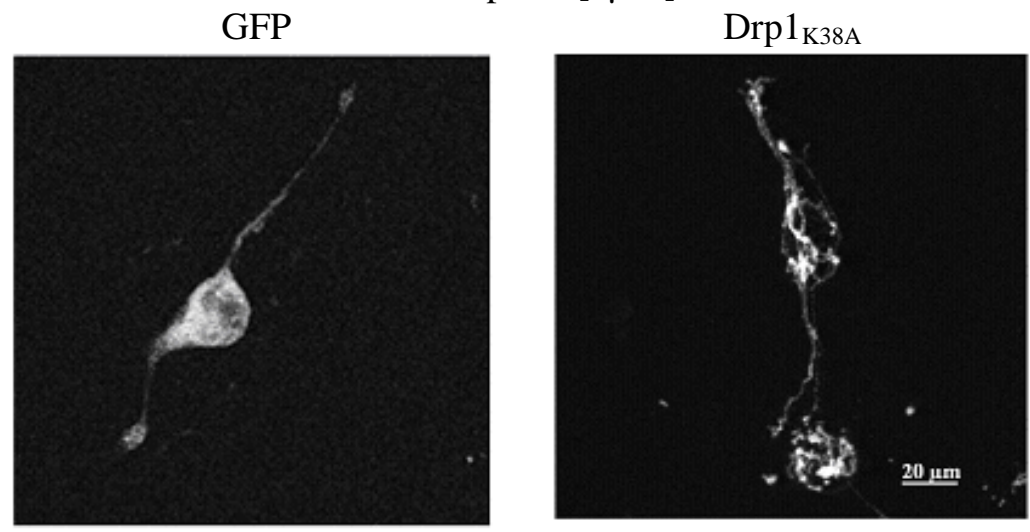

keine Apoptoseinduktion

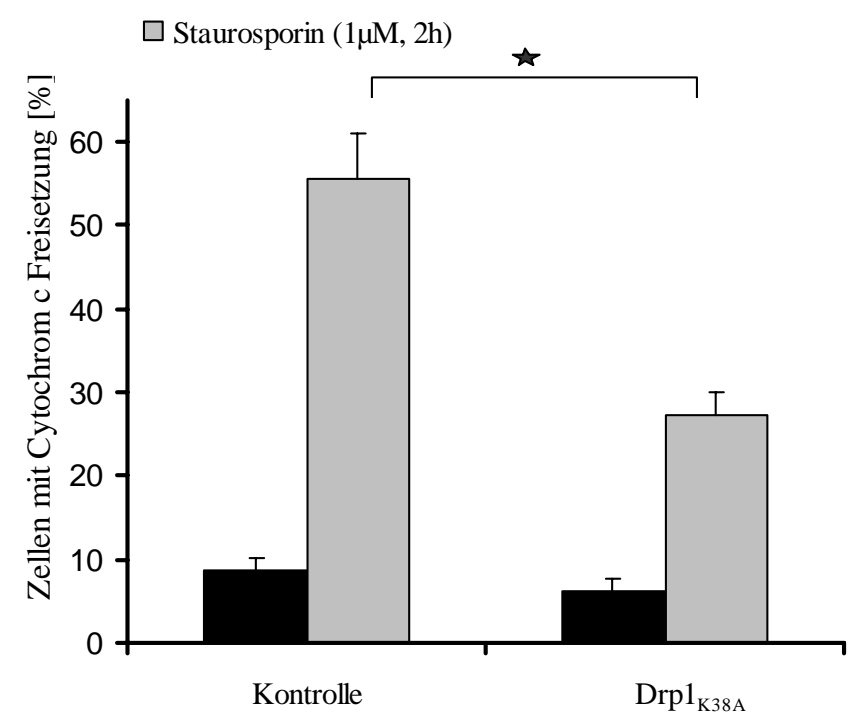

\section{Abbildung 27: Cytochrom c Verteilungsmuster.}

Links sind drei fluoreszenzmikroskopische Aufnahmen (CLSM) von Cytochrom c Antikörperfärbungen an dCSM14.1 Zellen dargestellt.

Bei nicht apoptotischen Zellen ist das Cytochrom c in abgrenzbaren Strukturen lokalisiert (links). Während der Apoptose (2 Stunden, $1 \mu \mathrm{M}$ Staurosporin) kommt es zur Freisetzung von Cytochrom c und einer daraus resultierenden diffusen Färbung des Zytoplasmas (Mitte). Die Ausschüttung von Cytochrom c wird durch Drp1 $1_{\mathrm{K} 38 \mathrm{~A}}$ Überexpression verhindert (rechts).

Im unten dargestellten Diagramm wurde die Anzahl der Neurone mit diffusem Cytochrom c Verteilungsmuster (Abszisse) mit und ohne Apoptoseinduktion durch Klassifizierung von jeweils 384 Neuronen (100 \%) aus drei unabhängigen Kulturen für jeden Messpunkt ermittelt.

Neben unbehandelten Neuronenpopulationen (Kontrolle) wurde die Wirkung Apoptose induzierender Substanzen (grau) unter Drp1 $1_{\mathrm{K} 38 \mathrm{~A}}$ Überexpression untersucht. Die Apoptoseinduktion (grau) resultiert in einem vermehrten Anteil an Neuronen mit diffusem Cytochrom c Verteilungsmuster. Durch Expression von Drp $1_{\mathrm{K} 38 \mathrm{~A}}$ ist dieser Anstieg allerdings signifikant reduziert $(*$ : $<<0,05)$, so dass nicht mehr $56 \%$ der Neurone, sondern nur noch 27 \% eine Cytochrom c Freisetzung aus ihren Mitochondrien erfahren. Ohne Apoptoseinduktion (schwarz) hat die Transfektion mit Drp1 $1_{\mathrm{K} 38 \mathrm{~A}}$ keinen Einfluss auf das Cytochrom c Verteilungsmuster, der Anteil an Neuronen mit diffusem Cytochrom c Verteilungsmuster ist in beiden Bedingungen annähernd gleich niedrig. 
Die Hemmung der mitochondrialen Fragmentation durch Drp1 $1_{\mathrm{K} 38 \mathrm{~A}}$ verhindert die Cytochrom c Freisetzung ins Zytoplasma nach Apoptoseinduktion. Somit scheint die Fragmentation der Mitochondrien die Cytochrom c Freisetzung zu fördern. Dies konnte auch durch Klassifizierung einer großen Neuronenpopulation auf Grund ihres Cytochrom c Verteilungsmuster bestätigt werden (siehe Abbildung 27). Bei der Klassifizierung der Cytochrom c Freisetzung in großen Neuronenpopulationen wurde der Anteil dieser Neurone durch Überexpression von Drp1 $1_{\mathrm{K} 38 \mathrm{~A}}$ halbiert.
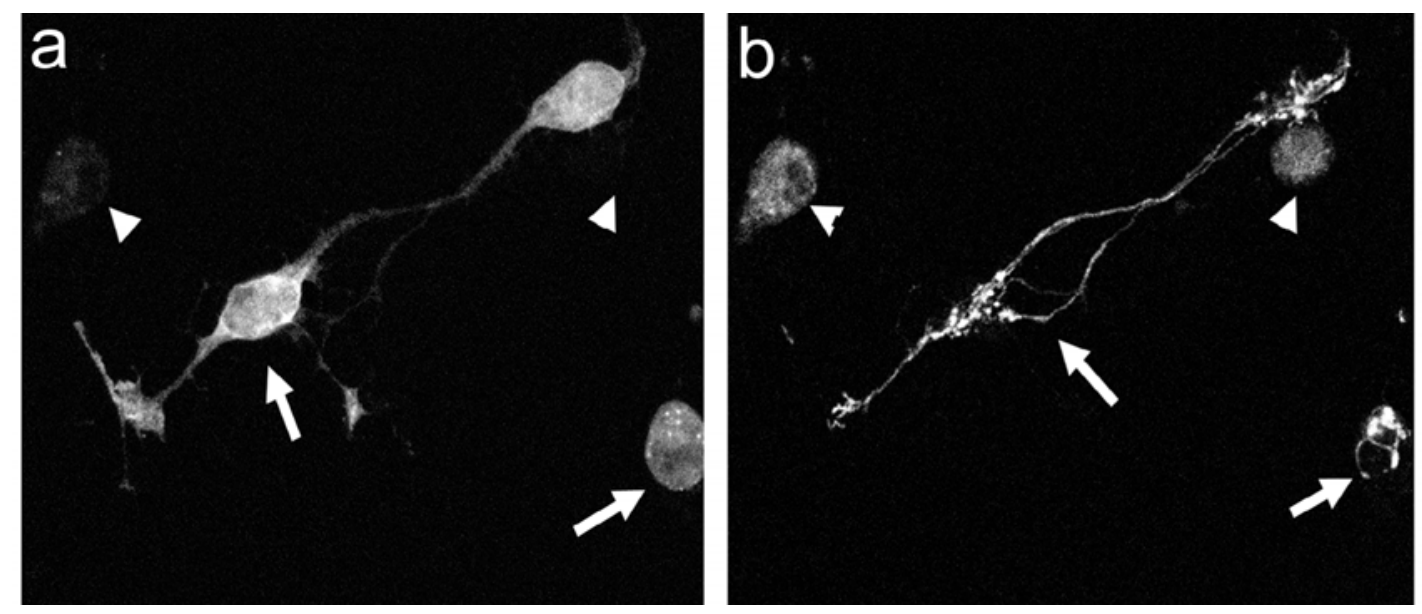

Abbildung 28: Drp1 $1_{\mathrm{K} 3 \mathrm{~A}}$ und Cytochrom c Freisetzung.

Links (a) ist eine fluoreszenzmikroskopische Aufnahme von Drp1 $1_{\mathrm{K} 38 \mathrm{~A}}$ transfizierten dCSM14.1 Neuronen dargestellt (Pfeile). Das Drp $1_{\mathrm{K} 38 \mathrm{~A}}$-ECFP Plasmid wurde durch transiente Transfektion in die Zelle eingebracht. Da die Transfektionseffizienz begrenzt ist, exprimieren nicht alle Neurone des Sichtfeldes Drp1 $1_{\mathrm{K} 38 \mathrm{~A}}$ (Dreiecke). Die sichtbaren und mit Pfeilen markierten Zellen exprimieren Drp1 $1_{\mathrm{K} 38 \mathrm{~A}}$. Das Protein liegt diffus verteilt im gesamtem Zytoplasma und den Zellfortsätzen vor.

Rechts (b) ist im gleichen Sichtfeld die immunzytochemische Färbung gegen Cytochrom c nach zweistündiger Behandlung mit Staurosporin $(1 \mu \mathrm{M})$ abgebildet. Da die Cytochrom c Färbung alle Neurone erfasst sind zwei weitere Neurone, die kein Drp1 $1_{\mathrm{K} 38 \mathrm{~A}}$ exprimieren, sichtbar (Dreiecke).

Drp1 $1_{\mathrm{K} 38 \mathrm{~A}}$ überexprimierende Neurone (Pfeile) zeigen Cytochrom c in abgrenzbaren intrazellulären Strukturen (Mitochondrien), wohingegen die nicht transfizierten Neurone (Dreiecke) unter Staurosporinbehandlung ein diffuses Verteilungsmuster aufweisen.

Um zu verifizieren, dass die Hemmung der Cytochrom c Freisetzung aus den Mitochondrien auch einen neuroprotektiven Effekt hat, wurde ebenfalls die Wirkung von Drp1 $1_{\mathrm{K} 38 \mathrm{~A}}$ Überexpression auf die Kernmorphologie nach Apoptoseinduktion untersucht.

Bereits ohne Apoptoseinduktion wurde ein geringer Anteil an Neuronen mit fragmentierten Kernen ermittelt (siehe Abbildung 29), der wie der leicht erhöhte Anteil an Neuronen mit fragmentierten Mitochondrien (siehe Abbildung 25) auf die geringfügige Toxizität der Transfektion zurück zuführen sein könnte. Die Transfektion mit Drp1 oder ihrer dominant negativen Mutante zeigt keinen Einfluss auf den spontanen Zelltod. Im Gegensatz hierzu führte die Fis1 Überexpression zu einer geringfügig erhöhten spontanen Todesrate. Aller- 
dings sind bemerkenswerter Weise trotz der anormalen Mitochondrienmorphologie (siehe Kapitel 3.1.3.1) 88 \% der Zellen nicht apoptotisch.

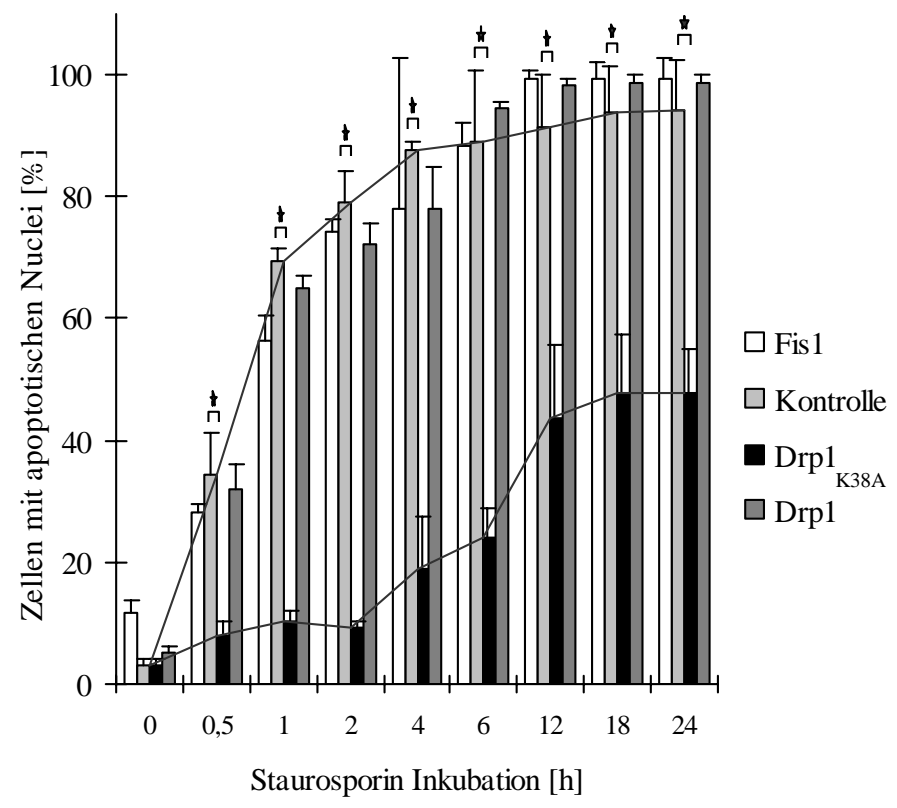

Abbildung 29: Einfluss der bekannten mitochondrialen Fissionsproteine auf die Apoptose.

Die Anzahl der apoptotischen Neurone (fragmentierte Nuclei, Abszisse) wurde nach unterschiedlichen Inkubationsdauern (Ordinate) mit $1 \mu \mathrm{M}$ Staurosporin durch Klassifizierung von 384 Neuronen (100 \%) aus drei unabhängigen Kulturen für jeden Messpunkt ermittelt. Alle dCSM14.1 Neurone wurden einer Transfektion mit pDsRed2-Mito unterzogen, je nach Versuchsbedingung erfolgten Kotransfektionen mit Fis1 (weiß), Drp1 (dunkelgrau) oder Drp1 $1_{\mathrm{K} 38 \mathrm{~A}}$ (schwarz).

Staurosporin induziert Apoptose (Kontrolle), diese Induktion wird durch Überexpression von Fis1 oder Drp1 kaum beeinflusst. Fis1 verstärkt dennoch in diesen Neuronen die Morphologieänderung der Mitochondrien beträchtlich (vergleiche Abbildung 25). Im Gegensatz zur Überexpression von Drp1, die keinen deutlichen Einfluss auf die Apoptoserate ausübte, führt eine Unterdrückung durch Expression von Drp1 $1_{\mathrm{K} 38 \mathrm{~A}}$ in den Neuronen signifikant (t-Test, *: p<0,05) zu deutlich verringerten Apoptoseraten (Zeitverläufe durch Linien hervorgehoben).

Die Induktion der Apoptose führte zu einem Anstieg an Neuronen mit fragmentierten Zellkernen. Der Anstieg der Neurone mit fragmentierten Mitochondrien während der Apoptose (siehe Abbildung 25) erfolgte schneller und früher als der Anstieg der Neurone mit apoptotischen Zellkernen (siehe Abbildung 29). Während die mitochondriale Fragmentation nach ca. einer Stunde Staurosporininkubation nahezu alle Neurone erfasste sind die meisten Zellkerne erst nach ca. vier Stunden zerfallen. Die Überexpression von Drp1 $1_{\mathrm{K} 38 \mathrm{~A}}$ zeigte einen neuroprotektiven Effekt. Die mitochondriale Fragmentation unter Drp1 $1_{\mathrm{K} 38 \mathrm{~A}}$ Überexpression setzt erst nach ca. 30 min ein, die Fragmentation der Kerne wird sogar für vier Stunden fast gänzlich unterdrückt. Bei ca. 50 \% der Neurone wird die Fragmentation beider Zellorganellen selbst durch $24 \mathrm{~h}$ Staurosporininkubation komplett unterbunden. Die Hemmung von Drp1 scheint neuroprotektiv zu wirken. 
Die vermehrte Zerteilung der Mitochondrien ist ein früh stattfindender Prozess innerhalb der Apoptose, der für den ungestörten Ablauf der Apoptosekaskade notwendig ist.

\subsubsection{Mitochondriale Fragmentation unter Tat Bcl-xL}

Die Hemmung von Drp1 durch die Überexpression von Drp1 $1_{\mathrm{K} 38 \mathrm{~A}}$ verzögert die mitochondriale Zerteilung (siehe Abbildung 24 und Abbildung 25) während der Apoptose wie auch die Apoptose selbst (siehe Abbildung 28 und Abbildung 29). Es ist unklar, ob die beiden Prozesse kausal nacheinander bzw. zeitlich gleichzeitig stattfinden müssen. Ebenso ist der Zerfall der Mitochondrien nicht selbstverständlich unabhängig von dem unumkehrbaren Ablauf der Apoptose. Somit ist zu prüfen, ob die beiden Zerfallsprozesse unabhängig voneinander stimuliert bzw. unterdrückt werden können.

a

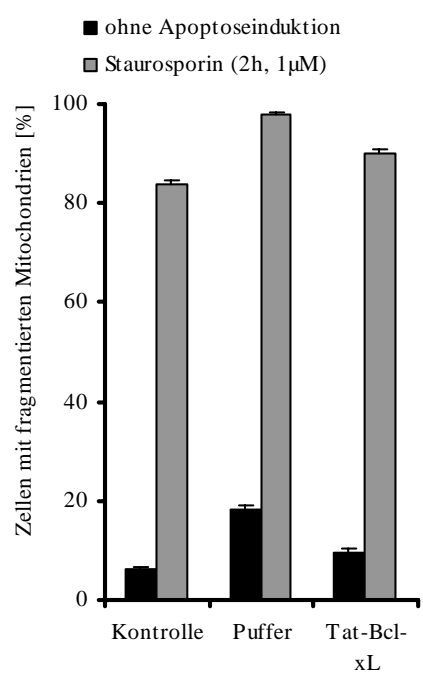

b

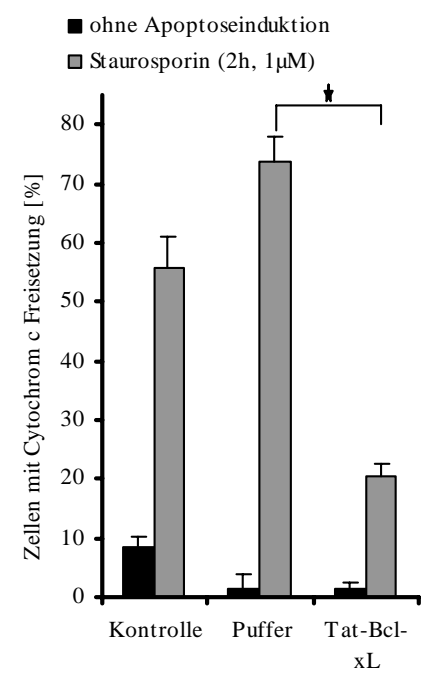

C

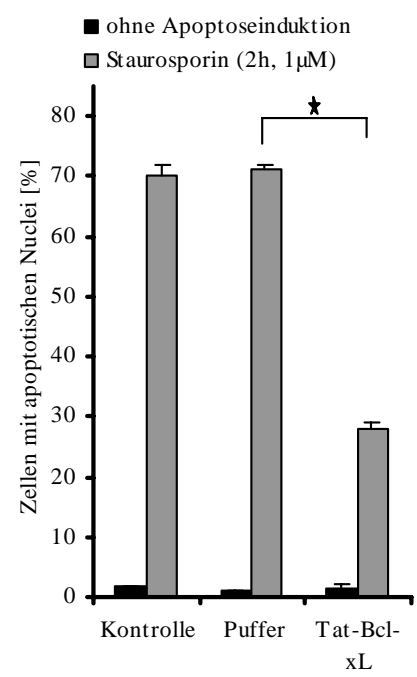

Abbildung 30: Effekte von Tat-Bcl-xL.

In obigen Diagrammen wurden je Messpunkt 384 Neurone (100 \%) aus drei unabhängigen Kulturen nach ihrer Fragmentation der Mitochondrien (a), Cytochrom c Freisetzung (b) bzw. dem Apoptosestatus (c) klassifiziert. Die Mitochondrien waren durch Transfektion mit pDsRed2-Mito markiert. Der Anteil apoptotischer Neurone oder fragmentierter Mitochondrien (Abszissen) wurde mit (grau) und ohne (schwarz) Apoptoseinduktion ermittelt. Neben dem Effekt einer Behandlung mit Tat-Bcl-xL sind als Referenz die Resultate unbehandelter Neurone dargestellt, Artefakte des Tat-Bcl-xL Lösungspuffers können durch die entsprechende Messungen ausgeschlossen werden.

Staurosporin induziert einen Anstieg der Kontrollneurone mit zellulärer Cytochrom c Freisetzung (b), fragmentierten Nuclei (c) und Mitochondrien (a). Die Behandlung mit Tat-Bcl-xL hat eine signifikante neuroprotektive Wirkung (b und c, t-test, ${ }^{*}: \mathrm{p}<0,05$ ), jedoch kaum Einfluss auf die mitochondriale Zerteilung während der Apoptose.

Die Proteine der Bcl-2- Familie nehmen eine herausragende Bedeutung innerhalb der Steuerung der mitochondrial vermittelten Apoptose ein. Durch sie erfolgt eine Integration verschiedener auf die Zelle einwirkender Überlebens- und Todessignale (Adams und Cory 2001). Somit sind sie mögliche Kandidaten für die Regulation der Mitochondrienform. Die Familie teilt sich in zwei Unterklassen, die anti- apoptotischen Proteine, welche die Zelle vor 
der Apoptose schützen, und die pro-apoptotischen, die den Ablauf der Apoptose fördern (Antonsson 2001). Eine wichtige Funktion der Mitglieder der Bcl-2 Familie ist die Kontrolle der mitochondrialen Membranpermeabilität.

Innerhalb der vorliegenden Arbeit wurde das anti- apoptotische Bcl-xL Protein genutzt, welches die mitochondriale Permeabilität blockiert (Adams und Cory 2001, Antonsson 2001). Es war mit einer Tat-Protein Transduktionsdomäne (Tat-Domäne) fusioniert, die es Proteinen fast jeglicher Größe und biochemischer Eigenschaften ermöglicht Zellmembranen zu passieren (Dietz und Bahr 2004). Der anti- apototische Effekt von Tat-Bcl-xL ist bekannt (Dietz et al. 2002). Er wurde in dieser Arbeit mittels Klassifizierung der verwendeten dopaminergen Neurone an Hand ihrer Kernmorphologie und Cytochrom c Verteilungsmuster erneut verifiziert (siehe Abbildung 30).

Nach Apoptoseinduktion steigt der Anteil an Neurone mit fragmentierten Mitochondrien in Tat-Bcl-xL behandelten Neuronen an. Obwohl die Apoptosekaskade zumindest ab der Freisetzung des Cytochrom c aus den Mitochondrien gehemmt oder unterbunden ist, wird die Zerteilung der Mitochondrien von Tat-Bcl-xL nicht beeinflusst (siehe Abbildung 30). Somit ist der neuroprotektive Effekt von Tat-Bcl-xL nicht über Beeinflussung der mitochondrialen Zerteilungsvorgängen innerhalb der Apoptose vermittelt.

Bcl-xL interferiert auf dem Level der Cytochromc Freisetzung während der Apoptosekaskade, hat aber keinen Einfluss auf die Zerteilungsvorgänge der Mitochondrien. Der finale Ablauf der Apoptose und die Cytochrom c Ausschüttung aus den Mitochondrien sind daher nicht notwendige physiologische Grundlage der apoptotischen mitochondrialen Zerteilung.

\subsubsection{Bedeutung des Zytoskeletts für die mitochondriale Zerteilung}

Mitochondrien werden durch Zytoskelettstrukturen innerhalb der Zelle gerichtet transportiert (siehe Kapitel 1.1.4). Drp1 befindet sich während der frühen Apoptose an den Mitochondrien und ist dort an der Regulation der mitochondrialen Fragmentation in dopaminergen Neuronen beteiligt (siehe Kapitel 3.1.3.1). Es ist unklar durch welche Mechanismen es dorthin transportiert wird und wie der Transport reguliert wird. Es ist jedoch vorstellbar, dass die Strukturen des Zytoskeletts hierbei eine Funktion übernehmen. So wurde die Beteiligung der Aktin- und Tubulinstrukturen am Transport von Drp1 während der Apoptose durch die Behandlung der Neurone mit Cytochalasin D und Nocodazol überprüft. Die beiden Substanzen depolymerisieren das entsprechende Zytoskelett und führen zu einer vollständigen Zerstörung der entsprechenden Strukturen (siehe Abbildung 31). Die Behandlung der Zellen mit Cytochalasin D führt zu stark verästelten Aktinstrukturen, die 
spindelförmig zum Zellkern ausgerichtet sind, wohingegen die Behandlung mit Nocodazol in einer Zerteilung der Tubulinstrukturen resultiert.
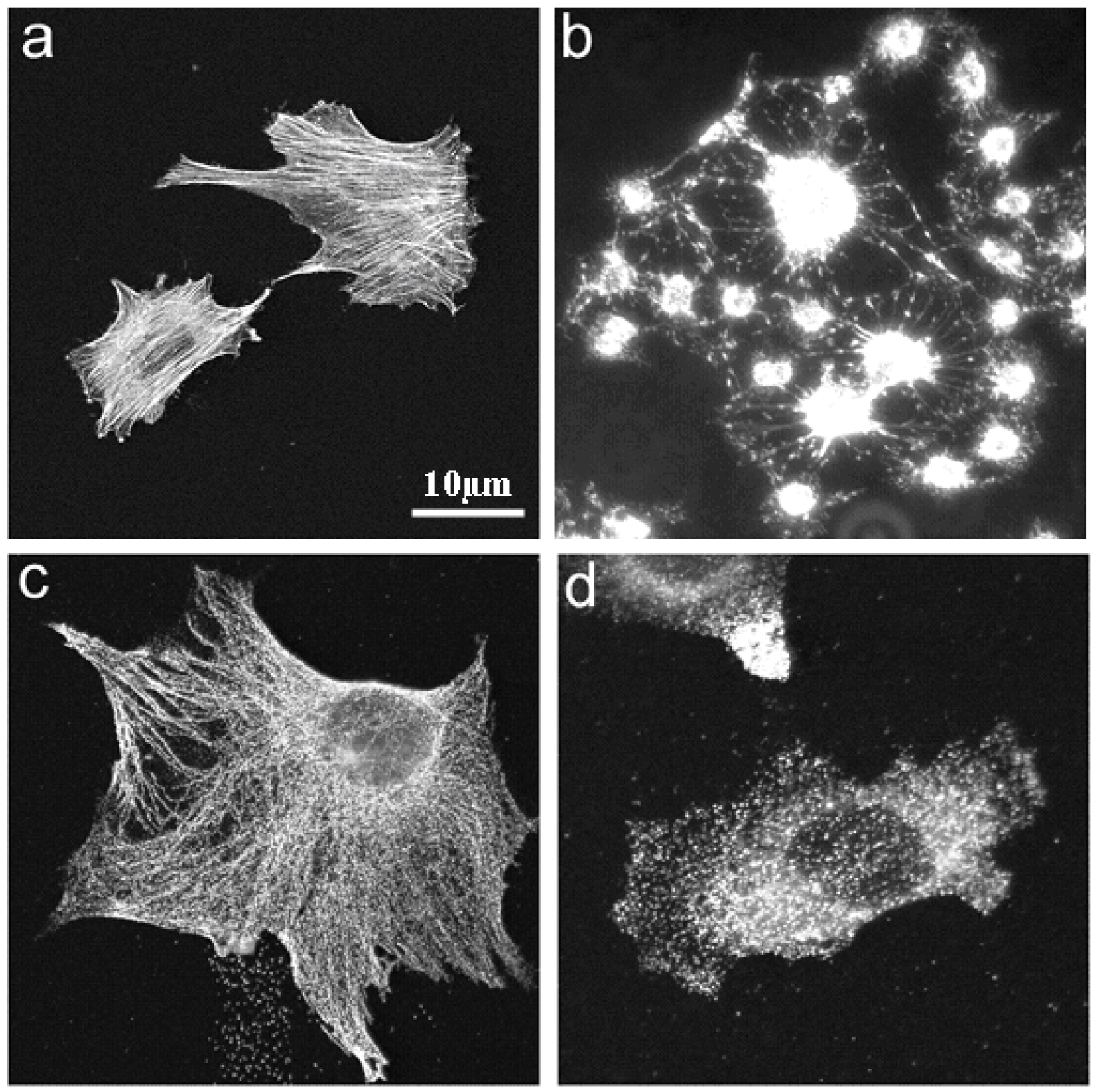

Abbildung 31: Zerstörung des Zytoskeletts.

Die dargestellten dCSM14.1 Zellen sind immunzytochemisch gegen Aktin (a und b) oder Tubulin (c und d) gefärbt. Die Neurone rechts wurden vor der Bildaufnahme mit $10 \mu \mathrm{g} / \mathrm{ml}$ Cytochalasin D (b) oder $10 \mu \mathrm{g} / \mathrm{ml}$ Nocodazol (d) für eine Stunde inkubiert.

Die unbehandelten Zellen (a und c) weisen ein intaktes Zytoskelett auf. Durch die Behandlung mit Cytochalasin D verschwindet die deutliche Längsstreifung des Aktinskeletts. Die Aktinfilamente depolymerisieren und verlaufen nun zur Zellmitte.

Die Behandlung mit Nocodazol führt zu einer vollständigen Zerstörung des Tubulinskeletts. Die Tubulinstrukturen liegen als kleine Bruchstücke diffus im Zytoplasma vor. Das Zellsoma ist deutlich verkleinert, die Zelle besitzt keine Fortsätze mehr.

Die Zerstörung des Zytoskeletts verhindert den Transport von Drp1 zu den Mitochondrien (siehe Abbildung 32). Die Drp1 Proteine befinden sich nach Depolymerisierung der Zytoskelettstrukturen trotz Apoptose diffus verteilt im Zytoplasma und nicht konzentriert bzw. 
transloziert an den Mitochondrien. Dieser Effekt ist sowohl bei Zerstörung der Aktin- wie auch Tubulinstrukturen sichtbar, was darauf schließen lässt, dass der Drp1 Transport vom Zytoplasma zu den Mitochondrien während der Apoptose von einem intakten Zytoskelett abhängig ist. Bei zerstörtem Zytoskelett ist die Fragmentation der Mitochondrien während der Apoptose gestört (siehe Abbildung 34). Dies verdeutlicht abermals, dass Drp1 für die Regulation der mitochondrialen Zerteilung verantwortlich ist.

Bei der Analyse der durchschnittlichen Mitochondrienlängen im Verlauf der Apoptose zeigt sich, dass die Fragmentation der Mitochondrien nach Zerstörung des Zytoskeletts verlangsamt ist im Vergleich zu Neuronen mit intaktem Zytoskelett (siehe Abbildung 33). Die Reduktion war sowohl bei Zerstörung der Aktin- wie auch Tubulinstrukturen vorhanden. Die gleichzeitige Zerstörung beider Zytoskelettstrukturen zeigte einen additiven Effekt, so dass ein Zerfall der Mitochondrien kaum noch nachweisbar ist (siehe Abbildung 33).
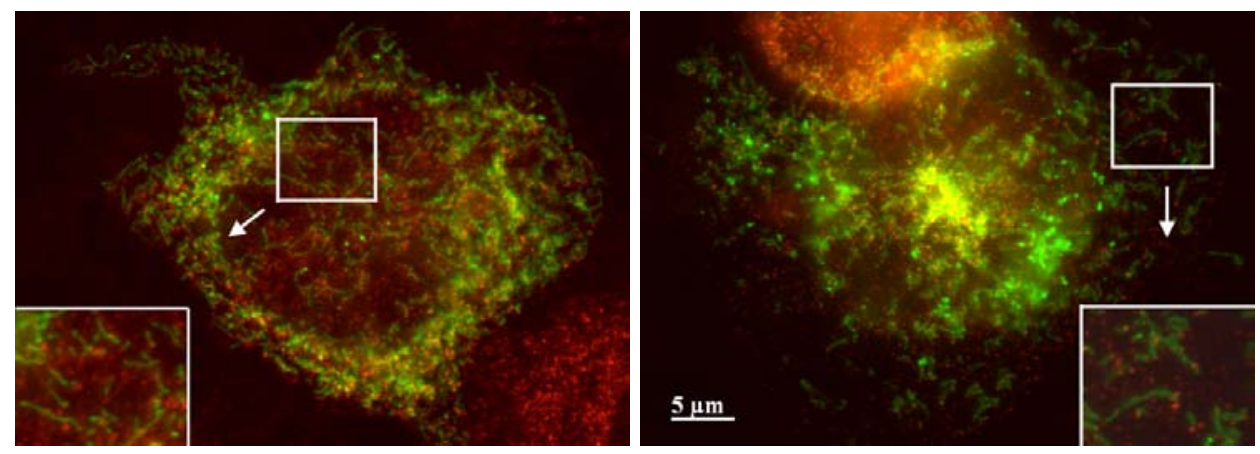

Abbildung 32: Drp1 Lokalisation während der Apoptose bei zerstörtem Zytoskelett.

Dargestellt sind fluoreszenzmikroskopische Aufnahmen von fixierten dCSM14.1 Zellen nach zweistündiger Staurosporinbehandlung $(1 \mu \mathrm{M})$. Das Zytoskelett der Neurone wurde durch Behandlung mit Cytochalasin D (Aktinskelett, $10 \mu \mathrm{g} / \mathrm{ml}$, rechts) oder Nocodazol (Tubulinskelett, $10 \mu \mathrm{g} / \mathrm{ml}$, links) zerstört. Die Mitochondrien sind durch Transfektion mit mt-GFP markiert. Endogenes Drp1 wurde immunzytochemisch angefärbt, der Sekundärantikörper ist mit Cy3 (rot) markiert.

Nach Zerstörung des Zytoskeletts befindet sich das Drp1 trotz Apoptoseinduktion nicht an den Mitochondrien (vergleiche Abbildung 20). Der Effekt ist unabhängig davon, welche Strukturen des Zytoskeletts zerstört wurden. Der Transport der Drp1-Cluster erfolgt Zytoskelett-abhängig.

Im Gegensatz zu dem drastischen Einfluss auf die Fragmentation der Mitochondrien scheint das Zytoskelett für den erfolgreichen Abschluss der Apoptose nicht von Bedeutung zu sein. Die Zellen zeigen nach Depolymerisation ihrer Zytoskelettstrukturen zwar eine deutlich abnormale Morphologie, dennoch wird durch diese Behandlung der programmierte Zelltod nicht oder nur mit mehr als zwei stündiger Verzögerung ausgelöst. Nach Inkubation mit einem Apoptoseinduktor wird der apoptotische Prozess ausgelöst (siehe Abbildung 35). Dies ist umso erstaunlicher, da wie beschrieben die apoptotische Zerteilung der Mitochondrien völlig aussetzt. Die Apoptoserate ist ohne Zytoskelett lediglich geringfügig vermindert, so dass unter Umständen ein schwacher Effekt der blockierten mitochondrialen Zerteilung 
sichtbar ist. Die Apoptose ist beachtenswerter Weise weiterhin mit einer Freisetzung von Cytochrom c aus den Mitochondrien verbunden. Somit ist eine vollständige Zerteilung der Mitochondrien für die Apoptose nicht notwendig.

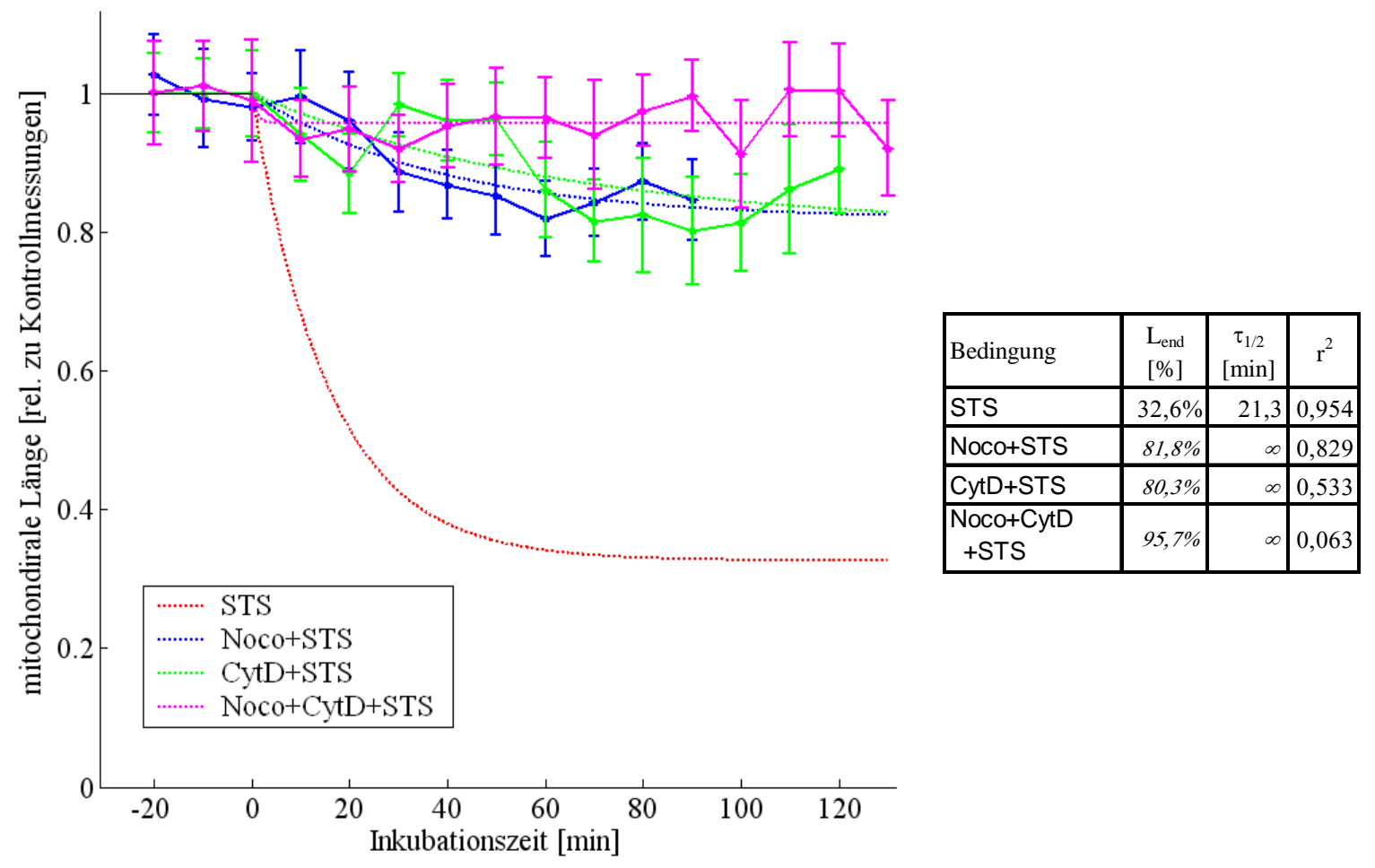

Abbildung 33: Hemmung der mitochondrialen Fragmentation durch die Zerstörung des Zytoskeletts.

Dargestellt ist die normierte Mitochondrienlänge in Abhängigkeit von der Staurosporininkubationsdauer, weitere Erläuterungen siehe Abbildung 16. Neurone wurden zuvor nicht (rot), mit Cytochalasin D (10 $\mu \mathrm{g} / \mathrm{ml}$, grün), mit Nocodazol (10 $\mu \mathrm{g} / \mathrm{ml}$, blau) oder mit beiden Substanzen (magenta) behandelt. Die gestrichelte rote Linien gibt die genäherte Reaktion der unbehandelten Neurone auf den Apoptose Stimulus wieder, während die andersfarbigen gestrichelten Linien die genäherten Reaktionen der behandelten Neuronen angeben.

Im Vergleich zu den Messungen an unbehandelten Zellen (rot) führte eine Zerstörung des Zytoskeletts zu wesentlich geringeren Fragmentationsraten der Mitochondrien (unendliche Halbwertszeiten, siehe Tabelle). Hierbei war der Einfluss des Aktinskeletts (grün) und der Mikrotubuli (blau) annähernd vergleichbar. Die kleinen Regressionskoeffizienten der genäherten Reaktionen behandelter Zellen lassen vermuten, dass kein natürlicher Zerfall mehr stattfindet. Die Zerstörung beider Zytoskelettstrukturen zeigt eine Verstärkung des protektiven Effektes. Trotz Apoptoseinduktion zeigen die Mitochondrien fast das gleiche Verhalten wie die Kontrollneurone, in denen weder Apoptose induziert noch das Zytoskelett zerstört wurde. Ohne intaktes Zytoskelett findet praktisch keine mitochondriale Fragmentation statt.

Der Transport von Drp1 zu den Mitochondrien scheint für die Fragmentation der Mitochondrien während der Apoptose notwendig zu sein. Hierzu sind die beiden Zytoskelettstrukturen Aktin und Tubulin notwendig. 
vor Apoptoseinduktion
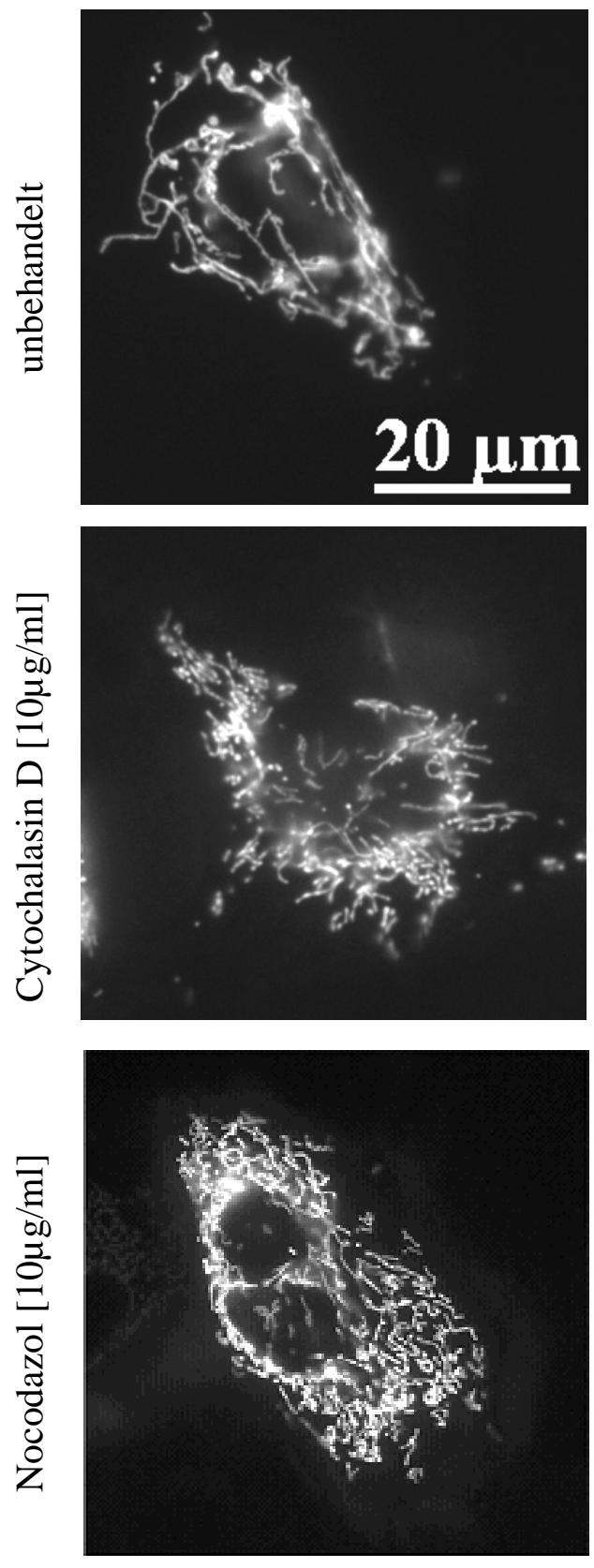

nach Apoptoseinduktion
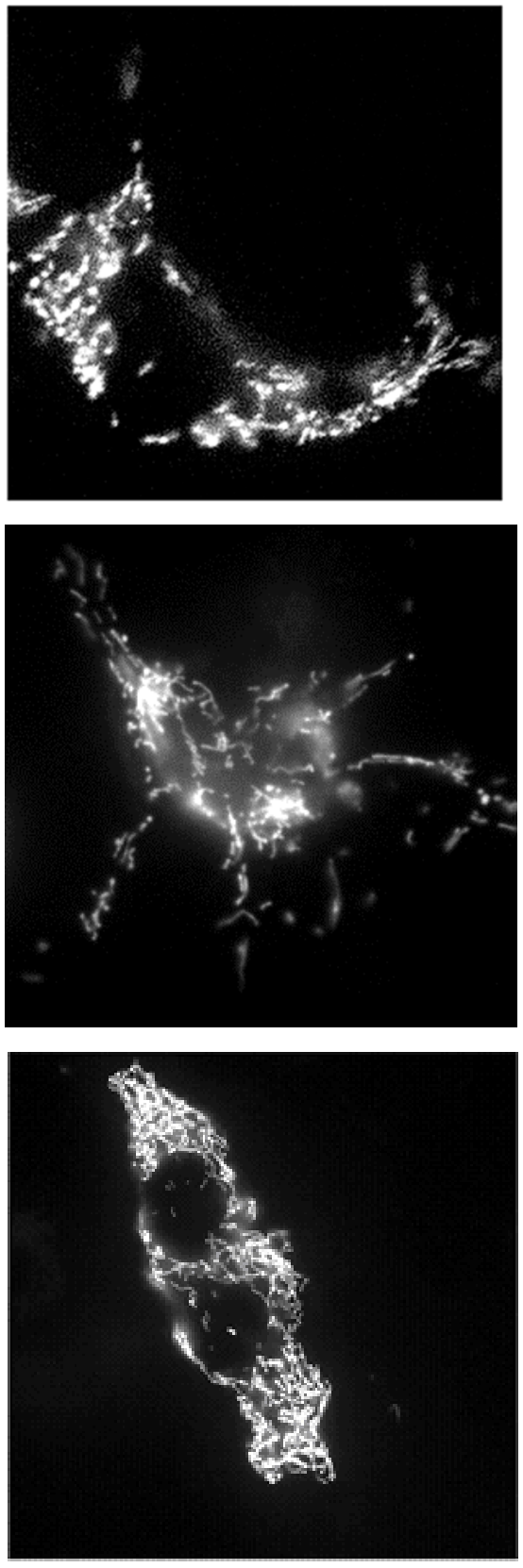

Abbildung 34: Zerstörung des Zytoskeletts und mitochondriale Fragmentation.

Dargestellt sind fluoreszenzmikroskopische Aufnahmen von dCSM 14.1 Neuronen vor (links) und nach Apoptoseinduktion (rechts, $2 \mathrm{~h}$ Staurosporininkubation, $1 \mu \mathrm{M}$ ). Die Mitochondrien sind durch Transfektion mit pDsRed2-Mito markiert. In den unteren Abbildungen (Mitte und unten) wurde das Zytoskelett durch einstündige Inkubation mit den angegebenen Substanzen zerstört.

Im Vergleich zur Kontrolle (oben) werden Neurone bei Zerstörung des Zytoskeletts durch Behandlung mit Cytochalasin D $(10 \mu \mathrm{g} / \mathrm{ml})$ oder Nocodazol $(10 \mu \mathrm{g} / \mathrm{ml})$ vor apoptotischen mitochondrialen Zerfall geschützt. Die Mitochondrien der behandelten Zellen (Mitte und unten) weisen im Gegensatz zu den Mitochondrien der unbehandelten Zellen (Kontrolle) nach Apoptoseinduktion weiterhin eine elongierte Form auf. Die morphologischen Veränderungen der Mitochondrien während der Apoptose sind in der Kontrollbedingung (oben rechts) wesentlich stärker als nach Zerstörung des Zytoskeletts.

Auch die morphologischen Veränderungen der Zellen durch Zerstörung des Zytoskeletts sind sichtbar, so sind die Mitochondrien nach Zerstörung der Tubulinstrukturen auf ein kleineres Zellsoma begrenzt (unten rechts). Nach Zerstörung der Aktinstrukturen zeigen sich filigrane Zellfortsätze, in denen Mitochondrien lokalisiert sind. 

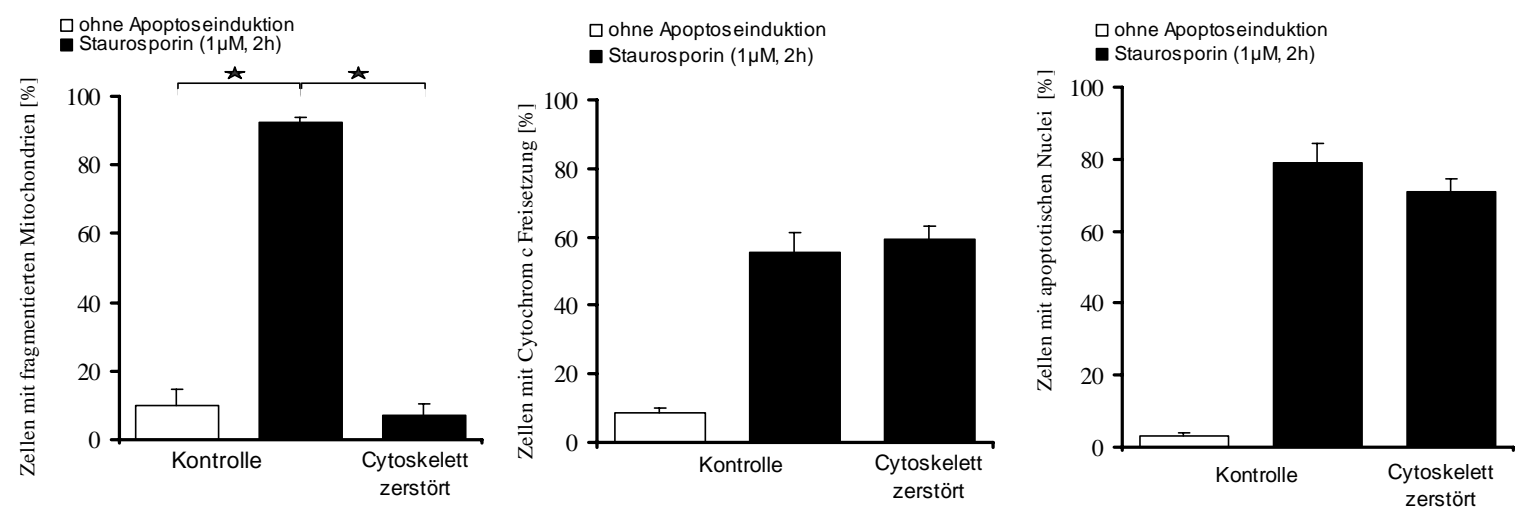

Abbildung 35: Apoptose ohne Zytoskelett.

Dargestellt ist der Anteil an Zellen mit fragmentierten Mitochondrien (links), Cytochrom c freisetzender Neurone (Mitte) bzw. die Zelltodrate (rechts) bei Auswertung von je 384 dCSM14.1 Neuronen pro Versuchsbedingung. Die Messungen wurden jeweils an drei Versuchsgruppen durchgeführt, weiß ist eine Kontrollgruppe ohne Apoptoseinduktion, während schwarze Balken die Wirkung der Apoptoseinduktion durch $2 \mathrm{~h}$ Staurosporininkubation zeigen. Der jeweils linke schwarze Balken bezieht sich wiederum auf eine Kontrollgruppe, die vor Apoptoseinduktion lediglich eine Transfektion zur Markierung der Mitochondrien erfuhr. Die rechten Balken zeigen Resultate von Neuronen, deren Zytoskelettstrukturen kurz vor Apoptoseinduktion zerstört wurden. Zum Abbau des Aktinskelettes diente $10 \mu \mathrm{g} / \mathrm{ml}$ Cytochalasin D, während die Mikrotubuli durch $10 \mu \mathrm{g} / \mathrm{ml}$ Nocodazol zerstört wurden.

Obwohl die Zerstörung des Zytoskelettes einen heftigen Eingriff in die Zellintegrität darstellt und es individuell zu starken Schwankungen kommt, zeigen die Zellen ähnliche Apoptoseraten (rechts). Die Zerstörung der Skelettstrukturen induzierte selbst keinen Zelltod, auch nach künstlicher Induktion scheint der Kernzerfall fast unbeeinflusst zu sein. Die Ausschüttung von Cytochrom c ist unabhängig von Strukturen des Zytoskelettes. Die Fragmentation der Mitochondrien während der Apoptose wird allerdings bei Zerstörung des Zytosklettes signifikant blockiert (t-test, *: $\mathrm{p}<0,05)$. In diesem Zustand weisen Neurone mit intakten Mitochondrien dennoch ein diffuses Cytochrom c Verteilungsmuster auf, wodurch der nachfolgende Zelltod ausgelöst wird.

\subsubsection{Einfluss der Cyclin- abhängigen Kinase 5 auf die Mitochondrien}

Fis1 und Drp1 sind die wichtigsten Proteine, die direkt an der Regulation der mitochondrialen Zerteilung bei Säugetieren beteiligt sind (Chan 2006). Fis1 steuert den Zerteilungsprozess vermutlich nicht, da es als Transmembranprotein immobil in der Membran verankert ist und durch Überexpression eine Anomalie der Mitochondrienform hervorruft (siehe Abbildung 18). Die mitochondriale Zerteilung wird vermutlich mittels Drp1 initiiert. Drp1 wird im Verlauf der Apoptose durch Strukturen des Zytoskeletts zu den Mitochondrien transportiert (siehe Abbildung 20), wo es an Fis1 bindet und die Zerteilung der Mitochondrien auslöst. Der Transport von Drp1 zu den Mitochondrien könnte durch verschiedene Regelmechanismen gesteuert werden, z.B. durch Modifikationen des Transportsystems oder der beteiligten Transportproteine (Strukturen des Zytoskeletts). Weiterhin könnte Drp1 selbst modifiziert werden z.B. durch eine während der Apoptose induzierte Konformationsänderung. Eine solche Konformationsänderung könnte durch Aktivierung von Drp1 (z.B. durch Phosphorylierung) oder durch eine Komplexbildung mit weiteren Faktoren verursacht werden. Eine Phosporylierungsreaktion könnte auch die benötigte Energie für die Zerteilung bereitstellen. 
Die rezeptorgesteuerte Endocytose ist ein der mitochondrialen Zerteilung ähnelnder zellulärer Prozess, da es hier ebenfalls zur Abschnürung von Membranvesikeln kommt. Ein Regulatorprotein der rezeptorgesteuerten Endocytose ist Dynamin (Takei et al. 2005). Dynamin erkennt spezifisch das Phosphoinositol der Membran. Die Dynaminmoleküle liegen wie die Drp1 Moleküle bei der mitochondrialen Zerteilung als rechtsgewundene Helix um die Abschnürstelle der Vesikel. Die Ursache für die Abstoßung des Vesikels von der Membran basiert auf einer Konformationsänderung des Dynamins, welche durch die Hydrolyse von GTP ermöglicht wird. Dadurch könnte die Ganghöhe der Dynaminhelix ansteigen (Stowell et al. 1999) oder eine Verringerung des Helixdurchmessers (Sweitzer und Hinshaw 1998) erreicht werden.

Analogien zur mitochondrialen Zerteilung sind neben der generellen Abschnürung und Komplexbildung eines mobilen und membrangebundenen Proteins, die Ausbildung von Dynamin Helices (siehe Kapitel 1.1.5.1), die den bekannten Drp1 Anordnungen bei der mitochondrialen Zerteilung ähneln. Des Weiteren nimmt Fis1 bei der Fragmentation der Mitochondrien eine dem Phosphoinositol analoge Funktion ein.

Dynamin besitzt weiterhin eine hohe Sequenzhomologie zu Drp1 (siehe Abbildung 64). Die Dynaminaktivität wird in der rezeptorgesteuerten Endocytose durch CDK5 vermittelte Phosphorylierung reguliert (Tomizawa et al. 2003). Wegen der hohe Sequenzhomologie und funktionellen Analogie könnte CDK5 ebenfalls in der Regulation von Drp1 beteiligt sein. Weitere Indizien für eine mögliche Beteiligung von CDK5 liefern die Ergebnisse aus Kapitel 3.1.5. Dort wurde der Zusammenhang zwischen einem intakten Zytoskelett und der mitochondrialen Zerteilung während der Apoptose aufgezeigt. CDK5 ist an der Regulierung des Aktin- und Tubulinzytoskeletts beteiligt (Dhavan und Tsai 2001) und übernimmt regulatorische Funktionen innerhalb der Membranumstrukturierung bei der Migration von Neuronen (siehe Kapitel 1.2). Es existieren Hinweise für eine mögliche Interaktion von CDK5 mit dem mitochondrialen Zerteilungsprozess.

\subsubsection{Einfluss von CDK5 auf die mitochondriale Morphologie}

CDK5 besitzt zwei spezifische Aktivatorproteine p39 und p35 (siehe Kapitel 1.2.1). p35 kann durch Calpain gespalten werden, so dass unter anderem p25 entsteht. In der vorliegenden Arbeit wurde ausschließlich das p25 Protein verwendet um CDK5 zu aktivieren, da der p25/CDK5 Komplex hochaktiv und langlebiger ist als das p35/CDK5 oder p39/CDK5 Dimer (Dhavan und Tsai 2001). In Abwesenheit der Aktivatorproteine besitzt CDK5 keine enzymatische Aktivität. Zur Klärung des generellen Einflusses von CDK5 auf die Mitochondrienform wurden dCSM14.1 Neurone mit CDK5 und p25 transfiziert. 
Die Überexpression von p25/CDK5 resultierte in einer veränderten Mitochondrienform (siehe Abbildung 36). Die Mitochondrien waren von kleiner runder Form und häufig vermehrt um den Zellkern lokalisiert. Die Mitochondrienmorphologie ähnelte stark der nach Apoptoseinduktion vorherrschenden mitochondrialen Form (siehe Abbildung 13). Die Mitochondrien unterliegen bedingt durch die Überexpression von p25/CDK5 einer vermehrten Zerteilungsrate. Diese Zerteilung geht ebenfalls mit dem Transport von Drp1 aus dem Zytoplasma zu den Mitochondrien einher (siehe Abbildung 37), was auf den gleichen Zerteilungsmechanismus hinweist.

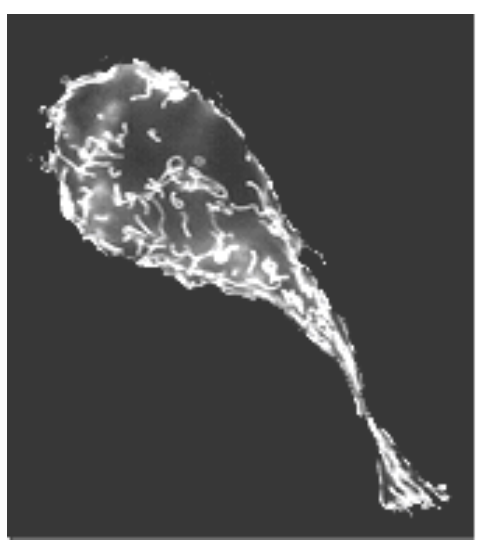

Kontrolle

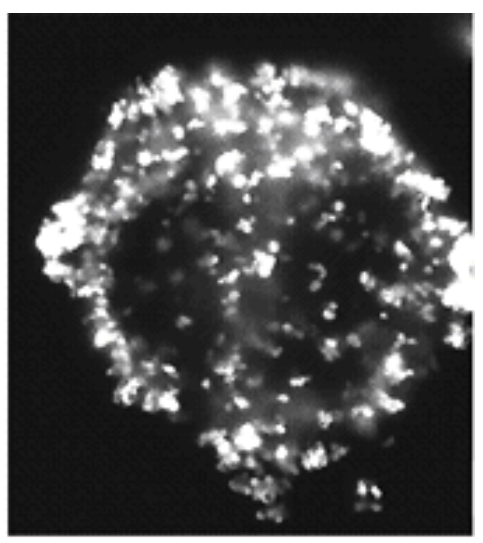

p25/CDK5

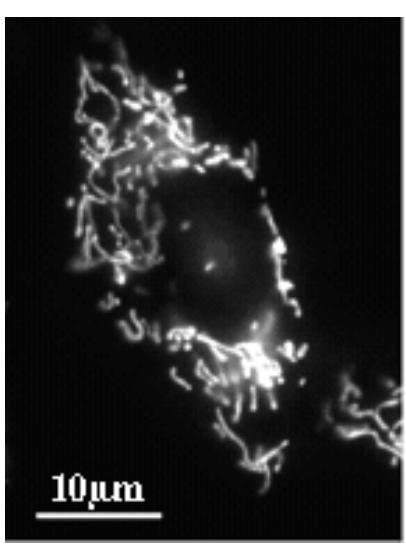

p25/CDK5/Drp1 ${ }_{\mathrm{K} 38 \mathrm{~A}}$

\section{Abbildung 36: p25/CDK5 und mitochondriale Fragmentation.}

Dargestellt sind fluoreszenzmikroskopische Aufnahmen der Mitochondrien von dCSM 14.1 Neuronen. Die Mitochondrien sind durch pDsRed2-Mito Transfektion markiert, zusätzlich exprimieren die Zellen p25/CDK5 (Mitte) oder p25/CDK5/Drp1 $1_{\mathrm{K} 38 \mathrm{~A}}$ (rechts). Die Aufnahmen erfolgten 24 Stunden nach der Transfektion.

Die Mitochondrien des Kontrollneurons (links) weisen eine physiologisch elongierte Form auf, wohingegen die Überexpression von p25/CDK5 (Mitte) in spontan fragmentierten Mitochondrien von runder Form resultiert. Die durch p25/CDK5 Überexpression induzierte mitochondriale Zerteilung wird durch gleichzeitige Expression von Drp $1_{\mathrm{K} 38 \mathrm{~A}}$ vermindert (rechts).

Um zu prüfen, ob der durch p25/CDK5 hervorgerufene und der durch Apoptosestimulus induzierte mitochondriale Zerfall die gleichen Proteine nutzt, wurde die Wirkung von Kotransfektionen mit Drp1 $1_{\mathrm{K} 38 \mathrm{~A}}$ untersucht.

Die Mitochondrien der Neurone, die p25/CDK5/Drp1 $1_{\mathrm{K} 38 \mathrm{~A}}$ überexprimierten behielten ihre natürliche elongierte Form und waren weiterhin im gesamten Zytoplasma verteilt (siehe Abbildung 36). Die durch Überexpression von p25/CDK5 induzierte mitochondriale Fragmentation scheint somit genauso wie der Zerfall der Mitochondrien während der Apoptose durch Drp1 vermittelt zu sein. Durch eine noch unbekannte Wechselwirkung ist p25/CDK5 in der Lage diesen Mechanismus zu aktivieren. 


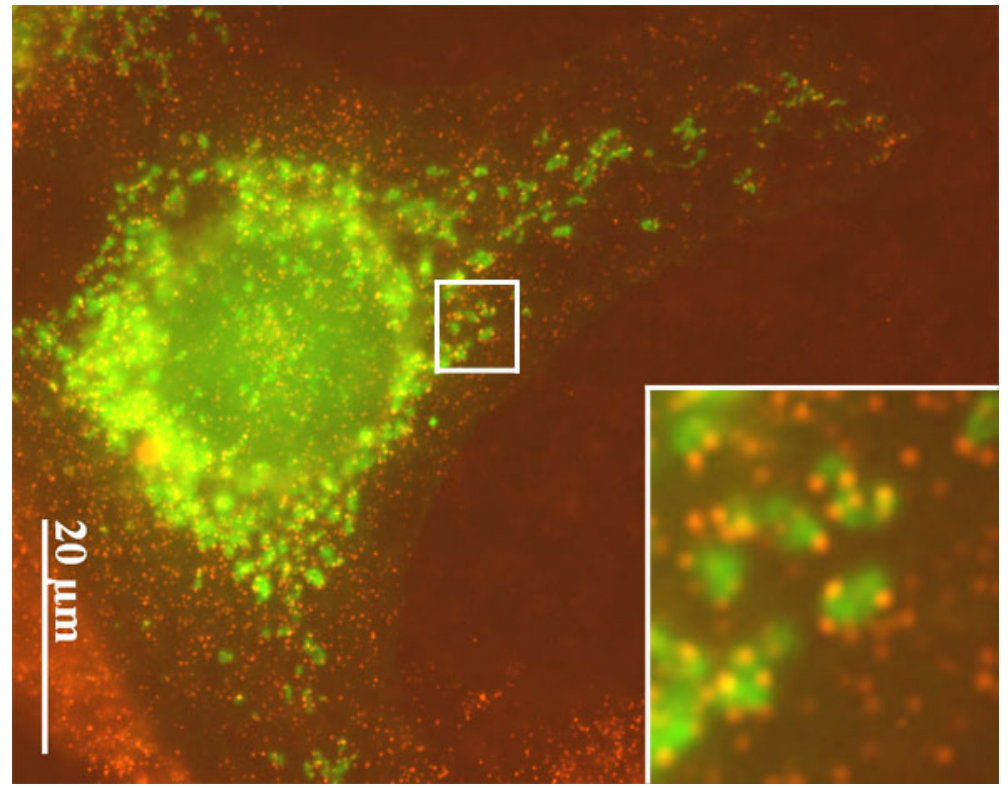

Abbildung 37: Drp1 Lokalisation bei p25/CDK5 Überexpression.

Abgebildet ist eine fluoreszenzmikroskopische Aufnahme einer p25/CDK5 überexprimierenden dCSM14.1 Zelle. Die Mitochondrien sind durch Transfektion mit mt-GFP (grün) markiert, endogenes Drp1 wurde immunzytochemisch mit einem Cy3 (rot) markiertem Sekundärantikörper angefärbt. Die Aufnahme erfolgte 24 Stunden nach Transfektion.

Die durch Überexpression von p25/CDK5 verursachte Fragmentation der Mitochondrien ist großteils bereits abgeschlossen. Bei noch nicht vollständiger Fragmentation der Mitochondrien liegt eine verstärkte Kolokalisation von Drp1 und den Mitochondrien vor (siehe Detailvergrößerung), meist scheint sich Drp1 an die Mitochondrien anzulagern.

Zur Verifizierung der Beobachtung wurden Neuronenpopulationen nach ihrer Mitochondrienform klassifiziert (siehe Abbildung 41). Es bestätigte sich, dass die Mitochondrien der p25/CDK5 überexprimierenden Neurone im Vergleich zu nicht p25/CDK5 überexprimierenden Zellen vorwiegend in kleine Bruchstücke fragmentiert waren. Durch gleichzeitige Überexpression von Drp $1_{\mathrm{K} 38 \mathrm{~A}}$ konnte dieser Effekt mehr als halbiert werden (siehe Abbildung 41). Auch hier resultierte die Zerstörung des Zytoskeletts in einer deutlich verminderten Fragmentation der Mitochondrien durch den p25/CDK5 Komplex. Die durch den p25/CDK5 Komplex induzierte mitochondriale Zerteilung benötigt ebenfalls den Zytoskelett abhängigen Drp1 Transport zu den Mitochondrien.

\subsubsection{Regulation der CDK5- Aktivität bei Apoptoseinduktion}

Mit Hilfe der Western Blot Analyse war es möglich nachzuweisen, dass dCSM14.1 Neurone CDK5 endogen exprimieren (siehe Abbildung 38, 0h Staurosporin). Ebenso konnte gezeigt werden, dass die verwendeten Zellen kein endogenes p35 besaßen, sondern p39 (siehe Abbildung 39). Die Expression von p35 wurde auch nicht durch Apoptoseinduktion angeschaltet. 
Staurosporininkubation [h]

$\begin{array}{lllllll}0 & 0,5 & 1 & 2 & 4 & 6 & 12\end{array}$

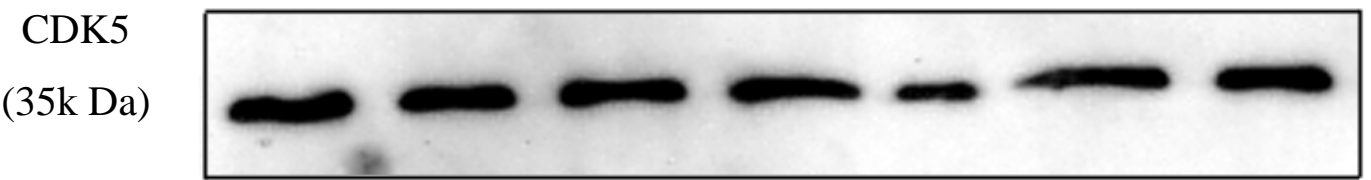

\section{Abbildung 38: CDK5 Expression.}

Abgebildet ist die Western Blot Analyse der CDK5 Proteinexpression nach unterschiedlichen Staurosporininkubationszeiten $(1 \mu \mathrm{M})$. Je Versuchsbedingung wurden $20 \mu \mathrm{g}$ Zelllysat von dCSM14.1 Neuronen eingesetzt. Zur Detektion wurde ein polyklonaler Antikörper gegen CDK5 (siehe Tabelle 6) verwendet, welcher eine Bande bei 35 kDa erkennt (Größenstandard nicht dargestellt).

Die Zellen exprimieren endogen CDK5 (Zeitpunkt 0). Während der durch Staurosporin induzierten Apoptose variiert die CDK5 Expression kaum.

$$
\text { p35 Überexpression unbehandelt p35 Überexpression unbehandelt }
$$

p35

(35 kDa)
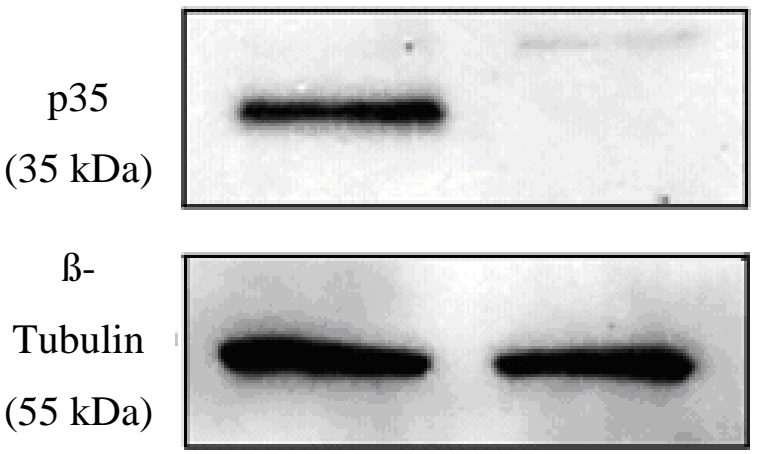
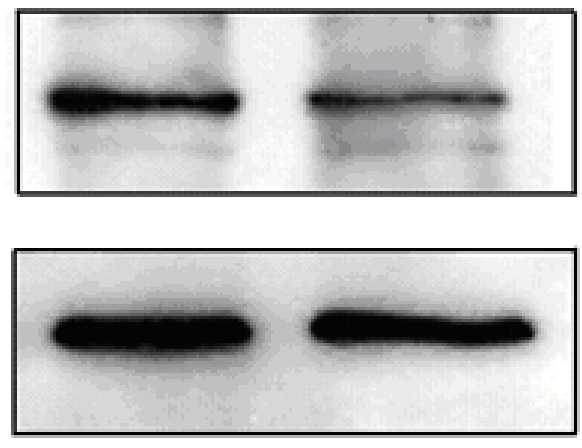

ß-

Tubulin (55 kDa)

\section{Abbildung 39: Endogene Aktivatoren von CDK5.}

In den beiden oberen Zeilen ist die Western Blot Analyse der p35 (links) und der p39 Proteinexpression (rechts) sowie die zugehörigen Ladekontrollen (ß-Tubulin) dargestellt. Vor der Lyse wurden die Kontrollkulturen mit p35 transient transfiziert, um eine entsprechende Kontrolle zu generieren. Zur Detektion wurde ein polyklonaler Antikörper gegen p35 bzw. p39 (siehe Tabelle 6) verwendet, welcher eine Bande bei $35 \mathrm{kDa}$ bzw. 39 kDa

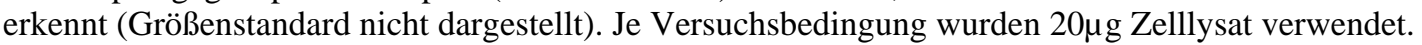

Das p35 Protein war nur bei künstlich erzeugter Überexpression nachweisbar, was daraufhin deutet, dass die Neurone p35 nicht endogen exprimieren.

CDK5 induziert mitochondriale Fragmentation, da es über unbekannte Mechanismen den Transport von Drp1 zu den Mitochondrien beeinflusst. Die rezeptorvermittelnde Endocytose wird durch die CDK5 abhängige Aktivierung von Dynamin induziert (Takei et al. 2005). Möglicherweise wird Drp1 ebenfalls durch CDK5 aktiviert, wodurch der Transport zu den Mitochondrien begünstigt werden könnte oder aber analog zu Dynamin die nötige Energie, um die Mitochondrien durchzuschnüren. Wenn Drp1 Aktivierung ein limitierender Faktor wäre müsste die Aktivierungsrate während der Apoptose erhöht sein. Dies könnte durch ein höheres Expressionslevel erreicht werden. Die Western Blot Analyse ergab allerdings, dass sich das CDK5 Expressionslevel während der Apoptose nicht verändert (siehe Abbildung 38). Sogar 12 Stunden nach Apoptoseinduktion war das Expressionslevel von 
gleicher Größe wie in nicht apoptotischen Zellen. Die CDK5 Protein Expression reguliert somit nicht die Aktivierung von Drp1, daher könnte eine veränderte CDK5 Enzymaktivität als Regulator fungieren.

Die enzymatische Aktivität von CDK5 kann über den Phosporylierungsgrad eines geeigneten Substrates bestimmt werden. Die Aktivität von CDK5 wurde durch Verwendung eines etablierten in vitro Aktivitäts-Tests bestimmt (siehe Kapitel 2.3.4). Dabei wird Histon H1 durch CDK5 phosphoryliert. Die Phosphorylierungsmessungen nach Staurosporininkubation zeigen eine deutlich verstärkte Phosphorylierung des Histon H1 durch CDK5 bereits kurz nach Apoptoseinduktion (sieheAbbildung 40). Durch Bestimmung der CDK5 Proteinmenge ist sichergestellt, dass dieser Effekt auf einer Aktivitätsänderung der CDK5's beruht und nicht auf die CDK5 Konzentration selbst zurück zuführen ist.

Der schnelle Anstieg der CDK5 Aktivierungspotenz zu Beginn der Apoptose sowie der darauffolgende Abfall auf das Grundaktivitätslevel erfolgt analog zu der schnell einsetzenden Fragmentation der Mitochondrien nach Apoptoseinduktion. Somit kann CDK5 während der Apoptose die verstärkte Aktivität von Drp1 und folglich auch den mitochondrialen Zerfall steuern.
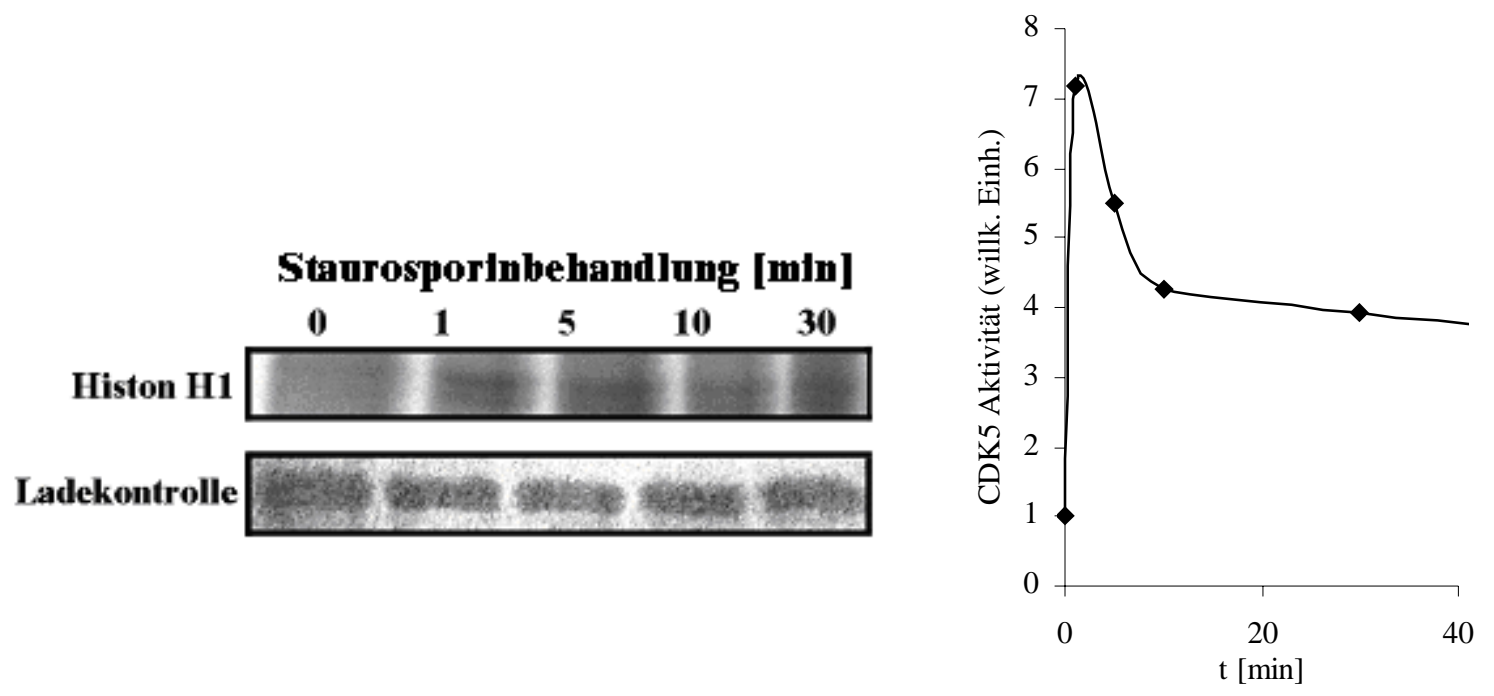

\begin{abstract}
Abbildung 40: CDK5- Aktivität.
Das obere rechte Bild zeigt eine Autoradiographie von phosphoryliertem Histon H1. Für jede Probe wurde 500 ng Proteinlysat von mit $1 \mu \mathrm{M}$ Staurosporin behandelten Neuronen (Inkubationsdauer siehe Bild) eingesetzt. Nachdem in Kapitel 2.3.4 beschriebenen Verfahren wurde aufgereinigtes Histon H1 zugegeben, welches durch das im Zelllysat befindliche CDK5 mit radioaktiv markierten ATP phosphoryliert wurde. Unter der Autoradiographie ist die Coomassiekontrollfärbung des SDS-Gels dargestellt.

Das Diagramm links gibt die gesamte Phosphorylierung der Histon H1 Banden der Proben in Abhängigkeit von der Staurosporininkubationsdauer wieder (Analyseverfahren siehe Kapitel 2.3.4).

Staurosporinbehandlung induziert mittelbar einen Anstieg der CDK5 gesteuerten Phosphorylierung des Histons H1. Da in jeder Versuchsbedingung die Menge an CDK5 konstant ist (Ladekontrolle), kann ausgeschlossen werden, dass die verschiedenen Phosphorylierungsstärken des Histons auf ungleicher CDK5 Konzentration beruhen. Zu Beginn der Apoptose wird somit die Aktivität von CDK5 erhöht.
\end{abstract}




\title{
3.1.6.3 Toxische Wirkung von CDK5 auf Mitochondrien und Zellkerne
}

Überexpression von p25/CDK5 führt zu einer verstärkten Fragmentation der Mitochondrien, der dem Effekt des mitochondrialen Zerfalls bei der Apoptose ähnelt. Der Zerfall der Mitochondrien könnte wiederum auslösend für den programmierten Zelltod sein.
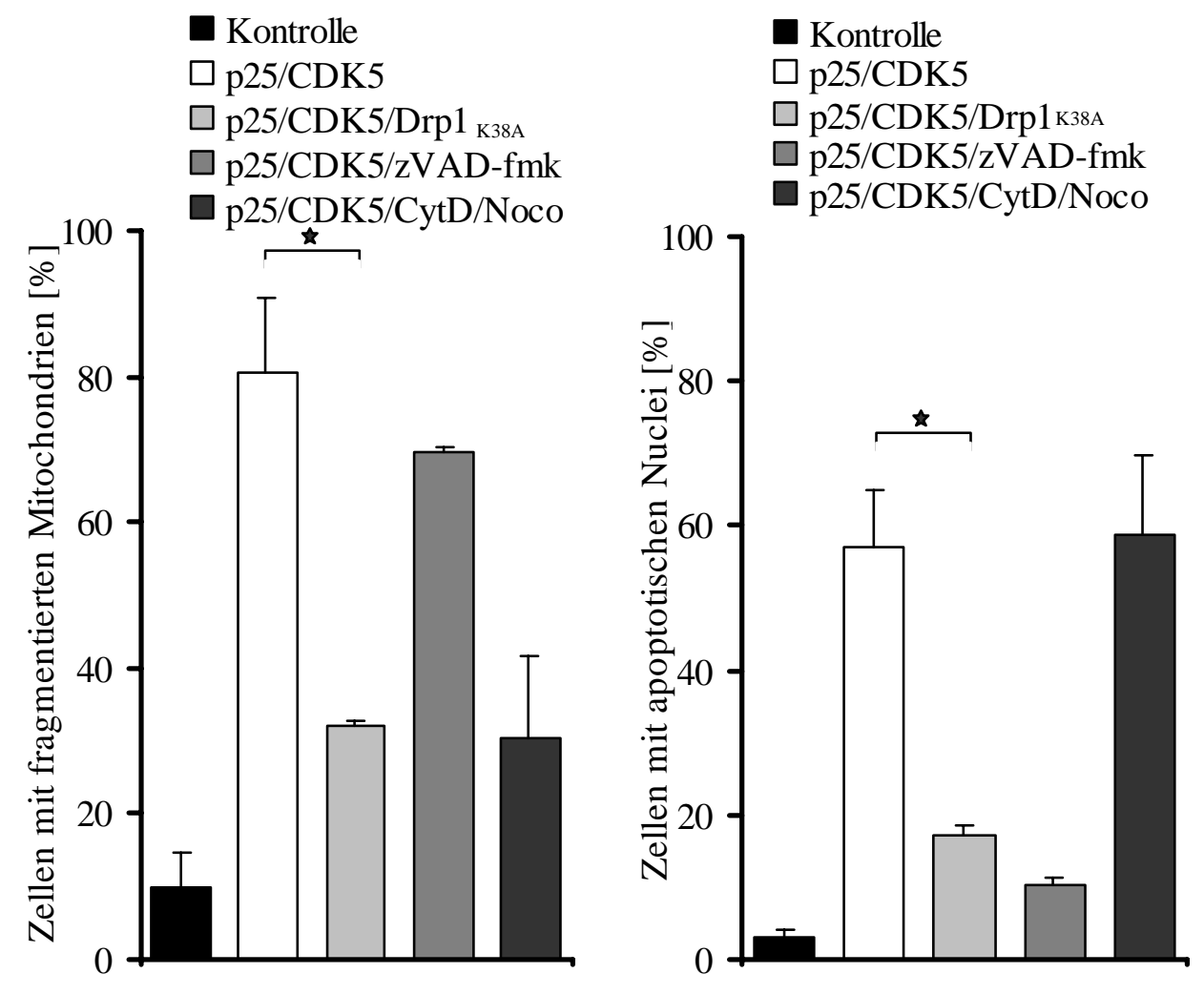

\begin{abstract}
Abbildung 41: p25/CDK5 und Zerfall der Zellorganelle.
Links ist der Anteil der Neurone dargestellt, die bei p25/CDK5 Überexpression (weiß) und mit kotransfizierten Drp1 $_{\mathrm{K} 38 \mathrm{~A}}$ (hellgrau) bzw. Caspaseinhibitor (grau) oder zerstörtem Zytoskelett (dunkelgrau) zerfallene Mitochondrien aufzeigen. Rechts ist der Anteil der Neurone dargestellt, die unter gleichen Bedingungen apoptotische Nuclei aufweisen. Beide Diagramme zeigen zur Beurteilung der Effekte eine Kontrollmessung unbehandelter Neurone (schwarz).

p25/CDK5 Überexpression induziert einen deutlichen Anstieg an Neuronen mit fragmentierten Mitochondrien und apoptotischen Zellkernen. Durch die parallele Überexpression von Drp1 ${ }_{\text {K38A }}$ können diese Effekte signifikant in ca. $2 / 3$ der betroffenen Neurone (t-Test, *: $\mathrm{p}<0,05)$ eliminiert werden. Die durch p25/CDK5 induzierte mitochondriale Fragmentation ist caspaseunabhängig.
\end{abstract}

Bei Überexpression von p25/CDK5 konnte ein vermehrter Anteil an Neuronen mit apoptotischen Kernen festgestellt werden (siehe Abbildung 41). Die Wirkung von p25/CDK5 ähnelt in vielen Aspekten der Zellreaktion bei Apoptoseinduktion, so ist der Zerfall der Zellkerne wiederum nicht vom Zytoskelett abhängig, wohl aber von einer nicht gehemmten Drp1 Aktivität. Die durch p25/CDK5 Überexpression induzierte mitochondriale Fragmentation ist Caspase unabhängig (siehe Abbildung 41). Dies deckt sich mit den Ergebnissen aus Kapitel 3.1.4, in dem sich bereits heraus kristallisierte, dass die mitochondriale Zerteilung 
unabhängig von oder ursächlich für die Apoptose ist und somit nicht selbst durch apoptotische Proteine reguliert wird.

Der neurotoxische Effekt der p25/CDK5 Überexpression konnte durch die gleichzeitige Überexpression von Drp1 $1_{\mathrm{K} 38 \mathrm{~A}}$ vermindert werden. Dies ist wiederum ein Indiz für eine apoptotische Wirkung der mitochondrialen Fragmentation selbst. Die Daten weisen darauf hin, dass der Mitochondrienzerfall durch p25/CDK5 das bekannte mitochondriale Zerteilungsprotein Drp1 verwendet und für die apoptotische Wirkung von p25/CDK5 notwendig ist.

\subsubsection{Bedeutung des endogenen CDK5 für die mitochondriale Zerteilung}

Bei den vorherigen Kapitel wurde CDK5 exogen überexprimiert. Daher ist es nicht klar, ob endogenes CDK5 ebenso die Mitochondrienzerteilung beeinflusst. Die Bedeutung von CDK5 für die mitochondriale Zerteilung bzw. den Ablauf der Apoptose wurde durch Inhibition des endogenen CDK5's untersucht. Hierbei kamen unterschiedliche Hemmungsverfahren zum Einsatz.

\subsection{Hemmung von CDK5 durch $\mathrm{CDK} 5_{\mathrm{N} 144}$}

CDK5 wurde zunächst durch Überexpression einer dominant negativen Mutante (CDK5 $\left.5_{\mathrm{N} 144}\right)$ gehemmt. Die Überexpression von $\mathrm{CDK} 5_{\mathrm{N} 144}$ hatte keinen Einfluss auf die Form der Mitochondrien nicht apoptotischer Zellen (Abbildung 42). Sie besaßen weiterhin eine elongierte Form und wiesen keine nennenswert veränderte Länge auf.

Wurde dagegen Apoptose induziert verminderte die Expression von $\mathrm{CDK}_{\mathrm{N} 144}$ die Fragmentation der Mitochondrien (siehe Abbildung 43). Die Inhibition von CDK5 scheint allerdings nicht zu einem dauerhaften Schutz der Mitochondrien zu führen, wie es z.B. bei Zerstörung der Zytoskelettstrukturen vorzufinden war. Die gleichzeitige Überexpression von Drp1 hebt den Effekt der CDK5 Hemmung auf (siehe Abbildung 43). Die mitochondriale Längenreduktion der mit $\mathrm{CDK}_{\mathrm{N} 144}$ und Drp1 kotransfizierten Neurone glich der während der Apoptose stattfindenden Längenreduktion unter Kontrollbedingung (ohne CDK5 Inhibition). 


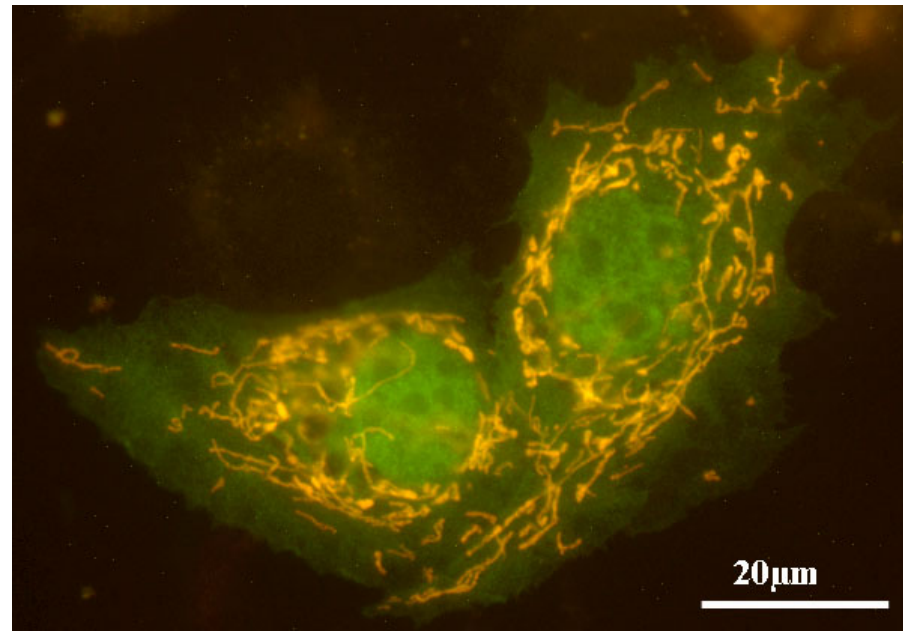

\section{Abbildung 42: Überexpression von $\mathrm{CDK} 5_{\mathrm{N} 144}$.}

Dargestellt ist eine fluoreszenzmikroskopische Aufnahme zweier dCSM14.1 Neurone, die pDsRed2-Mito und $\mathrm{CDK}_{\mathrm{N} 144}$-GFP überexprimieren. Die Überexpression von pDsRed2-Mito resultiert in einer spezifischen Markierung der Mitochondrien, wohingegen die Überexpression von $\mathrm{CDK} 5_{\mathrm{N} 144}$ durch diffuse grüne Fluoreszenz im Zytoplasma charakterisiert ist.

Die Überexpression von $\mathrm{CDK}_{\mathrm{N} 144}$ hat keinen offensichtlichen Einfluss auf die Form der Mitochondrien, sie weisen eine natürlich elongierte Morphologie auf. Auch der Gesamteindruck der transfizierten Neurone zeigt keine Anomalien.

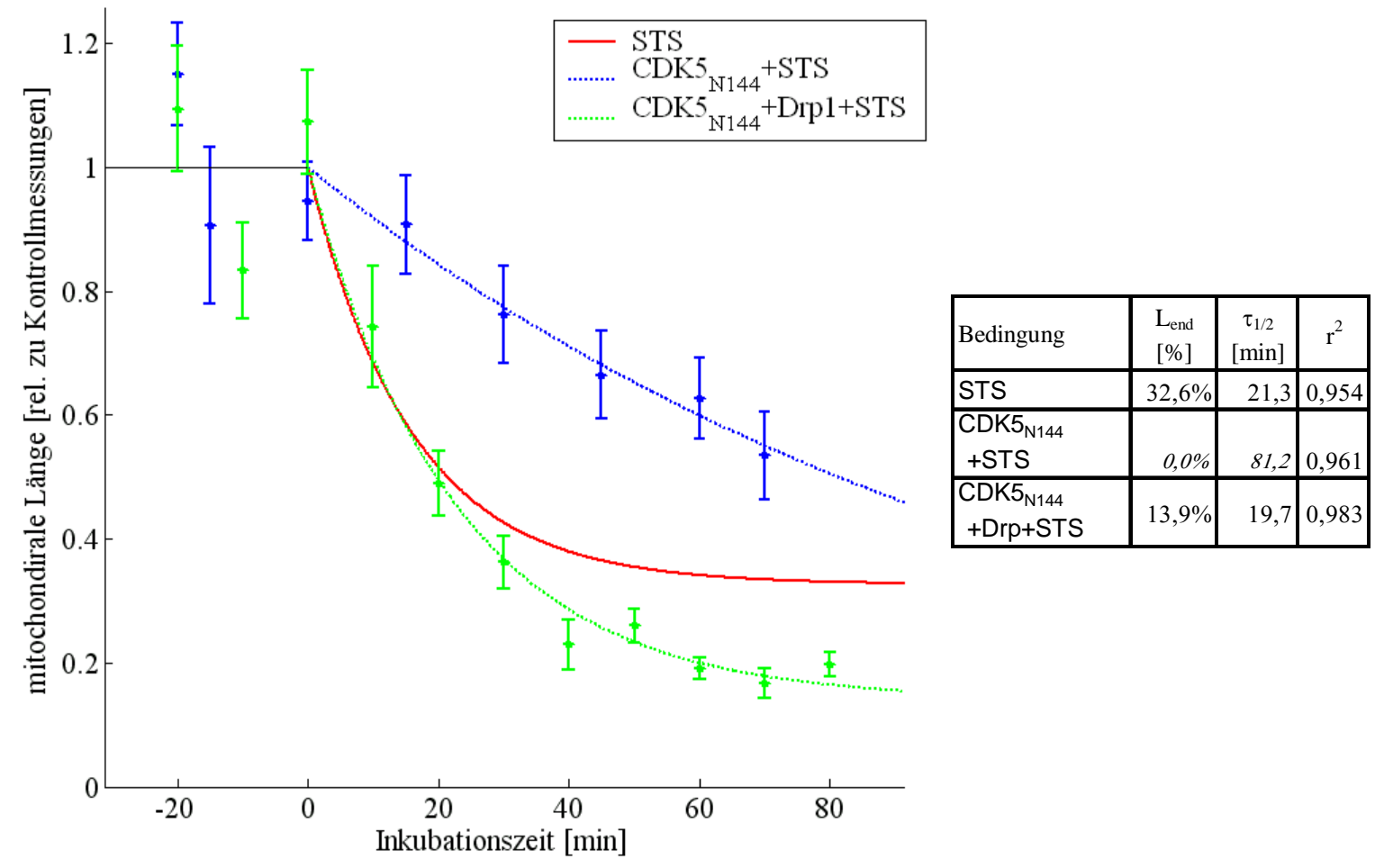

\section{Abbildung 43: Mitochondriale Fragmentation bei $\mathrm{CDK}_{\mathrm{N}_{144}}$ Überexpression.}

Dargestellt ist die normierte Mitochondrienlänge in Abhängigkeit von der Staurosporininkubationsdauer, nähere Beschreibungen siehe Abbildung 16. Die Messwerte mit Standardfehlern stammen von Neuronen, die mit $\mathrm{CDK}_{\mathrm{N} 144}$ alleine (blau) oder mit $\mathrm{CDK} 5_{\mathrm{N} 144}$ und Drp1 (grün) kotransfiziert sind. Die durchgezogene rote Linie gibt die genäherte Reaktion der ausschließlich mit pDsRed2-Mito transfizierten Neurone auf den Apoptosestimulus wieder, während die gestrichelten Linien den Zeitverlauf aus den dargestellten Messwerten nähern.

Die Überexpression von $\mathrm{CDK}_{\mathrm{N} 144}$ vermindert die Abnahme der mitochondrialen Länge auf die achtfache Halbwertszeit (siehe Tabelle rechts). Allerdings scheint der Zerfall der Mitochondrien letztendlich nicht völlig verhindert zu werden.

Der schützende Effekt kann allerdings durch die gleichzeitige Überexpression von Drp1 aufgehoben werden, was sich in einer deutlich verringerten Halbwertszeit wiederspiegelt. 


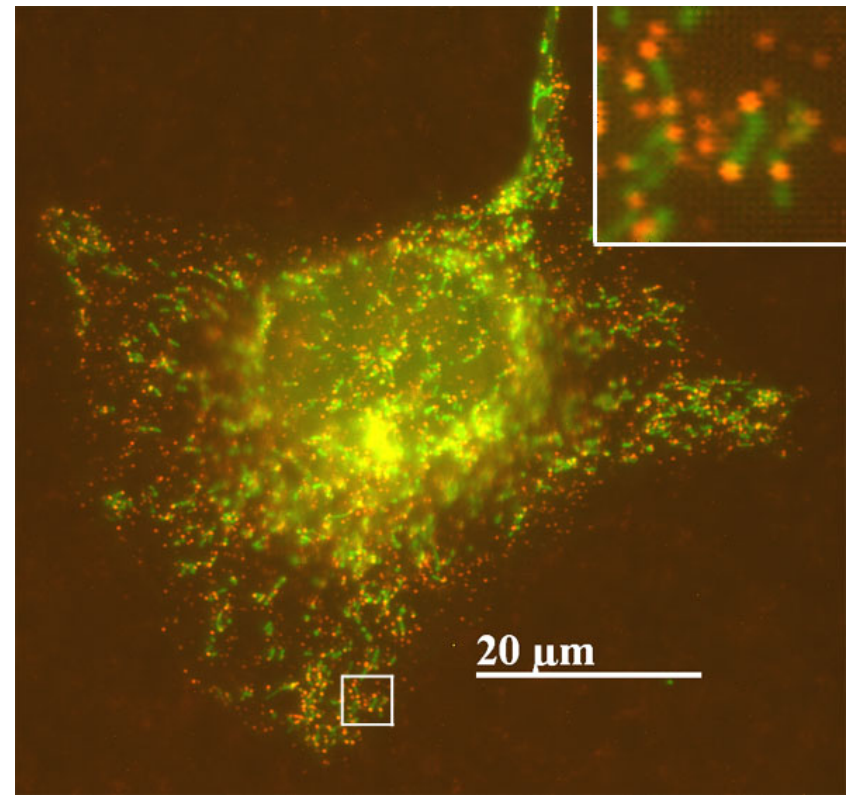

\section{Abbildung 44: Drp1 Lokalisation und CDK5 Hemmung.}

Abgebildet ist eine fluoreszenzmikroskopische Aufnahme einer $\mathrm{CDK} 5_{\mathrm{N} 144}$ überexprimierenden dCSM14.1 Zelle nach zweistündiger Behandlung mit Stauosporine $[1 \mu \mathrm{M}]$. Die Mitochondrien sind durch Transfektion mit mt-GFP markiert (grün), das endogene Drp1 ist immunzytochemisch angefärbt (rot).

Die Apoptoseinduktion führt zu einer verstärkten Kolokalisation von Drp1 mit den Mitochondrien (siehe Detailvergrößerung, vergleiche Abbildung 20 ohne Apoptoseinduktion).

Der Effekt der CDK5 Hemmung ließ sich durch Klassifizierung des mitochondrialen Fragmentierungszustandes von Neuronenpopulationen verifizieren (siehe Abbildung 45). Der innerhalb der Apoptose stattfindende Anstieg an Neuronen mit fragmentierten Mitochondrien konnte durch die Hemmung von CDK5 reduziert werden. Da bei Überexpression von Drp1 wieder der während der Apoptose übliche Zerfall der Mitochondrien auftritt scheint das endogene Drp1 durch $\mathrm{CDK}_{\mathrm{N} 144}$ an einer Aktivierung gehindert zu werden, so dass es zwar mit Fis1 an den Mitochondrien in Kontakt kommt, jedoch nicht die Abschnürung ausführen kann (siehe Abbildung 44). Überschüssiges Drp1 ist zwar auf Grund von $\mathrm{CDK}_{\mathrm{N} 144}$ Überexpression weniger aktiv, jedoch scheint der Überschuss an Drp1 die gehemmte Funktion von CDK5 auszugleichen.

Die an Neuronenpopulationen gewonnen Daten deuten allerdings im Gegensatz zu den Messungen an einzelnen Mitochondrien auf einen stärkern protektiven Effekt der CDK5 Hemmung hin, wenn auch der Anteil der Neurone mit fragmententierten Mitochondrien nur zu ca. $25 \%$ verringert bleibt. 


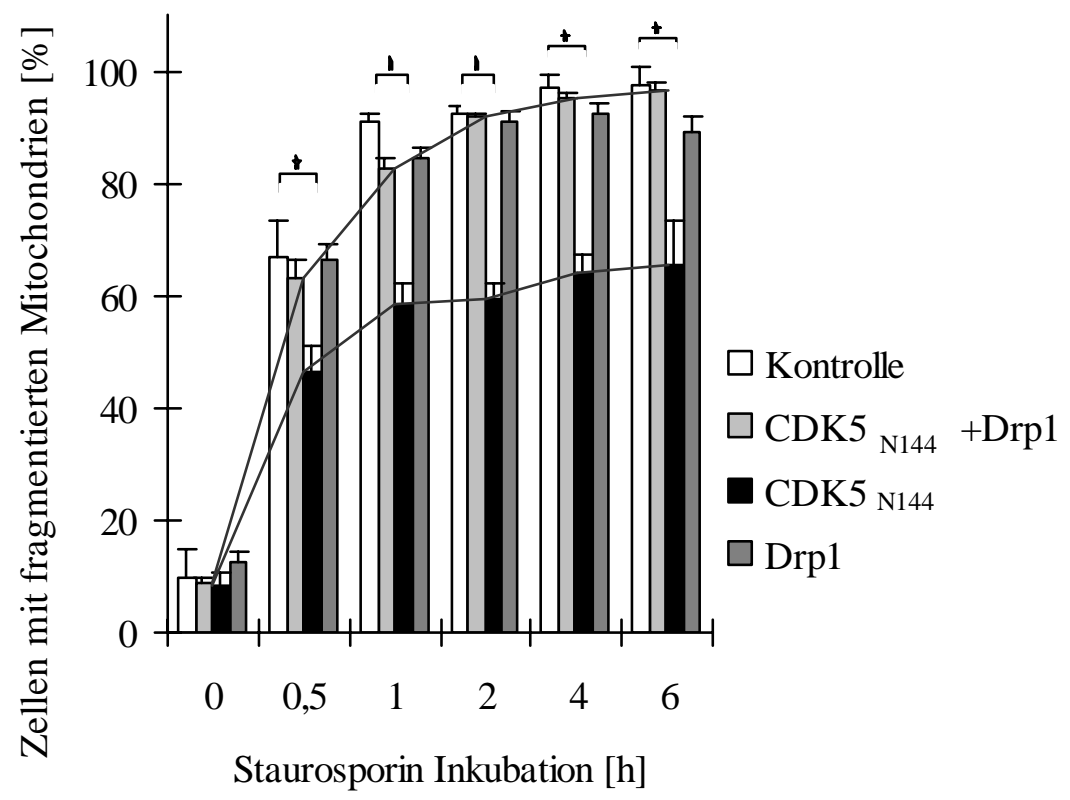

Abbildung 45: $\mathrm{CDK5}_{\mathrm{N} 144}$ und mitochondriale Fragmentation.

Die Anzahl der Neurone mit fragmentierten Mitochondrien (Abszisse) wurde nach unterschiedlichen Inkubationsdauern (Ordinate) mit $1 \mu \mathrm{M}$ Staurosporin durch Klassifizierung von 384 Neuronen (100 \%) aus drei unabhängigen Kulturen für jeden Messpunkt ermittelt. Die Mitochondrien aller Neurone waren durch pDsRed2-Mito Transfektion markiert. Außer der Kontrollbedingung (weiß) wurden Kotransfektionen mit Drp1 (dunkelgrau), $\mathrm{CDK}_{\mathrm{N} 144}$ (schwarz) und Drp1 und $\mathrm{CDK}_{\mathrm{N} 144}$ (hellgrau) untersucht.

Im Verlauf der Apoptose nimmt der Anteil der Kontrollneurone mit fragmentierten Mitochondrien zu. Die Überexpression von Drp1 resultiert nicht in einer signifikanten Veränderung in Relation zur Kontrolle. Überexpression von $\mathrm{CDK}_{\mathrm{N} 144}$ dagegen führt zu einer signifikanten Verminderung der mitochondrialen Fragmentation (Zeitverläufe durch Linien hervorgehoben, *: $\mathrm{p}<0,05$, t-Test), welche durch die gleichzeitige Expression von Drp1 allerdings aufgehoben wird. Die Expression von $\mathrm{CDK}_{\mathrm{N} 144}$ scheint bei langer Staurosporininkubation $34 \%$ der Neurone vor Zerfall der Mitochondrien zu schützen. Ohne Hemmung von CDK5 besitzen lediglich $10 \%$ der Neurone intakte Mitochondrien.

Die Expression von CDK5 fördert neben der mitochondrialen Fragmentation auch den Ablauf des programmierten Zelltodes. Bisher wurde gezeigt, dass im Apoptoseprozess die Hemmung der CDK5- Aktivität zu einer verminderten Zerfallsrate der Mitochondrien führt. Die Auswirkungen einer CDK5 Hemmung auf den Statuts der gesamten Zelle wurde wiederum durch Bestimmung der Cytochrom c Freisetzung und dem Anteil apoptotischer Kerne untersucht.

Überexpression von CDK5 führt neben der beschriebenen verminderten Zerteilungsrate der Mitochondrien auch zu einer verminderten Cytochrom c Freisetzung aus den Mitochondrien (siehe Abbildung 46). Dies führt vermutlich zu einer geringeren Effektivität der Apoptosekaskade was sich in der verminderten Zellkernfragmentation äußert (siehe Abbildung 47). 
Die durch Überexpression von CDK5 nachgewiesenen Effekte können bei Apoptoseinduktion durch Expression der dominant negativen Mutante gehemmt werden.

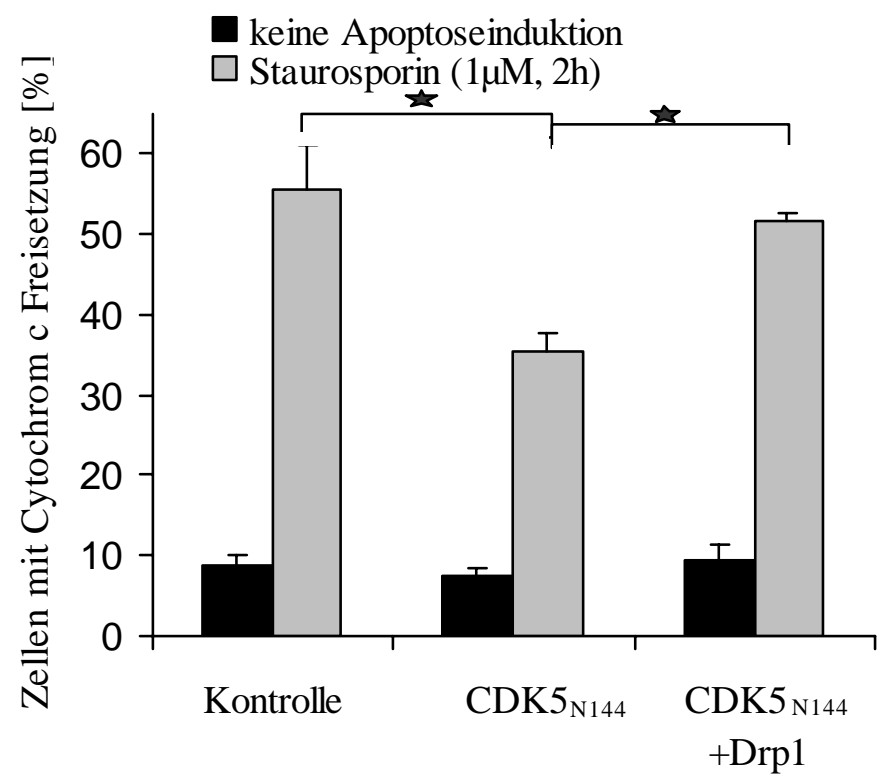

Abbildung 46: Cytochrom c Freisetzung unter $\mathrm{CDK}_{\mathrm{N} 144}$ Überexpression.

Dargestellt ist der Anteil der Neurone die ein diffuses Cytochrom c Verteilungsmuster (Abszisse) mit (grau) und ohne Apoptoseinduktion (schwarz) zeigen. Jeder Messwert resultiert aus der Klassifizierung von 384 Neuronen (100 \%) aus drei unabhängigen Kulturen. Die Neurone exprimierten pDsRed2-Mito (Kontrolle) und zusätzlich $\mathrm{CDK}_{\mathrm{N} 144}$ bzw. CDK5 ${ }_{\mathrm{N} 144}$ und Drp1.

Ohne Apoptoseinduktion (schwarz) ist der Anteil an Neuronen mit diffusem Cytochrom c Verteilungsmuster durch CDK5 ${ }_{\mathrm{N} 144} /$ Drp1 Überexpression nicht beeinflussbar. Diese Cytochrom c Freisetzung betrifft weniger als $10 \%$ der Neurone und ist vermutlich durch die nicht optimalen Kulturbedingungen im Experiment verursacht. Die zweistündige Staurosporininkubation (grau) induziert einen Anstieg der Kontrollneurone mit zellulärer Cytochrom c Freisetzung. Dieser Anstieg wird durch Überexpression von $\mathrm{CDK}_{\mathrm{N} 144}$ signifikant (t-Test, *: $\mathrm{p}<0,05)$ vermindert. Bei gleichzeitiger Expression von Drp1 zeigt sich wieder der Cytochrom c Freisetzungsgrad der unbehandelten Neurone.

Die Apoptoserate kann somit durch die Überexpression von $\mathrm{CDK} 5_{\mathrm{N} 144}$ reduziert werden, was CDK5 als notwendiges Protein für die Apoptose bestätigen. CDK5 scheint über Modifikationen an den Mitochondrien mit der Apoptosekaskade zu interagieren, da die Hemmung von CDK5 bereits in einer verminderten Cytochrom c Freisetzung resultiert, die verminderte Zellkernfragmentation kann als Folgeresultat der verminderten Cytochrom c Freisetzung interpretiert werden. Die vermehrte Zerteilung der Mitochondrien ist wie die Cytochrom c Freisetzung ein dem Zerfall der Kerne zeitlich vorgelagerter Prozess innerhalb der Apoptose (vergleiche Abbildung 45 und Abbildung 47). Ebenso wie für die Mitochondrien wird auch der neuroprotektive Effekt von $\mathrm{CDK}_{\mathrm{N} 144}$ auf die nucleäre Fragmentation durch Überexpression von Drp1 aufgehoben (siehe Abbildung 47). Der wieder verstärkte mitochondriale Zerfall bei Drp1 Expression geht ebenfalls mit einer fast völligen Anhebung der Cytochrom c Freisetzung auf das normal apoptotische Niveau einher (siehe Abbildung 46). 


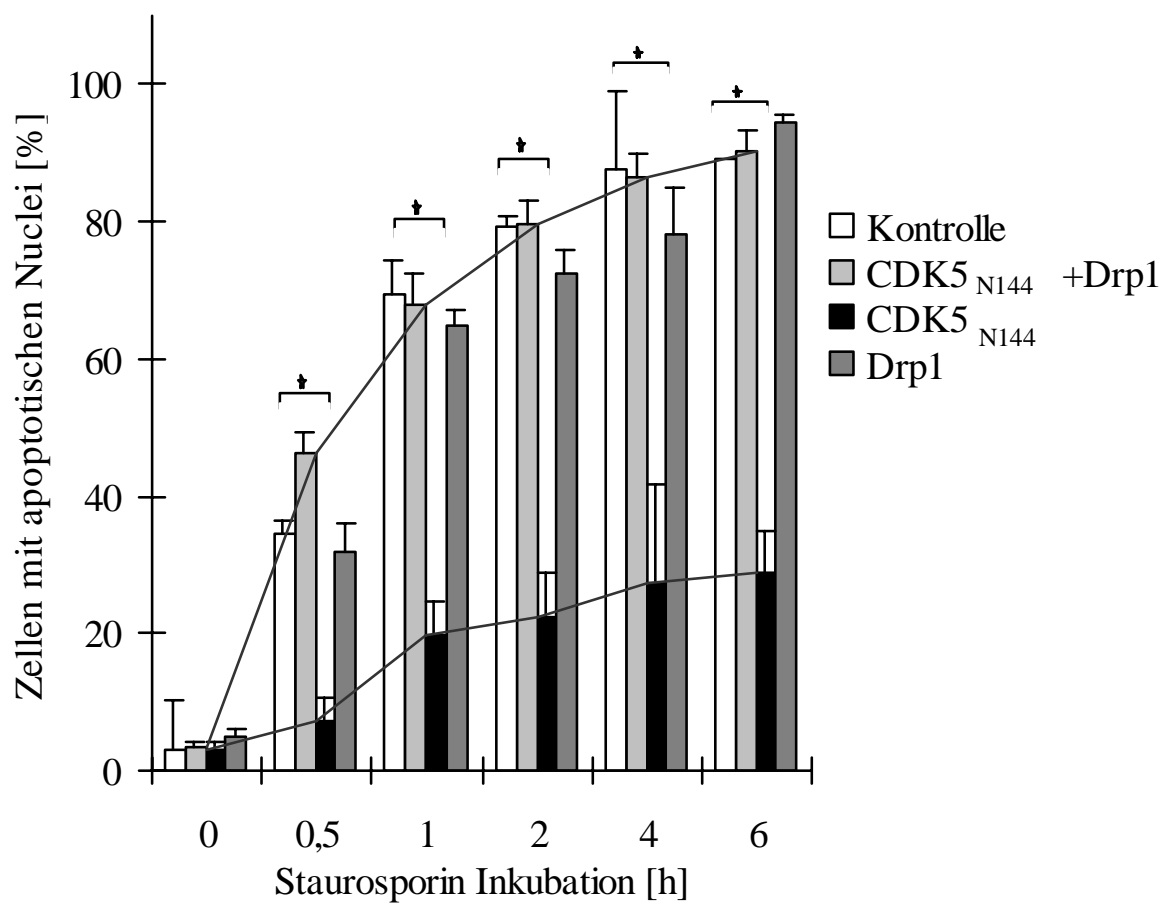

\section{Abbildung 47: Neuroprotektiver Effekt von $\mathrm{CDK}_{\mathrm{N} 144}$.}

Im obigen Diagramm wurden nach unterschiedlichen Inkubationsdauern (Ordinate) mit $1 \mu \mathrm{M}$ Staurosporin je Messpunkt 384 Neurone (100 \%) aus drei unabhängigen Kulturen nach ihrem Apoptosestatus (apoptotische Zellkerne, Abszisse) klassifiziert. Alle dCSM14.1 Neurone wurden einer Transfektion (pDsRed2-Mito) unterzogen, je nach Versuchsbedingung erfolgten Kotransfektionen mit Drp1 (dunkelgrau), CDK5 ${ }_{\mathrm{N} 144}$ (schwarz) oder $\mathrm{CDK}_{\mathrm{N} 144} / \mathrm{Drp} 1$ (hellgrau). Im Verlauf der induzierten Apoptose nimmt der Anteil der Kontrollneurone (weiß) mit apoptotischen Nuclei zu. Überexpression von $\mathrm{CDK}_{\mathrm{N} 144}$ führt zu einer signifikanten Verminderung der apoptotischen Neurone (Zeitverläufe durch Linien hervorgehoben, *: p<0,05, t-Test). Der Anteil apoptotischer Neurone scheint ein Plateau bei $29 \%$ der Neurone zu erreichen. Dieser neuroprotektive Effekt von CDK5 $5_{\mathrm{N} 144}$ wird durch die parallele Überexpression von Drp1 eliminiert. Die Expression von Drp1 alleine führt nicht zu einer vermehrten Apoptose, so dass die Aufhebung nicht auf die alleinige Expression von Drp1 zurückzuführen ist.

\subsection{Hemmung von CDK5 durch Indolinon A}

Zur Bestätigung der mit $\mathrm{CDK}_{\mathrm{N} 144}$ erhobenen Effekte wurde CDK5 zusätzlich pharmakologisch inhibiert. Dafür wurde die Substanz Indolinon A ( $\left.\mathrm{IC}_{50}: 5 \mathrm{nM}\right)$ verwendet, die sehr spezifisch für CDK5 ist und erst ab hohen Konzentrationen über $1 \mu \mathrm{M}$ andere Zelltod fördernde Kinasen wie z.B. JNK beeinflusst (Weishaupt et al. 2003). Indolinon A wurde von Boeringer Ingelheim KG produziert. Es ist bekannt, dass Indolinon A mit ATP um die Bindungsstelle von CDK5 konkurriert (Weishaupt et al. 2003). Durch Indolinon A können die Resultate bei Verwendung einer dominant negativen Mutante verifiziert und unter Umständen präzisiert werden. Die Hemmung von CDK5 durch die Behandlung der Neurone mit Indolinon A resultierte in einer verminderten mitochondrialen Fragmentation (siehe Abbildung 48). Es handelt sich wiederum um eine Verminderung der mitochondrialen Zerteilungsrate. 


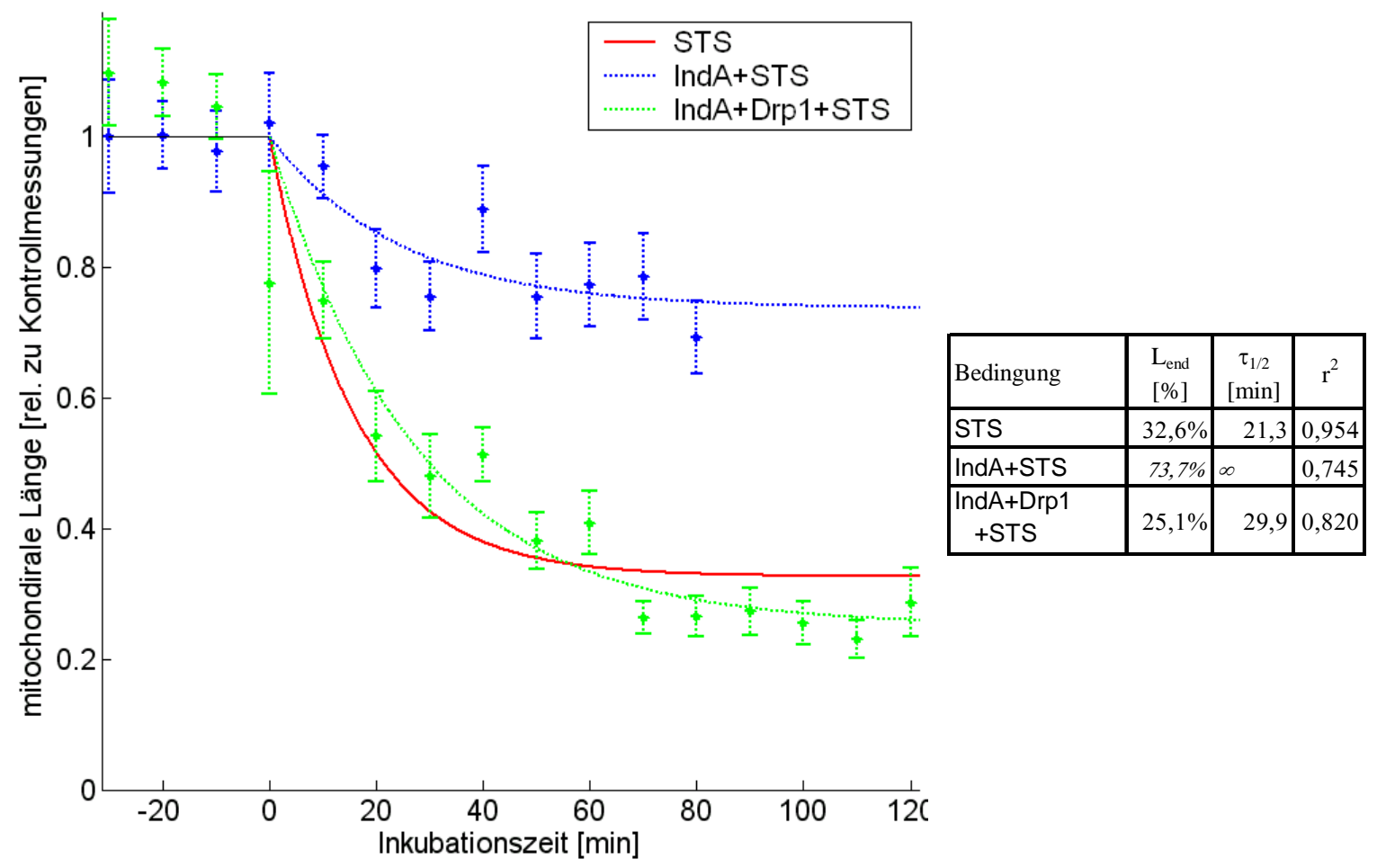

\section{Abbildung 48: Apoptotische Fragmentation der Mitochondrien bei Indolinon A Behandlung.}

Dargestellt ist die normierte Mitochondrienlänge in Abhängigkeit von der Staurosporininkubationsdauer, nähere Details siehe Abbildung 16. Die Messwerte mit Standardfehlern geben die mitochondriale Länge von Neuronen, die mit Drp1 kotransfiziert (grün) oder nur mit pDsRed2-mito transfiziert (blau) sind. Die Neurone wurden 12 Stunden vor Aufnahmebeginn mit Indolinon A behandelt. Die durchgezogene rote Linie gibt die genäherte Reaktion unbehandelter Neurone, die gestrichelten Linien Indolinon A behandelter Zellen wieder.

Die Behandlung mit dem chemischen CDK5 Inhibitor Indolinon A vergrößert die Halbwertszeit der mitochondrialen Fragmentationsgeschwindigkeit stark (vergleiche Tabelle). Der Effekt der Hemmung von CDK5 kann durch die gleichzeitige Überexpression von Drp1 aufgehoben werden (grün). Durch die gleichzeitige Expression von Drp1 stellt sich wieder ein exponentieller Zerfall der Mitochondrien ein (vergleiche Tabelle).

Die Klassifizierung nach dem Fragmentationsgrad zeigt eine Plateaubildung, so dass von einem langanhaltenden neuroprotektiven Effekt ausgegangen werden kann (siehe Abbildung 49). In beiden Experimenten wird der Indolinon A induzierte Effekt durch Überexpression von Drp1 vermindert. Beachtenswert ist allerdings, dass Überexpression von Drp1 in apoptotischen Neuronen zu keiner verstärkten mitochondrialen Zerteilung führt (siehe Abbildung 25 und Abbildung 49). 


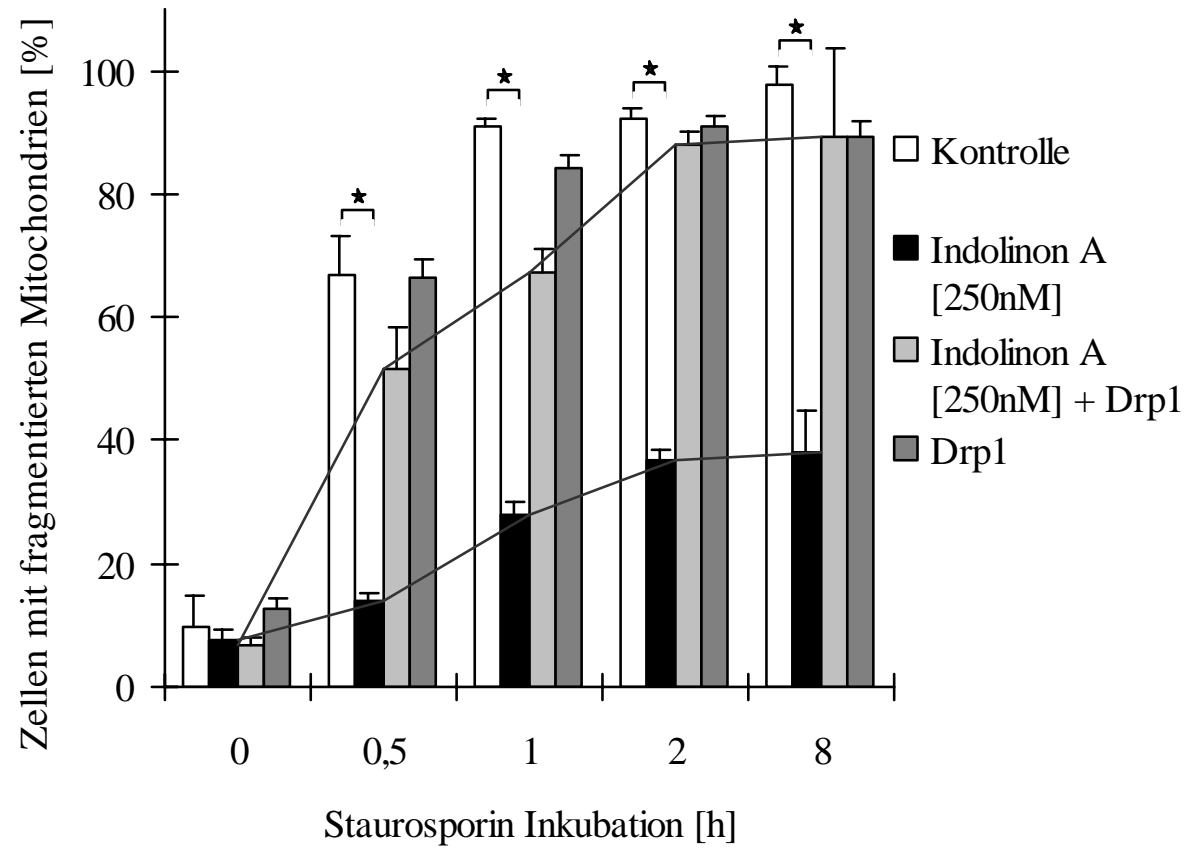

Abbildung 49: Indolinon A und Fragmentation der Mitochondrien.

Der Anteil der Neurone mit fragmentierten Mitochondrien (Abszisse) wurde nach unterschiedlichen Inkubationsdauern (Ordinate) mit $1 \mu \mathrm{M}$ Staurosporin durch Klassifizierung von je 384 Neuronen (100 \%) aus drei unabhängigen Kulturen für jeden Messpunkt ermittelt. Die Mitochondrien aller Neurone waren durch pDsRed2-Mito Transfektion markiert. Neben unbehandelten (weiß, Kontrolle) und Drp1 transfizierten Neuronen (dunkelgrau) wurde der Effekt der Indolinon A Behandlung (siehe Kapitel 2.4.1) mit (hellgrau) und ohne (schwarz) Drp1 Kotransfektion untersucht.

Im Verlauf der Apoptose nimmt der Anteil der Kontrollneurone mit fragmentierten Mitochondrien zu. Die Überexpression von Drp1 resultiert nicht in einer signifikanten Veränderung dieses Verhaltens.

Die Behandlung mit Indolinon A führt zu einem signifikant niedrigeren Fragmentationsanteil (38 \% statt $97 \%$ ) (Zeitverläufe durch Linien hervorgehoben, *: $\mathrm{p}<0,05$, t- Test), welcher durch die gleichzeitige Expression von Drp1 aufgehoben wird.

Die bekannten Effekte der $\mathrm{CDK} 5_{\mathrm{N} 144}$ Überexpression auf die Apoptose können mit Indolinon A verifiziert werden (siehe Abbildung 50 und Abbildung 51). Die Behandlung der Neurone mit Indolinon A zeigt einen vergleichbaren neuroprotektiven Effekt. Bei gleichzeitiger Überexpression von Drp1 konnte der neuroprotektive Effekt ebenfalls nicht aufrecht erhalten werden, die Neurone waren nicht mehr vor der Apoptose geschützt.

Die starke Ähnlichkeit der Ergebnisse bei unterschiedlicher Beeinflussung von CDK5 (Indolinon A und $\mathrm{CDK}_{\mathrm{N} 144}$ ) bestätigt die Funktion von CDK5 als ein regulatorisches Protein während der apoptotischen mitochondrialen Zerteilung und neuronalen Apoptose. Allerdings ist beachtenswert, dass Indolinon A, obwohl es nach Herstellerangaben spezifisch CDK5 direkt inaktiviert, ebenfalls durch Drp1 Überexpression abgeschwächt werden kann. 


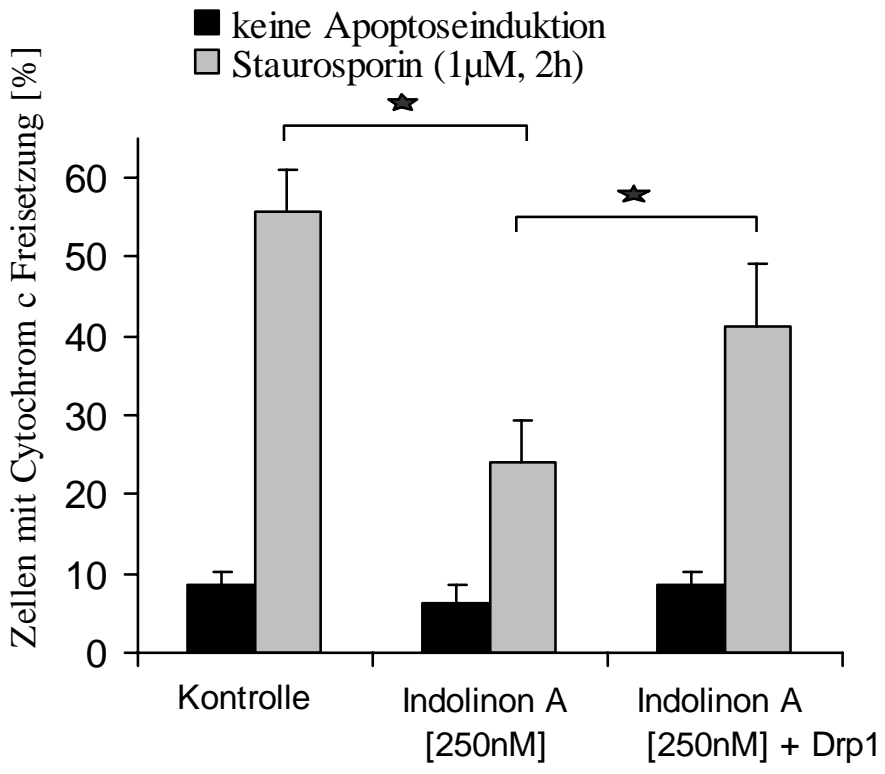

\section{Abbildung 50: Cytochrom c Freisetzung unter Indolinon A Behandlung.}

Dargestellt ist der Anteil der Neurone die ein diffuses Cytochrom c Verteilungsmuster (Abszisse) mit (grau) und ohne Apoptoseinduktion (schwarz) zeigen. Jeder Messwert resultiert aus der Klassifizierung von 384 Neuronen (100 \%) aus drei unabhängigen Kulturen. Die Neurone exprimierten pDsRed2-Mito (Kontrolle) und zusätzlich Drp1. Der Effekt der Indolinon A Behandlung wurde sowohl in Drp1 exprimierenden Zellen wie auch nicht Drp1 exprimierenden Zellen untersucht.

Ohne Apoptoseinduktion (schwarz) ist der Anteil an Neuronen mit diffusem Cytochrom c Verteilungsmuster durch Indolinon A Behandlung bzw. zusätzlicher Drp1 Überexpression nicht beeinflussbar. Diese Cytochrom c Freisetzung betrifft weniger als $9 \%$ der Neurone und ist vermutlich durch die nicht optimalen Kulturbedingungen im Experiment verursacht. Die zweistündige Staurosporininkubation (grau) induziert einen Anstieg der Kontrollneurone mit zellulärer Cytochrom c Freisetzung. Dieser Anstieg wird durch die Behandlung mit Indolinon A signifikant (t-Test, *: $\mathrm{p}<0,05)$ vermindert. Bei gleichzeitiger Expression von Drp1 wird der Effekt der CDK5 Inhibition auf die Cytochrom c Freisetzung teilweise aufgehoben. 


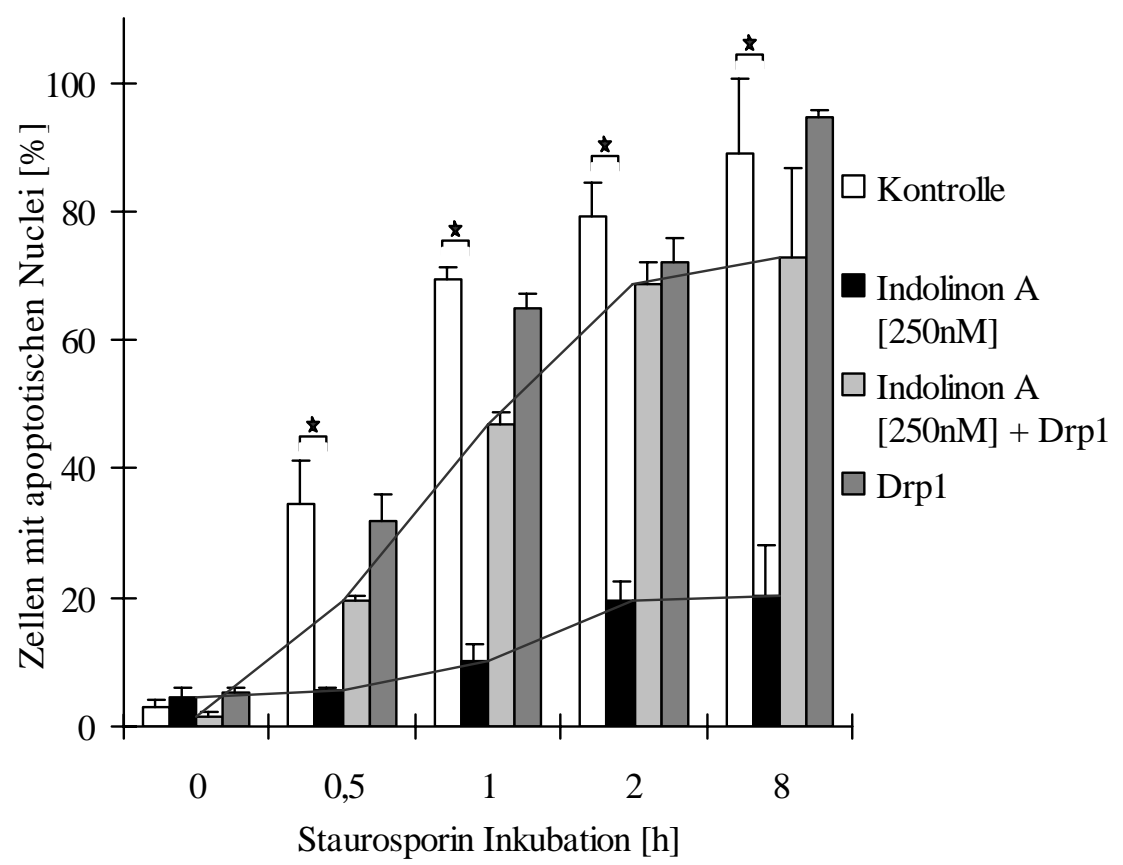

\section{Abbildung 51: Indolinon A und Apoptose.}

Im obigen Diagramm wurden nach unterschiedlichen Inkubationsdauern (Ordinate) mit $1 \mu \mathrm{M}$ Staurosporin je Messpunkt 384 Neurone (100 \%) aus drei unabhängigen Kulturen nach ihrem Apoptosestatus (apoptotische Zellkerne, Abszisse) klassifiziert. Alle dCSM14.1 Neurone wurden einer Transfektion (pDsRed2-Mito) unterzogen. Als Kontrollen wurden Neurone genutzt, die entweder pDsRed2-Mito (weiß) oder zusätzlich Drp1 (dunkelgrau) exprimierten. Der Effekt der Indolinon A Behandlung wurde für beide Bedingungen untersucht (schwarz und hellgrau). Im Verlauf der Apoptose nimmt der Anteil der Kontrollneurone (weiß) mit apoptotischen Nuclei zu. Die Überexpression von Drp1 veränderte die Apoptoserate nicht signifikant. Inkubation mit Indolinon A führt dagegen zu einer signifikanten Verminderung der apoptotischen Neurone (Zeitverläufe durch Linien hervorgehoben, *: $\mathrm{p}<0,05$, t-Test). Die durch die Behandlung mit Indolinon A verringerte Apoptoserate wird durch die parallele Überexpression von Drp1 wieder etwas erhöht, erreicht allerdings nicht ganz das Ausgangsniveau (Kontrolle). Drp1 exprimierende Neurone zeigen geringe Veränderungen der Apoptosereaktion bei Zugabe von Indolinon A.

\subsection{Herabregulation von CDK5 durch siRNS}

Die CDK5 Hemmung erfolgte bisher durch eine dominant negative Mutante von CDK5 und einen pharmakologischen CDK5 Inhibitor. Um mögliche Artefakte auszuschließen, die bei Hemmung der endogenen CDK5's auftreten könnten (z.B. Co-Hemmung anderer Kinasen), wurde das CDK5 Proteinexpressionslevel zusätzlich durch siRNS Transfektionen herabreguliert (siehe Abbildung 52). Das Verfahren der siRNS Transfektion ist wesentlich spezifischer für CDK5 und schließt weitere CDK5 beeinflusste Effekte gänzlich aus, da CDK5 bereits endogen in geringeren Maßen translatiert wird. Weder die Morphologie der Zelle noch der Mitochondrien wurde durch Transfektion mit siRNS gegen CDK5 verändert (siehe Abbildung 52), so dass die Neurone ohne Apoptoseinduktion eine natürliche Morphologie zeigten. 

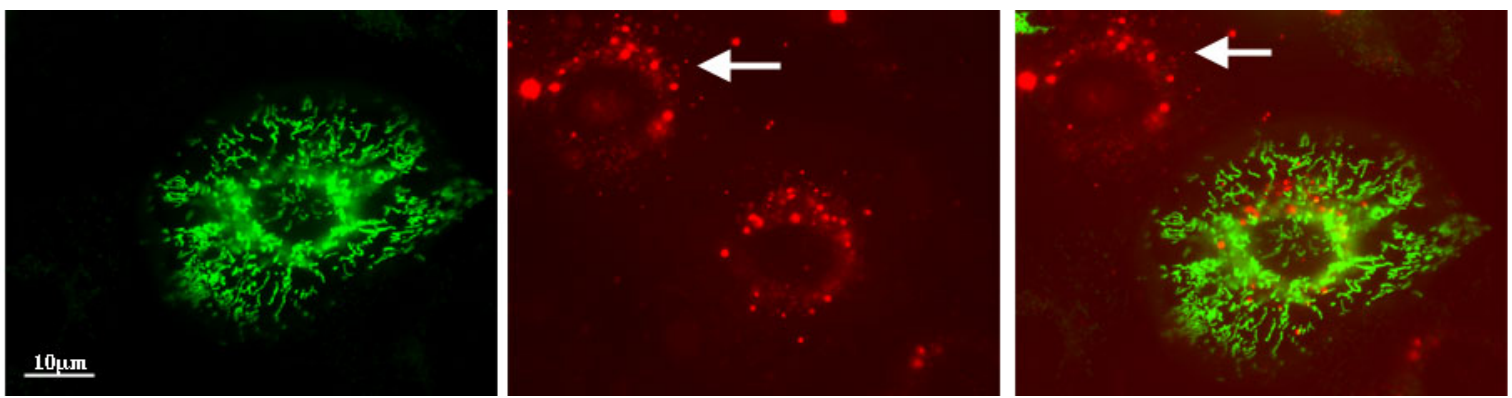

\section{Abbildung 52: siRNS Transfektionen.}

Dargestellt sind fluoreszenzmikroskopische Aufnahmen einer Zelle, deren Mitochondrien durch mt-GFP markiert sind (links, grün). Die siRNS gegen CDK5 ist mit Cy3 markiert (Mitte, rot). Rechts ist die Überlagerung der beiden Aufnahmen dargestellt.

Nicht alle Neurone sind mit mt-GFP und siRNS kotransfiziert (Pfeil). Die transfizierten Neurone zeigen keine morphologischen Anomalien. Die Fluoreszenz-markierte siRNS war im gesamten Zytoplasma punktiert und diffus nachweisbar. Allerdings war die Transfektionseffizienz gering, für die weiteren Experimente wurden ausschließlich Neurone verwendet, die sowohl mt-GFP und siRNS exprimierten.

Die Transfektion mit siRNS gegen CDK5 erwies sich als erfolgreich. Densiometrische Auswertungen von Western Blot Analysen ergaben eine Reduktion des CDK5 Expressionslevels um 62 \% (siehe Abbildung 53). Die Herabregulierung von CDK5 auf mRNS Ebene resultierte ebenso wie die anderen CDK5 Inhibitionsformen in einer verminderten Fragmentation der Mitochondrien und Zellkerne (siehe Abbildung 54 und Abbildung 55) während der Apoptose. Der Effekt ist mit siRNS sogar deutlich stärker als bei den vorangegangenen Experimenten. Die Daten der siRNS Transfektionen bestätigen, dass CDK5 ein Regulator der mitochondrialen Zerteilung ist.

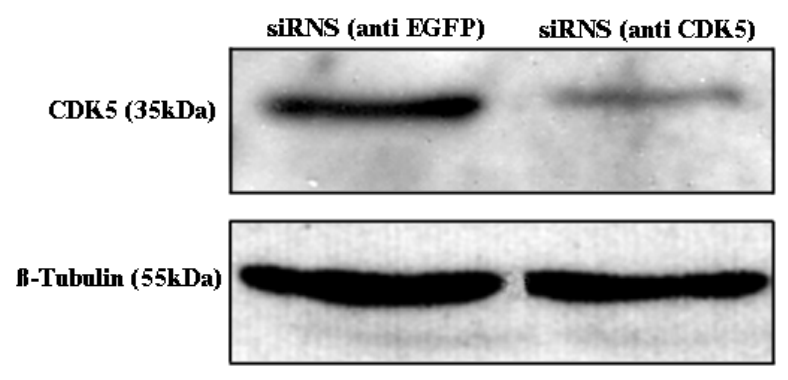

Abbildung 53: CDK5 Proteinexpression bei siRNS.

Abgebildet ist eine Western Blot Analyse der CDK5 Expression nach siRNS Transfektionen sowie die dazuge-

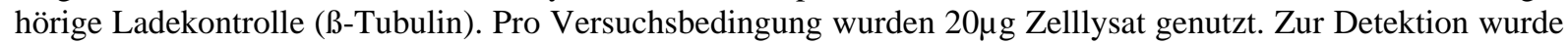
ein polyklonaler Antikörper gegen CDK5 (siehe Tabelle 6) verwendet, welcher eine CDK5-Bande wie erwartet bei $35 \mathrm{kDa}$ erkennt.

Die Transfektion mit siRNS (anti CDK5) regulierte das CDK5 Proteinlevel auf $38 \%$ der Kontrolltransfektion (anti EGFP) herab (densiometrische Auswertung, siehe Kapitel 2.3.4). 


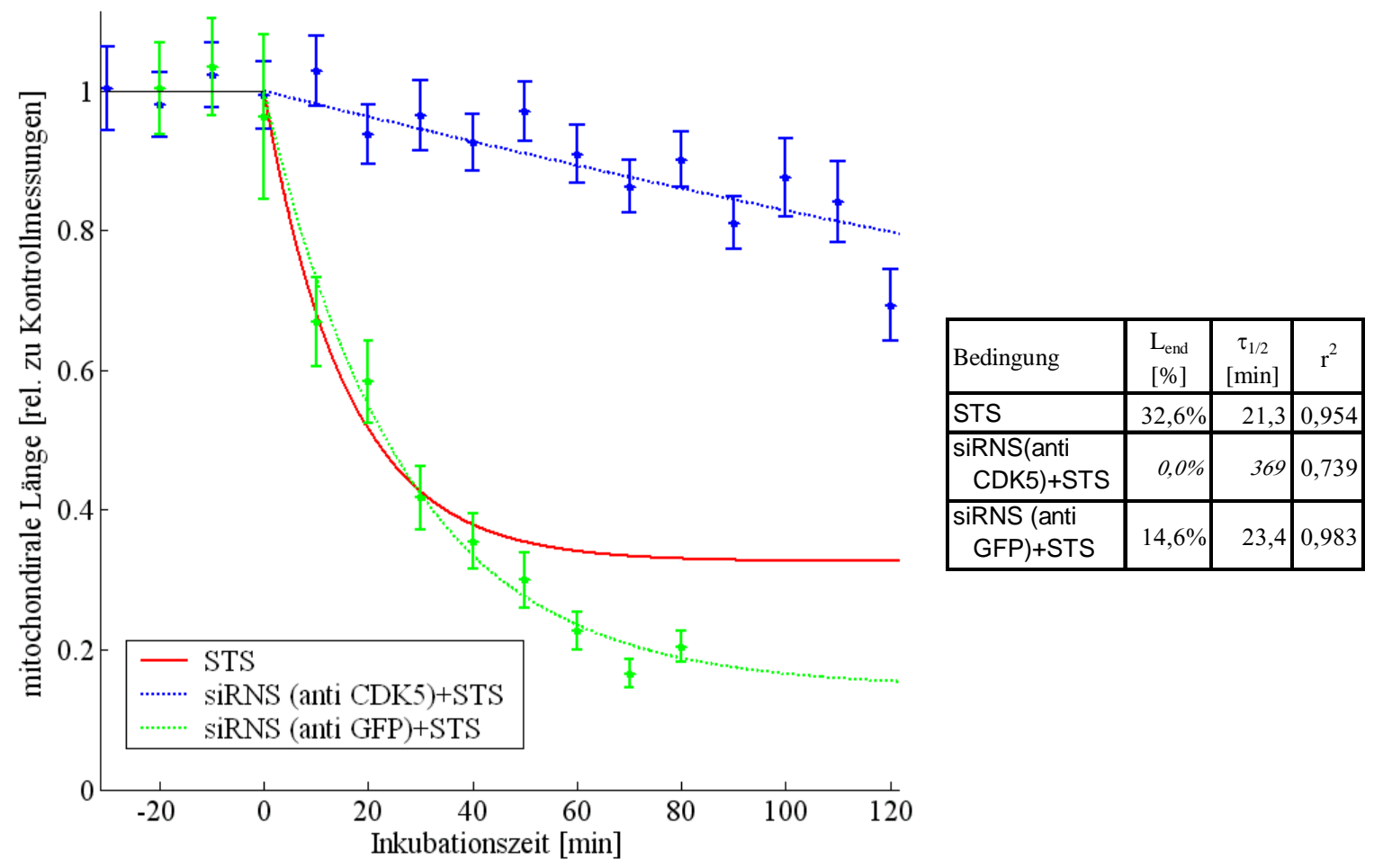

Abbildung 54: Apoptotische mitochondriale Fragmentation in Abwesenheit von CDK5.

Dargestellt ist die normierte Mitochondrienlänge in Abhängigkeit von der Staurosporininkubationsdauer, weitere Erläuterung siehe Abbildung 16. Die Neurone wurden mit 33nM anti GFP siRNS (grün) oder mit 33nM anti CDK5 siRNS (blau) transfiziert. Die durchgezogene rote Linie gibt die genäherte Reaktion der unbehandelten Neurone auf den Apoptosestimulus, die gestrichelten Linien geben die genäherten Reaktionen der siRNS transfizierten Neurone wieder.

Die Expression der anti CDK5 siRNS erhöht die Halbwertzeit der mitochondrialen Fragmentation auf das 17-fache, wohingegen die Halbwertszeit bei Expression von anti GFP siRNS nur unwesentlich beeinflusst wird (siehe Tabelle).
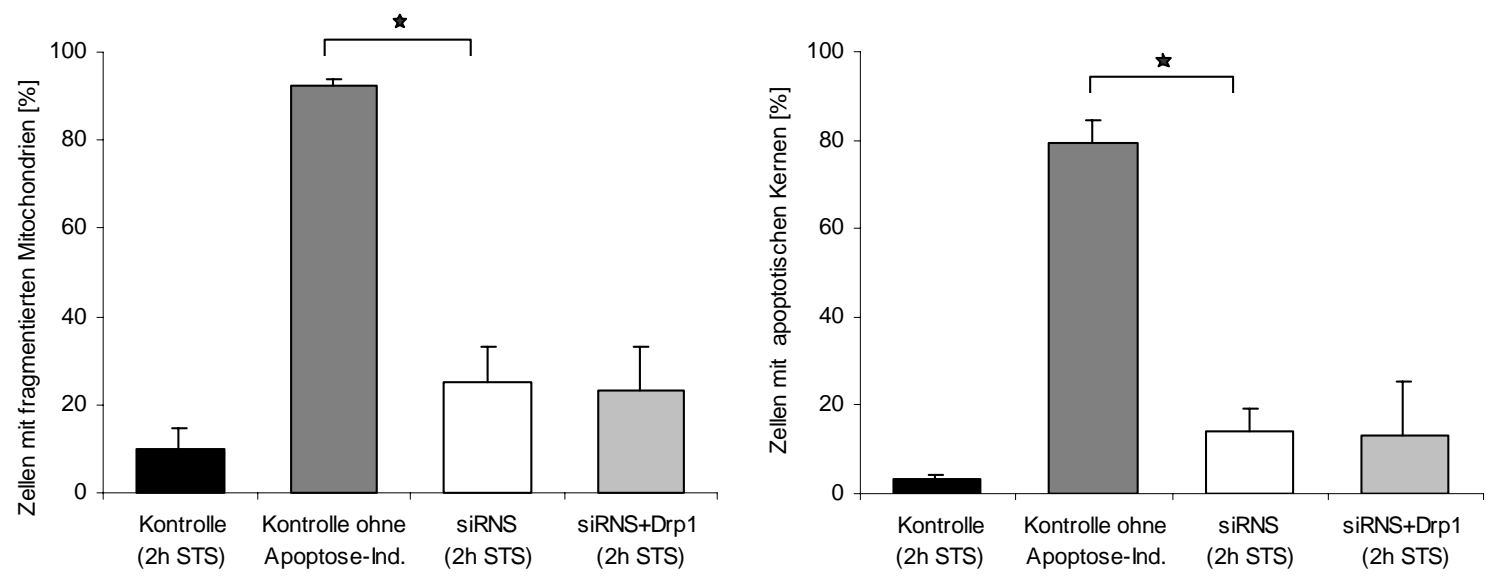

\section{Abbildung 55: siRNS und der Zerfall der Zellorganelle.}

Rechts ist der Anteil apoptotischer Neurone bei siRNS (anti-CDK5) Transfektion mit (hellgrau) und ohne (weiß) kotransfiziertem Drp1 dargestellt. Links ist der Anteil der Neurone dargestellt, die unter gleichen Bedingungen zerfallene Mitochondrien aufzeigen. Beide Diagramme haben zur Beurteilung der Effekte eine Kontrollmessung nicht siRNS exprimierender Neurone mit (schwarz) und ohne Apoptoseinduktion (dunkelgrau).

Die Herabregulation von CDK5 durch siRNS weist einen signifikant verminderten Anstieg an Neuronen mit fragmentierten Mitochondrien und apoptotischen Zellkernen auf (t-Test, *: $\mathrm{p}<0,05)$, der durch die parallele Überexpression von Drp1 nicht aufgehoben wird. 


\subsection{Primäre Mittelhirnneurone}

Die bisher vorgestellten Daten wurden an einer immortalen Zelllinie (dCSM14.1 Neurone) erhoben. Diese Neurone sind auf Grund ihres großen Zytoplasmas und der hohen Transfektionseffizienz prädestiniert für Beobachtung intrazellulärer Prozesse mit hoher räumlicher Auflösung. Um mögliche Artefakte auszuschließen, wurden die grundlegendsten Experimente jedoch an Kulturen primärer Mittelhirnneurone wiederholt und verifiziert.

Die Mittelhirnneurone entsprechen weitgehend den Neuronen im intakten Organismus und sind im Gegensatz zu den Neuronen der dCSM14.1 Zelllinie direkt aus dem Gehirn isoliert (siehe Kapitel 2.1.2) und genetisch nicht modifiziert, sie unterliegen allerdings auch Einflüssen aus ihrer Kultivierung. dCSM14.1 Neurone und primäre Mittelhirnneurone gehören zu den dopaminergen Neuronen. Diese Neurone sind besonders relevant, um Rückschlüsse auf verschiedene Krankheitsbilder zu ziehen.
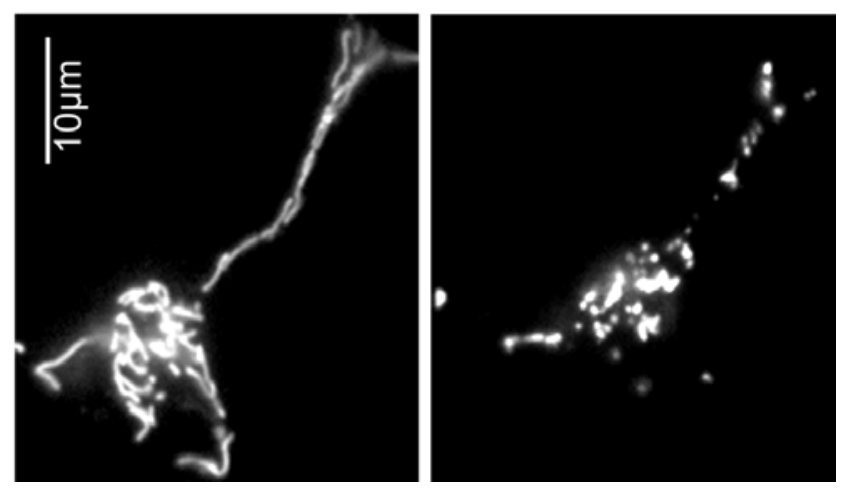

Abbildung 56: Primäre Mittelhirnneurone vor und nach Apoptoseinduktion.

Dargestellt sind zwei fluoreszenzmikroskopische Aufnahmen der Mitochondrien von einem pDsRed2-Mito transfizierten Neuron. Das Neuron stammt aus dem Mittelhirn einer embryonalen Ratte (E14) und war zum Zeitpunkt der Aufnahme zwei Tage in Kultur (siehe Kapitel 2.1.2). Nach der Bildaufnahme links wurde die Zelle für $2 \mathrm{~h}$ mit $1 \mu \mathrm{M}$ Staurosporin inkubiert, die apoptotischen Veränderungen der Mitochondrien sind rechts sichtbar. Die Mitochondrien der unbehandelten Zelle (links) besitzen eine elongierte Form mit einer durchschnittlichen Länge von 5,7 $\mu \mathrm{m} \pm 1,8 \mu \mathrm{m}$. Die Messwerte und Standardfehler ermitteln sich aus der Vermessung von je zehn Mitochondrien fünf einzelner fixierter primärer Mittelhirnneurone. Nach Apoptoseinduktion (rechts) sind die Mitochondrien von kleiner runder Form und das Zellvolumen ist verringert.

Die Mitochondrien der primären Mittelhirnneurone wiesen eine elongierte Form auf, die sich während der Apoptose analog zu den Mitochondrien der dCSM14.1 Neurone veränderte (siehe Abbildung 56). Im Gegensatz zu den Mitochondrien der dCSM14.1 Neurone befanden sich die Mitochondrienfragmente der primären Mittelhirnneurone während der Apoptose auch in den Fortsätzen. 


\subsubsection{Zeitverlauf des mitochondrialen Zerfalls}

Die Formveränderung der Mitochondrien nach Apoptoseinduktion basierte ebenfalls auf einer erhöhten Zerteilungsrate (siehe Abbildung 57). Infolgedessen wurde wiederum die Mitochondrienlänge als Parameter für die mitochondriale Formveränderung genutzt. Die Vermessung der Mitochondrienlänge zu verschiedenen Zeitpunkten der Apoptose ergab ein den dCSM14.1 Neuronen ähnlichen exponentiellen Zerfall (siehe Abbildung 58), der annähernd die gleiche Zerfallsgeschwindigkeit aufweist. Die Extrapolation des Zerfalls in primären Mittelhirnneuronen zeigt eine kürzere Endlänge der Mitochondrien als in dCSM14.1 Neuronen.

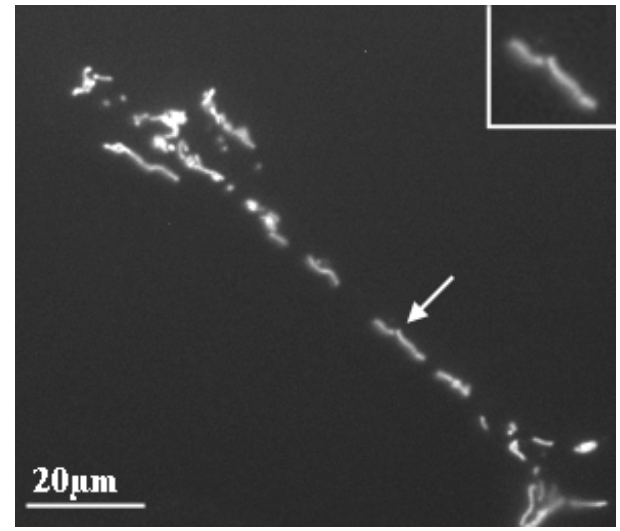

$0 \mathrm{~min}$

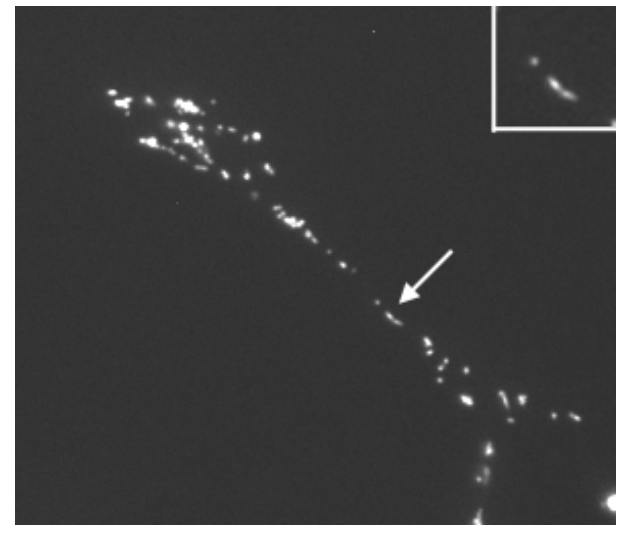

$60 \min$

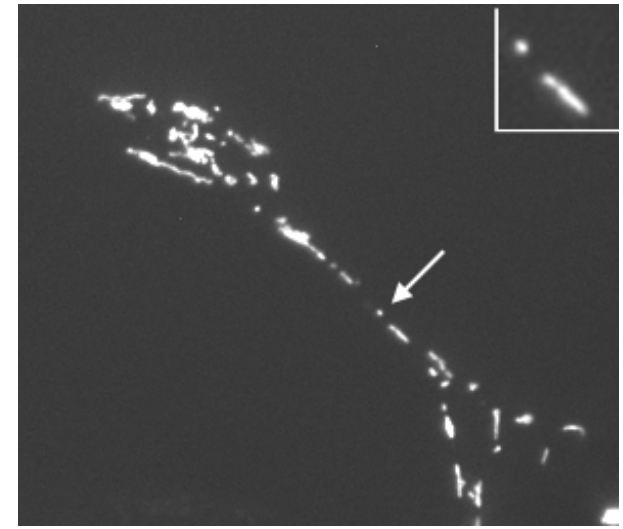

$30 \min$

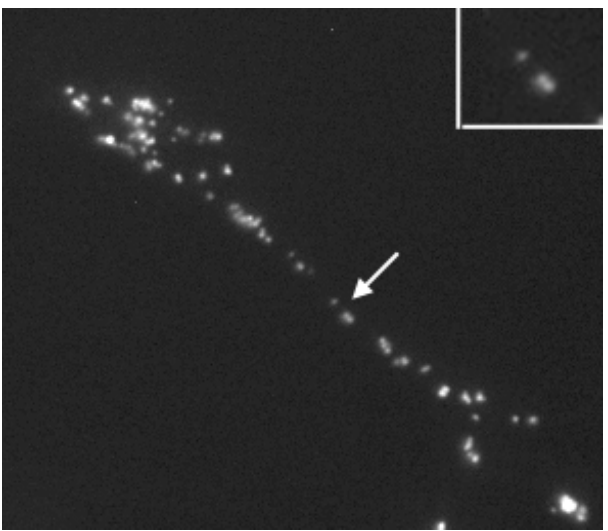

$90 \min$

\section{Abbildung 57: Morphologische Veränderung der Mitochondrien während der Apoptose.}

Dargestellt sind fluoreszenzmikroskopische Aufnahmen der Mitochondrien eines pDsRed2-Mito transfizierten primären Mittelhirnneurons, welches sich seit zwei Tagen in Kultur befand. Die Zeitangaben geben die Beobachtungsdauer einer Zeitreihenaufnahme (siehe Kapitel 2.4.5) an, nach der ersten Aufnahme (Zeitpunkt 0) wurde durch Zugabe von $1 \mu \mathrm{M}$ Staurosporin Apoptose induziert. Der Bildausschnitt (oben rechts) zeigt die vergrößerte Darstellung eines Mitochondriums im Verlauf der Apoptose.

Das obere linke Bild zeigt Mitochondrien (unbehandelt) von elongierter Form. Schon nach halb stündiger Staurosporininkubation ändern die Mitochondrien des Neurons ihre Morphologie von einer elongierten zu einer fragmentierten Form. Die Ausschnittsvergrößerung zeigt exemplarisch die Zerteilung eines Mitochondriums in zwei Fragmente. Nach 90 min Staurosporininkubation sind die Mitochondrien des Neurons kleine, runde Strukturen (rechts unten). Im Gegensatz zu den dCSM14.1 Zellen (siehe Abbildung 15) sammeln sich die fragmentierten Mitochondrien nicht vorwiegend um den Zellkern, sondern verbleiben auch in den Fortsätzen des primären Mittelhirnneurons. 


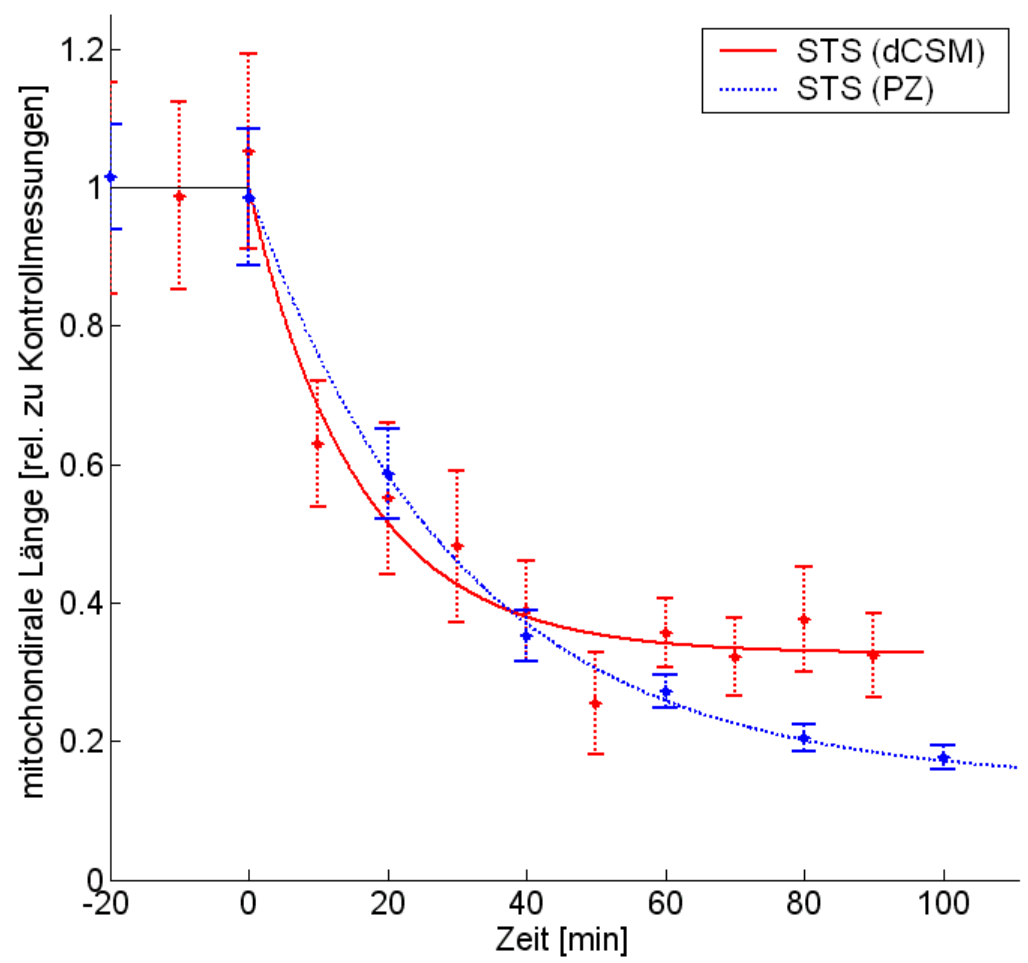

\begin{tabular}{|l|c|c|c|}
\hline Bedingung & $\begin{array}{c}\mathrm{L}_{\text {end }} \\
{[\%]}\end{array}$ & $\begin{array}{c}\tau_{1 / 2} \\
{[\mathrm{~min}]}\end{array}$ & $\mathrm{r}^{2}$ \\
\hline STS (dCSM) & $32,6 \%$ & 21,3 & 0,954 \\
\hline STS (PZ) & $13,9 \%$ & 26,4 & 0,997 \\
\hline
\end{tabular}

Abbildung 58: Kinetik der mitochondrialen Fragmentation in Mittelhirnneuronen.

Dargestellt ist die normierte Mitochondrienlänge in Abhängigkeit von der Staurosporininkubationsdauer. Nähere Beschreibung siehe Abbildung 16. Die Messwerte mit Standardfehlern stammen von je zehn Mitochondrien aus je drei einzelnen primären Mittelhirnneuronen (blau) und dCSM Zellen (rot). Die durchgezogenen Linien geben die genäherten Reaktionen der Neurone auf die Staurosporininduktion (STS) durch einen exponentiellen Abfall wieder.

Die Mitochondrienlänge beider Neuronentypen reagiert auf den Apoptosestimulus ähnlich. Die Zerfallsgeschwindigkeit ist bei den primären Mittelhirnneuronen annähernd gleich zu den dCSM 14.1 Zellen (vergleiche rechte Tabelle).

\subsubsection{Drp1 in Mittelhirnneuronen}

Drp1 konnte als notwendiger Faktor für die mitochondriale Fragmentation in dCSM14.1 Neuronen identifiziert werden. Durch Drp1 Hemmung wurde die mitochondriale Fragmentation während der Apoptose vermindert (siehe Abbildung 24). Analog dazu resultierte die Überexpression von Drp1 $1_{\mathrm{K} 38 \mathrm{~A}}$ in primären Mittelhirnneuronen auch in einer verminderten mitochondrialen Fragmentation (siehe Abbildung 59). Durch Klassifizierung der Neurone nach ihrer Mitochondrienform konnte dies quantifiziert werden (siehe Abbildung 60). Unbehandelte Neurone zeigen in beiden Neuronentypen einen sehr ähnlichen Anstieg der Neurone mit fragmentierten Mitochondrien. Diese Ähnlichkeit ist auch in den Messungen des Anteils apoptotischer Neurone erkennbar, allerdings scheinen primäre Neurone auf Staurosporinbehandlung etwas später als dCSM Neurone zu reagieren. Der Anteil an Neuronen mit fragmentierten Mitochondrien erhöhte sich unter Drp1 $1_{\mathrm{K} 38 \mathrm{~A}}$ Einwirkung nach einer Stunde Staurosporinbehandlung bei dCSM14.1 Zellen schneller als bei primären Mittelhirnneuronen. So erhöht sich der Anteil in dCSM14.1 Neuronen von 11,9 auf 43,2 \%, 
in Primärzellen jedoch nur von 14,7 auf 18,24 \%. Während dCSM14.1 Neurone nach dieser schnellen Fragmentation nur noch langsame Änderungen zeigen, steigt der Anteil an Neuronen mit fragmentierten Mitochondrien in den primären Mittelhirnneuronen stark an (73,4 \% nach zwei Stunden Apoptoseinduktion). Dieser hohe Messwert lässt auf einen verzögerten und nicht dauerhaft unterdrückten Zerfall der Mitochondrien in primären Mittelhirnneuronen schließen.

Die mitochondriale Fragmentation während der Apoptose scheint in dopaminergen Neuronen generell von Drp1 abhängig zu sein.
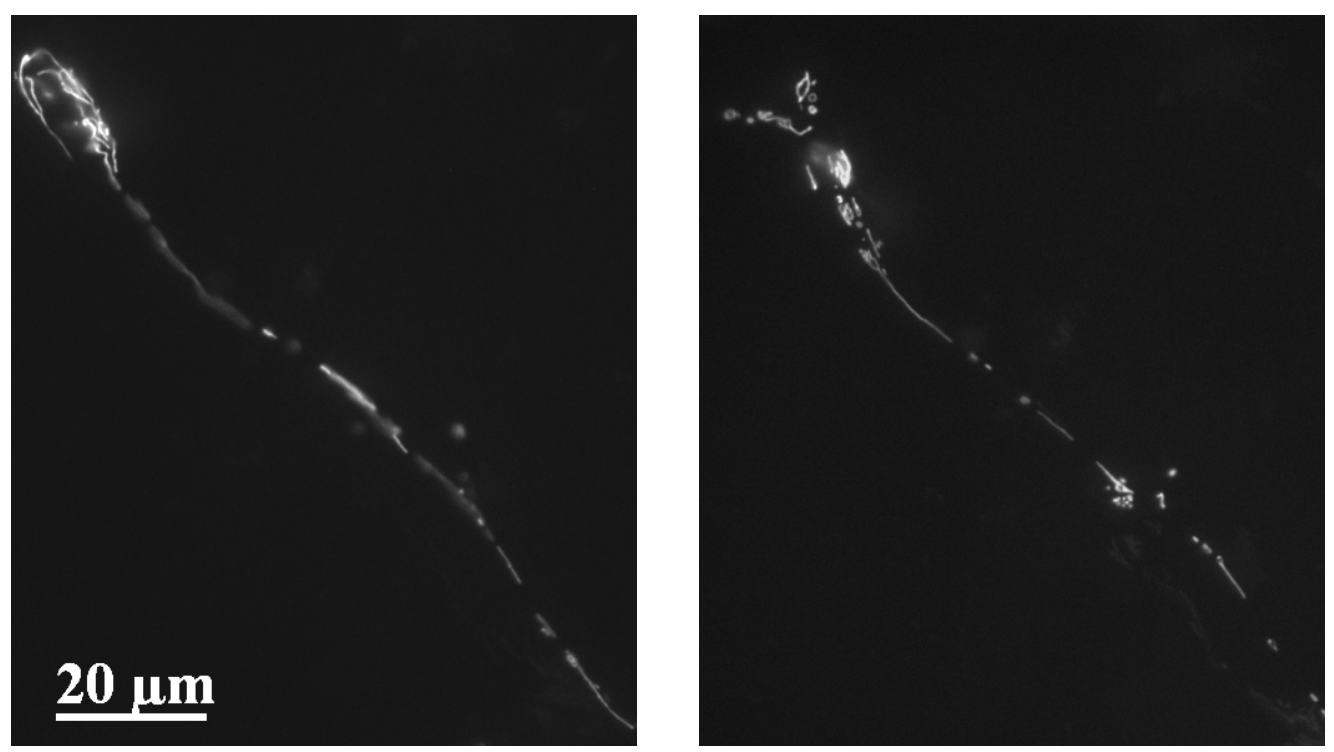

Abbildung 59: Drp1 $1_{\mathrm{K} 38 \mathrm{~A}}$ Überexpression und mitochondriale Fragmentation.

Abgebildet sind zwei fluoreszenzmikroskopische Aufnahmen eines primären Mittelhirnneurons. Die Mitochondrien sind durch pDsRed2-Mito Transfektion markiert, zusätzlich exprimiert die Zelle Drp1 $1_{\mathrm{K} 38 \mathrm{~A}}$.

Unbehandelt (links) besitzen die Mitochondrien eine elongierte Form. Nach zweistündiger Behandlung mit $1 \mu \mathrm{M}$ Staurosporin (rechts) zeigen die Mitochondrien weiterhin eine elongierte Form und ähneln den Mitochondrien der Zelle vor Apoptoseinduktion. Wie bei den dCSM14.1 Neuronen hemmt die Überexpression von Drp1 $1_{\text {Kз8A }}$ die Fragmentation der Mitochondrien während der Apoptose.

Neben der Funktion für die mitochondriale Zerteilung besitzt Drp1 $1_{\mathrm{K} 38 \mathrm{~A}}$ in dCSM14.1 Zellen einen neuroprotektiven Effekt (siehe Abbildung 29). Dieser Effekt war in primären Mittelhirnkulturen ebenfalls vorhanden. Neurone besitzen bei $\operatorname{Drp} 1_{\mathrm{K} 38 \mathrm{~A}}$ Überexpression weitaus weniger apoptotische Zellkerne als nicht $\operatorname{Drp} 1_{\mathrm{K} 38 \mathrm{~A}}$ überexprimierende Neurone (siehe Abbildung 60). Der schützende Effekt der Drp $1_{\mathrm{K} 38 \mathrm{~A}}$ Überexpression auf die Morphologie der Zellkerne ist bei dCSM14.1 Neuronen (vergleiche Abbildung 29) und primären Mittelhirnneuronen nach einer Stunde Apoptoseinduktion annähernd gleich groß (10,4 \% vs. 14,1 \%), nach zwei Stunden Apoptoseinduktion ist der höhere Apoptoseanteil der Mittelhirnneurone etwas deutlicher (9,3\% vs. 17,1\%). Der geringe Anstieg des Anteils apoptotischer Neurone nach einer bzw. zwei Stunden Apoptoseinduktion ist analog zu Mess- 
werten an dCSM14.1 Neuronen. Dort sind die Messwerte in Drp1 $1_{\mathrm{K} 38 \mathrm{~A}}$ überexprimierenden Neuronen bei kurzen Staurosporininkubationszeiten annähernd konstant und erst ab einer Inkubationszeit von ca. vier Stunden ist ein deutlicher Anstieg des Anteils mit apoptotischer Zellkerne zu verzeichnen (siehe Abbildung 29). Die primären Mittelhirnneurone wiesen bereits ohne Apoptoseinduktion einen größeren Anteil von Neuronen mit apoptotischen Zellkernen auf, was durch deren Empfindlichkeit auf die Transfektion bedingt sein könnte.

Die Funktion von Drp1 in dCSM14.1 Zellen und primären Mittelhirnneuronen zeigt Parallelen, was die Funktion des Drp1 bei der mitochondrialen Zerteilung wie auch innerhalb der Apoptosekaskade in dopaminergen Neuronen bestätigte.
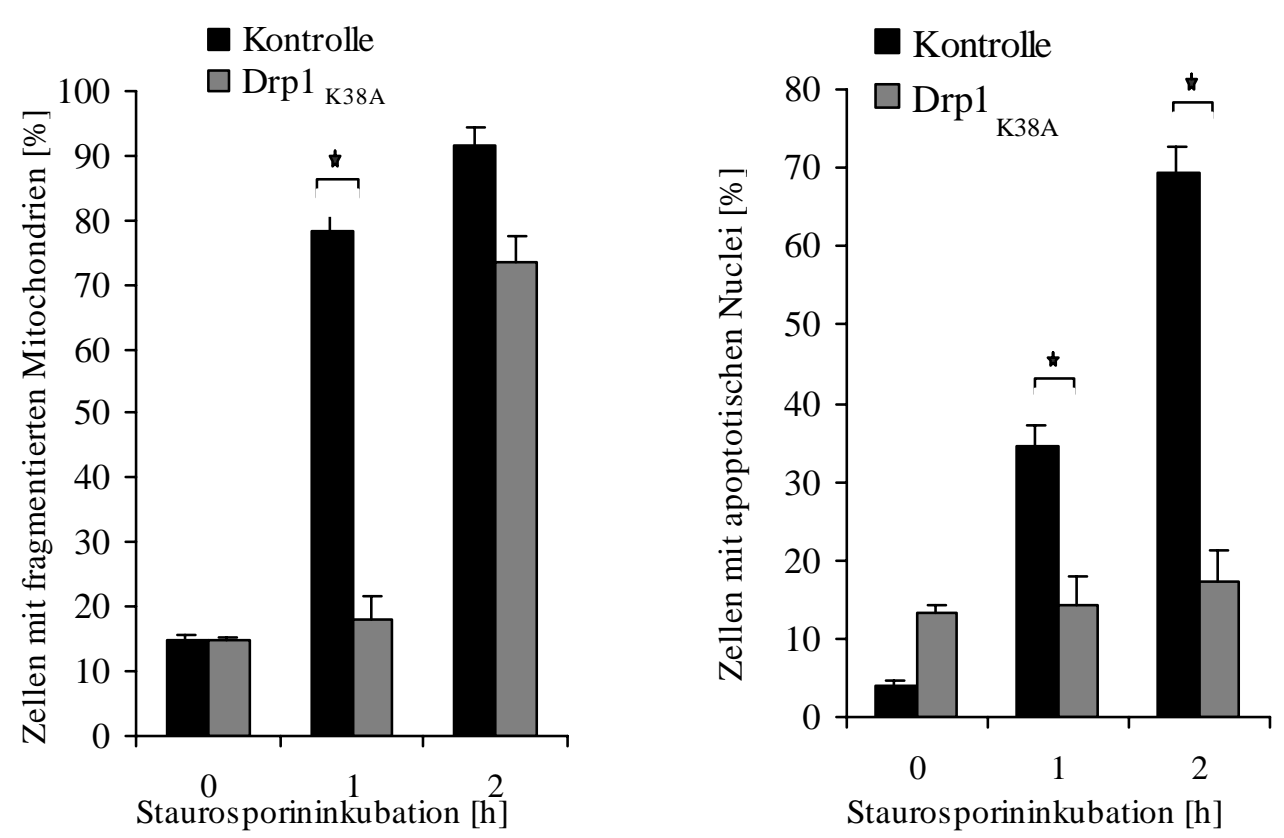

Abbildung 60: Drp1 $1_{\mathrm{K} 38 \mathrm{~A}}$ und Zerfall der Zellorganelle.

Der Anteil der Neurone mit fragmentierten Mitochondrien und apoptotischen Zellkernen (Abszisse) wurde nach unterschiedlichen Inkubationsdauern (Ordinate) mit 1 $\mu \mathrm{M}$ Staurosporin durch Klassifizierung von jeweils 210 Neuronen (100 \%) aus je drei unabhängigen Kulturen für jeden Messpunkt ermittelt. Die Mitochondrien aller Neurone waren durch pDsRed2-Mito Transfektion markiert. Neben den unbehandelten Kulturen (schwarz) wurden Kotransfektionen mit Drp1 $1_{\mathrm{K} 38 \mathrm{~A}}$ (grau) untersucht.

Im Verlauf der Apoptose nimmt der Anteil der Kontrollneurone mit fragmentierten Mitochondrien und Zellkernen zu. Die Überexpression von Drp1 $1_{\mathrm{K} 38 \mathrm{~A}}$ zeigt eine signifikant verminderte Fragmentationsrate der Mitochondrien und Zellkerne $(*$ : $\mathrm{p}<0,05$, t-Test).

\subsubsection{CDK5 in Mittelhirnneuronen}

Die Ergebnisse der dCSM14.1 Neurone zeigen die Beteiligung von CDK5 an der mitochondrialen Zerteilung (siehe Kapitel 3.2.3). Der Drp1 Effekt scheint zumindest teilweise durch Drp1 vermittelt zu werden. Primäre Mittelhirnneurone zeigen wie die Zelllinienneuronen eine spontane Fragmentation der Mitochondrien bei Überexpression von p25/CDK5 (siehe Abbildung 61). Ebenfalls führt die Überexpression von p25/CDK5 zu 
einem vermehrten Anteil an Neuronen mit apoptotischen Nuclei (siehe Abbildung 62), die primären Neurone weisen eine größere Sensibilität als dCSM Neurone auf (siehe Abbildung 41). Die gleichzeitige Überexpression von Drp1 verminderte den Effekt der p25/CDK5 Überexpression, eine Interaktion zwischen CDK5 und Drp1 existierte ebenfalls in primären Mittelhirnneuronen, wobei die Minderung der mitochondrialen Fragmentation in Primärzellen schwächer ist.
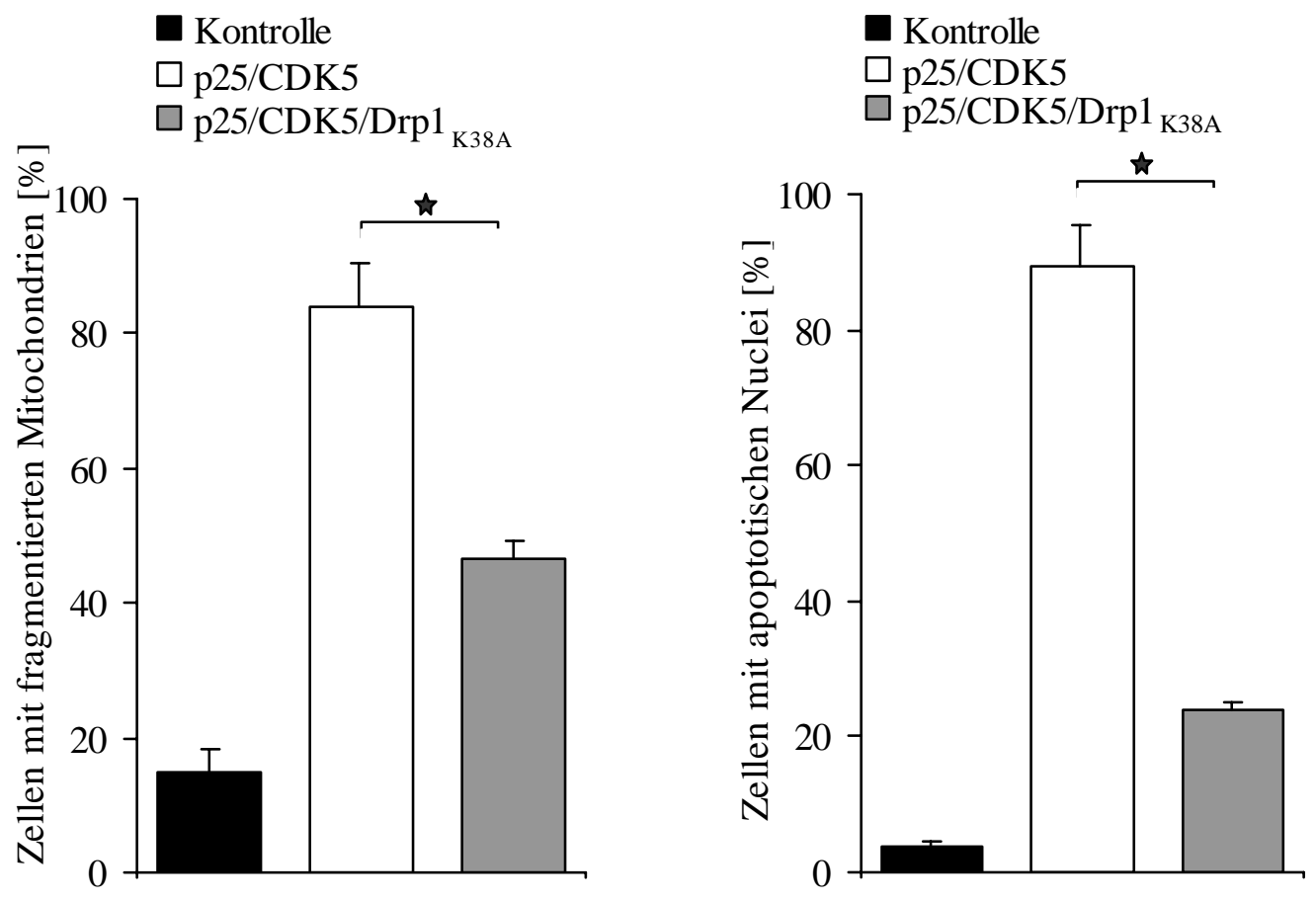

\section{Abbildung 61: CDK5 und Apoptose.}

In obigen Diagrammen wurden je Messpunkt 210 Neurone (100 \%) aus drei jeweils unabhängigen Kulturen nach ihrer Mitochondrienform (rechts) bzw. ihrem Apoptosestatus (links) klassifiziert. Die Mitochondrien waren durch Transfektion mit pDsRed2-Mito markiert. Neben unbehandelten Zellen (Kontrolle) wurden p25/CDK5 (weiß) oder p25/CDK5/Drp1 K38A $_{\text {überexprimierenden Zellen untersucht (hellgrau). }}$

p25/CDK5 Überexpression induziert in primären Mittelhirnneuronen einen Anstieg der Neuronen mit fragmentierten Mitochondrien und apoptotischen Zellkernen. Der Anstieg der beiden Messgrößen wird durch die parallele Überexpression von Drp $1_{\mathrm{K} 38 \mathrm{~A}}$ signifikant $(*$ : $\mathrm{p}<0,05$, t-Test) vermindert, so dass der Anteil der Neurone mit fragmentierten Mitochondrien auf $46 \%$ der mit apoptotischen Kernen auf $23 \%$ sinkt.

Um den Einfluss von endogenem CDK5 auf den mitochondrialen Zerteilungsapparat exemplarisch in primären Mittelhirnneuronen zu verifizieren, wurde das endogene CDK5 durch die Überexpression von $\mathrm{CDK}_{\mathrm{N} 144}$ inhibiert. Die Hemmung resultierte in einer verminderten Längenreduktion der Mitochondrien während der Apoptose (siehe Abbildung 62), die sogar stärker gehemmt ist als bei den Zelllinienneuronen. Die Halbwertszeit des mitochondrialen Zerfalls ist mehr als doppelt so groß im Vergleich zu dCSM14.1 Neuronen (Halbwertszeit: dCSM14.1=81 min, PZ=224 min). 


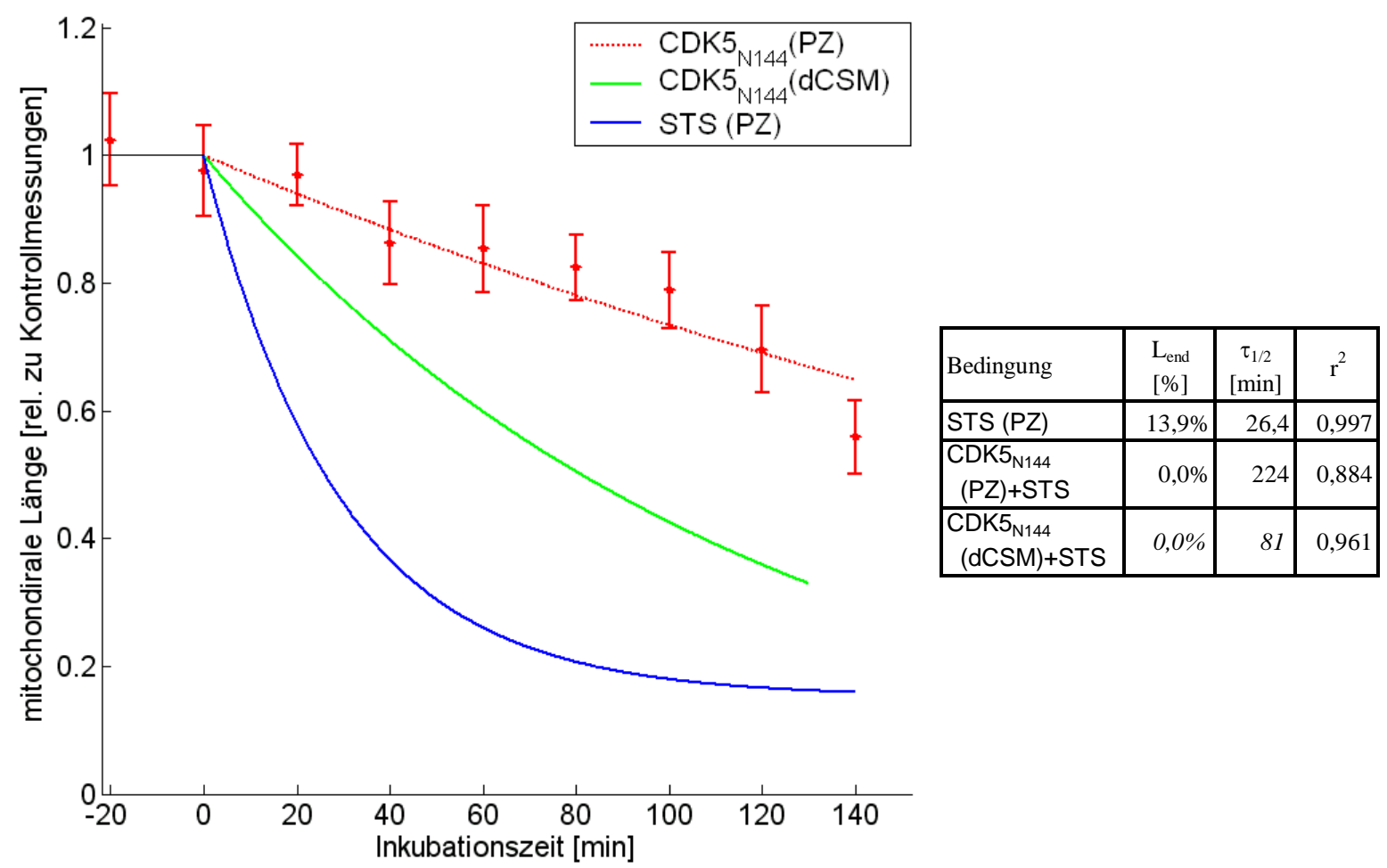

\section{Abbildung 62: Dynamik des mitochondrialen Zerfalls bei CDK5 Hemmung.}

Dargestellt ist die normierte Mitochondrienlänge in Abhängigkeit von der Staurosporininkubationsdauer, nähere Beschreibung siehe Abbildung 16. Die Messwerte mit Standardfehlern stammen von primären Mittelhirnneuronen, die entweder mit pDsRed2-mito (blau) oder zusätzlich mit $\mathrm{CDK}_{\mathrm{N} 144}$ (rot) transfiziert sind.

Zum direkten Vergleich ist der genäherte exponentielle Zerfall der $\mathrm{CDK}_{\mathrm{N} 144}$ überexprimierenden dCSM14.1 Neuronen dargestellt (grün). Die durchgezogene blaue Linie zeigt die genäherte exponentielle Zerfallskurve der unbehandelten primären Mittelhirnneurone bei Staurosporinbehandlung.

Die Abnahme der mitochondrialen Länge bei $\mathrm{CDK}_{\mathrm{N} 144}$ Überexpression erfolgt bei achtfacher Halbwertszeit (siehe Tabelle). Die Zerfallsgeschwindigkeit ist somit durch $\mathrm{CDK}_{\mathrm{N} 144}$ Überexpression bei den primären Mittelhirnneuronen noch stärker vermindert als bei dCSM14.1 Zellen (siehe Abbildung 43). Wie bei den Zelllinienneuronen scheint $\mathrm{CDK}_{\mathrm{N} 144}$ Überexpression in primären Neuronen keinen dauerhaften protektiven Effekt auf die Mitochondrien auszuüben.

Die Ähnlichkeit der Reaktionen beider Zelltypen (dCSM14.1 Neurone und primäre Mittelhirnneurone) verdeutlicht eine allgemeine Funktion von CDK5 in dopaminergen Neuronen und zeigt, dass die an dCSM14.1 Neuronen gewonnenen Daten ebenso auf Kulturen primärer Mittelhirnneurone übertragen werden können. 


\section{Diskussion}

\subsection{Mitochondriale Morphologie}

Die natürliche Morphologie der Mitochondrien beruht auf einem Gleichgewicht zwischen Zerteilungs- und Verschmelzungsvorgängen (Bossy-Wetzel et al. 2003). In dieser Arbeit wurden elongierte Mitochondrien in dCSM14.1 Neuronen sowie in primären Mittelhirnneuronen nachgewiesen. Mitochondrien mit vergleichbarer Morphologie sind auch in anderen Zelltypen üblich. So konnten unter anderem in kortikalen Neuronen (Yuan et al. 2006), Cos-7 Zellen, HeLa Zellen und humanen Fibroblasten (Karbowski et al. 2002) sowie in Hefen (Messerschmitt et al. 2003) elongierte Mitochondrien nachgewiesen werden. Die durchschnittliche Länge der Mitochondrien konnte in dopaminergen dCSM 14.1 und Mittelhirnneuronen mit ca. $5 \mu \mathrm{m}$ (siehe Abbildung 13 und Abbildung 56) bestimmt werden. In anderen Zelltypen wurden meist ähnliche Mitochondrienlängen ermittelt. So beträgt die durchschnittliche Mitochondrienlänge in primären kortikalen Neuronen 2-4 $\mu$ m (Rintoul et al. 2003).

Die Morphologie der Mitochondrien änderte sich auffällig durch Apoptoseinduktion. In der vorliegenden Studie wurden drei unterschiedliche Apoptosestimuli eingesetzt. Alle drei Substanzen induzieren den intrinsischen Apoptoseweg, wenn sie dem Kulturmedium in geeigneter Konzentration zugesetzt werden. A23187 ist ein Calciumionophor, welches die Calciumkonzentration im Zytosol erhöht (Petersen et al. 2000). Es kommt dabei zur Ausbildung einer mitochondrialen Permeabilitätspore, die zu einer Öffnung der inneren und äußeren Membran führt (Green und Kroemer 2004). Durch die Permeabilisierung der Membran werden apoptotische Proteine wie z.B. Cytochrom c ins Zytosol freigesetzt und der Apoptoseprozess aktiviert. Auch Staurosporin induziert den Apoptoseweg, indem es Caspase-3 aktiviert (Ceccatelli et al. 2004). $\mathrm{MPP}^{+}$ein nigrostriales Toxin, hemmt den Komplex-I der Elektronentransportkette der Atmungskette (Kotake und Ohta 2003). Die Hemmung ist auf dopaminerge Neurone beschränkt und resultiert in einer verminderten ATP-Produktion. Ein zweiter Effekt der Komplex-I Blockade ist die erhöhte Produktion reaktiver Sauerstoffverbindungen, die zur DNS Schädigungen führen. Es kommt zur Freisetzung von Cytochrom c aus den Mitochondrien und zur intrinsischen Aktivierung der Apoptosekaskade (Fiskum et al. 2003).

Morphologische Veränderungen der Mitochondrien konnten auch mit anderen Apoptosestimuli in einer Vielzahl anderer Zelltypen beobachtet werden. Als weitere apoptoseinduzierende Substanzen die morphologische Veränderungen der Mitochondrien verursachen sind zum Beispiel Ceramide (Pinton et al. 2001), NO (Barsoum et al. 2006), Etoposid (Sugioka et 
al. 2004) und Glutamat (Rintoul et al. 2003) bekannt. Ebenso induziert die Überexpression von pro- apoptotischen Proteinen wie z.B. Bax und Bid (Arnoult et al. 2005) und auch mitochondrialen Influenza A Proteinen (Chen et al. 2001) sowie humanen mitochondrialen Cytomegalviren Proteinen (Chen et al. 2001, McCormick et al. 2003) mitochondriale Fragmentation. Die Vielzahl der beschriebenen Apoptose fördernden Substanzen, die zu einer Fragmentation der Mitochondrien beitragen, deuten darauf hin, dass ein genereller Zusammenhang zwischen mitochondrialer Zerteilung und Apoptose vorliegt, der nicht vom Stimulus abhängt. Die in dieser Arbeit genutzte Hemmung der ATP Synthese durch MPP führte in kortikalen Neuronen nicht zu einer veränderten mitochondrialen Morphologie, sondern lediglich zu einer Hemmung der Mitochondrienbewegung (Rintoul et al. 2003). Dies könnte auf eine Besonderheit der dopaminergen Neurone hindeuten.

In der vorliegenden Studie zeigten dopaminerge Neurone unter Einfluss von drei unterschiedlichen Apoptoseinduktoren eine deutliche Verkürzung der durchschnittlichen Mitochondrienlänge. Alle drei Stimuli überführten die elongierte Form der Mitochondrien zu kleinen runden Strukturen, deren Länge um mindestens $60 \%$ vermindert ist (siehe Abbildung 16). Die mitochondriale Fragmentation während der Apoptose ist für verschiedene Zelltypen innerhalb der Literatur beschrieben. In COS-7 Zellen zeigt sich eine Veränderung der Mitochondrienmorphologie während der Apoptose (Frank et al. 2001). Auch in primären kortikalen Neuronen (Barsoum et al. 2006) und in primären Neuronen des basalen Vorderhirns (Rintoul et al. 2003) wurden solche morphologischen Veränderungen der Mitochondrien während der Apoptose beobachtet. In Myoblasten, Astrocyten und HeLa Zellen wurde eine mitochondriale Fragmentation nach erhöhter Calciumkonzentration beschrieben (Duncan et al. 1980, Pinton et al. 2001). Neben den Beobachtungen in vitro beschreibt die Literatur sogar in niederen Lebewesen wie Caenorhabditis elegans eine Zerteilung der Mitochondrien während der in der Entwicklung stattfindenden Apoptose (Jagasia et al. 2005). Die in dieser Studie bei Apoptose beschriebene Verlagerung der Mitochondrienfragmente zum Zellkern bestätigten die Experimente anderer Autoren (De Vos et al. 1998). Die beobachteten Veränderungen der Mitochondrienmorphologie innerhalb der Apoptose sind vom Apoptosestimulus unabhängig. Die drei genutzten Stimuli führen zu ähnlichen Zerfallskurven (siehe Abbildung 16). In allen drei Fällen zeigt sich ein exponentieller Zerfall mit fast gleicher Halbwertszeit auf einen ähnlichen Endwert. Wenn die Schwelle zur Apoptoseinduktion überschritten ist, scheint ein stereotyper Prozess stattzufinden, vergleichbar mit der Cytochrom c Freisetzung. Die hohen Regressionswerte an einen exponentiellen Zerfall sind durch eine konstante Zerteilungswahrscheinlichkeit und begrenzte Anzahl an Zerteilungsstellen erklärbar. So ist auch erklärbar warum die 
Mitochondrien selbst nach vollzogenen Zelltod eine minimale Größe nicht unterschreiten. Die Zerteilungsstellen könnten mit den in Kapitel 1.1.5.1 beschriebenen Matrixkonstriktionen bzw. Ansammlungen des Fis1 Proteins identisch sein.

In den verwendeten dopaminergen dCSM14.1 Zellen konnte die mitochondriale Fragmentation bei Apoptoseinduktion bereits nach einer Minute nachgewiesen werden (siehe Abbildung 14). Diese schnelle Reduktion der Mitochondrienlänge nach Apoptoseinduktion deckt sich mit Angaben aus der Literatur. In kortikalen Neuronen wurde ein Zerfall der Mitochondrien in den ersten 10 min nach NO-Behandlung beschrieben (Barsoum et al. 2006, Yuan et al. 2006). In Kulturen von basalen Vorderhirnneuronen wurde sogar bereits nach fünfminütiger Glutamatbehandlung von einer drastischen morphologischen Veränderung berichtet (Rintoul et al. 2003).

Die morphologische Veränderung der Mitochondrien während der Apoptose ist somit in verschiedenen Zelltypen bzw. Lebewesen ein weit verbreitetes Phänomen. Eine mögliche Erklärung für den Ursprung und die Bedeutung der starken morphologischen Veränderungen der Mitochondrien während der Apoptose könnte die Sporenbildung bei Bakterien aufzeigen. Mitochondrien sind mit $\alpha$-Proteobakterien verwandt, von denen sie evolutionär abstammen (Endosymbiontentheorie). Bakterien reagieren als Stressantwort auf äußere Signale bzw. extreme Störung mit Sporulation, die analog zu der Fragmentation der Mitochondrien abläuft (Frank et al. 2003). Da die Sporulation von Bakterien ein Anpassungsmechanismus auf die Umwelt darstellt, könnte die vermehrte Teilung der Mitochondrien ebenfalls als eine Anpassung an veränderte Umgebungsbedingungen angesehen werden. Die Fragmentation wäre somit ursprünglich eine Art Schutzfunktion, um auf Defizite im Energiehaushalt mit erhöhter Mitochondrienzahl zu reagieren. Während der Apoptose könnte diese Fähigkeit der Mitochondrien eine neue funktionelle Bedeutung bekommen haben.

Die Veränderung der Mitochondrienmorphologie könnte auf prinzipiell unterschiedliche Mechanismen zurückzuführen sein. Neben einer erhöhten Zerteilungsrate könnte das Gleichgewicht zwischen Zerteilung und Verschmelzung durch eine verminderte Fusionsrate gestört sein. Weiterhin ist es denkbar, dass Mitochondrien durch Stoffwechselprozesse abgebaut werden oder ihre elongierte Form durch Anschwellen verlieren.

Das Prinzip der morphologischen Veränderung der Mitochondrien ist aktuell in der Literatur umstritten. Viele Studien gehen ebenfalls von einer Erhöhung der Zerteilungsrate während der Apoptose aus. So wurden beispielsweise in primären kortikalen Neuronen nach Glutamatbehandlung von einer Abnahme der durchschnittlichen Länge berichtet (Rintoul et al. 2003). Im Gegensatz hierzu stehen Beobachtungen, dass die Verschmelzung der Mitochondrien innerhalb der Apoptose blockiert ist (Karbowski et al. 2004). 
Formveränderungen von Mitochondrien ohne Volumenänderung konnten bisher nicht nachgewiesen werden. In einzelnen Untersuchungen konnte ein Anschwellen der Mitochondrien zwar nachgewiesen werden (Rintoul et al. 2003), hierauf folgt allerdings meist ein Zerteilungsvorgang. Einzelne Studien weisen darauf hin, dass Mitochondrien im Verlauf der Apoptose aufgelöst werden, wobei dieser Abbauprozess selbst Caspase unabhängig verläuft (Skulachev 2002, Tolkovsky et al. 2002). Diese Autophagie scheint allerdings, ein der mitochondrialen Zerteilung nachgelagerter Prozess zu sein, da er durch bekannte Zerteilungsproteine beeinflussbar ist (Xue et al. 2001). Obwohl die mitochondrialen Veränderungen auf vielen Mechanismen beruhen könnten, scheint eine Störung des Gleichgewichtes von Zerteilungs- und Verschmelzungsraten der vorherrschende Auslöser zu sein.

In den Untersuchungen dieser Studie konnte eine Häufung von Zerteilungsvorgängen nach Apoptoseinduktion beobachtet werden. Eine gleichzeitig verminderte Fusionsrate kann nicht völlig ausgeschlossen werden. Dieser Mechanismus ist allerdings weniger wahrscheinlich, da die morphologischen Veränderungen durch die Überexpression von Drp1 $1_{\mathrm{K} 38 \mathrm{~A}}$ fast vollständig unterdrückt wurden.

\subsection{Funktion von Drp1 und Fis1}

Es existiert eine Modellvorstellung des molekularen Ablaufes der mitochondrialen Zerteilung (Bossy-Wetzel et al. 2003). Vermutlich nehmen Drp1 und Fis1 eine Schlüsselrolle ein (siehe Abbildung 5). Der Zerfall der Mitochondrien ist ein sehr schnell ablaufender Prozess der sofort nach Induktion der Apoptose einsetzt. Daher müssen die bei der Fragmentation beteiligten Proteine stetig in der Zelle vorhanden und jederzeit aktivierbar sein.

In dieser Studie konnte belegt werden, dass Drp1 endogen in dopaminergen Neuronen vorhanden ist (siehe Abbildung 20). Dabei wurde gezeigt, dass Drp1 (ohne Apoptoseinduktion) in einem spezifischen Verteilungsmuster vorliegt und nicht kolokalisiert mit den Mitochondrien ist. Der Lokalisationsort konnte allerdings keiner zellulären Struktur zugeordnet werden. Andere Studien konnten eine Kolokalisation mit dem endoplasmatischen Retikulum (Yoon et al. 1998) oder aber den Peroxisomen (Li und Gould 2003) zeigen. Eine solche Assoziation ist in dopaminergen Neuronen ebenso vorstellbar, da sie mit dem endogenen Drp1 Verteilungsmuster vereinbar ist (siehe Abbildung 19).

Das andere postulierte Hauptprotein der mitochondrialen Zerteilung (Fis1) ist selbst bei Überexpression ausschließlich mit den Mitochondrien kolokalisiert (James et al. 2003). Die Position von Fis1 in der äußeren Mitochondrienmembran wurde durch Experimente in HeLa Zellen gezeigt (James et al. 2003). Durch Fis1 Mutanten konnte nachgewiesen werden, dass 
das Protein mit seinem C-Terminus in den Mitochondrien verankert ist (James et al. 2003). Die Überexpression von Fis1 resultierte in Mitochondrien mit abnormalen Formen (siehe Abbildung 17 und Abbildung 18). Solche abnormalen Mitochondrienformen wurden ebenfalls in Cos-7 Zellen nach Expression von Fis1 beobachtet (James et al. 2003, Stojanovski et al. 2004) und stellenweise als Aggregate von Mitochondrien beschrieben (Koch et al. 2005). Der optische Eindruck lässt allerdings eher auf eine Vereinigung oder Anschwellung der Mitochondrien schließen, insbesondere da ringförmige Anordnungen von Fis1 sichtbar sind (siehe Abbildung 17). Diese ringförmigen Strukturen könnten potentielle Zerteilungsstellen der Mitochondrien darstellen.

Die Überexpression von Drp1 zeigt keinen Effekt auf die Mitochondrienmorphologie bzw. auf ihren Zerfall während der Apoptose (Abbildung 22 und Abbildung 59). Die Mitochondrien besaßen bei Drp1 Überexpression die gleiche elongierte Form und Länge wie die Mitochondrien nicht Drp1 überexprimierender Neurone. In der Literatur werden meist ähnliche Beobachtungen beschriebenen (Mozdy et al. 2000, Smirnova et al. 1998), im Gegensatz hierzu zeigen einige Studien eine vermehrte Zerteilung bei Drp1 Überexpression (Szabadkai et al. 2004). Innerhalb der Apoptose ändert die Überexpression von Drp1 weder die Zerfallsgeschwindigkeit noch die bis zum Zelltod verbleibende Restgröße der Mitochondrien (siehe Abbildung 22). Im Gegensatz hierzu übt die Inhibition von Drp1 eine starke Wirkung auf die Mitochondrien innerhalb der Apoptose aus. Ohne Apoptoseinduktion zeigten die Mitochondrien keine morphologischen Veränderung bei Drp1 Hemmung (siehe Abbildung 21). Bei Apoptoseinduktion allerdings behielten die Mitochondrien der Drp $1_{\mathrm{K} 38 \mathrm{~A}}$ transfizierten Neuronen ihre elongierte Form bei (siehe Abbildung 23 und Abbildung 59). Die verminderte mitochondriale Fragmentation während der Apoptose durch Inhibition von Drp1 konnte sowohl in den Zelllinienneuronen wie in Kulturen primärer Mittelhirnneuronen gezeigt werden (siehe Abbildung 24 und Abbildung 60). Ebenfalls wurde in Cos-7 Zellen (Frank et al. 2001, Smirnova et al. 2001), Fibroblasten (Breckenridge et al. 2003) und kortikalen Neuronen (Barsoum et al. 2006) eine Verminderung der mitochondrialen Fragmentation nach Drp1 $1_{\mathrm{K} 38 \mathrm{~A}}$ Überexpression beschrieben. Der Effekt der Drp1 $1_{\mathrm{K} 38 \mathrm{~A}}$ Überexpression in dCSM14.1 Neuronen ist durch eine langanhaltende Blockierung der Fis1 Bindungsstellen durch die dominant negative Mutante erklärbar. Die dominant negative Mutante ist auf Grund der Punktmutation nicht funktional. Da eine Bindung mit funktionalem Drp1 nicht mehr möglich ist, teilen sich die Mitochondrien nicht. Somit konnte gezeigt werden, dass Drp1 für die Fragmentation der Mitochondrien zwingend erforderlich ist. Da seine Überexpression jedoch nicht zu einer Fragmentation der Mitochondrien führte, ist eine Regulation des Vorgangs mittels Erhöhung des Expressionslevels während der 
Apoptose unwahrscheinlich. Drp1 scheint ständig in so hoher Konzentration vorzuliegen, dass es kein limitierender Faktor für die mitochondriale Zerteilung ist. Dies steht in Einklang mit dem gemessenen schnellen Zerfall. Weiterhin könnte die bereits endogen hohe Konzentration die Voraussetzung für eine konstante Zerfallswahrscheinlichkeit der Mitochondrien darstellen, wie im Kapitel 4.1 auf Grund des exponentiellen Abfalls postuliert. Als regulatorische Mechanismen kommen ein Transport des Drp1 zu den Mitochondrien oder eine Aktivitätserhöhung bzw. eine Aktivierung durch weitere Kofaktoren in Betracht. Die regulierenden Mechanismen dieser Prozesse sind noch nicht bekannt, und wurden unter anderem in dieser Arbeit erforscht.

Drp1 steht in nicht apoptotischen Zellen mit den Mitochondrien nicht unmittelbar in Kontakt. Es konnte gezeigt werden, dass Drp1 Proteine nach Apoptoseinduktion mit den Mitochondrien kolokalisieren (siehe Abbildung 20), wo sie mit dem zweiten Protein Fis1 einen Komplex bilden können, der die Zerteilung der Mitochondrien verursacht. Häufig scheinen sich die Drp1 Cluster wie eine Perlenschnur an die Mitochondrien anzulagern (siehe Abbildung 20), was den eingangs erwähnten Modellvorstellung zur mitochondrialen Fragmentation entspricht. Eine ähnliche Verschiebung von Drp1 zu den Mitochondrien nach Apoptoseinduktion wurde in HeLa Zellen beschrieben (Sugioka et al. 2004).

Mitochondrien nutzen zur Aufrechterhaltung einer heterogenen Verteilung die Strukturen des Zytoskeletts (Anesti und Scorrano 2006). Aufgrund der ungleichen Größenverhältnisse und der schnellen apoptotischen Reaktion kann jedoch eher ein Transport von Drp1 bei der mitochondrialen Zerteilung postuliert werden. Der Transport von Drp1 zu den Mitochondrien ist abhängig von intakten Zytoskelettstrukturen (Abbildung 32). Er war in der vorliegenden Studie sowohl von den Aktin- wie Tubulinstrukturen abhängig und stellt ein möglichen Regelmechanismus der mitochondrialen Fragmentation dar. Die Messungen stehen im Einklang zu anderen Untersuchungen, in denen eine Assoziation zwischen Drp1 und den Mikrotubuli beschrieben ist (Yoon et al. 1998). In HeLa Zellen konnte nachgewiesen werden, dass die Rekrutierung von Drp1 zu den Mitochondrien auf dem Tubulinskelett sowie den Motorproteinen Dynein und Dynaktin basiert (Varadi et al. 2004). Des Weiteren ist aus Versuchen mit nichtneuronalen Säugetierzellen bekannt, dass die Zerstörung des Aktinzytoskeletts zu einer verminderten Zerteilung der Mitochondrien führt (De Vos et al. 2005). In dieser Studien wurde gezeigt, dass Drp1 mit den Aktinstrukturen des Zytoskeletts kolokalisiert und das die Zerstörung von Aktin die Rekrutierung von Drp1 zu den Mitochondrien inhibiert. Im Gegensatz zu den hiesigen Beobachtung konnte teilweise kein Einfluss des Tubulinzytoskeletts auf die mitochondriale Zerteilung während der Apoptose beobachtet werden (De Vos et al. 2005). De Vos et al. erklärten ihre Beobachtungen 
dadurch, dass die mitochondriale Zerteilung bei Abwesenheit eines intakten Tubulinzytoskeletts durch die bereits während der Zerstörung rekrutierten Drp1 Proteine vollzogen wird.

\subsection{Einfluss von Drp1 und Fis1 auf die Apoptose}

Die mitochondriale Fragmentation wurde durch Apoptose induzierende Substanzen ausgelöst. Während bereits nach halbstündiger apoptoseinduzierender Staurosporininkubation die Hälfte der Neurone fragmentierte Mitochondrien aufwiesen, zeigten erst nach ca. einer Stunde die Hälfte der Neurone apoptotische Kerne (siehe Abbildung 25, Abbildung 29). Somit wird die mitochondriale Fragmentation durch Apoptoseinduktion schneller induziert als der Zerfall der Kerne. Dies lässt die Deutung des mitochondrialen Zerfalls als frühes Ereignis der Apoptosekaskade zu.

Auch bei Überexpression und Hemmung der direkt beteiligten Protein zeigte sich immer eine verzögerte apoptotische Reaktion. Die Überexpression der beiden wichtigsten Proteine (Fis1 und Drp1) beeinflusste den Verlauf der Apoptose nur marginal. Die Überexpression von Fis1 führte trotz der abnormalen Mitochondrien nicht zu einem vermehrten Auftreten von apoptotischen Zellkernen (siehe Abbildung 29). Fis1 beeinflusst somit zwar die Morphologie der Mitochondrien sehr deutlich, dies ist jedoch nicht hinreichend für die Induktion der Apoptose. Die Funktion von Fis1 innerhalb der Apoptose wird in der Literatur kontrovers diskutiert. Im Gegensatz zu den Messwerten der vorliegenden Arbeit konnte z.B. in HeLa, HEK 293 und Cos-7 Zellen (James et al. 2003) Apoptose durch Überexpression von Fis1 induziert werden. In HeLa Zellen wurde eine Hemmung des Zelltod durch Herabregulierung von Fis1 beschrieben (Lee et al. 2004). In der selben Zelllinie konnte jedoch gezeigt werden, dass eine Herabregulierung von Fis1 den Verlauf der Apoptose (UVStrahlen induziert) nicht verzögert (Parone et al. 2006). Daher ergibt sich kein eindeutiges Bild, welche Auswirkungen Fis1 auf die Apoptose ausübt, in unterschiedlichen Zelltypen werden konträre Wirkungen beschrieben.

Das zweite Hauptprotein des mitochondrialen Zerfalls (Drp1) zeigte in dieser Studie bei Überexpression keinen Einfluss auf den Verlauf der Apoptose. Drp1 Überexpression zeigte ebenso keinen Einfluss auf den apoptoseinduzierten Zerfall der Mitochondrien. Dies deckt sich mit der im vorangehenden Kapitel dargelegten Vermutung, dass Drp1 bereits endogen in so hoher Konzentration vorliegt, dass es für die betrachteten Vorgänge kein limitierenden Faktor darstellt (siehe Kapitel 4.2). Drp1 scheint bei einigen Zelltypen dennoch eine Sensibilisierung für Apoptoseinduktion durch Staurosporin zu bewirken (Karbowski et al. 2002). Dieser apoptotische Effekt kann jedoch nicht immer belegt werden (Szabadkai et al. 
2004). Apoptose kann durch Hemmung der mitochondrialen Fragmentation beeinflusst werden. Drp1 $1_{\mathrm{K} 38 \mathrm{~A}}$ überexprimierende Neurone zeigen eine verminderte Ausbildung von apoptotischen Zellkernen (sieheAbbildung 29 und Abbildung 60). Der neuroprotektive Effekt der Inhibition von Drp1 deckt sich mit dem, der in anderen Zelltypen beschrieben ist. In HeLa und Cos-7 Zellen konnte bei Hemmung von Drp1 ebenso eine Blockade des Zelltodes nach Staurosporinbehandlung gefunden werden (Frank et al. 2001), in primären kortikalen Neuronen nach NO Behandlung (Barsoum et al. 2006). Die Resultate dieser Studie deuten daraufhin, dass durch das Verdrängen des Drp1 mittels der dominant negativen Mutante in ca. der Hälfte der Neurone die Apoptose verhindert wird. In diesen Neuronen zerfallen weder die Mitochondrien noch die Kerne. Bei Neuronen die trotz Drp1 $1_{\mathrm{K} 38 \mathrm{~A}}$ Überexpression Apoptose erfahren ist der Verlauf wesentlich langsamer, der Zerfall setzt erst nach ca. vier Stunden ein (siehe Abbildung 29). Eine solche Verzögerung des Verlaufs der Apoptose kann auch durch direkte Herabregulation von Drp1 mittels siRNS erreicht werden (Sugioka et al. 2004). Dies deutet darauf hin, dass die morphologischen Veränderungen der Mitochondrien nicht bloß ein Epiphänomen während der Apoptose sind, sondern elementarer Bestandteil der initialen Apoptosekaskade.

Bei Hemmung des mitochondrialen Zerfalls durch Überexpression von Drp1 $1_{\mathrm{K} 38 \mathrm{~A}}$ konnte eine vermindert Cytochrom c Freisetzung nachgewiesen werden (Abbildung 28). Diese Befunde deuten daraufhin, dass die Cytochrom c Freisetzung zumindest anteilig eine Folge des mitochondrialen Zerfalls sein könnte. Beide Prozesse sind von ähnlicher Dauer und weisen eine invariante Zeitdynamik auf (Goldstein et al. 2000, Goldstein et al. 2005). In Drp1 $1_{\mathrm{K} 38 \mathrm{~A}}$ überexprimierenden HeLa und Cos-7 Zellen ist ebenso eine verminderte Cytochrom c Freisetzung innerhalb der Apoptose beschrieben (Frank et al. 2001). Ebenfalls führt die Hemmung von Drp1 durch siRNS in den gleichen Zelltypen zu einer verminderten Freisetzung von Cytochrom c nach Apoptoseinduktion (Parone et al. 2006). Da Cytochrom c Freisetzung notwendigerweise die Apoptosekaskade aktiviert (Polster und Fiskum 2004) könnte dies der Grund für die anti- apoptotische Wirkung von verminderter mitochondrialer Zerteilung sein.

Tat-Bcl-xL zählt zu den anti- apoptotischen Proteinen der Bcl2 Familie (Kilic et al. 2006). Die Hemmung der Apoptose wird durch eine verminderte Cytochrom c Ausschüttung verursacht (Frieden et al. 2004), die wiederum auf einer Interaktion mit dem pro-apoptotischen Protein Bax beruht (Danial und Korsmeyer 2004). Auch in dopaminergen Neuronen führt die Behandlung mit Tat-Bcl-xL erwartungsgemäß zu einer deutlich verminderten Cytochrom c Freisetzung aus den Mitochondrien und verminderten Ausbildung apoptotischer Zellkerne nach Staurosporinbehandlung (siehe Abbildung 30). Die Behandlung der Neurone 
mit Tat-Bcl-xL besaß allerdings keinen schützenden Effekt für die Fragmentation der Mitochondrien während der Apoptose (siehe Abbildung 30). Dies bestätigen Experimente aus HeLa Zellen und primären kortikalen Neuronen, in denen die Expression von Bcl-xL ebenfalls die Apoptose hemmt ohne die mitochondriale Zerteilung zu vermindern (James et al. 2003, Sugioka et al. 2004, Yuan et al. 2006). Die beschriebene Wirkung von Bcl-xL ist allerdings nicht allen anti- apoptotischen Proteinen der Bcl-2 Familie gemein, da beispielsweise Bcl-2 die mitochondriale Zerteilung blockiert (Kong et al. 2005). Mitochondrien können somit zerfallen ohne gleichzeitig Cytochrom c freizusetzen, aber eine Hemmung des Zerfalls vermindert umgekehrt die Cytochrom c Freisetzung in den bekannten Fällen (siehe Abbildung 27).

Die Notwendigkeit des mitochondrialen Zerfalls für den Ablauf des Apoptoseprozesses wird von Experimenten bei zerstörten Zytoskelett in Frage gestellt. Wie bereits dargelegt verschiebt sich das Drp1 Verteilungsmuster zu Begin der neuronalen Apoptose zu den Mitochondrien hin (Abbildung 20, De Vos et al. 2005, Karbowski et al. 2002). Für diesen Transport sind intakte Zytoskelettstrukturen notwendig. Für den Zerfall der Zellkerne selbst ist das Zytoskelett allerdings nicht von Bedeutung. Während der mitochondriale Zerfall sowohl bei Zerstörung des Aktinskelettes, also auch der Mikrotubuli vermindert ist (siehe Abbildung 33), zeigt sich kein vergleichbarer Einfluss auf die Apoptose selbst (Abbildung 35). Bei Zerstörung der beiden Skelettstrukturen geben die Mitochondrien Cytochrom c ab (Abbildung 35), obwohl sie nicht durch einen Drp1-Fis1-Komplex zerteilt werden und ihre elongierte Form beibehalten. Die Zerstörung des Zytoskeletts stellt einen äußerstes unphysiologischen Zustand der Zelle dar. Nach Zerstörung des Zytoskeletts könnte die Apoptose durch unphysiologische Effekte bzw. andere Zelltodkaskaden, welche keine Zerteilung der Mitochondrien benötigen ermöglicht werden. Aktiviertes Drp1 könnte auch in geringem Umfang trotz Depolymerisierung des Zytoskeletts durch Diffusionsprozesse zu den Fis1 Bindungsstellen der Mitochondrien gelangen. Da die Zufuhr von Drp1 vermindert ist, ist die Ausbildung einer geschlossenen Struktur um das Mitochondrium nicht möglich, so dass eine Abschnürung unwahrscheinlich ist. Die Lokalisation geringer Mengen von Drp1 könnte jedoch ausreichen, um die Freisetzung von Cytochrom c zu ermöglichen.

In dem klassischen Apoptosemodell (Apoptoseinduktion durch Staurosporin), welches in der vorliegenden Arbeit überwiegend verwendet wurde, lässt sich jedoch feststellen, dass die mitochondriale Zerteilung zwar nicht hinreichend, aber notwendig für die neuronale Apoptose ist . 


\subsection{Mitochondrialer Zerfall und Apoptose}

Die Freisetzung von pro-apoptotischen Proteinen, wie Cytochrom c aus den Mitochondrien ist von entscheidender Bedeutung für die Apoptose (Green und Kroemer 2004). Es ist weitgehend akzeptiert, dass die Freisetzung pro-apoptotischer Proteine durch eine Permeabilisierung der äußeren Membran der Mitochondrien gesteuert wird (Cory und Adams 2002). Dieser Effekt wird durch pro-apoptotische Proteine der Bcl2 Familie vermittelt, insbesondere ist das Protein Bax essentiell (Wei et al. 2001), welches eine Pore in der mitochondrialen Membran formen kann. Wie Drp1 in der vorliegenden Studie liegt Bax zunächst inaktiv im Zytosol vor. Bei Apoptoseinduktion wird Bax aktiviert (Bouchier-Hayes et al. 2005, Huang und Strasser 2000) und zu den Mitochondrien transportiert. Die Proteine Bax und Drp1 kolokalisieren dann gemeinsam an den vermutlichen zukünftigen Teilungsstellen (Karbowski et al. 2002, Neuspiel et al. 2005). Diese Positionen könnten durch Fis1 definiert sein, da in Abwesenheit von Fis1 Bax nicht mehr zu den Mitochondrien verschoben wird (Lee et al. 2004). Beide Proteine werden vermutlich durch verschiedene Prozesse zuvor aktiviert. Für Bax ist eine Aktivierung durch tBit bekannt (Desagher et al. 1999, Sugioka et al. 2004), die Aktivierung von Drp1 ist bisher unbekannt.

Derzeit werden drei mögliche Zusammenhänge der mitochondrialen Zerteilung mit der Apoptosekaskade (Bax Pore) diskutiert (siehe Abbildung 63). Die Apoptose könnte in kausaler Abhängigkeit zum Zerfall der Mitochondrien stehen oder auch ein unabhängiger Prozess mit gleichem Auslöser sein.

Die Befunde dieser Studie legen den Schluss nahe, dass die Zerteilung der Mitochondrien der Permeabilisierung der Mitochondrienmembran notwendigerweise vorausgeht. Es konnte nachgewiesen werden, dass die Ausschüttung von Cytochrom c den mitochondrialen Zerfall erfordert (siehe Abbildung 27). Hemmung von Drp1 durch eine dominant negative Mutante scheint die Bildung einer Bax Pore zu hemmen. Dies erlaubt eine plausible Erklärung der selektiven Hemmung der Apoptose durch Bcl-xL (siehe Abbildung 30), ohne die Drp1 gesteuerte Rekrutierung von Bax zu behindern. Die Resultate mit Bcl-xL können nicht ausschließen, dass Drp1 und Bax unabhängig voneinander wirken. In diesem Fall müsste allerdings Drp1 $1_{\mathrm{K} 38 \mathrm{~A}}$ neben Drp1 auch die Permeabilisierung der Mitochondrienmembran hemmen, was für eine spezifische dominant negative Mutante ungewöhnlich wäre. Beobachtungen bei Zerstörung des Zytoskeletts, scheinen diese Erklärung in Frage zu stellen. Wie allerdings bereits im Kapitel 4.2 erläutert, ist die Einordnung dieser Resultate problematisch und steht nicht unbedingt im Widerspruch zu den Drp1 Inhibitionsbefunden.

Der Transport von Bax zu den Mitochondrien scheint durch Drp1 gesteuert zu sein, da Drp1 $1_{\mathrm{K} 38 \mathrm{~A}}$ die Rekrutierung von Bax zu den Mitochondrien verhindert (Yuan et al. 2006). 
Dies unterstützen Beobachtungen in Krebszelllinien, bei denen ein Ausschalten des Drp1 Gens zu einer Reduktion von Bax Akkumulationen an den Mitochondrien führt (Neuspiel et al. 2005). Es konnte in einer Vielzahl von Experimenten gezeigt werden, dass die Cytochrom c Freisetzung durch eine Hemmung von Drp1 während der Apoptose vermindert wird (Neuspiel et al. 2005, Sugioka et al. 2004). Die Freisetzung von Cytochrom c ist von der Bildung einer Bax Pore in der mitochondrialen Membran abhängig. In Einklang dazu stehen Studien an verschiedenen Zelllinien und C. elegans die zeigen, dass eine vermehrte mitochondriale Zerteilung für die Apoptose notwendig ist (Bossy-Wetzel et al. 2003, Jagasia et al. 2005, Youle und Karbowski 2005). Dies deckt sich mit dem Befund, dass die Zerteilung der Mitochondrien der Aktivierung von Bax vorausgeht (Breckenridge et al. 2003). Einige Studien konnten jedoch eine gegensinnige zeitliche Reihenfolge feststellen (Arnoult et al. 2005, Esseiva et al. 2004, Gao et al. 2001) und teilweise konnte kein Einfluss von Drp $1_{\mathrm{K} 38 \mathrm{~A}}$ auf die Bax Dynamik festgestellt werden (Frank et al. 2001, Lee und Kim 2004).

Der heutige Stand der Literatur vermittelt noch kein eindeutiges Bild (siehe Abbildung 63), unter Umständen existieren Unterschiede zwischen den einzelnen Spezies. In dieser Studie wurden Hinweise gefunden, dass in dopaminergen Neuronen die Freisetzung von Cytochrom c von Drp1 abhängig ist. 
A.
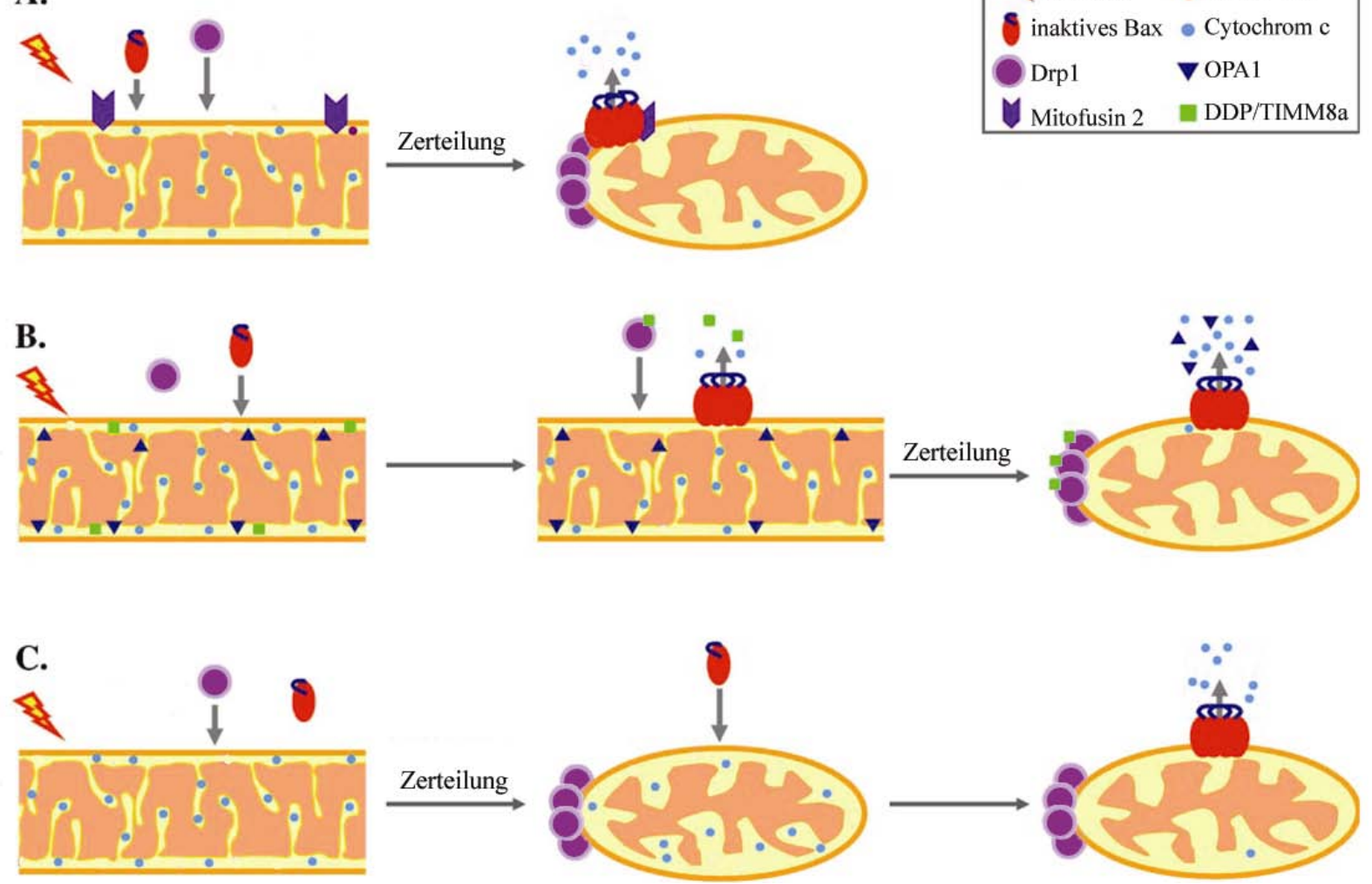

Abbildung 63: Mögliche Aktivierung der mitochondrialen Zerteilung während der Apoptose (nach Parone und Martinou 2006).

\section{Zwei parallele Prozesse (A)}

Der Apoptosestimulus führt zu einer Anlagerung von Bax und Drp1 an die Mitochondrien. Das aktive Bax induziert die Drp1 abhängige Zerteilung der Mitochondrien und inhibiert gleichzeitig die Verschmelzung der Mitochondrien durch eine Interaktion mit Mitofusin 2. Ebenso bildet das aktive Bax eine Pore in der äußeren Mitochondrienmembran, wodurch es zur Freisetzung pro-apototischer Proteine kommt.

Apoptose führt zu mitochondrialer Zerteilung (B)

Der Apoptosestimulus führt zu einer Translokalisation von Bax an die Mitochondrien. Die Bildung von Bax Oligomeren resultiert in einer Freisetzung von Proteinen (u.a. DDP/TIMM8a und Cytochrom c). Das nun im Zytosol befindliche DDP/TIMM8a rekrutiert Drp1 zu den Mitochondrien und es kommt zur Zerteilung der Organellen.

\section{Mitochondriale Zerteilung führt zu Apoptose (C)}

Pro-apoptotische Signale führen zu einer Translokalisation von Drp1 zu den Mitochondrien. Als Folge der Drp1 abhängigen mitochondrialen Fragmentierung wird eine Bax Pore gebildet, durch die pro-apototische Proteine freigesetzt werden.

\subsection{Regulation der mitochondrialen Zerteilung durch CDK5}

Der Zerfall der Mitochondrien konnte in dieser Arbeit als integraler Bestandteil des programmierten Zelltodes bestimmt werden. Darüber hinaus war es möglich, die Mechanismen, welche die Spaltung eines Mitochondriums bewirken weiter aufzuklären. Um Erkenntnisse über die Regulation der mitochondrialen Morphologie zu erhalten war es in der vorliegenden Studie hilfreich die Regulation anderer vergleichbarer zelluläre Mechanismen zu betrachten. Besonders deutlich sind Analogien zwischen der Umgestaltung der äußeren Mitochondrienmembran und der Zellmembran. An der Regulation von Umgestaltungsprozessen der Zellmembran ist häufig die Cyclin-abhängige Kinase 5 (CDK5) beteiligt. Innerhalb der Exo- 
cytose ist bekannt, dass die synaptischen Proteine Synapsin 1 (Matsubara et al. 1996) und Munc 18 (Fletcher et al. 1999) Substrate von CDK5 sind. Die Phosphorylierung von Munc 18 durch CDK5 ermöglicht die Abspaltung des Proteins von t-SNARE Syntaxin 1 und erlaubt somit eine Ausbildung des SNARE Komplex (siehe Kapitel 1.1.5.2).

Die Abschnürung von Vesikeln aus der Zellmembran innerhalb der Endocytose zeigt noch deutlicher Analogien zu den mitochondrialen Zerteilungsvorgängen. Bei beiden Vorgängen handelt es sich um Membranabschnürungen, während das Regulatorprotein der rezeptorgesteuerten Endocytose Dynamin ist, übernimmt Drp1 eine analoge Funktion für die Mitochondrienmembran. Beide Proteine gehören zu der Familie der Dynamin-ähnlichen GTPasen, deren Mitglieder meist an Membranumstrukturierungen beteiligt sind (siehe Abbildung 64, De Camilli et al. 1995, van der Bliek 1999). Sie weisen starke Domänen- und Sequenzhomologien auf (van der Bliek 1999). Die Funktion von Dynamin ist am besten in Säugetierzellen beschrieben. Bei der Vesikelausbildung während der Endocytose lagert es sich an die Clathrin-ummantelten Membraneinstülpungen an und induziert durch die Hydrolyse von GTP getrieben, die Abschnürung der endozytotischen Vesikel von der Membran (Sever et al. 2000, Sweitzer und Hinshaw 1998). CDK5 ist auch in der Regulation der Endocytose von herausragender Bedeutung. Dynamin wird zur Abschnürung der Membran durch CDK5 vermittelte Phosphorylierung aktiviert (Tan et al. 2003, Tomizawa et al. 2003). Wegen der Ähnlichkeit der Wirkweise und des Aufbaus von Dynamin und Drp1 und der Analogien zwischen den Prozessen in denen sie wirken, beeinflusst CDK5 vermutlich auch die mitochondriale Zerteilung durch Interaktion mit Drp1.

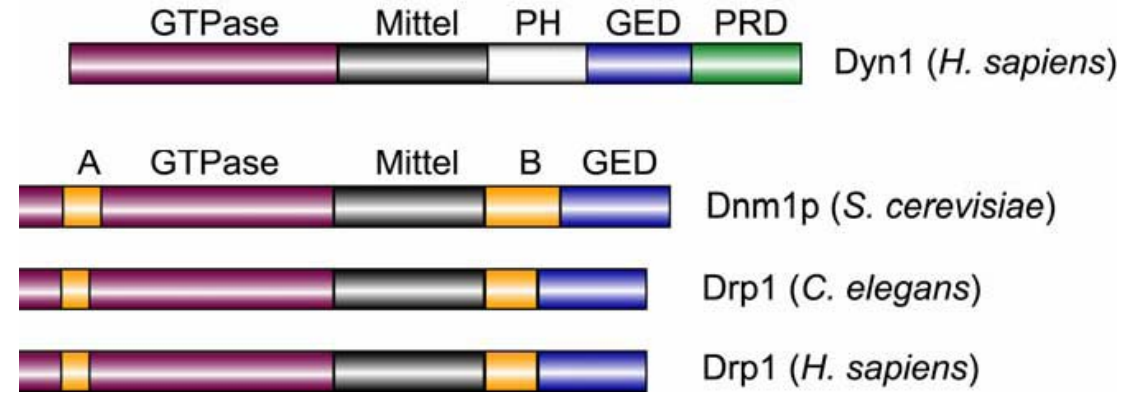

Abbildung 64: Vergleich der Domänenstruktur einiger Mitglieder der Dynamin- Familie (van der Bliek 1999).

Alle Dynamin Familienmitglieder besitzen eine GTPase-, eine Mittel- und GTPase Effektor Domäne (GED). Bei dem Dyn1 Protein des Menschen ist zusätzlich zwischen Mittel- und GTPase Effektor Domäne eine PleckstrinHomologie Domäne beschrieben sowie eine C-terminale Protein reiche Domäne (PRD). Andere Familienmitglieder dagegen besitzen abweichende Segmente im N- Terminus in der GTPasen Domäne (A) und zwischen Mittel- und GTPase Effektor Domäne (B).

In der vorliegenden Arbeit konnte erstmalig gezeigt werden, dass CDK5 auch an der Regulation der mitochondrialen Fragmentation beteiligt ist (siehe Abbildung 41). Es ist bekannt, 
dass CDK5 nur im Komplex mit einem Aktivatorprotein enzymatische Aktivität besitzt. Entsprechend konnte in dieser Studie keine Wirkung der Überexpression von CDK5 alleine festgestellt werden (unpublizierte Experimente). Ein bekanntes potentes Aktivatorprotein von CDK5 ist p25 (Patrick et al. 1999). Die Überexpression von p25 und CDK5 resultiert in einer spontanen Zerteilung der Mitochondrien, die dem apoptotischen Zerfall der Mitochondrien gleicht (siehe Abbildung 36, Abbildung 41 und Abbildung 61). Die durch den p25/CDK5 Komplex induzierte mitochondriale Fragmentation verläuft Caspase unabhängig (siehe Abbildung 41).

Der spontane Zerfall der Mitochondrien durch p25/CDK5 Überexpression ist auf eine Regulation von Drp1 zurückzuführen, da bei Hemmung des Drp1 Proteins p25/CDK5 den Zerfall der Mitochondrien nicht mehr induzieren kann (siehe Abbildung 41 und Abbildung 61). Umgekehrt kann in der Staurosporin induzierten Apoptose eine Hemmung des CDK5 induzierten mitochondrialen Zerfalls durch Überexpression von Drp1 wieder abgeschwächt werden (siehe Abbildung 43, Abbildung 48, Abbildung 54 und Abbildung 62). Hieraus folgt, dass CDK5 und Drp1 für den apoptotischen Zerfall der Mitochondrien notwendig sind und CDK5 die Aktivität von Drp1 reguliert.

Da CDK5 an der Organisation des Zytoskeletts beteiligt ist (Feng und Walsh 2001, Rashid et al. 2001), wäre neben einer direkten Aktivierung von Drp1 durch CDK5 auch vorstellbar, dass der p25/CDK5 Komplex den Transport der Drp1 Proteine zu den Mitochondrien reguliert (vergleiche Abbildung 20 mit Abbildung 37). Wie der durch Staurosporin induzierte mitochondriale Zerfall ist auch der p25/CDK5 induzierte von intakten Zytoskelettstrukturen abhängig (Abbildung 32), da nach Zerstörung der Aktin- und Tubulinstrukturen nur eine stark verminderte Fragmentation durch p25/CDK5 Überexpression eintritt (siehe Abbildung 41). Bei CDK5 Überexpression zeigten sich keine abweichende Befunde bezüglich des Zytoskeletts im Vergleich zu Staurosporininkubation.

Eine erhöhte Aktivierung von CDK5 übt einen toxischen Effekt aus (Patrick et al. 1999), dieser Effekt konnte auch in der vorliegenden Studie beobachte werden (siehe Abbildung 41, Abbildung 61). Die Hemmung von CDK5 vermindert die Cytochrom c Freisetzung (siehe Abbildung 46, Abbildung 50) und somit die Apoptoserate nach Staurosporininkubation (Abbildung 47, Abbildung 51, Abbildung 62). CDK5 nimmt in vielen neuronalen ZelltodKaskaden eine wichtige Position ein (Dhavan und Tsai 2001, Nguyen et al. 2001, Osuga et al. 2000, Smith et al. 2003, Zheng et al. 2005). Es ist jedoch bis zum heutigen Zeitpunkt unklar wie CDK5 genau in die intrinsische Zelltodkaskade eingreift. Erstmalig wurde in der vorliegenden Arbeit eine Hemmung des p25/CDK5 induzierten Zelltodes durch eine Überexpression von Drp1 $1_{\mathrm{K} 38 \mathrm{~A}}$ beschrieben (siehe Abbildung 41 und Abbildung 61). Diese domi- 
nant negative Mutante verdrängt Drp1 und verhindert so den Zerfall der Mitochondrien. Dies deutet daraufhin, dass CDK5 den neuronalen Zelltod mittels des mitochondrialen Zerfalls induzieren könnte (siehe Abbildung 65). Dieser Zusammenhang wird auch durch die antagonistische Wirkung von Drp1 Überexpression auf eine Hemmung von CDK5 mittels einer dominant negativen Mutante verdeutlicht (siehe Abbildung 45).

\subsection{Einordnung von CDK5 in die neuronale Apoptosekaskade}

Wenn CDK5 den Zerfall der Mitochondrien reguliert, sollte seine Expression oder Aktivität nach Apoptoseinduktion erhöht sein. Ein erhöhtes CDK5 Expressionsniveau konnte nach Staurosporinbehandlung in dCSM14.1 Zellen nicht nachgewiesen werden (siehe Abbildung 38). Das Expressionsmuster von CDK5 scheint völlig unbeeinflusst vom Verlauf der Apoptose zu sein. Ein ähnliches Expressionsmuster zeigen auch G108-15 Zellen, die nach Staurosporinbehandlung weiterhin CDK5 konstant exprimieren (Zhang et al. 2003). Dieses Verhalten ist allerdings nicht für alle Zelltypen charakteristisch, so zeigen hippokampale Neurone (Kerokoski et al. 2001) und auch sympathische Neurone von Hühnern (Shirvan et al. 1998) nach der Behandlung mit verschiedenen Apoptose induzierenden Substanzen sogar eine Herabregulierung von CDK5.

In den Zellkulturen dieser Arbeit könnte die apoptotische Wirkung von CDK5 über eine Aktivitätssteigerung vermittelt werden. Es konnte gezeigt werden, dass die enzymatische Aktivität von CDK5 innerhalb der Apoptose tatsächlich erhöht ist (siehe Abbildung 40). Diese Aktivität ist übereinstimmend mit dem schnellen Begin der mitochondrialen Zerteilung, bereits eine Minute nach Apoptoseinduktion deutlich erhöht.

Bisher ist weitgehend geklärt, dass erhöhte CDK5- Aktivität toxisch wirkt (siehe Kapitel 1.2), es sind jedoch nur wenige Mechanismen bekannt, wie CDK5 in den intrinsischen Apoptoseweg eingreifen kann. In der vorliegenden Arbeit wurde ein neuer Mechanismus über die CDK5 vermittelte Zerteilung der Mitochondrien aufgezeigt.

Es scheint sich um einen hochkonservierten Prozess zu handeln. Neben den Untersuchungen an dCSM14.1 Neuronen konnte der fast gleiche Effekt in primären Mittelhirnneuronen der Ratte nachgewiesen werden. Auch in niederen Eukaryonten wie der Bäckerhefe S. cerevisiae zeigt das CDK5 homologe PHO85 (Huang et al. 1999) Einfluss auf die Mitochondrienmorphologie (Meuer et al. 2007). Apho85 Hefedeletionsstämme zeigen neben anderen Anomalien (Nishizawa et al. 1999) auch elongiertere Mitochondrien als der Wildtyp-Stamm (Meuer et al. 2007).

Der Einfluss einer erhöhten Aktivierungspotenz von CDK5 auf die Mitochondrien könnte auf direktem Wege vermittelt sein. Wie erläutert besitzen Drp1 und Dynamin hohe Sequenz- 
homologien (siehe Abbildung 64). Da Dynamin von CDK5 direkt phosphoryliert wird (Tomizawa et al. 2003) ist eine entsprechende Wirkung auf Drp1 naheliegend. Diese Wechselwirkung würde auch die bereits postulierte Steuerung der mitochondrialen Zerteilung durch Aktivierung von Drp1 belegen. Leider konnte im Rahmen dieser Arbeit nicht nachgewiesen werden, dass Drp1 ein direktes Substrat von CDK5 ist. Es konnte allerdings gezeigt werden, dass der Effekt der p25/CDK5 Überexpression auf die Mitochondrienmorphologie durch Hemmung von Drp1 vermindert wird (siehe Abbildung 41 und Abbildung 61). Auf Grund der Größe des Drp1 Proteins (80 kDa) war eine Aufreinigung nicht möglich, folglich konnten keine Phospohorylierungsuntersuchungen durchgeführt werden. Versuche diese Experimente mit Drp1 überexprimierenden Zellen zu wiederholen misslangen vermutlich wegen der zu geringen Drp1 Konzentration im Zelllysat. Wenn eine direkte Wechselwirkung vorliegt, so scheint diese jedoch nicht langanhaltend und stark zu sein, da es nicht möglich war die Protein-Protein Interaktion mittels Immunopräzipitation nachzuweisen, dennoch ist eine Interaktion wahrscheinlich.

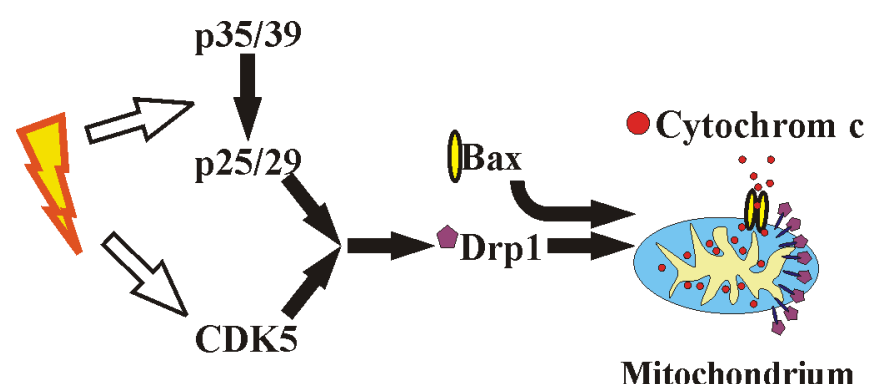

\section{Abbildung 65: Modell zur CDK5 Interaktion während der Apoptose.}

Dargestellt ist ein Modell zur Wirkweise von CDK5 nach Apoptoseinduktion, das die meisten Resultate der vorliegenden Studie berücksichtigt. Ein Apoptosestimulus (Blitz, links) führt zur Bildung eines aktiven CDK5 \& p25/p29 Komplexes. Die Komplexbildung könnte durch die Umwandlung von p35/39 zu p25/29 begünstigt werden, beispielsweise durch erhöhte Calpain Expression (Smith et al. 2006). Alternativ wäre eine Komplexbildung mit weiteren Proteinen oder Interaktion mit den Reaktionspartnern denkbar. Der CDK5 Komplex aktiviert Drp1, das darauf zu den Mitochondrien transportiert wird. Durch Drp1 wird ebenso Bax zu den Mitochondrien transportiert. Am Mitochondrium bilden sich ein Drp1-Fis1 Komplex und eine Bax-Pore. Ersterer verursacht die Zerteilung des Mitochondriums, zweiterer verursacht einen Cytochrom c Ausstrom der den Ablauf der Apoptosekaskade fördert.

Weitere indirekte Hinweise für eine Wechselwirkung zwischen CDK5 und Drp1 liefern Inhibitionsexperimente. Der mitochondriale Zerfall und die Apoptoserate nach Staurosporin Inkubation sind deutlich vermindert, wenn die Verfügbarkeit von CDK5 mittels siRNS herabgesetzt ist (siehe Abbildung 52). Die gleiche Wirkung kann durch Überexpression einer dominant negativen Mutante $\left(\mathrm{CDK}_{\mathrm{N} 144}\right)$ erreicht werden (vergleiche Abbildung 43). Der Effekt der Hemmung von CDK5 durch $\mathrm{CDK}_{\mathrm{N} 144}$ wird bei Kotransfektion von Drp1 deutlich gemindert (siehe Abbildung 45). Diese Aufhebung der Inhibition ist im Gegensatz 
hierzu bei Einsatz von siRNS nicht möglich (siehe Abbildung 55). Die Resultate zeigen mehrere mögliche Inhibitionsmechanismen für $\mathrm{CDK}_{\mathrm{N} 144}$ auf. Erstens könnte der Inhibitor direkt das endogene CDK5 inaktivieren und selbst wiederum durch Drp1 in hoher Konzentration aus dieser Interaktion verdrängt werden bzw. könnte die erhöhte Drp1 Konzentration die verminderte CDK5- Aktivität kompensieren. Weiterhin könnte der Inhibitor die Reaktionspartner (Drp1 Proteine) des endogenen CDK5 blockieren und erst die Überexpression von Drp1 stellt wieder genügend Reaktionspartner zu Verfügung. Diese Überlegungen deuten daraufhin, dass CDK5 und Drp1 sich beeinflussen. Dies steht im Einklang zu ersten Indizien, dass Drp1 ein Substrat von CDK5 ist (K. Tomizawa, persönliche Mitteilung).

Die Kontrolle der mitochondrialen Fragmentation könnte für viele neurodegenerative Erkrankungen von besonderer Bedeutung sein. Daher wurde in dieser Arbeit auch versucht CDK5 pharmakologisch zu beeinflussen. Erfolgreiche Experimente waren mit dem Wirkstoff Indolinon A möglich. Die Substanz von der Firma Boeringer Ingelheim wurde ursprünglich bei einem Screening-Verfahren nach CDK1-4 Inhibitoren zur Tumorbehandlung entdeckt (F. Gillardon, persönliche Mitteilung) und erwies sich im Tierversuch als wirksames Schlaganfalltherapeutikum (Weishaupt et al. 2003). Es wurde festgestellt, dass Indolinon A ein hochwirksamer CDK5 Inhibitor ist (Bain et al. 2003). In dieser Arbeit zeigte sich eine deutliche Hemmung der mitochondrialen Fragmentation bei Apoptose durch Indolinon A. Indolinon A übertrifft hinsichtlich der Hemmung der mitochondrialen Zerteilung den Effekt von CDK5 $5_{\mathrm{N} 144}$, zeigt aber tendenziell gleiche Wirkung.

Mit Indolinon A ist ein Substrat identifiziert, welches eine pharmakologische Beeinflussung der mitochondrialen Zerteilung erlaubt. In dieser Studie wurde gezeigt, dass die CDK5 regulierte mitochondriale Fragmentation ein Bestandteil der frühe neuronalen Apoptosekaskade ist und somit die mitochondrialen Zerteilungsprozesse ein vielversprechendes Ziel für therapeutische Beeinflussung neurodegenerativer Krankheiten sein könnten. 


\section{Zusammenfassung}

Unter physiologischen Bedingungen befinden sich die Mitochondrien in einem Gleichgewicht aus Teilungs- und Verschmelzungsvorgängen. Während der Apoptose ist dieses Gleichgewicht gestört, die Mitochondrien werden vermehrt zerteilt und liegen als kleine Fragmente im Zytosol vor.

Die Cyclin- abhängige Kinase 5 (CDK5) übernimmt wichtige regulatorische Funktionen während der neuronalen Apoptose. Sie greift sehr früh in die neuronale Zelltodkaskade ein, noch bevor es zur mitochondrialen Dysfunktion kommt (Weishaupt et al. 2003). Ebenso steuert sie Membranabschnürungen der Zelle, die durch ähnliche Abläufe wie die Zerteilung der Mitochondrien erfolgen.

Bisher war sehr wenig über die Mechanismen bekannt, welche die Morphologie der Mitochondrien regulieren. In der vorliegenden Studie wurde daher untersucht, ob CDK5 als Regulator der mitochondrialen Morphologie während der neuronalen Apoptose in Betracht kommt.

Es konnte gezeigt werden, dass die mitochondriale Fragmentation ein sehr früh stattfindendes Ereignisse während der neuronalen Apoptose ist, welche eine invariante Zeitdynamik aufweist. Ohne Induktion des mitochondrialen Zerfalls kann Cytochrom c nicht aus den Mitochondrien freigesetzt werden. Die mitochondriale Fragmentation erwies sich als notwendig, jedoch nicht hinreichend für die neuronale Apoptose.

Die Verwendung eines pharmakologischen CDK5 Inhibitor, einer dominant negativen Mutante von CDK5 oder von siRNS gegen CDK5 charakterisierten CDK5 als eine regulatorische Kinase der mitochondrialen Zerteilung während der neuronalen Apoptose. Weiter konnte gezeigt werden, dass die mitochondriale Fragmentation ein Modulator der CDK5 vermittelte Neurotoxizität sein kann. Somit konnte in der vorliegenden Arbeit die regulatorische Funktion von CDK5 während der Apoptose in die bereits bekannte neuronale Apoptosekaskade eingegliedert werden. 


\section{Literaturverzeichnis}

Abbott BJ, Fukuda DS, Dorman DE, Occolowitz JL, Debono M und Farhner L (1979) Microbial transformation of A23187, a divalent cation ionophore antibiotic. Antimicrob.Agents Chemother. 16, 808-812.

Adams JM und Cory S (2001) Life-or-death decisions by the Bcl-2 protein family. Trends Biochem Sci. 26, 61-66.

Alberts B, Bray D und Lewis J (1997) Molekularbiologie der Zelle. VCH Verlagsgesellschaft mbH 3.

Alexander C, Votruba M, Pesch UE, Thiselton DL, Mayer S, Moore A, Rodriguez M, Kellner U, LeoKottler B, Auburger G, Bhattacharya SS und Wissinger B (2000) OPA1, encoding a dynaminrelated GTPase, is mutated in autosomal dominant optic atrophy linked to chromosome 3q28. Nat.Genet. 26, 211-215.

Alnemri ES (1999) Hidden powers of the mitochondria. Nat.Cell Biol. 1, E40-E42.

Alvarez A, Munoz JP und Maccioni RB (2001) A Cdk5-p35 stable complex is involved in the betaamyloid-induced deregulation of Cdk5 activity in hippocampal neurons. Exp.Cell Res. 264, 266-274.

Amin ND, Albers W und Pant HC (2002) Cyclin-dependent kinase 5 (cdk5) activation requires interaction with three domains of p35. J.Neurosci.Res. 67, 354-362.

Anesti V und Scorrano L (2006) The relationship between mitochondrial shape and function and the cytoskeleton. Biochim.Biophys.Acta 1757, 692-699.

Antonsson B (2001) Bax and other pro-apoptotic Bcl-2 family "killer-proteins" and their victim the mitochondrion. Cell Tissue Res. 306, 347-361.

Arnoult D, Rismanchi N, Grodet A, Roberts RG, Seeburg DP, Estaquier J, Sheng M und Blackstone C (2005) Bax/Bak-dependent release of DDP/TIMM8a promotes Drp1-mediated mitochondrial fission and mitoptosis during programmed cell death. Curr.Biol. 15, 2112-2118.

Bain J, McLauchlan H, Elliott M und Cohen P (2003) The specificities of protein kinase inhibitors: an update. Biochem J. 371, 199-204.

Bajaj NP, Al Sarraj ST, Anderson V, Kibble M, Leigh N und Miller CC (1998) Cyclin-dependent kinase- 5 is associated with lipofuscin in motor neurones in amyotrophic lateral sclerosis. Neurosci.Lett. 245, 45-48.

Bakeeva LE, Chentsov Y und Skulachev VP (1978) Mitochondrial framework (reticulum mitochondriale) in rat diaphragm muscle. Biochim.Biophys.Acta 501, 349-369.

Barsoum MJ, Yuan H, Gerencser AA, Liot G, Kushnareva Y, Graber S, Kovacs I, Lee WD, Waggoner J, Cui J, White AD, Bossy B, Martinou JC, Youle RJ, Lipton SA, Ellisman MH, Perkins GA und Bossy-Wetzel E (2006) Nitric oxide-induced mitochondrial fission is regulated by dynamin-related GTPases in neurons. EMBO J.

Barylko B, Binns D, Lin KM, Atkinson MA, Jameson DM, Yin HL und Albanesi JP (1998) Synergistic activation of dynamin GTPase by Grb2 and phosphoinositides. J.Biol.Chem. 273, 3791-3797.

Bereiter-Hahn J und Voth M (1994) Dynamics of mitochondria in living cells: shape changes, dislocations, fusion, and fission of mitochondria. Microsc.Res.Tech. 27, 198-219.

Birnboim HC und Doly J (1979) A rapid alkaline extraction procedure for screening recombinant plasmid DNA. Nucleic Acids Res. 7, 1513-1523.

Bleazard W, McCaffery JM, King EJ, Bale S, Mozdy A, Tieu Q, Nunnari J und Shaw JM (1999) The dynamin-related GTPase Dnm1 regulates mitochondrial fission in yeast. Nat.Cell Biol. 1, 298304.

Boldogh IR, Yang HC, Nowakowski WD, Karmon SL, Hays LG, Yates JR, III und Pon LA (2001) Arp2/3 complex and actin dynamics are required for actin-based mitochondrial motility in yeast. Proc.Natl.Acad.Sci.U.S.A 98, 3162-3167.

Bossy-Wetzel E, Barsoum MJ, Godzik A, Schwarzenbacher R und Lipton SA (2003) Mitochondrial fission in apoptosis, neurodegeneration and aging. Curr.Opin.Cell Biol. 15, 706-716.

Bouchier-Hayes L, Lartigue L und Newmeyer DD (2005) Mitochondria: pharmacological manipulation of cell death. J.Clin.Invest 115, 2640-2647.

Breckenridge DG, Stojanovic M, Marcellus RC und Shore GC (2003) Caspase cleavage product of BAP31 induces mitochondrial fission through endoplasmic reticulum calcium signals, enhancing cytochrome $c$ release to the cytosol. J.Cell Biol. 160, 1115-1127.

Brion JP und Couck AM (1995) Cortical and brainstem-type Lewy bodies are immunoreactive for the cyclin-dependent kinase 5. Am.J.Pathol. 147, 1465-1476.

Budihardjo I, Oliver H, Lutter M, Luo X und Wang X (1999) Biochemical pathways of caspase activation during apoptosis. Annu.Rev.Cell Dev.Biol. 15, 269-290. 
Cai XH, Tomizawa K, Tang D, Lu YF, Moriwaki A, Tokuda M, Nagahata S, Hatase O und Matsui H (1997) Changes in the expression of novel Cdk5 activator messenger RNA (p39nck5ai mRNA) during rat brain development. Neurosci.Res. 28, 355-360.

Canudas AM, Jorda EG, Verdaguer E, Jimenez A, Sureda FX, Rimbau V, Camins A und Pallas M (2004) Cyclosporin A enhances colchicine-induced apoptosis in rat cerebellar granule neurons. Br.J.Pharmacol. 141, 661-669.

Carelli V, Rugolo M, Sgarbi G, Ghelli A, Zanna C, Baracca A, Lenaz G, Napoli E, Martinuzzi A und Solaini G (2004) Bioenergetics shapes cellular death pathways in Leber's hereditary optic neuropathy: a model of mitochondrial neurodegeneration. Biochim.Biophys.Acta 1658, 172179.

Carr JF und Hinshaw JE (1997) Dynamin assembles into spirals under physiological salt conditions upon the addition of GDP and gamma-phosphate analogues. J.Biol.Chem. 272, 2803028035.

Ceccatelli S, Tamm C, Sleeper E und Orrenius S (2004) Neural stem cells and cell death. Toxicol.Lett. 149, 59-66.

Cerveny KL und Jensen RE (2003) The WD-repeats of Net2p interact with Dnm1p and Fis1p to regulate division of mitochondria. Mol.Biol.Cell 14, 4126-4139.

Chae HJ, Kang JS, Byun JO, Han KS, Kim DU, Oh SM, Kim HM, Chae SW und Kim HR (2000) Molecular mechanism of staurosporine-induced apoptosis in osteoblasts. Pharmacol.Res. 42, 373-381.

Chan DC (2006) Mitochondrial fusion and fission in mammals. Annu.Rev.Cell Dev.Biol. 22, 79-99.

Chen W, Calvo PA, Malide D, Gibbs J, Schubert U, Bacik I, Basta S, O'Neill R, Schickli J, Palese P, Henklein P, Bennink JR und Yewdell JW (2001) A novel influenza A virus mitochondrial protein that induces cell death. Nat.Med. 7, 1306-1312.

Ching YP, Pang AS, Lam WH, Qi RZ und Wang JH (2002) Identification of a neuronal Cdk5 activatorbinding protein as Cdk5 inhibitor. J.Biol.Chem. 277, 15237-15240.

Cikala M, Wilm B, Hobmayer E, Bottger A und David CN (1999) Identification of caspases and apoptosis in the simple metazoan Hydra. Curr.Biol. 9, 959-962.

Collins TJ, Berridge MJ, Lipp P und Bootman MD (2002) Mitochondria are morphologically and functionally heterogeneous within cells. EMBO J. 21, 1616-1627.

Cory S und Adams JM (2002) The Bcl2 family: regulators of the cellular life-or-death switch. Nat.Rev.Cancer 2, 647-656.

Croteau DL, Stierum RH und Bohr VA (1999) Mitochondrial DNA repair pathways. Mutat.Res. 434, 137-148.

Danial NN und Korsmeyer SJ (2004) Cell death: critical control points. Cell 116, 205-219.

De Camilli P, Takei K und McPherson PS (1995) The function of dynamin in endocytosis. Curr.Opin.Neurobiol. 5, 559-565.

De Vos K, Goossens V, Boone E, Vercammen D, Vancompernolle K, Vandenabeele P, Haegeman G, Fiers W und Grooten J (1998) The 55-kDa tumor necrosis factor receptor induces clustering of mitochondria through its membrane-proximal region. J.Biol.Chem. 273, 96739680.

De Vos KJ, Allan VJ, Grierson AJ und Sheetz MP (2005) Mitochondrial function and actin regulate dynamin-related protein 1-dependent mitochondrial fission. Curr.Biol. 15, 678-683.

Delalle I, Bhide PG, Caviness VS, Jr. und Tsai LH (1997) Temporal and spatial patterns of expression of p35, a regulatory subunit of cyclin-dependent kinase 5 , in the nervous system of the mouse. J.Neurocytol. 26, 283-296.

Delettre C, Lenaers G, Griffoin JM, Gigarel N, Lorenzo C, Belenguer P, Pelloquin L, Grosgeorge J, Turc-Carel C, Perret E, Astarie-Dequeker C, Lasquellec L, Arnaud B, Ducommun B, Kaplan J und Hamel CP (2000) Nuclear gene OPA1, encoding a mitochondrial dynamin-related protein, is mutated in dominant optic atrophy. Nat.Genet. 26, 207-210.

Desagher S, Osen-Sand A, Nichols A, Eskes R, Montessuit S, Lauper S, Maundrell K, Antonsson B und Martinou JC (1999) Bid-induced conformational change of Bax is responsible for mitochondrial cytochrome c release during apoptosis. J.Cell Biol. 144, 891-901.

Dhavan R und Tsai LH (2001) A decade of CDK5. Nat.Rev.Mol.Cell Biol. 2, 749-759.

Dietz GP und Bahr M (2004) Delivery of bioactive molecules into the cell: the Trojan horse approach. Mol.Cell Neurosci. 27, 85-131.

Dietz GP, Kilic E und Bahr M (2002) Inhibition of neuronal apoptosis in vitro and in vivo using TATmediated protein transduction. Mol.Cell Neurosci. 21, 29-37.

Drubin DG, Jones HD und Wertman KF (1993) Actin structure and function: roles in mitochondrial organization and morphogenesis in budding yeast and identification of the phalloidin-binding site. Mol.Biol.Cell 4, 1277-1294. 
Duncan CJ, Greenaway HC, Publicover SJ, Rudge MF und Smith JL (1980) Experimental production of "septa" and apparent subdivision of muscle mitochondria. J.Bioenerg.Biomembr. 12, 1333.

Earnshaw WC, Martins LM und Kaufmann SH (1999) Mammalian caspases: structure, activation, substrates, and functions during apoptosis. Annu.Rev.Biochem 68, 383-424.

Egner A, Jakobs S und Hell SW (2002) Fast 100-nm resolution three-dimensional microscope reveals structural plasticity of mitochondria in live yeast. Proc.Natl.Acad.Sci.U.S.A 99, 3370-3375.

Esseiva AC, Chanez AL, Bochud-Allemann N, Martinou JC, Hemphill A und Schneider A (2004) Temporal dissection of Bax-induced events leading to fission of the single mitochondrion in Trypanosoma brucei. EMBO Rep. 5, 268-273.

Feng Y und Walsh CA (2001) Protein-protein interactions, cytoskeletal regulation and neuronal migration. Nat.Rev.Neurosci. 2, 408-416.

Fiskum G, Starkov A, Polster BM und Chinopoulos C (2003) Mitochondrial mechanisms of neural cell death and neuroprotective interventions in Parkinson's disease. Ann.N.Y.Acad.Sci. 991, 111119.

Fletcher Al, Shuang R, Giovannucci DR, Zhang L, Bittner MA und Stuenkel EL (1999) Regulation of exocytosis by cyclin-dependent kinase 5 via phosphorylation of Munc18. J.Biol.Chem. 274, 4027-4035.

Frank S, Gaume B, Bergmann-Leitner ES, Leitner WW, Robert EG, Catez F, Smith CL und Youle RJ (2001) The role of dynamin-related protein 1, a mediator of mitochondrial fission, in apoptosis. Dev.Cell 1, 515-525.

Frank S, Robert EG und Youle RJ (2003) Scission, spores, and apoptosis: a proposal for the evolutionary origin of mitochondria in cell death induction. Biochem Biophys.Res.Commun. 304, 481-486.

Frey TG und Mannella CA (2000) The internal structure of mitochondria. Trends Biochem.Sci. 25, 319-324.

Frieden M, James D, Castelbou C, Danckaert A, Martinou JC und Demaurex N (2004) Ca(2+) homeostasis during mitochondrial fragmentation and perinuclear clustering induced by hFis1. J.Biol.Chem. 279, 22704-22714.

Fritz S, Rapaport D, Klanner E, Neupert W und Westermann B (2001) Connection of the mitochondrial outer and inner membranes by Fzo1 is critical for organellar fusion. J.Cell Biol. 152, 683-692.

Fu WY, Wang JH und Ip NY (2002) Expression of Cdk5 and its activators in NT2 cells during neuronal differentiation. J.Neurochem. 81, 646-654.

Fukushima NH, Brisch E, Keegan BR, Bleazard W und Shaw JM (2001) The GTPase effector domain sequence of the Dnm1p GTPase regulates self-assembly and controls a rate-limiting step in mitochondrial fission. Mol.Biol.Cell 12, 2756-2766.

Gao W, Pu Y, Luo KQ und Chang DC (2001) Temporal relationship between cytochrome c release and mitochondrial swelling during UV-induced apoptosis in living HeLa cells. J.Cell Sci. 114, 2855-2862.

Goldstein JC, Munoz-Pinedo C, Ricci JE, Adams SR, Kelekar A, Schuler M, Tsien RY und Green DR (2005) Cytochrome $c$ is released in a single step during apoptosis. Cell Death.Differ. 12, 453462.

Goldstein JC, Waterhouse NJ, Juin P, Evan GI und Green DR (2000) The coordinate release of cytochrome c during apoptosis is rapid, complete and kinetically invariant. Nat.Cell Biol. 2, 156-162.

Gong X, Tang X, Wiedmann M, Wang X, Peng J, Zheng D, Blair LA, Marshall J und Mao Z (2003) Cdk5-mediated inhibition of the protective effects of transcription factor MEF2 in neurotoxicity-induced apoptosis. Neuron 38, 33-46.

Grand P, Sharma P und Pant HC (2001) Cyclin-dependent protein kinase 5 (cdk5) and the regulation of neurofilament metabolism. Eur.J.Biochem 268, 1534-1546.

Gray MW, Burger G und Lang BF (1999) Mitochondrial evolution. Science 283, 1476-1481.

Green DR und Kroemer G (2004) The pathophysiology of mitochondrial cell death. Science 305, 626629.

Griffin EE, Graumann J und Chan DC (2005) The WD40 protein Caf4p is a component of the mitochondrial fission machinery and recruits Dnm1p to mitochondria. J.Cell Biol. 170, 237248.

Griparic L und van der Bliek AM (2001) The many shapes of mitochondrial membranes. Traffic. 2, 235-244.

Haas SJ und Wree A (2002) Dopaminergic differentiation of the Nurr1-expressing immortalized mesencephalic cell line CSM14.1 in vitro. J.Anat. 201, 61-69. 
Hales KG und Fuller MT (1997) Developmentally regulated mitochondrial fusion mediated by a conserved, novel, predicted GTPase. Cell 90, 121-129.

Halestrap AP, Kerr PM, Javadov S und Woodfield KY (1998) Elucidating the molecular mechanism of the permeability transition pore and its role in reperfusion injury of the heart. Biochim.Biophys.Acta 1366, 79-94.

Harada T, Morooka T, Ogawa S und Nishida E (2001) ERK induces p35, a neuron-specific activator of Cdk5, through induction of Egr1. Nat.Cell Biol. 3, 453-459.

Harder Z, Zunino R und McBride H (2004) Sumo1 conjugates mitochondrial substrates and participates in mitochondrial fission. Curr.Biol. 14, 340-345.

Hayashi T, Warita H, Abe K und Itoyama Y (1999) Expression of cyclin-dependent kinase 5 and its activator p35 in rat brain after middle cerebral artery occlusion. Neurosci.Lett. 265, 37-40.

Henchcliffe C und Burke RE (1997) Increased expression of cyclin-dependent kinase 5 in induced apoptotic neuron death in rat substantia nigra. Neurosci.Lett. 230, 41-44.

Hermann GJ und Shaw JM (1998) Mitochondrial dynamics in yeast. Annu.Rev.Cell Dev.Biol. 14, 265303.

Herskovits JS, Shpetner HS, Burgess CC und Vallee RB (1993) Microtubules and Src homology 3 domains stimulate the dynamin GTPase via its C-terminal domain. Proc.Natl.Acad.Sci.U.S.A 90, 11468-11472.

Hinshaw JE und Schmid SL (1995) Dynamin self-assembles into rings suggesting a mechanism for coated vesicle budding. Nature 374, 190-192.

Hobbs AE, Srinivasan M, McCaffery JM und Jensen RE (2001) Mmm1p, a mitochondrial outer membrane protein, is connected to mitochondrial DNA (mtDNA) nucleoids and required for mtDNA stability. J.Cell Biol. 152, 401-410.

Hollenbeck PJ (1996) The pattern and mechanism of mitochondrial transport in axons. Front Biosci. 1, d91-102.

Huang D, Patrick G, Moffat J, Tsai LH und Andrews B (1999) Mammalian Cdk5 is a functional homologue of the budding yeast Pho85 cyclin-dependent protein kinase. Proc.Natl.Acad.Sci.U.S.A 96, 14445-14450.

Huang DC und Strasser A (2000) BH3-Only proteins-essential initiators of apoptotic cell death. Cell 103, 839-842.

Hwa JJ, Hiller MA, Fuller MT und Santel A (2002) Differential expression of the Drosophila mitofusin genes fuzzy onions (fzo) and dmfn. Mech.Dev. 116, 213-216.

Ingerman E, Perkins EM, Marino M, Mears JA, McCaffery JM, Hinshaw JE und Nunnari J (2005) Dnm1 forms spirals that are structurally tailored to fit mitochondria. J.Cell Biol. 170, 10211027.

Jacobson MD, Weil M und Raff MC (1997) Programmed cell death in animal development. Cell 88, 347-354.

Jagasia R, Grote P, Westermann B und Conradt B (2005) DRP-1-mediated mitochondrial fragmentation during EGL-1-induced cell death in C. elegans. Nature 433, 754-760.

James DI, Parone PA, Mattenberger Y und Martinou JC (2003) hFis1, a novel component of the mammalian mitochondrial fission machinery. J.Biol.Chem. 278, 36373-36379.

Jeong YG, Rosales JL, Marzban H, Sillitoe RV, Park DG, Hawkes R und Lee KY (2003) The cyclindependent kinase 5 activator, p39, is expressed in stripes in the mouse cerebellum. Neuroscience 118, 323-334.

Karbowski M, Arnoult D, Chen H, Chan DC, Smith CL und Youle RJ (2004) Quantitation of mitochondrial dynamics by photolabeling of individual organelles shows that mitochondrial fusion is blocked during the Bax activation phase of apoptosis. J.Cell Biol. 164, 493-499.

Karbowski M, Lee YJ, Gaume B, Jeong SY, Frank S, Nechushtan A, Santel A, Fuller M, Smith CL und Youle RJ (2002) Spatial and temporal association of Bax with mitochondrial fission sites, Drp1, and Mfn2 during apoptosis. J.Cell Biol. 159, 931-938.

Kaufmann SH und Earnshaw WC (2000) Induction of apoptosis by cancer chemotherapy. Exp.Cell Res. 256, 42-49.

Kerokoski P, Suuronen T, Salminen A, Soininen H und Pirttila T (2001) The levels of cdk5 and p35 proteins and tau phosphorylation are reduced during neuronal apoptosis. Biochem Biophys.Res.Commun. 280, 998-1002.

Kerr JF, Wyllie AH und Currie AR (1972) Apoptosis: a basic biological phenomenon with wide-ranging implications in tissue kinetics. Br.J.Cancer 26, 239-257.

Kesavapany S, Amin N, Zheng YL, Nijhara R, Jaffe H, Sihag R, Gutkind JS, Takahashi S, Kulkarni A, Grant P und Pant HC (2004) p35/cyclin-dependent kinase 5 phosphorylation of ras guanine nucleotide releasing factor 2 (RasGRF2) mediates Rac-dependent Extracellular Signalregulated kinase $1 / 2$ activity, altering RasGRF2 and microtubule-associated protein $1 b$ distribution in neurons. J.Neurosci. 24, 4421-4431. 
Khodjakov A, Lizunova EM, Minin AA, Koonce MP und Gyoeva FK (1998) A specific light chain of kinesin associates with mitochondria in cultured cells. Mol.Biol.Cell 9, 333-343.

Kilic E, Kilic U und Hermann DM (2006) TAT fusion proteins against ischemic stroke: current status and future perspectives. Front Biosci. 11, 1716-1721.

Klockow B, Tichelaar W, Madden DR, Niemann HH, Akiba T, Hirose K und Manstein DJ (2002) The dynamin A ring complex: molecular organization and nucleotide-dependent conformational changes. EMBO J. 21, 240-250.

Koch A, Yoon Y, Bonekamp NA, McNiven MA und Schrader M (2005) A Role for Fis1 in Both Mitochondrial and Peroxisomal Fission in Mammalian Cells. Mol.Biol.Cell.

Kochs G, Trost M, Janzen C und Haller O (1998) MxA GTPase: oligomerization and GTP-dependent interaction with viral RNP target structures. Methods 15, 255-263.

Kong D, Xu L, Yu Y, Zhu W, Andrews DW, Yoon Y und Kuo TH (2005) Regulation of Ca2+-induced permeability transition by Bcl-2 is antagonized by Drpl and hFis1. Mol.Cell Biochem 272, 187199.

Kotake Y und Ohta S (2003) MPP+ analogs acting on mitochondria and inducing neuro-degeneration. Curr.Med.Chem. 10, 2507-2516.

Kroemer G (1998) The mitochondrion as an integrator/coordinator of cell death pathways. Cell Death.Differ. 5, 547.

Kroemer G und Reed JC (2000) Mitochondrial control of cell death. Nat.Med. 6, 513-519.

Kusakawa G, Saito T, Onuki R, Ishiguro K, Kishimoto T und Hisanaga S (2000) Calpain-dependent proteolytic cleavage of the p35 cyclin-dependent kinase 5 activator to p25. J.Biol.Chem. 275, 17166-17172.

Labrousse AM, Zappaterra MD, Rube DA und van der Bliek AM (1999) C. elegans dynamin-related protein DRP-1 controls severing of the mitochondrial outer membrane. Mol.Cell 4, 815-826.

Laemmli UK (1970) Cleavage of structural proteins during the assembly of the head of bacteriophage T4. Nature 227, 680-685.

Larsen W.J. (1970) Genesis of mitochondria in insect fat body. J.Cell Biol. 47, 373-383.

Lazzarino DA, Boldogh I, Smith MG, Rosand J und Pon LA (1994) Yeast mitochondria contain ATPsensitive, reversible actin-binding activity. Mol.Biol.Cell 5, 807-818.

Lee JH und Kim KT (2004) Induction of cyclin-dependent kinase 5 and its activator p35 through the extracellular-signal-regulated kinase and protein kinase A pathways during retinoic-acid mediated neuronal differentiation in human neuroblastoma SK-N-BE(2)C cells. J.Neurochem. 91, 634-647.

Lee MS, Kwon YT, Li M, Peng J, Friedlander RM und Tsai LH (2000) Neurotoxicity induces cleavage of p35 to p25 by calpain. Nature 405, 360-364.

Lee YJ, Jeong SY, Karbowski M, Smith CL und Youle RJ (2004) Roles of the mammalian mitochondrial fission and fusion mediators Fis1, Drp1, and Opa1 in apoptosis. Mol.Biol.Cell $15,5001-5011$.

Legros F, Lombes A, Frachon P und Rojo M (2002) Mitochondrial fusion in human cells is efficient, requires the inner membrane potential, and is mediated by mitofusins. Mol.Biol.Cell 13, 43434354.

Li X und Gould SJ (2003) The dynamin-like GTPase DLP1 is essential for peroxisome division and is recruited to peroxisomes in part by PEX11. J.Biol.Chem. 278, 17012-17020.

Ligon LA und Steward O (2000) Role of microtubules and actin filaments in the movement of mitochondria in the axons and dendrites of cultured hippocampal neurons. J.Comp Neurol. 427, 351-361.

Lim AC, Hou Z, Goh CP und Qi RZ (2004) Protein kinase CK2 is an inhibitor of the neuronal Cdk5 kinase. J.Biol.Chem. 279, 46668-46673.

Luo X, Budihardjo I, Zou H, Slaughter C und Wang X (1998) Bid, a Bcl2 interacting protein, mediates cytochrome $\mathrm{c}$ release from mitochondria in response to activation of cell surface death receptors. Cell 94, 481-490.

Maccioni RB, Otth C, Concha II und Munoz JP (2001) The protein kinase Cdk5. Structural aspects, roles in neurogenesis and involvement in Alzheimer's pathology. Eur.J.Biochem 268, 15181527.

Matsubara M, Kusubata M, Ishiguro K, Uchida T, Titani K und Taniguchi H (1996) Site-specific phosphorylation of synapsin I by mitogen-activated protein kinase and Cdk5 and its effects on physiological functions. J.Biol.Chem. 271, 21108-21113.

Matsushita M, Tomizawa K, Lu YF, Moriwaki A, Tokuda M, Itano T, Wang JH, Hatase O und Matsui H (1996) Distinct cellular compartment of cyclin-dependent kinase 5 (Cdk5) and neuron-specific Cdk5 activator protein (p35nck5a) in the developing rat cerebellum. Brain Res. 734, 319-322. 
McCormick AL, Smith VL, Chow D und Mocarski ES (2003) Disruption of mitochondrial networks by the human cytomegalovirus UL37 gene product viral mitochondrion-localized inhibitor of apoptosis. J.Virol. 77, 631-641.

Meeusen S, McCaffery JM und Nunnari J (2004) Mitochondrial fusion intermediates revealed in vitro. Science 305, 1747-1752.

Messerschmitt M, Jakobs S, Vogel F, Fritz S, Dimmer KS, Neupert W und Westermann B (2003) The inner membrane protein Mdm33 controls mitochondrial morphology in yeast. J.Cell Biol. 160, 553-564.

Meuer K, Pitzer C, Teismann P, Kruger C, Goricke B, Laage R, Lingor P, Peters K, Schlachetzki JC, Kobayashi K, Dietz GP, Weber D, Ferger B, Schabitz WR, Bach A, Schulz JB, Bahr M, Schneider A und Weishaupt JH (2006) Granulocyte-colony stimulating factor is neuroprotective in a model of Parkinson's disease. J.Neurochem. 97, 675-686.

Meuer K, Suppanz IE, Lingor P, Planchamp V, Goricke B, Fichtner L, Braus GH, Dietz GP, Jakobs S, Bahr M und Weishaupt $\mathrm{JH}$ (2007) Cyclin-dependent kinase 5 is an upstream regulator of mitochondrial fission during neuronal apoptosis. Cell Death.Differ.1-11.

Mitchell P (1961) Coupling of phosphorylation to electron and hydrogen transfer by a chemi-osmotic type of mechanism. Nature144-148.

Moorthamer M und Chaudhuri B (1999) Identification of ribosomal protein L34 as a novel Cdk5 inhibitor. Biochem Biophys. Res.Commun. 255, 631-638.

Moorthamer M, Zumstein-Mecker S und Chaudhuri B (1999) DNA binding protein dbpA binds Cdk5 and inhibits its activity. FEBS Lett. 446, 343-350.

Mozdy AD, McCaffery JM und Shaw JM (2000) Dnm1p GTPase-mediated mitochondrial fission is a multi-step process requiring the novel integral membrane component Fis1p. J.Cell Biol. 151, 367-380.

Nakada K, Inoue K, Ono T, Isobe K, Ogura A, Goto YI, Nonaka I und Hayashi JI (2001) Intermitochondrial complementation: Mitochondria-specific system preventing mice from expression of disease phenotypes by mutant mtDNA. Nat.Med. 7, 934-940.

Nakamura S, Kawamoto Y, Nakano S, Akiguchi I und Kimura J (1997) p35nck5a and cyclindependent kinase 5 colocalize in Lewy bodies of brains with Parkinson's disease. Acta Neuropathol.(Berl) 94, 153-157.

Nangaku M, Sato-Yoshitake R, Okada Y, Noda Y, Takemura R, Yamazaki H und Hirokawa N (1994) KIF1B, a novel microtubule plus end-directed monomeric motor protein for transport of mitochondria. Cell 79, 1209-1220.

Nath R, Davis M, Probert AW, Kupina NC, Ren X, Schielke GP und Wang KK (2000) Processing of cdk5 activator p35 to its truncated form (p25) by calpain in acutely injured neuronal cells. Biochem Biophys.Res.Commun. 274, 16-21.

Neupert W (1997) Protein import into mitochondria. Annu.Rev.Biochem 66, 863-917.

Neuspiel M, Zunino R, Gangaraju S, Rippstein P und McBride H (2005) Activated mitofusin 2 signals mitochondrial fusion, interferes with Bax activation, and reduces susceptibility to radical induced depolarization. J.Biol.Chem. 280, 25060-25070.

Neystat M, Rzhetskaya M, Oo TF, Kholodilov N, Yarygina O, Wilson A, El Khodor BF und Burke RE (2001) Expression of cyclin-dependent kinase 5 and its activator p35 in models of induced apoptotic death in neurons of the substantia nigra in vivo. J.Neurochem. 77, 1611-1625.

Nguyen MD, Lariviere RC und Julien JP (2001) Deregulation of Cdk5 in a mouse model of ALS: toxicity alleviated by perikaryal neurofilament inclusions. Neuron 30, 135-147.

Nishizawa M, Kanaya Y und Toh E (1999) Mouse cyclin-dependent kinase (Cdk) 5 is a functional homologue of a yeast Cdk, pho85 kinase. J.Biol.Chem. 274, 33859-33862.

Olichon A, Baricault L, Gas N, Guillou E, Valette A, Belenguer P und Lenaers G (2003) Loss of OPA1 perturbates the mitochondrial inner membrane structure and integrity, leading to cytochrome c release and apoptosis. J.Biol.Chem. 278, 7743-7746.

Ono T, Isobe K, Nakada K und Hayashi JI (2001) Human cells are protected from mitochondrial dysfunction by complementation of DNA products in fused mitochondria. Nat.Genet. 28, 272275.

Osuga H, Osuga S, Wang F, Fetni R, Hogan MJ, Slack RS, Hakim AM, Ikeda JE und Park DS (2000) Cyclin-dependent kinases as a therapeutic target for stroke. Proc.Natl.Acad.Sci.U.S.A 97, 10254-10259.

Palade G (1952) The fine structure of the mitochondria. Anat.Rec. 114, 427-451.

Parone PA, James DI, Da Cruz S, Mattenberger Y, Donze O, Barja F und Martinou JC (2006) Inhibiting the mitochondrial fission machinery does not prevent Bax/Bak-dependent apoptosis. Mol.Cell Biol. 26, 7397-7408.

Parone PA und Martinou JC (2006) Mitochondrial fission and apoptosis: an ongoing trial. Biochim.Biophys.Acta 1763, 522-530. 
Patrick GN, Zhou P, Kwon YT, Howley PM und Tsai LH (1998) p35, the neuronal-specific activator of cyclin-dependent kinase 5 (Cdk5) is degraded by the ubiquitin-proteasome pathway. J.Biol.Chem. 273, 24057-24064.

Patrick GN, Zukerberg L, Nikolic M, de La MS, Dikkes P und Tsai LH (1999) Conversion of p35 to p25 deregulates Cdk5 activity and promotes neurodegeneration. Nature 402, 615-622.

Patzke H und Tsai LH (2002) Calpain-mediated cleavage of the cyclin-dependent kinase- 5 activator p39 to p29. J.Biol.Chem. 277, 8054-8060.

Pelloquin L, Belenguer P, Menon Y und Ducommun B (1998) Identification of a fission yeast dynamin-related protein involved in mitochondrial DNA maintenance. Biochem Biophys.Res.Commun. 251, 720-726.

Pereira AJ, Dalby B, Stewart RJ, Doxsey SJ und Goldstein LS (1997) Mitochondrial association of a plus end-directed microtubule motor expressed during mitosis in Drosophila. J.Cell Biol. 136, 1081-1090.

Petersen A, Castilho RF, Hansson O, Wieloch T und Brundin P (2000) Oxidative stress, mitochondrial permeability transition and activation of caspases in calcium ionophore A23187-induced death of cultured striatal neurons. Brain Res. 857, 20-29.

Pinton P, Ferrari D, Rapizzi E, Di Virgilio F, Pozzan T und Rizzuto R (2001) The Ca2+ concentration of the endoplasmic reticulum is a key determinant of ceramide-induced apoptosis: significance for the molecular mechanism of Bcl-2 action. EMBO J. 20, 2690-2701.

Polster BM und Fiskum G (2004) Mitochondrial mechanisms of neural cell apoptosis. J.Neurochem. 90, 1281-1289.

Poon RY, Lew J und Hunter T (1997) Identification of functional domains in the neuronal Cdk5 activator protein. J.Biol.Chem. 272, 5703-5708.

Qu D, Li Q, Lim HY, Cheung NS, Li R, Wang JH und Qi RZ (2002) The protein SET binds the neuronal Cdk5 activator p35nck5a and modulates Cdk5/p35nck5a activity. J.Biol.Chem. 277, 7324-7332.

Rashid T, Banerjee M und Nikolic M (2001) Phosphorylation of Pak1 by the p35/Cdk5 kinase affects neuronal morphology. J.Biol.Chem. 276, 49043-49052.

Rintoul GL, Filiano AJ, Brocard JB, Kress GJ und Reynolds IJ (2003) Glutamate decreases mitochondrial size and movement in primary forebrain neurons. J.Neurosci. 23, 7881-7888.

Saito T, Onuki R, Fujita Y, Kusakawa G, Ishiguro K, Bibb JA, Kishimoto T und Hisanaga S (2003) Developmental regulation of the proteolysis of the p35 cyclin-dependent kinase 5 activator by phosphorylation. J.Neurosci. 23, 1189-1197.

Sawyer DE und Van Houten B (1999) Repair of DNA damage in mitochondria. Mutat.Res. 434, 161176.

Scaffidi C, Fulda S, Srinivasan A, Friesen C, Li F, Tomaselli KJ, Debatin KM, Krammer PH und Peter ME (1998) Two CD95 (APO-1/Fas) signaling pathways. EMBO J. 17, 1675-1687.

Schatz G und Dobberstein B (1996) Common principles of protein translocation across membranes. Science 271, 1519-1526.

Scheffler IE (2001) A century of mitochondrial research: achievements and perspectives. Mitochondrion. 1, 3-31.

Schneider A, Araujo GW, Trajkovic K, Herrmann MM, Merkler D, Mandelkow EM, Weissert R und Simons M (2004) Hyperphosphorylation and aggregation of tau in experimental autoimmune encephalomyelitis. J.Biol.Chem. 279, 55833-55839.

Sesaki $H$ und Jensen RE (1999) Division versus fusion: Dnm1p and Fzo1p antagonistically regulate mitochondrial shape. J.Cell Biol. 147, 699-706.

Sesaki H und Jensen RE (2001) UGO1 encodes an outer membrane protein required for mitochondrial fusion. J.Cell Biol. 152, 1123-1134.

Sever S, Damke H und Schmid SL (2000) Dynamin:GTP controls the formation of constricted coated pits, the rate limiting step in clathrin-mediated endocytosis. J.Cell Biol. 150, 1137-1148.

Sharma P, Veeranna, Sharma M, Amin ND, Sihag RK, Grant P, Ahn N, Kulkarni AB und Pant HC (2002) Phosphorylation of MEK1 by cdk5/p35 down-regulates the mitogen-activated protein kinase pathway. J.Biol.Chem. 277, 528-534.

Shaw JM und Nunnari J (2002) Mitochondrial dynamics and division in budding yeast. Trends Cell Biol. 12, 178-184.

Shimoda K, Sauve Y, Marini A, Schwartz JP und Commissiong JW (1992) A high percentage yield of tyrosine hydroxylase-positive cells from rat E14 mesencephalic cell culture. Brain Res. 586, 319-331.

Shirvan A, Ziv I, Zilkha-Falb R, Machlyn T, Barzilai A und Melamed E (1998) Expression of cell cyclerelated genes during neuronal apoptosis: is there a distinct pattern? Neurochem.Res. 23, 767-777. 
Shpetner HS und Vallee RB (1989) Identification of dynamin, a novel mechanochemical enzyme that mediates interactions between microtubules. Cell 59, 421-432.

Shub DA (1994) Bacterial viruses. Bacterial altruism? Curr.Biol. 4, 555-556.

Simon VR, Swayne TC und Pon LA (1995) Actin-dependent mitochondrial motility in mitotic yeast and cell-free systems: identification of a motor activity on the mitochondrial surface. J.Cell Biol. 130, 345-354.

Skulachev VP (2002) Programmed death phenomena: from organelle to organism. Ann.N.Y.Acad.Sci. 959, 214-237.

Smirnova E, Griparic L, Shurland DL und van der Bliek AM (2001) Dynamin-related protein Drp1 is required for mitochondrial division in mammalian cells. Mol.Biol.Cell 12, 2245-2256.

Smirnova E, Shurland DL, Ryazantsev SN und van der Bliek AM (1998) A human dynamin-related protein controls the distribution of mitochondria. J.Cell Biol. 143, 351-358.

Smith DS, Greer PL und Tsai LH (2001) Cdk5 on the brain. Cell Growth Differ. 12, 277-283.

Smith PD, Crocker SJ, Jackson-Lewis V, Jordan-Sciutto KL, Hayley S, Mount MP, O'Hare MJ, Callaghan S, Slack RS, Przedborski S, Anisman H und Park DS (2003) Cyclin-dependent kinase 5 is a mediator of dopaminergic neuron loss in a mouse model of Parkinson's disease. Proc.Natl.Acad.Sci.U.S.A 100, 13650-13655.

Smith PD, Mount MP, Shree R, Callaghan S, Slack RS, Anisman H, Vincent I, Wang X, Mao Z und Park DS (2006) Calpain-regulated p35/cdk5 plays a central role in dopaminergic neuron death through modulation of the transcription factor myocyte enhancer factor 2 . J.Neurosci. 26, 440-447.

Stojanovski D, Koutsopoulos OS, Okamoto K und Ryan MT (2004) Levels of human Fis1 at the mitochondrial outer membrane regulate mitochondrial morphology. J.Cell Sci. 117, 12011210.

Stowell MH, Marks B, Wigge P und McMahon HT (1999) Nucleotide-dependent conformational changes in dynamin: evidence for a mechanochemical molecular spring. Nat.Cell Biol. 1, $27-$ 32.

Sturmer K, Baumann O und Walz B (1995) Actin-dependent light-induced translocation of mitochondria and ER cisternae in the photoreceptor cells of the locust Schistocerca gregaria. J.Cell Sci. 108 ( Pt 6), 2273-2283.

Suelmann R und Fischer R (2000) Mitochondrial movement and morphology depend on an intact actin cytoskeleton in Aspergillus nidulans. Cell Motil.Cytoskeleton 45, 42-50.

Sugioka R, Shimizu S und Tsujimoto Y (2004) Fzo1, a protein involved in mitochondrial fusion, inhibits apoptosis. J.Biol.Chem. 279, 52726-52734.

Sweitzer SM und Hinshaw JE (1998) Dynamin undergoes a GTP-dependent conformational change causing vesiculation. Cell 93, 1021-1029.

Szabadkai G, Simoni AM, Chami M, Wieckowski MR, Youle RJ und Rizzuto R (2004) Drp-1dependent division of the mitochondrial network blocks intraorganellar $\mathrm{Ca} 2+$ waves and protects against Ca2+-mediated apoptosis. Mol.Cell 16, 59-68.

Takei K, McPherson PS, Schmid SL und De Camilli P (1995) Tubular membrane invaginations coated by dynamin rings are induced by GTP-gamma $S$ in nerve terminals. Nature 374, 186190.

Takei K, Yoshida Y und Yamada H (2005) Regulatory mechanisms of dynamin-dependent endocytosis. J.Biochem (Tokyo) 137, 243-247.

Tamaoki T, Nomoto H, Takahashi I, Kato Y, Morimoto M und Tomita F (1986) Staurosporine, a potent inhibitor of phospholipid/Ca++dependent protein kinase. Biochem Biophys. Res.Commun. 135, 397-402.

Tan TC, Valova VA, Malladi CS, Graham ME, Berven LA, Jupp OJ, Hansra G, McClure SJ, Sarcevic B, Boadle RA, Larsen MR, Cousin MA und Robinson PJ (2003) Cdk5 is essential for synaptic vesicle endocytosis. Nat.Cell Biol. 5, 701-710.

Tanaka T, Veeranna, Ohshima T, Rajan P, Amin ND, Cho A, Sreenath T, Pant HC, Brady RO und Kulkarni AB (2001) Neuronal cyclin-dependent kinase 5 activity is critical for survival. J.Neurosci. 21, 550-558.

Tanaka Y, Kanai Y, Okada Y, Nonaka S, Takeda S, Harada A und Hirokawa N (1998) Targeted disruption of mouse conventional kinesin heavy chain, kif5B, results in abnormal perinuclear clustering of mitochondria. Cell 93, 1147-1158.

Tandler B, Erlandson RA, Smith AL und Wynder EL (1969) Riboflavin and mouse hepatic cell structure and function. II. Division of mitochondria during recovery from simple deficiency. J.Cell Biol. 41, 477-493.

Tarricone C, Dhavan R, Peng J, Areces LB, Tsai LH und Musacchio A (2001) Structure and regulation of the CDK5-p25(nck5a) complex. Mol.Cell 8, 657-669. 
Tieu Q und Nunnari J (2000) Mdv1p is a WD repeat protein that interacts with the dynamin-related GTPase, Dnm1p, to trigger mitochondrial division. J.Cell Biol. 151, 353-366.

Tieu Q, Okreglak V, Naylor K und Nunnari J (2002) The WD repeat protein, Mdv1p, functions as a molecular adaptor by interacting with Dnm1p and Fis1p during mitochondrial fission. J.Cell Biol. 158, 445-452.

Tokuoka H, Saito T, Yorifuji H, Wei F, Kishimoto T und Hisanaga S (2000) Brain-derived neurotrophic factor-induced phosphorylation of neurofilament- $\mathrm{H}$ subunit in primary cultures of embryo rat cortical neurons. J.Cell Sci. 113 ( Pt 6), 1059-1068.

Tolkovsky AM, Xue L, Fletcher GC und Borutaite V (2002) Mitochondrial disappearance from cells: a clue to the role of autophagy in programmed cell death and disease? Biochimie 84, 233-240.

Tomizawa K, Matsui H, Matsushita M, Lew J, Tokuda M, Itano T, Konishi R, Wang JH und Hatase O (1996) Localization and developmental changes in the neuron-specific cyclin-dependent kinase 5 activator (p35nck5a) in the rat brain. Neuroscience 74, 519-529.

Tomizawa K, Sunada S, Lu YF, Oda Y, Kinuta M, Ohshima T, Saito T, Wei FY, Matsushita M, Li ST, Tsutsui K, Hisanaga S, Mikoshiba K, Takei K und Matsui H (2003) Cophosphorylation of amphiphysin I and dynamin I by Cdk5 regulates clathrin-mediated endocytosis of synaptic vesicles. J.Cell Biol. 163, 813-824.

Towbin H, Staehelin T und Gordon J (1979) Electrophoretic transfer of proteins from polyacrylamide gels to nitrocellulose sheets: procedure and some applications. Proc.Natl.Acad.Sci.U.S.A 76, 4350-4354.

Tsai LH, Delalle I, Caviness VS, Jr., Chae T und Harlow E (1994) p35 is a neural-specific regulatory subunit of cyclin-dependent kinase 5 . Nature 371, 419-423.

Tsai LH, Takahashi T, Caviness VS, Jr. und Harlow E (1993) Activity and expression pattern of cyclin-dependent kinase 5 in the embryonic mouse nervous system. Development 119, 10291040.

Tuma PL und Collins CA (1994) Activation of dynamin GTPase is a result of positive cooperativity. J.Biol.Chem. 269, 30842-30847.

Tuma PL, Stachniak MC und Collins CA (1993) Activation of dynamin GTPase by acidic phospholipids and endogenous rat brain vesicles. J.Biol.Chem. 268, 17240-17246.

van der Bliek AM (1999) Functional diversity in the dynamin family. Trends Cell Biol. 9, 96-102.

Varadi A, Johnson-Cadwell LI, Cirulli V, Yoon Y, Allan VJ und Rutter GA (2004) Cytoplasmic dynein regulates the subcellular distribution of mitochondria by controlling the recruitment of the fission factor dynamin-related protein-1. J.Cell Sci. 117, 4389-4400.

Wang J, Liu S, Fu Y, Wang JH und Lu Y (2003) Cdk5 activation induces hippocampal CA1 cell death by directly phosphorylating NMDA receptors. Nat.Neurosci. 6, 1039-1047.

Warnock DE, Hinshaw JE und Schmid SL (1996) Dynamin self-assembly stimulates its GTPase activity. J.Biol.Chem. 271, 22310-22314.

Wei MC, Zong WX, Cheng EH, Lindsten T, Panoutsakopoulou V, Ross AJ, Roth KA, MacGregor GR, Thompson CB und Korsmeyer SJ (2001) Proapoptotic BAX and BAK: a requisite gateway to mitochondrial dysfunction and death. Science 292, 727-730.

Weishaupt JH, Kussmaul L, Grotsch P, Heckel A, Rohde G, Romig H, Bahr M und Gillardon F (2003) Inhibition of CDK5 is protective in necrotic and apoptotic paradigms of neuronal cell death and prevents mitochondrial dysfunction. Mol.Cell Neurosci. 24, 489-502.

Xue L, Fletcher GC und Tolkovsky AM (2001) Mitochondria are selectively eliminated from eukaryotic cells after blockade of caspases during apoptosis. Curr.Biol. 11, 361-365.

Yaffe MP, Harata D, Verde F, Eddison M, Toda T und Nurse P (1996) Microtubules mediate mitochondrial distribution in fission yeast. Proc.Natl.Acad.Sci.U.S.A 93, 11664-11668.

Yamaguchi H, Ishiguro K, Uchida T, Takashima A, Lemere CA und Imahori K (1996) Preferential labeling of Alzheimer neurofibrillary tangles with antisera for tau protein kinase (TPK) I/glycogen synthase kinase- 3 beta and cyclin-dependent kinase 5, a component of TPK II. Acta Neuropathol.(Berl) 92, 232-241.

Yang DD, Kuan CY, Whitmarsh AJ, Rincon M, Zheng TS, Davis RJ, Rakic P und Flavell RA (1997) Absence of excitotoxicity-induced apoptosis in the hippocampus of mice lacking the Jnk3 gene. Nature 389, 865-870.

Yoon Y, Pitts KR, Dahan S und McNiven MA (1998) A novel dynamin-like protein associates with cytoplasmic vesicles and tubules of the endoplasmic reticulum in mammalian cells. J.Cell Biol. 140, 779-793.

Youle RJ und Karbowski M (2005) Mitochondrial fission in apoptosis. Nat.Rev.Mol.Cell Biol. 6, 657663.

Yuan H, Gerencser AA, Liot G, Lipton SA, Ellisman M, Perkins GA und Bossy-Wetzel E (2006) Mitochondrial fission is an upstream and required event for bax foci formation in response to nitric oxide in cortical neurons. Cell Death.Differ. 
Zhang BF, Peng FF, Zhang JZ und Wu DC (2003) Staurosporine induces apoptosis in NG108-15 cells. Acta Pharmacol.Sin. 24, 663-669.

Zhang J, Krishnamurthy PK und Johnson GV (2002) Cdk5 phosphorylates p53 and regulates its activity. J.Neurochem. 81, 307-313.

Zhang M, Li J, Chakrabarty P, Bu B und Vincent I (2004) Cyclin-dependent kinase inhibitors attenuate protein hyperphosphorylation, cytoskeletal lesion formation, and motor defects in NiemannPick Type C mice. Am.J.Pathol. 165, 843-853.

Zhang Z, Hong Z und Verma DP (2000) Phragmoplastin polymerizes into spiral coiled structures via intermolecular interaction of two self-assembly domains. J.Biol.Chem. 275, 8779-8784.

Zheng YL, Kesavapany S, Gravell M, Hamilton RS, Schubert M, Amin N, Albers W, Grant P und Pant $\mathrm{HC}$ (2005) A Cdk5 inhibitory peptide reduces tau hyperphosphorylation and apoptosis in neurons. EMBO J. 24, 209-220. 


\section{Abkürzungsverzeichnis}

\begin{tabular}{|c|c|}
\hline ADP & Adenosindiphosphat \\
\hline Apaf-1 & apoptotic peptidase activating factor 1 \\
\hline APS & Ammoniumperoxidisulfat \\
\hline ATP & Adenosintriphosphat \\
\hline BSA & Rinderserumalbumin \\
\hline cAMP & zyklisches Adenosinmonophosphat \\
\hline CDK5 & Cyclin-abhängige Kinase 5 \\
\hline $\mathrm{Ci}$ & Curie \\
\hline DABCO & 1,4-diazabicyclo[2.2.2]octane \\
\hline DAPI & 4',6-Diamidino-2- Phenylindol \\
\hline DNS & Desoxyribonukleinsäure \\
\hline DsRed & Disosoma spec. Red \\
\hline $\mathrm{FADH}_{2}$ & Flavin-Adenin-Dinucleotid \\
\hline FCS & fetales Kälberserum \\
\hline GABAerg & auf $\gamma$-Aminobuttersäure (GABA) reagierend \\
\hline GDP & Guanosindiphosphat \\
\hline GFP & Green Fluorescent Protein \\
\hline GTP & Guanosintriphosphat \\
\hline $\mathrm{kb}$ & Kilobase \\
\hline $\mathrm{kDa}$ & Kilodaton \\
\hline LB & Luria Bertani \\
\hline $\mathrm{MPP}^{+}$ & 1-Methyl-4-phenyl-pyridine \\
\hline MPTP & 1-Methyl-4-phenyl-1,2,3,6-tetrahydropyridin \\
\hline mRNS & Boten -Ribonukleinsäure \\
\hline mt-GFP & mitochondriales GFP \\
\hline $\mathrm{NADH} / \mathrm{H}$ & Nicotinamid-Adenosin-Dinukleotid \\
\hline NMDA & ionotropher Glutamatrezeptor \\
\hline OD & Optische Dichte \\
\hline PBS & Phosphat-gepufferte Saline \\
\hline PFA & Paraformaldehyd \\
\hline rpm & rounds per minute \\
\hline SDS & Sodium Dodecylsulfat \\
\hline siRNS & small interfering RNS \\
\hline TEMED & N,N,N,N-Tetramethylethylendiamin \\
\hline $\mathrm{TH}$ & Tyrosin-Hydroxylase \\
\hline$\Delta$ & Deletion \\
\hline
\end{tabular}




\section{Wissenschaftliche Veröffentlichungen}

Meuer K, Pitzer C, Teismann P, Kruger C, Goricke B, Laage R, Lingor P, Peters K, Schlachetzki JC, Kobayashi K, Dietz GP, Weber D, Ferger B, Schabitz WR, Bach A, Schulz JB, Bahr M, Schneider A und Weishaupt JH (2006) Granulocyte-colony stimulating factor is neuroprotective in a model of Parkinson's disease. J.Neurochem. 97, 675-686.

Dietz GP, Valbuena PC, Dietz B, Meuer K, Müller P, Weishaupt JH, Bähr M (2006) Application of a blood-brain-barrier-penetrating form of GDNF in a mouse model for Parkinson's disease. Brain Res.1082, 61-66

Meuer K, Suppanz IE, Lingor P, Planchamp V, Göricke B, Fichtner L, Braus GH, Dietz PH, Jakobs S, Bähr M, Weishaupt JH (2007) Cyclin-dependent kinase 5 is an upstream regulator of mitochondrial fission. Cell Death.Differ. 1-11.

Baier PC, Paulus W, Meuer K, Bähr M, Weishaupt JH, Liebetanz D (2007) A highly sensitive automated complex running wheel test to detect latent motor deficits in the mouse MPTP model of Parkinson's disease. Exp Neurol. in press 


\section{Danke}

Herrn Dr. J.H. Weishaupt danke ich für die Überlassung des Themas und die Gelegenheit zur freien, selbstständigen Arbeit. Danke für die Möglichkeit, mich wissenschaftlich auf Kongressen im In- und Ausland fortzubilden und die zielorientierte Ausrichtung meines wissenschaftlichen Arbeitens. Herr Prof. M. Bähr hat mich dankenswerter Weise in sein Forschungslabor in der Abteilung Neurologie der Uniklinik Göttingen aufgenommen.

Herrn Prof. R. Hardeland möchte ich für die Übernahme des Referats am Fachbereich Biologie und ebenso Herrn Prof. K. von Figura für das Korreferat danken.

Dr. P Lingor und V. Planchamp halfen mir bei der Präparation der primären Mittelhirnkulturen und bei den siRNS Versuchen. Vielen Dank auch an Prof. R. Jahn, in dessen Labor ich die radioaktiven Experimente durchführen durfte. Ein großes Dankeschön an Dr. S. Jakobs, Dr. G. Mieske und Dr. D. Schmitt, die mir bei diesen Versuchen immer hilfreich zur Seite standen. Dr. S. Jakobs und I. Suppanz möchte ich auch für die Hilfe und Unterstützung während der Hefeversuche und die freundliche Aufnahme in ihrem Labor danken.

Ebenso möchte ich mich bei meinen Kollegen Johannes Schlachetzki, Sandra Siedenberg, Petranka Krumova, Florian Nagel, Dr. Jan Liman und Dr. Pawel Kermer bedanken, dass sie trotz der manchmal widrigen Umstände stets für eine angenehme Atmosphäre sorgten. Ina Bogner hat unsere Probleme mit der Nachbestellung von Arbeitsmaterial entschärft, vielen Dank.

Christine Poser war mir insbesondere gegen Ende der Promotion bei vielen Experimenten eine wichtige Stütze. Ich danke ihr auch für das zuverlässige Korrekturlesen der Dissertation. Ein riesiges Dankeschön an Michael, der mich in zu vielen Dingen unterstützt hat, als das ich sie hier einzeln aufzählen könnte. 


\section{Lebenslauf}

Name

Geburtsdatum

Geburtsort

Familienstand

Staatsangehörigkeit
Katrin Charlotte Meuer

10.08.1978

Darmstadt

ledig

Deutsch

\section{Schulbildung und Hochschulstudium}

2003- 2007 Promotion zum Thema: „Regulation des mitochondrialen Zerfalls innerhalb der neuronalen Apoptose“ in der Abteilung Neurologie an der Georg-August-Universität Göttingen. Arbeitsgruppe von Prof. Bähr.

2002-2003 Diplomarbeit zum Thema: „Nachweis und Analyse efferenter Verbindungen vom Colliculus inferior zum Lemniscus lateralis am Hirnschnittpräparat der Wüstenrennmaus (Meriones unguiculatus) in der Arbeitsgruppe von Prof. Langner an der Technischen Universität Darmstadt.

1997-2003 Studium der Biologie an der Technischen Universität Darmstadt. Abschluss Diplom Biologin.

1988-1997 Gymnasium Viktoriaschule in Darmstadt.

Erwerb der allgemeine Hochschulreife.

1984-1988 Grundschule Schillerschule in Griesheim. 